\title{
Optimization of a Heavy-Duty Hybrid Transit Bus Operated over Transient Cycles
}

\author{
Pingen Chen \\ West Virginia University
}

Follow this and additional works at: https://researchrepository.wvu.edu/etd

\section{Recommended Citation}

Chen, Pingen, "Optimization of a Heavy-Duty Hybrid Transit Bus Operated over Transient Cycles" (2010). Graduate Theses, Dissertations, and Problem Reports. 4569.

https://researchrepository.wvu.edu/etd/4569

This Thesis is protected by copyright and/or related rights. It has been brought to you by the The Research Repository @ WVU with permission from the rights-holder(s). You are free to use this Thesis in any way that is permitted by the copyright and related rights legislation that applies to your use. For other uses you must obtain permission from the rights-holder(s) directly, unless additional rights are indicated by a Creative Commons license in the record and/ or on the work itself. This Thesis has been accepted for inclusion in WVU Graduate Theses, Dissertations, and Problem Reports collection by an authorized administrator of The Research Repository @ WVU. For more information, please contact researchrepository@mail.wvu.edu. 
Optimization of a Heavy-Duty Hybrid Transit Bus Operated over Transient Cycles

\author{
Pingen Chen
}

\author{
Thesis submitted to the \\ College of Engineering and Mineral Resources \\ at West Virginia University \\ in partial fulfillment of the requirements \\ for the degree of
}

\begin{abstract}
Master of Science
in

Mechanical Engineering

Hailin Li, Ph.D., Chair

Scott W. Wayne, Ph.D.

Nigel N. Clark, Ph.D.
\end{abstract}

Department of Mechanical and Aerospace Engineering

\author{
Morgantown, West Virginia \\ 2010
}

Keywords: Hybrid Transit Bus, Optimization, Modeling, PSAT, Air Conditioning 


\section{Abstract \\ Optimization of a Heavy-Duty Hybrid Transit Bus Operated over Transient Cycles Pingen Chen}

This thesis centers on the simulation and optimization of a hybrid transit bus when operated over transient emissions cycles. The simulation was conducted using Powertrain System Analysis Toolkit (PSAT) as a platform by integrating components' data and operation maps of a "pretransmission" parallel hybrid transit bus. The model was validated against the limited experimental data when operated over the China's Urban Bus (CUB) driving cycle and the Beijing cycle. The validated model was then used to predict the performance and exhaust emissions of this hybrid bus operated over typical U.S. cycles. The potential of a real-time control strategy in improving the performance and reducing the exhaust emissions was investigated. The significant effect of air conditioning (A/C) system on the fuel economy was examined using the $\mathrm{A} / \mathrm{C}$ model developed in this research.

Compared to the operation with the baseline control strategy, the application of the conventional engine efficiency-based control strategy reduced the fuel consumption by $1.5 \%, 1.7 \%$ and $-0.4 \%$ when operated over Central Business District (CBD) cycle, Manhattan Bus cycle, and New York Bus cycle, respectively; $\mathrm{NO}_{\mathrm{x}}$ emissions were reduced only by $5.6 \%, 5.6 \%$ and $0.4 \%$, respectively. Simulation results indicated potential of the real-time overall efficiency-based control strategy in improving the performance of hybrid bus. Compared with the baseline control strategy, the realtime control strategy has the potential to reduce the fuel consumption and $\mathrm{NO}_{\mathrm{x}}$ emissions respectively by $8.1 \%$ and $6.1 \%$ when operated over New York Bus cycle.

The A/C model developed in this research was integrated into the PSAT model to investigate the effect of $\mathrm{A} / \mathrm{C}$ system operation on the fuel consumption. The effects of ambient conditions (temperature, relative humidity, and solar radiation) and heat/humidity generation on board on the fuel consumption were investigated when operated over the featured summer weather of West Virginia, Arizona, and Florida. When operated over scaled SFTP-SC03 cycle, the operation of $\mathrm{A} / \mathrm{C}$ system could increase the fuel consumption by $31.9 \%, 45.9 \%$, and $50.2 \%$, respectively. 


\section{Dedication}

I dedicate this work to my wife, Lijun Sun, who encourages me continuously and gives me the sweetest love and unselfish support in my life. 


\section{Acknowledgement}

I would like to express the deepest appreciation to my committee chair, Dr. Hailin Li, who continually and convincingly delivered knowledge and methods in regard to my research. He always inspired me, encouraged me, and provided me with financial support. Without his persistent guidance, patience and assistance this thesis would not have been possible.

I would like to thank my committee members, Dr. Scott W. Wayne and Dr. Nigel N. Clark, whose work and suggestions inspired me and kept my research moving in an excellent direction. Without their support and help, my research work would not have been so unique and successful. I would like to thank my undergraduate research advisor Dr. Xiaohua Zeng at Jilin University for his persistent instruction to me after my graduation. Without his generosity of sharing experimental data with me, this thesis would have not been possible.

I would like to thank Dr. Christ Atkinson, Dr. John P. Nuszkowski and Dr. Benjamin C. Shade for their time and kindness to help me solve the problems time and time again.

I would like to thank Lijuan Wang. Working with her really inspired me and expanded my knowledge in many ways.

I would like to thank Clay Bell and Timothy Gatts, whose editing suggestions and precise sense of language improved the quality of the final copy.

I would also like to thank Wei Qi and Shiyu Liu for their time and willingness to proofread the thesis and discuss the problems I met. Without their help in and out of office, my graduate study at West Virginia University would not have been so easy.

I would like to thank my parents, who supported me both materially and spiritually in the past twenty-six years. Without their encouragement and good care, I would not have been so deep in research.

Finally, I would like to thank my wife, Lijun Sun, for her deep love, continuous encouragement, and unselfish support to me. Without her, my life would have not been so happy. 


\section{Table of Contents}

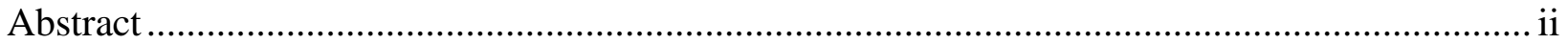

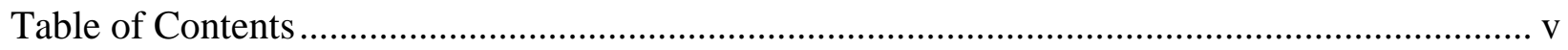

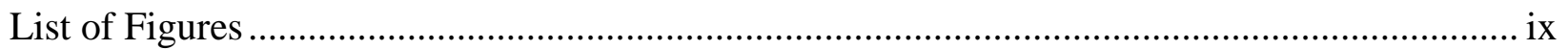

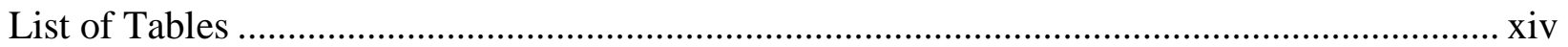

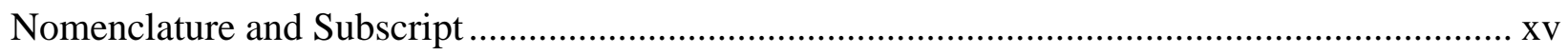

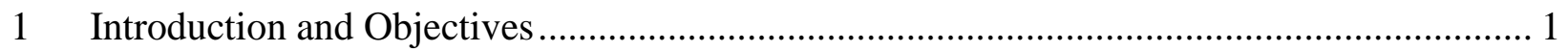

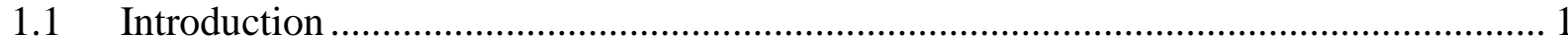

1.1.1 Vehicle Fuel Consumption ........................................................................... 1

1.1.2 Vehicle Development and Emissions ………………....................................... 5

1.1.3 Approaches to Reduce Fuel Consumption........................................................... 8

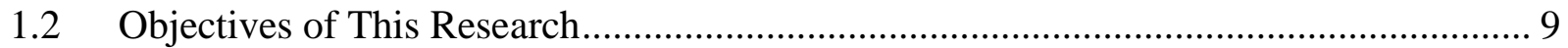

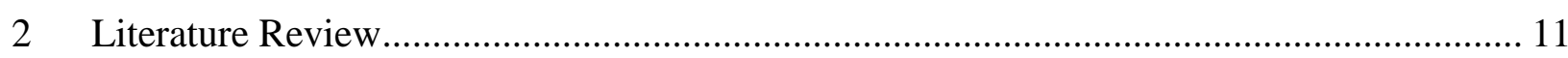

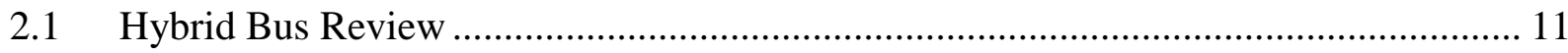

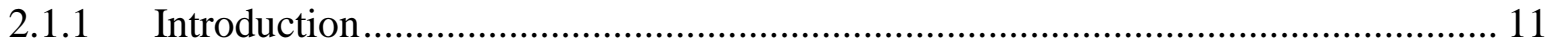

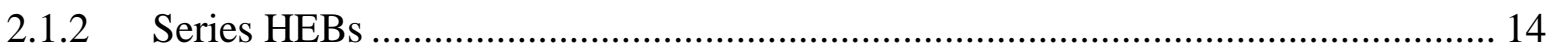

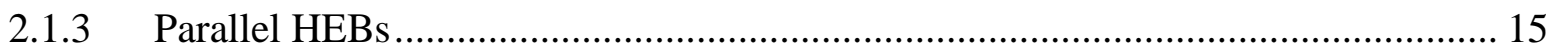

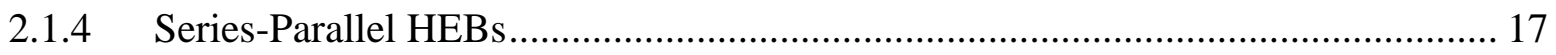

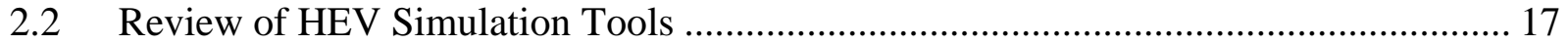

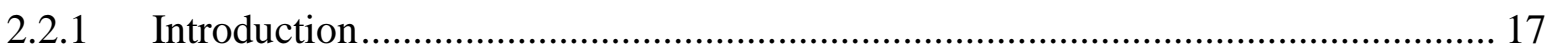

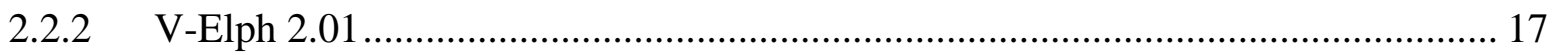

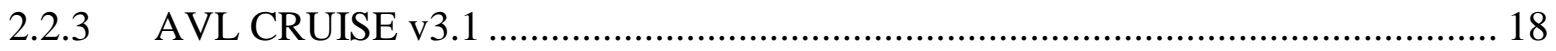

2.2.4 ADvanced VehIcle SimulatOR (ADVISOR) ………......................................... 18 
2.2.5 Powertrain System Analysis Toolkit@ (PSAT) ............................................... 18

2.3 Review of HEV Control Strategies and Impact of Driving Cycle on Fuel Economy.... 20

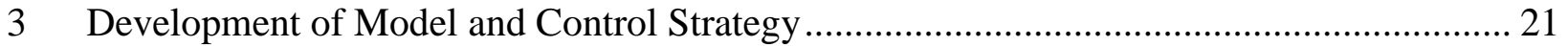

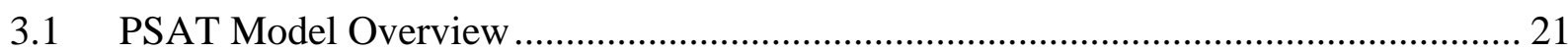

3.2 Parallel Hybrid Bus Powertrain Model ...................................................................... 24

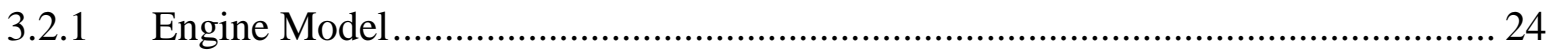

3.2.2 Motor Model .................................................................................................... 28

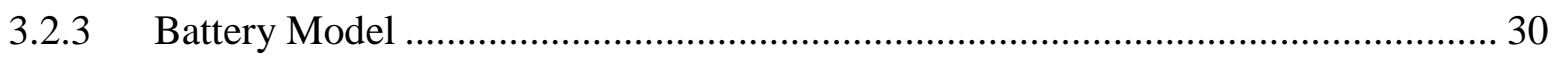

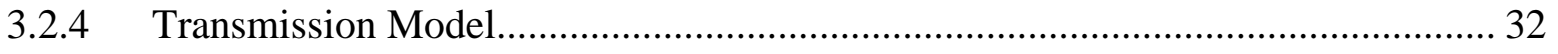

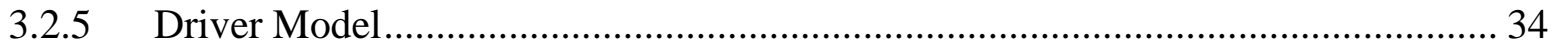

3.2.6 Torque Coupler Model......................................................................... 34

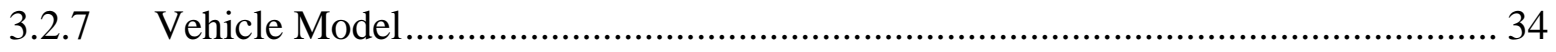

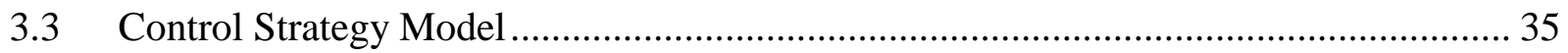

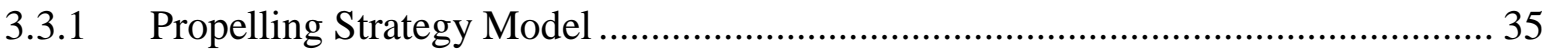

3.3.2 Gear-Shifting Strategy Model ................................................................. 37

3.3.3 Regenerative Braking Strategy Model ........................................................... 38

4 Model Validation and Control Strategy Optimization Using PSAT ............................... 39

4.1 Introduction of China's Bus Driving Cycles and the U.S. Bus Driving Cycles ........... 39

4.1.1 China’s Urban Bus Driving Cycle ............................................................... 39

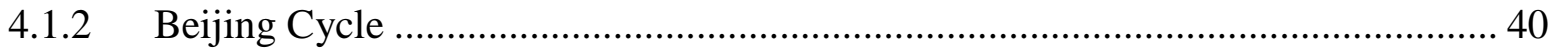

4.1.3 Central Business District Cycle ............................................................. 41

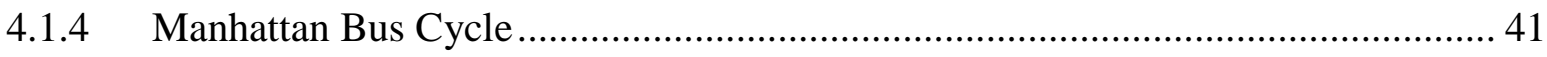

4.1.5 New York Bus Cycle ............................................................................ 41

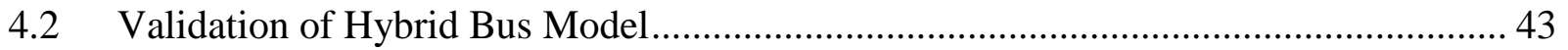


4.3 Development of the Preliminary Engine Efficiency-Based Control Strategy............... 47

4.3.1 Description of the Preliminary Engine Efficiency-Based Control Strategy .......... 47

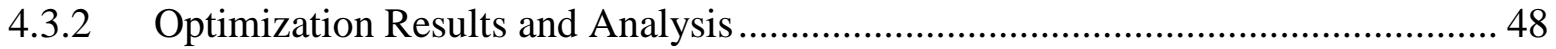

4.4 Development of the Real-Time Overall Efficiency-Based Control Strategy............... 52

4.4.1 Description of the Real-Time Overall Efficiency-Based Control Strategy ........... 52

4.4.2 Optimization Results and Analysis .......................................................... 56

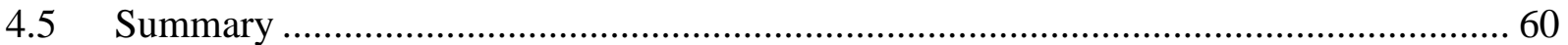

5 Development of Electrical Accessory Model for PSAT ................................................ 61

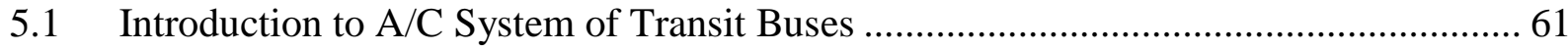

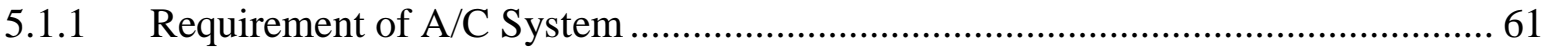

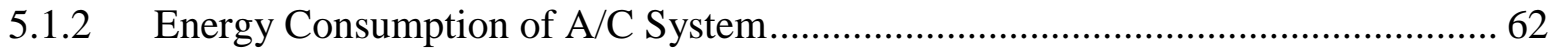

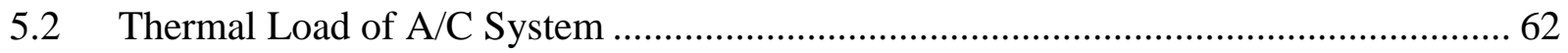

5.2.1 Passenger Thermal and Moisture Load........................................................... 62

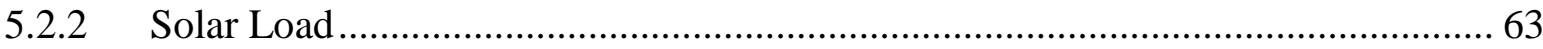

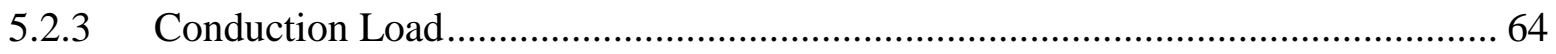

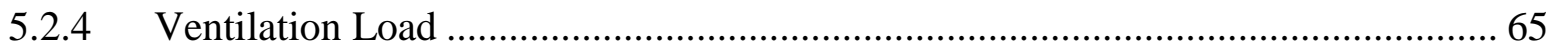

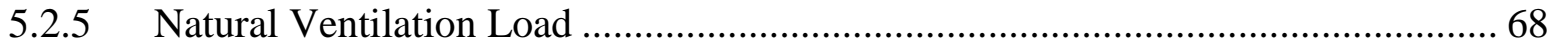

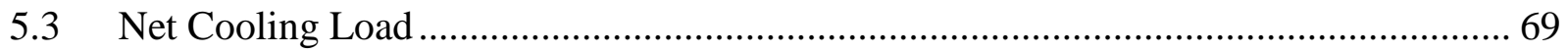

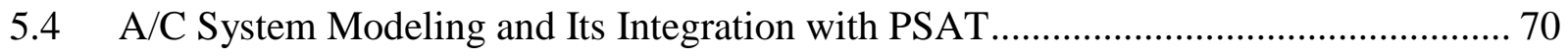

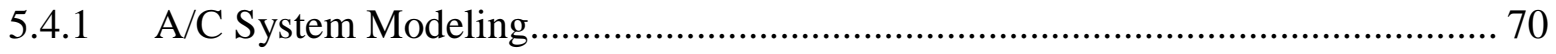

5.4.2 Integration of A/C System with PSAT ….................................................. 72

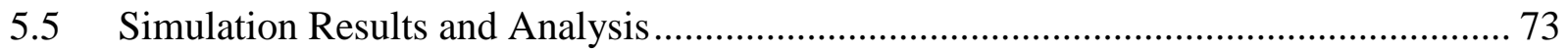

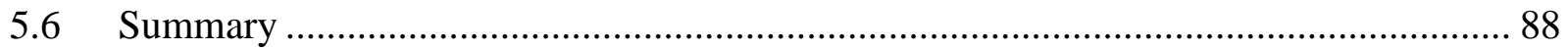

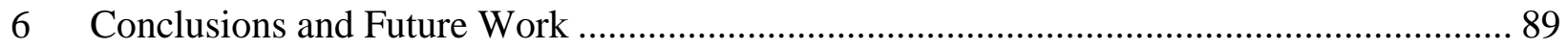




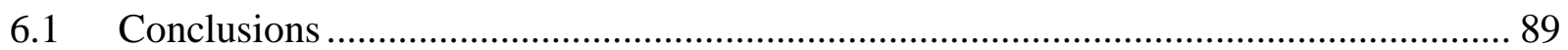

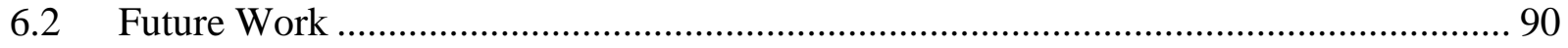

6.2.1 Development of Mechanical Auxiliary Model in PSAT ..................................... 90

6.2.2 Optimization of Control Strategy for both Fuel Economy and $\mathrm{NO}_{\mathrm{x}}$ Emissions ..... 91

6.2.3 Intelligent Hybrid Bus Control Strategies................................................... 92

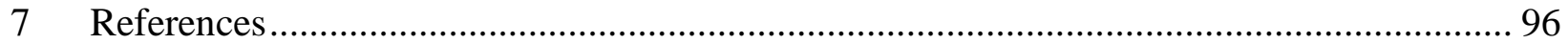




\section{List of Figures}

Figure 1.1 Population of Vehicles Registered in the U.S., 1960-2008 [1] ............................... 2

Figure 1.2 Fuel Consumption by Vehicle in the U.S., 1960-2008 [1] ..................................... 2

Figure 1.3 Overview of the U.S. Petroleum Imports and Consumption [1] .............................. 3

Figure 1.4 Weekly U.S. Regular Conventional Retail Gasoline Prices [2] .............................. 3

Figure 1.5 Average Fuel Economy of Motor Vehicles in the U.S., 1960-2008 [1].................... 4

Figure 1.6 $\mathrm{CO}_{2}$ Emissions in the U.S., 1990-2007 [1] ................................................... 4

Figure 1.7 Estimated National Emissions of $\mathrm{NO}_{\mathrm{x}}$ in the U.S., 1970-2008 [1] .......................... 6

Figure 1.8 Estimated National Emissions of CO in the U.S., 1970-2008 [1] ........................... 6

Figure 1.9 Estimated National Emissions of VOC in the U.S., 1970-2008 [1] ......................... 7

Figure 1.10 Estimated National Emissions of PM by Highway Vehicles in the U.S [1] ............. 7

Figure 2.1 Population of Buses in the U.S., 1960-2008 [1] ................................................. 12

Figure 2.2 Fuel Consumption by Buses in the U.S., 1960-2005 [1]........................................ 12

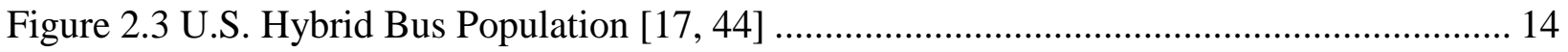

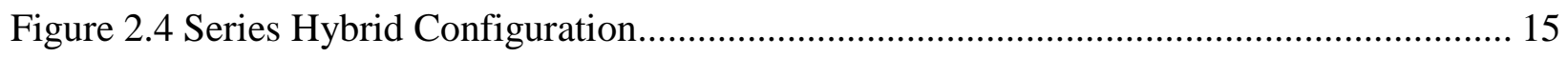

Figure 2.5 Pre-Transmission Parallel Configuration ....................................................... 16

Figure 2.6 Post-Transmission Parallel Configuration.................................................... 16

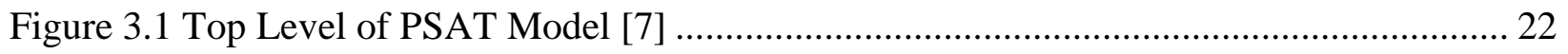

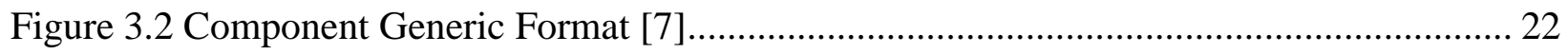

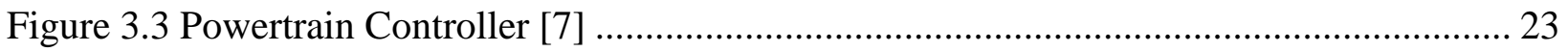

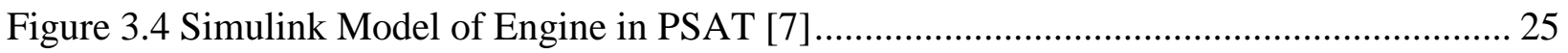

Figure 3.5 BSFC Map of Engine (Unit: g/kW-hr) [65] ................................................... 26

Figure 3.6 Brake Specific $\mathrm{NO}_{\mathrm{x}}$ Emission Map (Unit: g/kW-hr) [65] ..................................... 27 
Figure 3.7 Motor Torque Map and Efficiency Map [65] ................................................... 29

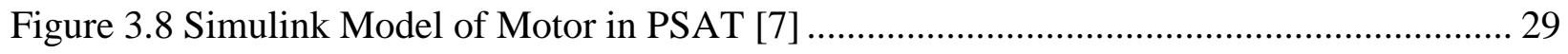

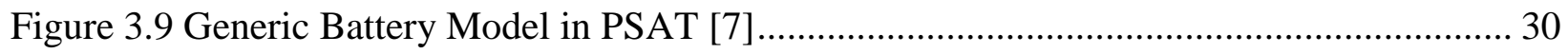

Figure 3.10 Internal Resistance of NiMH Battery Packs as a Function of SOC at $40^{\circ} \mathrm{C}$ [7] ...... 31

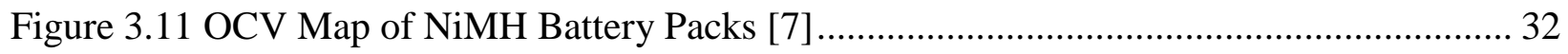

Figure 3.12 Transmission Efficiency Map at Each Gear Position [7] ................................... 33

Figure 3.13 Vehicle Speed Controller in Driver Model [7] ................................................ 34

Figure 3.14 Baseline Control Strategy for Test Hybrid Transit Bus (SOC>SOC $\min$ ) [34] .......... 36

Figure 3.15 Baseline Control Strategy for Test Hybrid Transit Bus ( $\mathrm{SOC}<\mathrm{SOC}_{\min }$ ) [34] .......... 36

Figure 3.16 Gear Up-shifting Map as a Function of Vehicle Speed and Load [65] .................. 37

Figure 3.17 Gear Down-shifting Map as a Function of Vehicle Speed and Load [65] ............... 37

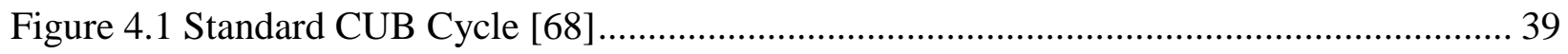

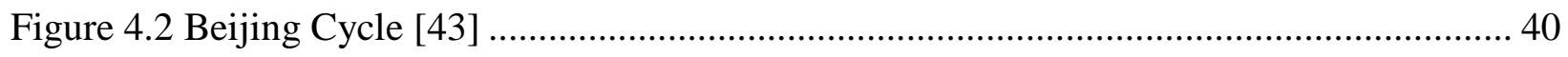

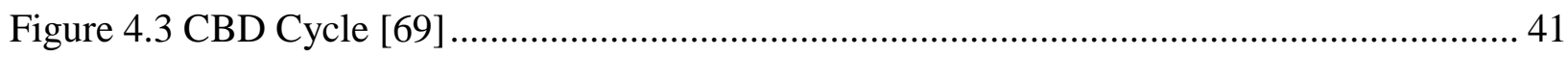

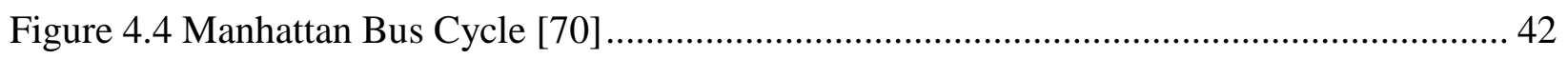

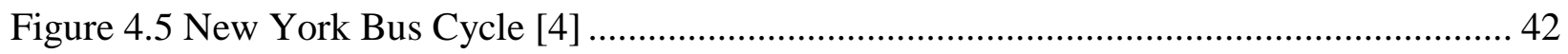

Figure 4.6 Comparison of Vehicle Speed between Test and Simulation over CUB-5 Cycle ...... 44

Figure 4.7 Distribution of Engine Operating Point over CUB-5 Cycle (Initial SOC=65\%) ....... 44

Figure 4.8 Distribution of Motor Operating Points over CUB-5 Cycle (Initial SOC $=65 \%$ )..... 45

Figure 4.9 Simulation of SOC over CUB-5 Cycle (Initial SOC=65\%) .................................45

Figure 4.10 Comparison of Fuel Consumption between Test and Simulation ......................... 46

Figure 4.11 Comparison of Final SOC between Test and Simulation.................................... 46

Figure 4.12 Engine Peak Efficiency Region ................................................................ 48 
Figure 4.13 Comparison of Fuel Consumption between Control Strategy A and Baseline Control over the CBD Cycle 49

Figure 4.14 Comparison of Fuel Consumption between Control Strategy A and Baseline Control over the Manhattan Bus Cycle 50

Figure 4.15 Comparison of Fuel Consumption between Control Strategy A and Baseline Control over the New York Bus Cycle 50

Figure 4.16 Comparison of Tailpipe $\mathrm{NO}_{\mathrm{x}}$ Emissions between Control Strategy A and Baseline Control over the CBD Cycle.....

Figure 4.17 Comparison of Tailpipe $\mathrm{NO}_{\mathrm{x}}$ Emissions between Control Strategy A and Baseline Control over the Manhattan Bus Cycle

Figure 4.18 Comparison of Tailpipe $\mathrm{NO}_{\mathrm{x}}$ Emissions between Control Strategy A and Baseline Control over the New York Bus Cycle 52

Figure 4.19 Engine Operating Points in New York Bus Cycle under Control A (Initial SOC= $70 \%)$

Figure 4.20 Engine Operating Points in New York Bus Cycle under Control B (Initial SOC= $70 \%)$

Figure 4.21 Engine Operating Points in Manhattan Bus Cycle under Control A (Initial SOC= $70 \%)$

Figure 4.22 Engine Operating Points in Manhattan Bus Cycle under Control B (Initial SOC= $70 \%)$

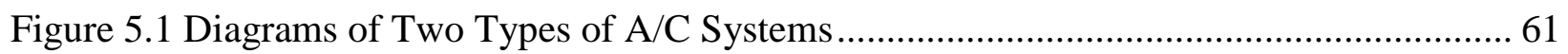

Figure 5.2 Mixing of Outside Air and Recirculated Air .................................................... 65

Figure 5.3 Ventilation Process on Psychrometric Chart [28] .............................................. 67

Figure 5.4 Net Cooling Load as a Function of Cabin Temperature........................................ 70

Figure 5.5 Schematic of Vapor Compression Cycle ....................................................... 71

Figure 5.6 COP of R-134a A/C System as a Function of Outdoor Temperature [31, 62].......... 72 


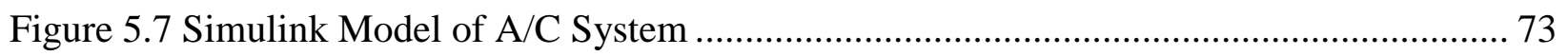

Figure 5.8 Scaled SFTP-SC03 Cycle Used in Parametric Study ................................................ 75

Figure 5.9 Simulation of Cabin Temperature with Different Ambient Temperatures (RH=50\%)75

Figure 5.10 Simulation of A/C Power with Different Ambient Temperatures $(\mathrm{RH}=50 \%)$........... 76

Figure 5.11 Impact of Ambient Temperature on Fuel Consumption $(\mathrm{RH}=50 \%)$.......................... 76

Figure 5.12 Simulation of Humidity Ratio with Different Ambient RH $\left(\mathrm{T}_{\text {cab }}=30^{\circ} \mathrm{C}\right) \ldots \ldots \ldots \ldots \ldots \ldots . . . .77$

Figure 5.13 Simulation of A/C Power with Different Ambient RH $\left(\mathrm{T}_{\mathrm{cab}}=30^{\circ} \mathrm{C}\right) \ldots \ldots \ldots \ldots \ldots \ldots \ldots \ldots . . . . . . . . . . .77$

Figure 5.14 Impact of Ambient RH on Fuel Consumption under Different Ambient Temperatures .78

Figure 5.15 Simulation of Solar Load on Vehicle with Different Apparent Solar Radiation

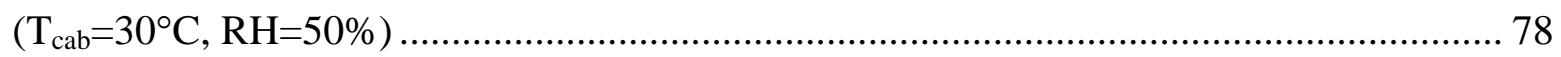

Figure 5.16 Simulation of A/C Power with Different Solar Radiation $\left(\mathrm{T}_{\mathrm{cab}}=30^{\circ} \mathrm{C}, \mathrm{RH}=50 \%\right) \ldots 79$

Figure 5.17 Impact of Solar Radiation on Fuel Consumption $\left(\mathrm{T}_{\text {cab }}=30^{\circ} \mathrm{C}, \mathrm{RH}=50 \%\right)$............... 79

Figure 5.18 Simulation of Natural Ventilation Load over Scaled Manhattan Bus Cycle.............. 81

Figure 5.19 Variation of Cabin Temperature over Scaled Manhattan Bus Cycle ......................... 81

Figure 5.20 Variation of Cabin RH over Scaled Manhattan Bus Cycle ....................................... 82

Figure 5.21 Variation of A/C Power over Scaled Manhattan Bus Cycle ...................................... 82

Figure 5.22 Climate Zones of the Continental United States [13] ............................................. 83

Figure 5.23 Simulation of Cabin Temperature in Florida, Arizona, and West Virginia ............... 84

Figure 5.24 Simulation of Cabin Humidity Ratio in Florida, Arizona, and West Virginia........... 85

Figure 5.25 Simulation of Ventilation Load in Florida, Arizona, and West Virginia ................... 85

Figure 5.26 Simulation of Conduction Load in Florida, Arizona, and West Virginia ................. 86

Figure 5.27 Simulation of Solar Load in Florida, Arizona, and West Virginia............................. 86

Figure 5.28 Simulation of A/C Power in Florida, Arizona, and West Virginia ........................... 87 
Figure 5.29 Impact of A/C Influence on Fuel Consumption in Florida, Arizona, and West Virginia .......

Figure 6.1 Cost of Urea Solution Consumption by the SCR System in Equivalent BSFC (Unit:

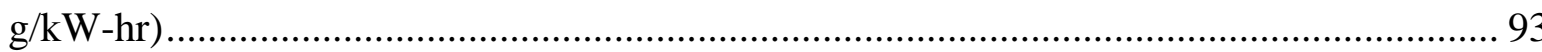

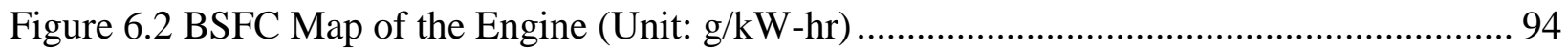

Figure 6.3 Overall BSFC Map Considering the Cost of Urea Solution Consumption and the Cost of Fuel Consumption (Unit: g/kW-hr) ………………………………………………..... 95 


\section{List of Tables}

Table 2.1 EPA Emission Standard for Urban Bus Engines since 1991 [3] .............................. 13

Table 3.1 Parameters in Vehicle Model ........................................................................... 35

Table 4.1 Characteristics of Bus Driving Cycles in China and the U.S. ................................ 40

Table 4.2 Initial SOCs for Each Test Cycle........................................................................ 43

Table 4.3 Relative Errors of Fuel Consumption and SOC ................................................ 47

Table 4.4 Comparison of Simulation Results in PSAT between Control A and Control B ......... 57

Table 4.5 Comparison of Component and Powertrain Efficiencies between Control A and

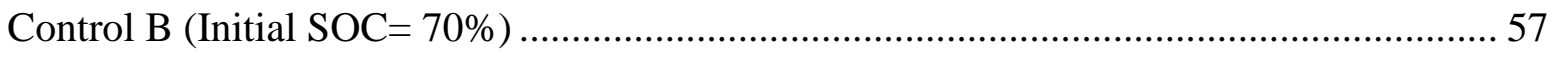

Table 5.1 Main Parameters for Calculation of Solar Load $[14,36]$....................................... 64

Table 5.2 Effect of Ambient Condition on the Overall Fuel Consumption.............................. 80

Table 5.3 Average Ambient Parameters in West Virginia, Arizona, and Florida when A/C is on

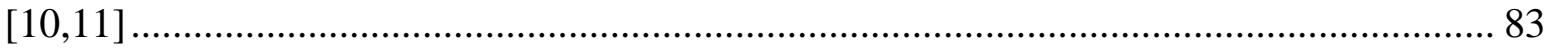




\section{Nomenclature and Subscript}

\section{Nomenclature Description}

A

Area

$\mathrm{AC}$

Alternating Current

$\mathrm{A} / \mathrm{C}$

Air Conditioning

ADVISOR

ADvanced VehIcle SimulatOR

AMT

Automated Manual Transmission

AT

Automatic Transmission

BSFC

Brake Specific Fuel Consumption

C

Cost

CAFE

Corporate Average Fuel Efficiency

Capacity

Capacity of energy storage system

CARB

California Air Resources Board

CBD

Central Business District

$\mathrm{C}_{\mathrm{D}}$

Drag Coefficient

$\mathrm{CNG}$

Compressed Natural Gas

$\mathrm{CO}$

Carbon Monoxide

$\mathrm{CO}_{2}$

Carbon Dioxide

COP

Coefficient of Performance

CRC

Coordinating Research Council

CTT

Closed Throttle Torque

CUB

China's Urban Bus

CVT

Continuously Variable Transmission 


\begin{tabular}{|c|c|}
\hline $\mathrm{DC}$ & Direct Current \\
\hline DOE & Department of Energy \\
\hline ESS & Energy Storage System \\
\hline EPA & Environmental Protection Agency \\
\hline EV & Electric Vehicle \\
\hline FCV & Fuel Cell Vehicle \\
\hline $\mathrm{FE}$ & Fuel Economy \\
\hline $\mathrm{g} / \mathrm{bhp}-\mathrm{hr}$ & grams per brake horsepower hour \\
\hline $\mathrm{g} / \mathrm{kWh}$ & grams per kilowatt hour \\
\hline $\mathrm{g}$ & Gravity \\
\hline $\mathrm{g}^{\prime}$ & Reduced gravity \\
\hline GHG & Greenhouse Gas \\
\hline GPS & Global Positioning System \\
\hline GUI & Graphical User Interface \\
\hline $\mathrm{h}$ & Enthalpy \\
\hline $\mathrm{H}$ & Height \\
\hline $\mathrm{HC}$ & Hydrocarbons \\
\hline HEB & Hybrid Electric Bus \\
\hline HEV & Hybrid Electric Vehicle \\
\hline HIL & Hardware-In-the-Loop \\
\hline i & Enthalpy of air \\
\hline I & Current \\
\hline ICE & Internal Combustion Engine \\
\hline LEV & Low Emission Vehicle \\
\hline
\end{tabular}




\begin{tabular}{|c|c|}
\hline LNG & Liquefied Natural Gas \\
\hline LPG & Liquefied Petroleum Gas \\
\hline $\mathrm{M} / \mathrm{G}$ & Motor/Generator \\
\hline MPG & Miles Per Gallon \\
\hline MT & Manual Transmission \\
\hline NHTSA & National Highway Traffic Safety Administration \\
\hline $\mathrm{NiMH}$ & Nickel-Metal Hydride \\
\hline NMHC & Non-methane Hydrocarbon \\
\hline $\mathrm{NO}_{\mathrm{x}}$ & Oxides of Nitrogen \\
\hline NO & Nitrogen Monoxide \\
\hline $\mathrm{NO}_{2}$ & Nitrogen Dioxide \\
\hline NREL & National Renewable Energy Laboratory \\
\hline $\mathrm{OCV}$ & Open-Circuit Voltage \\
\hline$P$ & Power \\
\hline PI & Proportional and Integral \\
\hline $\mathrm{PM}$ & Particulate Matter \\
\hline PSAT & Powertrain System Analysis Toolkit \\
\hline $\mathrm{R}$ & Resistance \\
\hline $\mathrm{RH}$ & Relative Humidity \\
\hline SCR & Selective Catalytic Reduction \\
\hline SI & Spark-Ignition \\
\hline SOC & State of Charge \\
\hline $\mathrm{T}$ & Torque \\
\hline Temp & Temperature \\
\hline
\end{tabular}




$\begin{array}{ll}\text { V } & \text { Voltage } \\ \text { VOC } & \text { Volatile Organic Compounds } \\ \text { WOT } & \text { Wide Open Throttle } \\ \beta & \text { Mass ratio of fresh air } \\ \omega & \text { Absolute humidity of air } \\ \eta & \text { Efficiency } \\ v & \text { Velocity } \\ \rho & \text { Density }\end{array}$




\begin{tabular}{ll} 
Subscript & Description \\
a & air \\
abs & absolute \\
acc & acceleration \\
ambient & \\
b & recirculated air \\
blower & \\
brake & mechanical braking system \\
cabin & vehicle cabin \\
cargo & vehicle cargo \\
charge & battery charging \\
cmd & command \\
cond & conduction \\
e & engine \\
ess & inside \\
diff & energy storage system \\
dir & diffuse \\
door & direct \\
electrical & vehicle door \\
fd & grade \\
\hline gb & hearbox \\
\hline
\end{tabular}




\begin{tabular}{|c|c|}
\hline in & input \\
\hline $\mathrm{m}$ & motor \\
\hline $\max$ & maximum \\
\hline mech & mechanical \\
\hline $\min$ & minimum \\
\hline o & outside \\
\hline occupan & \\
\hline operatio & \\
\hline out & output \\
\hline overall & overall system \\
\hline prop & propelling \\
\hline $\mathrm{r}$ & rolling \\
\hline range & \\
\hline regen & regenerative braking \\
\hline relative & \\
\hline ref & reflected \\
\hline request & \\
\hline solar & \\
\hline step & variable step \\
\hline t & transmission \\
\hline tc & torque coupler \\
\hline used & \\
\hline $\mathrm{v}$ & vapor \\
\hline
\end{tabular}


ventilation

W

wd water

wind 


\section{Introduction and Objectives}

\subsection{Introduction}

\subsubsection{Vehicle Fuel Consumption}

The first modern vehicle powered by an internal combustion engine (ICE) was invented by Karl Benz in 1888. Since then, vehicle technology has undergone significant development to address concerns in different phases such as vehicle performance, reliability, durability, safety, fuel economy and emission control, and greenhouse gas (GHG) emissions recently. The population of vehicles has grown dramatically due to its indispensable role in various aspects of current lives. As shown in Figure 1.1, the U.S. had as many as 256 million registered motor vehicles by 2008, which was almost 3.5 times the vehicle population in 1960.

Although automobiles have brought a lot of benefits to the society, issues caused by vehicles came forth at the same time. For example, gasoline equivalent fuel consumption by motor vehicles in the U.S. during 2008 was nearly three times that in 1960 as shown in Figure 1.2. As shown in Figure 1.3 the U.S. imported more than half of the oil it consumed in 2008, which raised a lot of concern for national security of energy. Much attention has been paid to the current shortage of fossil oil. The improvement of fuel efficiency and applications of alternative fuels have become important areas. Figure 1.4 shows weekly U.S. regular conventional retail gasoline prices. Automobile manufacturers, under the pressure of high oil prices, government regulation of emissions and fuel consumption, and competition from the other manufacturers, are seeking solutions to improve fuel economy. Because of their efforts, fuel economy of vehicles has been improved dramatically since the 1970s. Figure 1.5 shows average gasoline equivalent fuel economy of motor vehicles in the U.S. during the last fifty years. It can be found that fuel economy experienced three main phases. Since 1975, fuel economy rapidly was improved until it reached its peak in 1987 due to an oil crisis. Then from 1987 to 2001, fuel economy was stagnated mainly due to increase of vehicle weight, safety concern, and the implementation of emission regulations. Since 2001 fuel economy has started to be improved slowly again. In 2006, National Highway Traffic Safety Administration (NHTSA) published a final rule to slightly increase corporate average fuel efficiency (CAFE) standard for SUVs, minivans and pickup trucks for 2008-2011. 


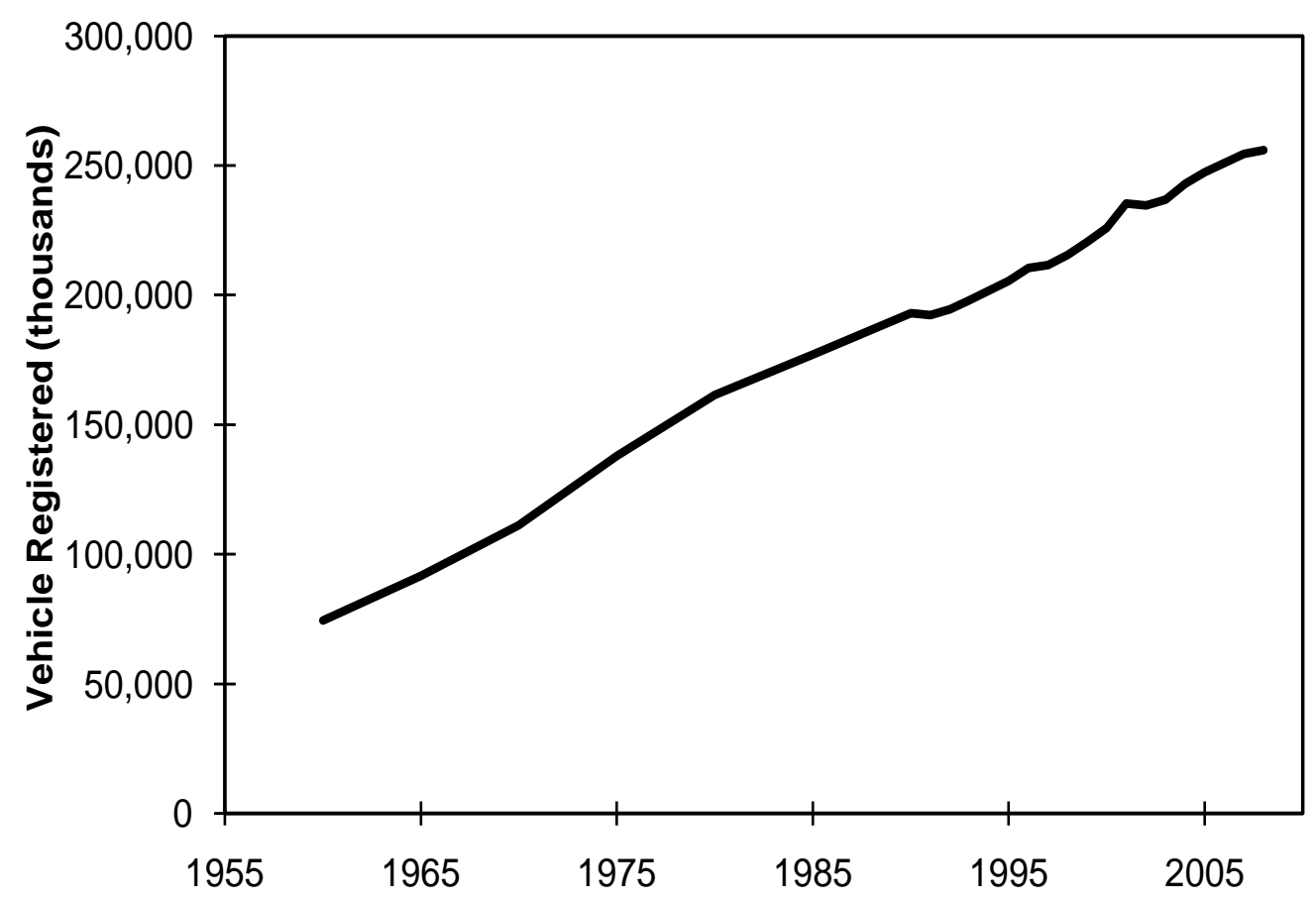

Figure 1.1 Population of Vehicles Registered in the U.S., 1960-2008 [1]

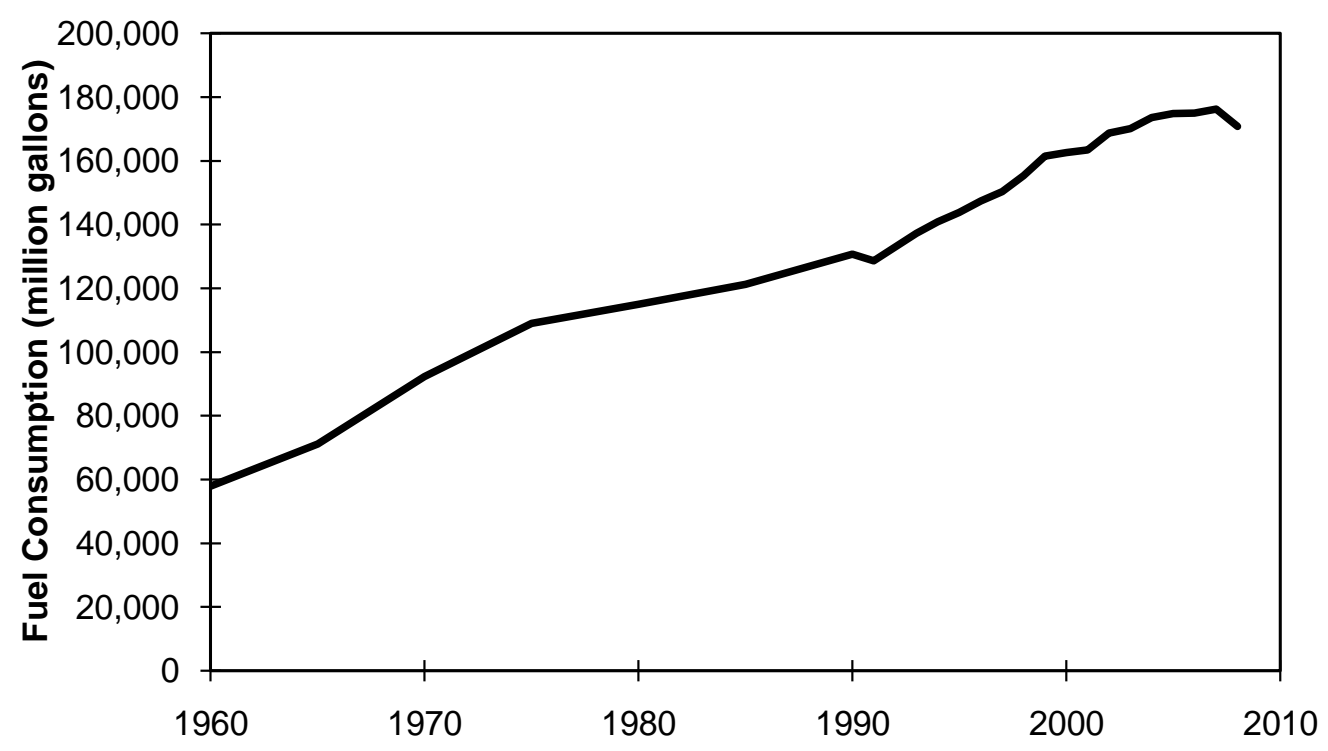

Figure 1.2 Fuel Consumption by Vehicle in the U.S., 1960-2008 [1] 


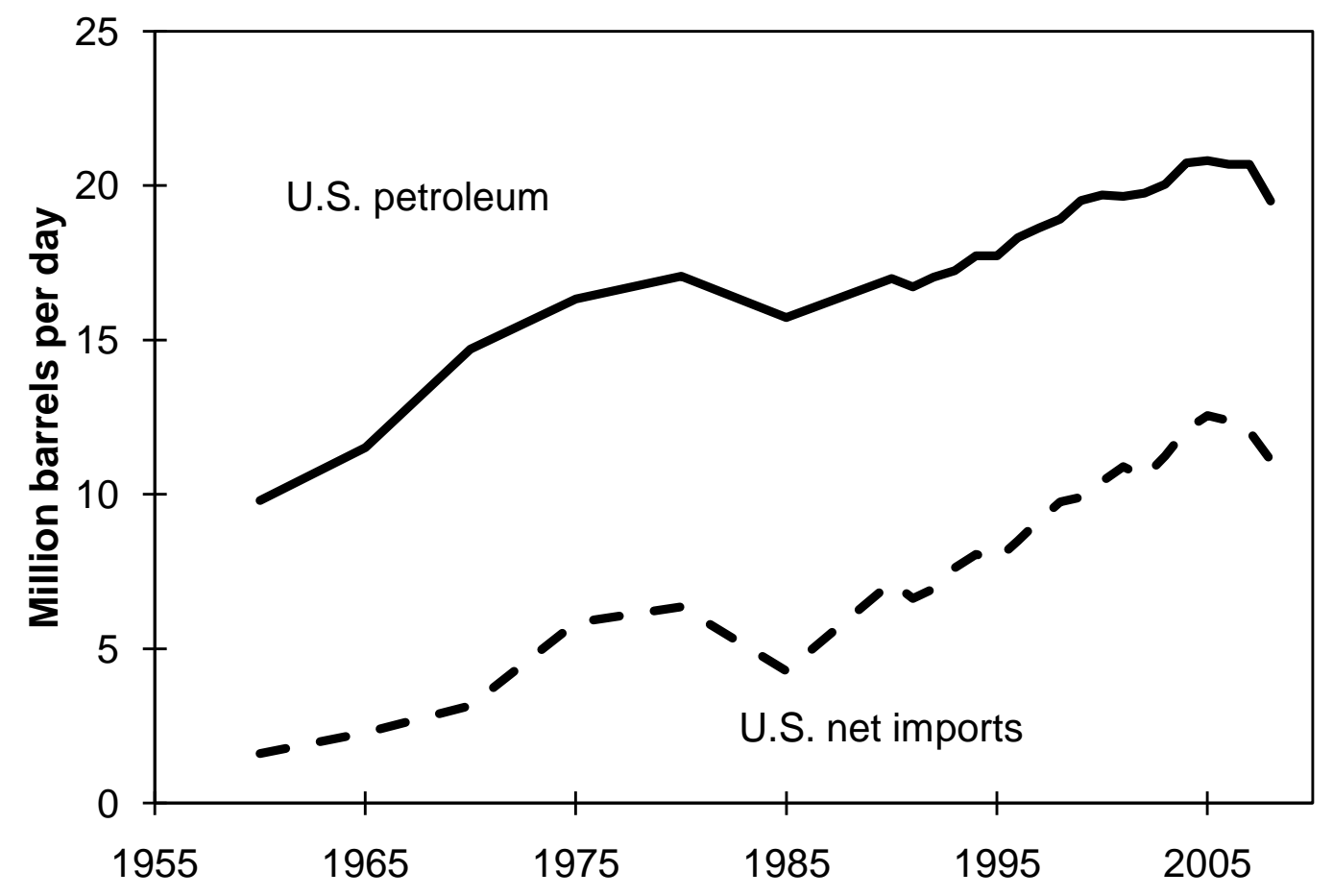

Figure 1.3 Overview of the U.S. Petroleum Imports and Consumption [1]

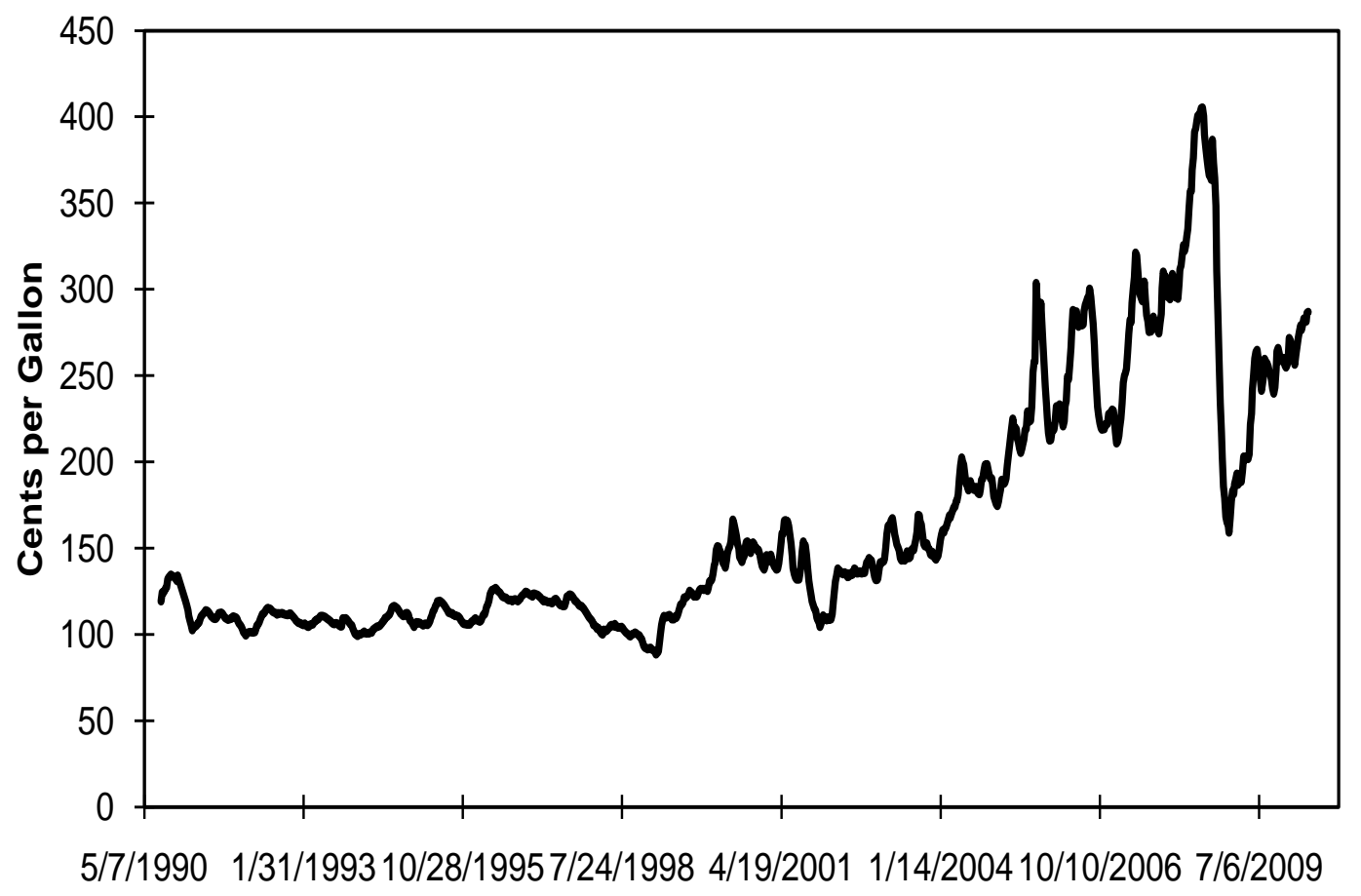

Figure 1.4 Weekly U.S. Regular Conventional Retail Gasoline Prices [2] 


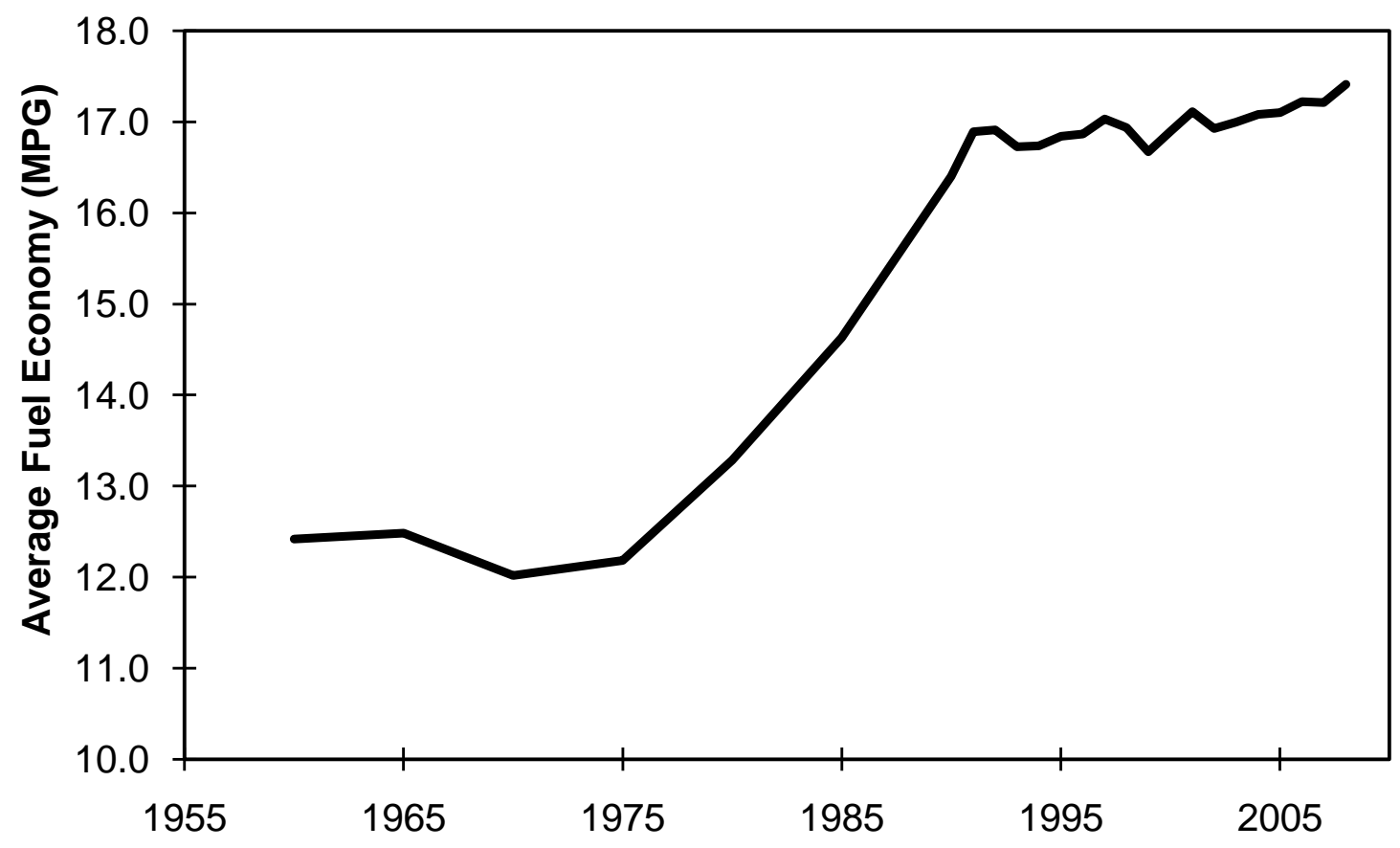

Figure 1.5 Average Fuel Economy of Motor Vehicles in the U.S., 1960-2008 [1]

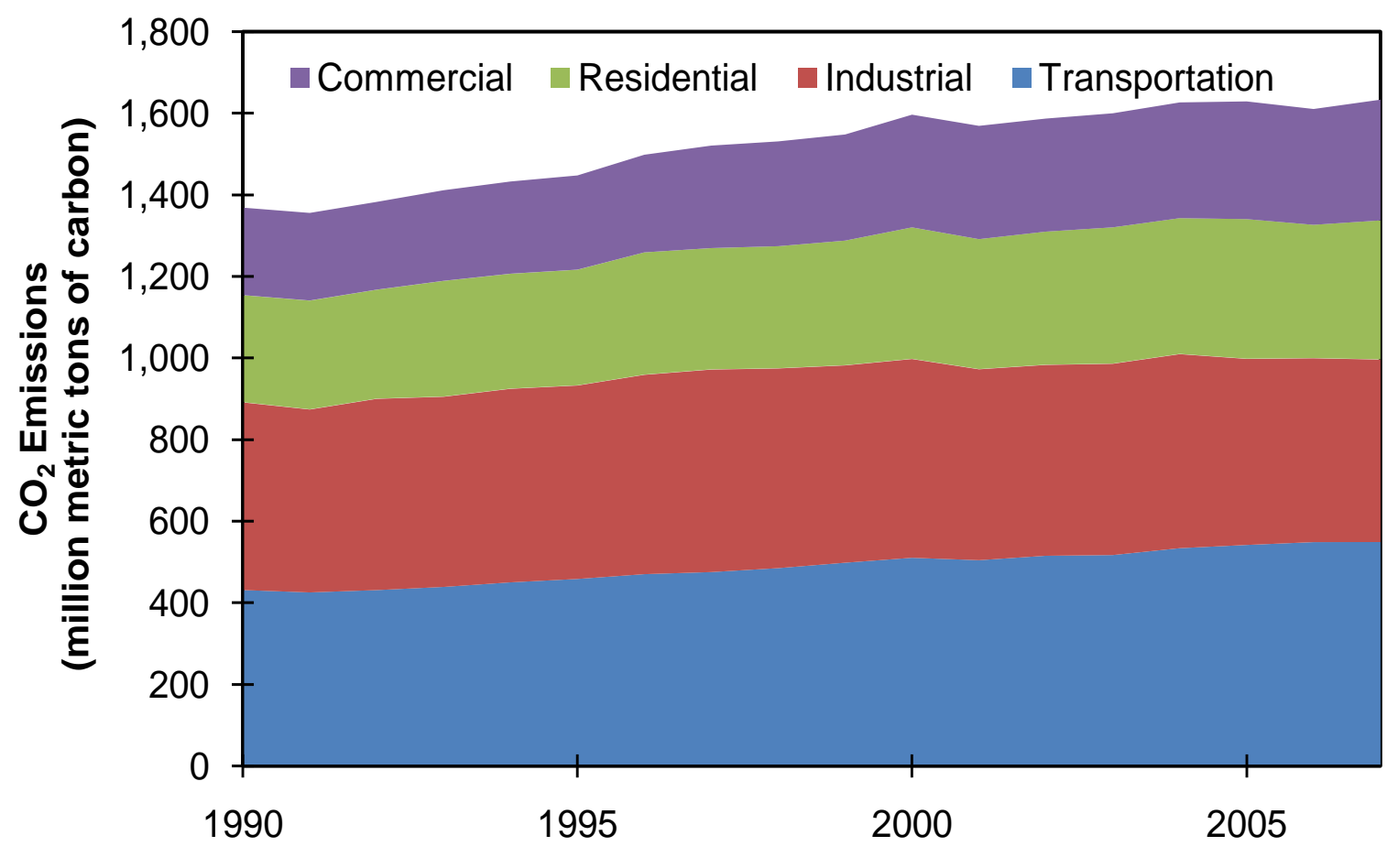

Figure 1.6 $\mathrm{CO}_{2}$ Emissions in the U.S., 1990-2007 [1] 
In addition, transportation contributed to one third of the national GHG emissions in the U.S. as shown in Figure 1.6. Regulation of GHG is so far-reaching that on September 15, 2009, the Environmental Protection Agency (EPA) proposed the first-ever light-duty vehicle GHG emissions standards under the Clean Air Act for MY2012-2016 (74 Federal Register 49454, September 28, 2009) [67]. As GHG is put under regulation, reducing GHG will become another tough challenge in vehicle development.

\subsubsection{Vehicle Development and Emissions}

The reduction of air pollutions from combustion devices, such as spark ignition (SI) engines and diesel engines, is becoming an increasingly serious concern due to the rise in fuel consumption, especially in the transportation area [40]. The main pollutants from IC engines include oxides of nitrogen $\left(\mathrm{NO}_{\mathrm{x}}\right)$, carbon monoxide $(\mathrm{CO})$, volatile organic compounds (VOC), and particulate matter (PM). Figure 1.7, Figure 1.8, Figure 1.9, and Figure 1.10 show $\mathrm{NO}_{\mathrm{x}}, \mathrm{CO}, \mathrm{VOC}$, and PM emissions including highway and others (such as off-highway, fuel combustion, industrial processes, waste disposal and recycling and miscellaneous) in the U.S. from 1970 to 2008. It was found that all the four pollutants have been reduced dramatically in the past 40 years. In 2008, highway vehicles contributed $32 \% \mathrm{NO}_{\mathrm{x}}, 50 \% \mathrm{CO}, 21 \% \mathrm{VOC}$, and $1.4 \% \mathrm{PM}_{10}\left(4.5 \% \mathrm{PM}_{2.5}\right)$ to those of national emissions [71]. $\mathrm{NO}_{\mathrm{x}}$ emissions can cause harmful effects such as acid rain, fine particles and ozone smog, which result in illness and deaths. CO, a product of incomplete combustion, reduces the flow of oxygen in the bloodstream and may cause death of people. PM from diesel engines can be inhaled into the lungs causing aggravated asthma and lung damage, especially in children who are more susceptible to air pollution than adults. Hydrocarbon (HC) emissions resulting from incomplete combustion of fuel molecules in the engine react with $\mathrm{NO}_{\mathrm{x}}$ to form ozone, which causes damage of lungs and eyes. 


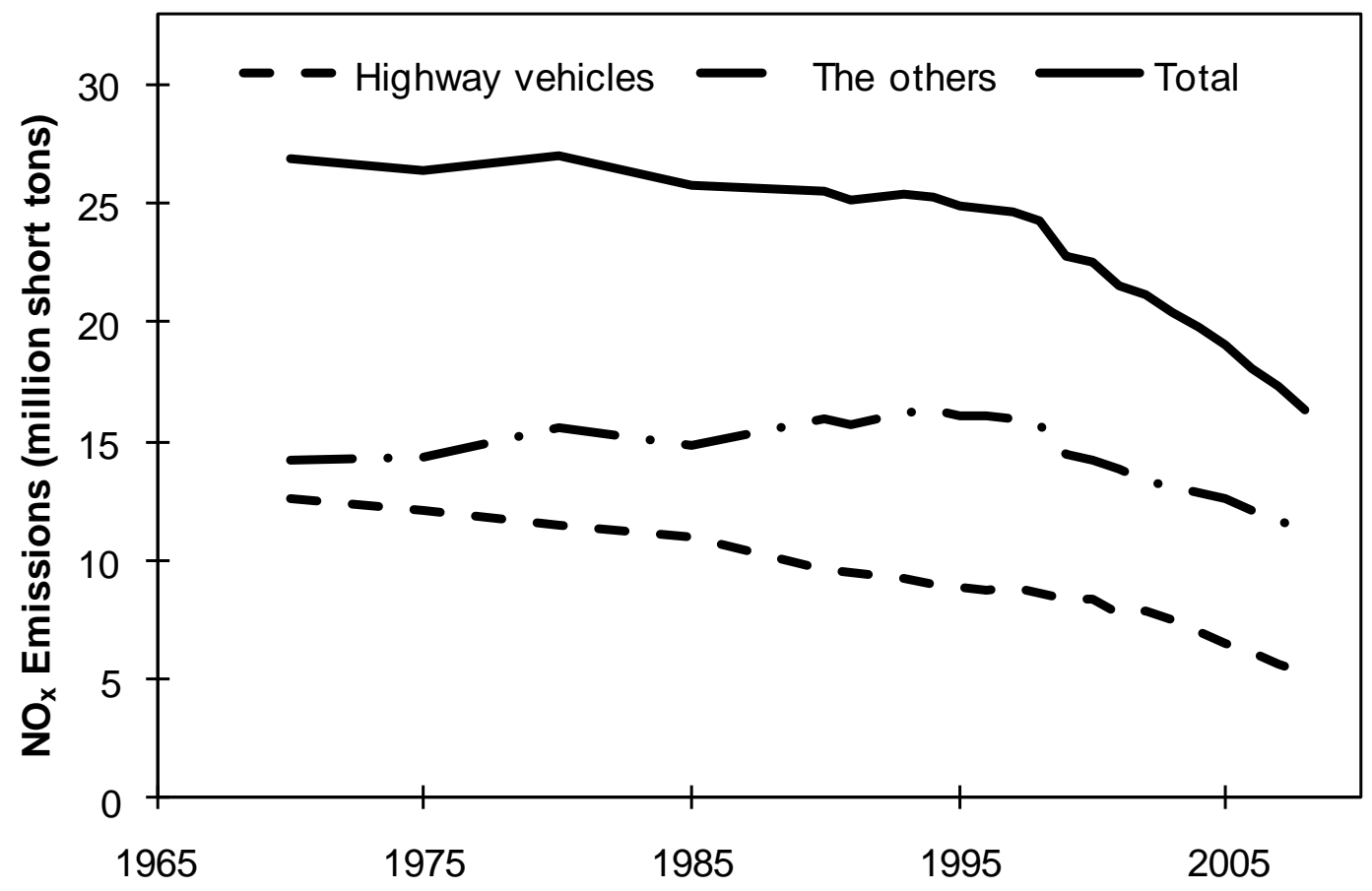

Figure 1.7 Estimated National Emissions of $\mathrm{NO}_{\mathrm{x}}$ in the U.S., 1970-2008 [1]

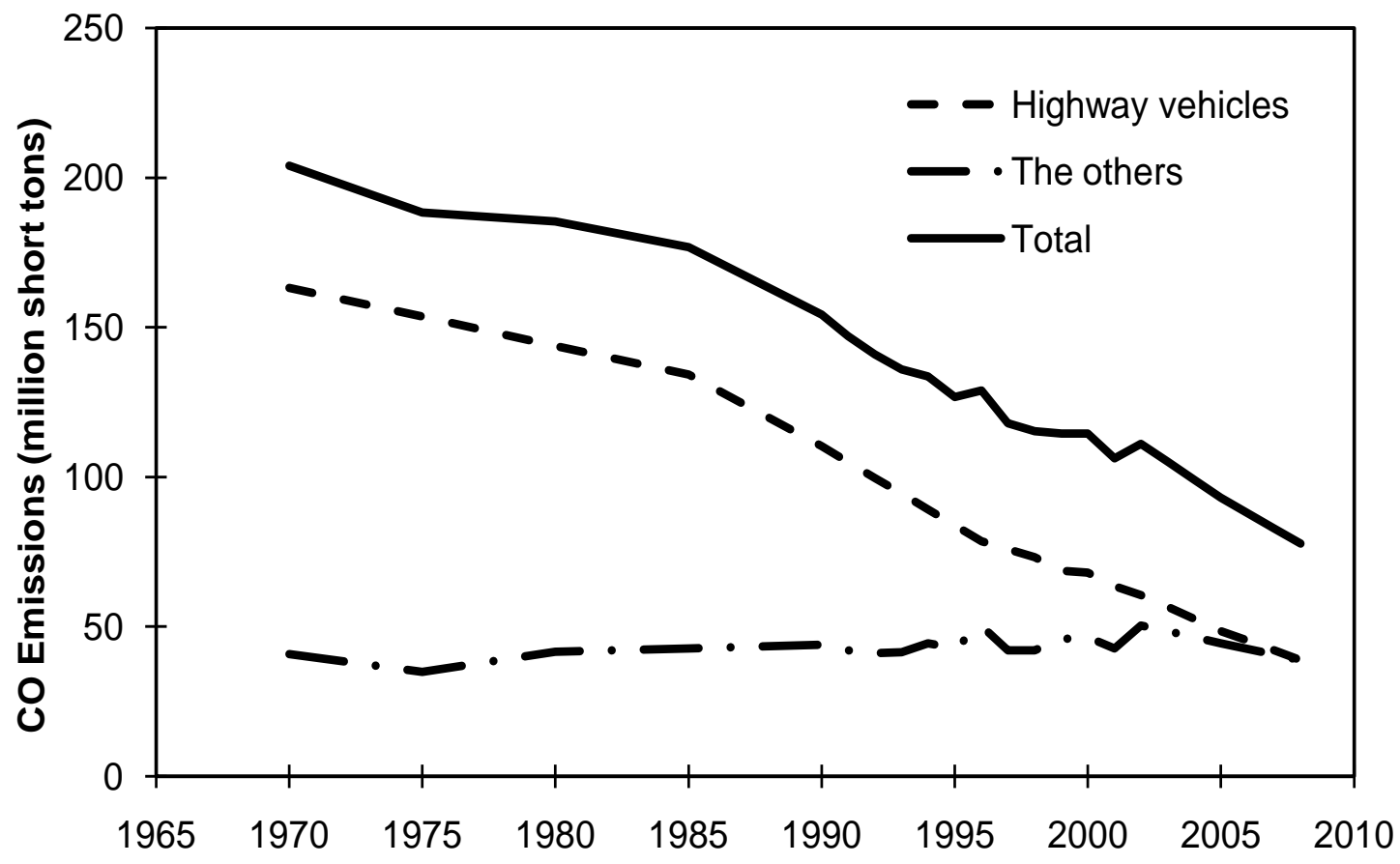

Figure 1.8 Estimated National Emissions of CO in the U.S., 1970-2008 [1] 


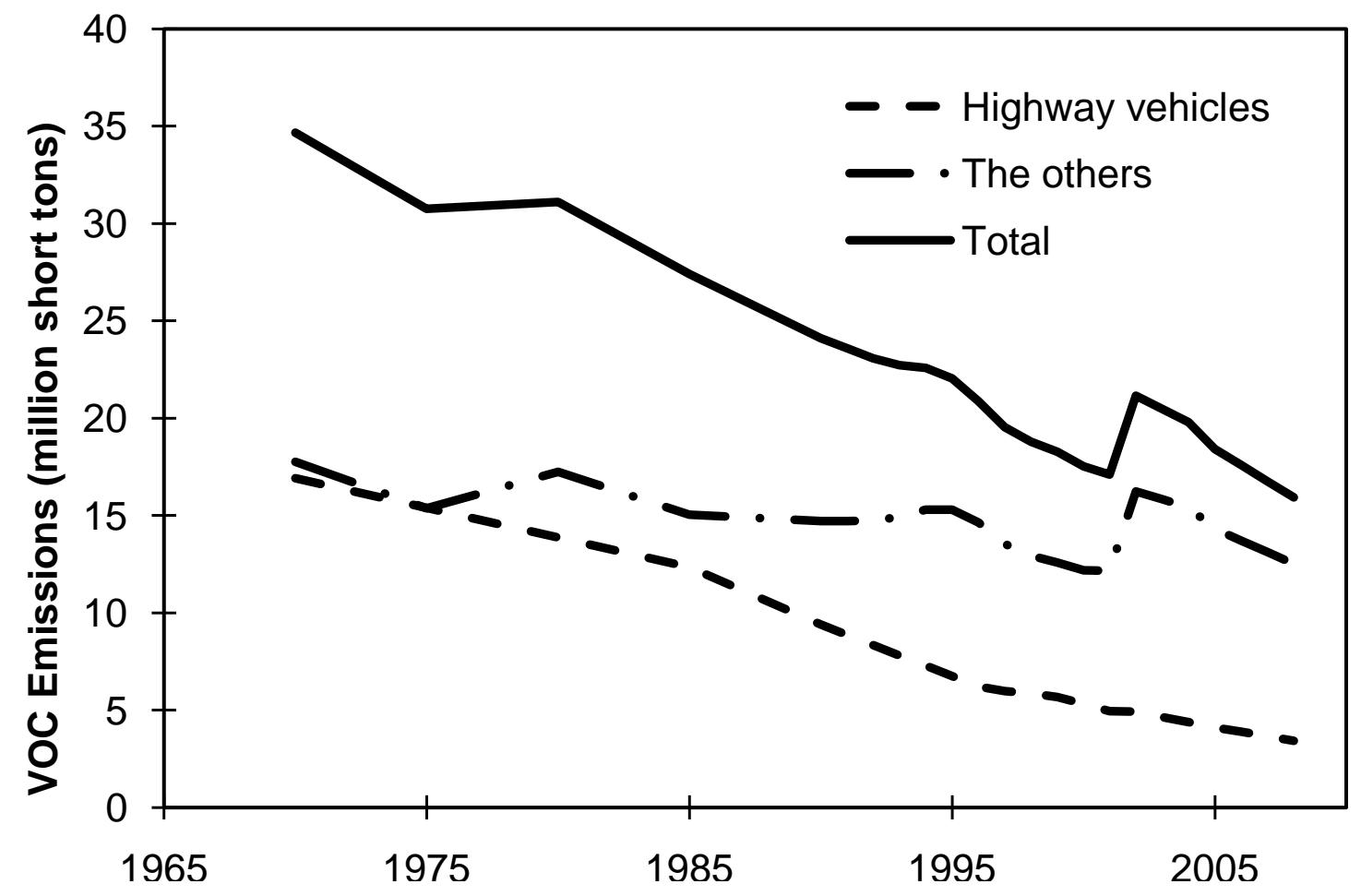

Figure 1.9 Estimated National Emissions of VOC in the U.S., 1970-2008 [1]

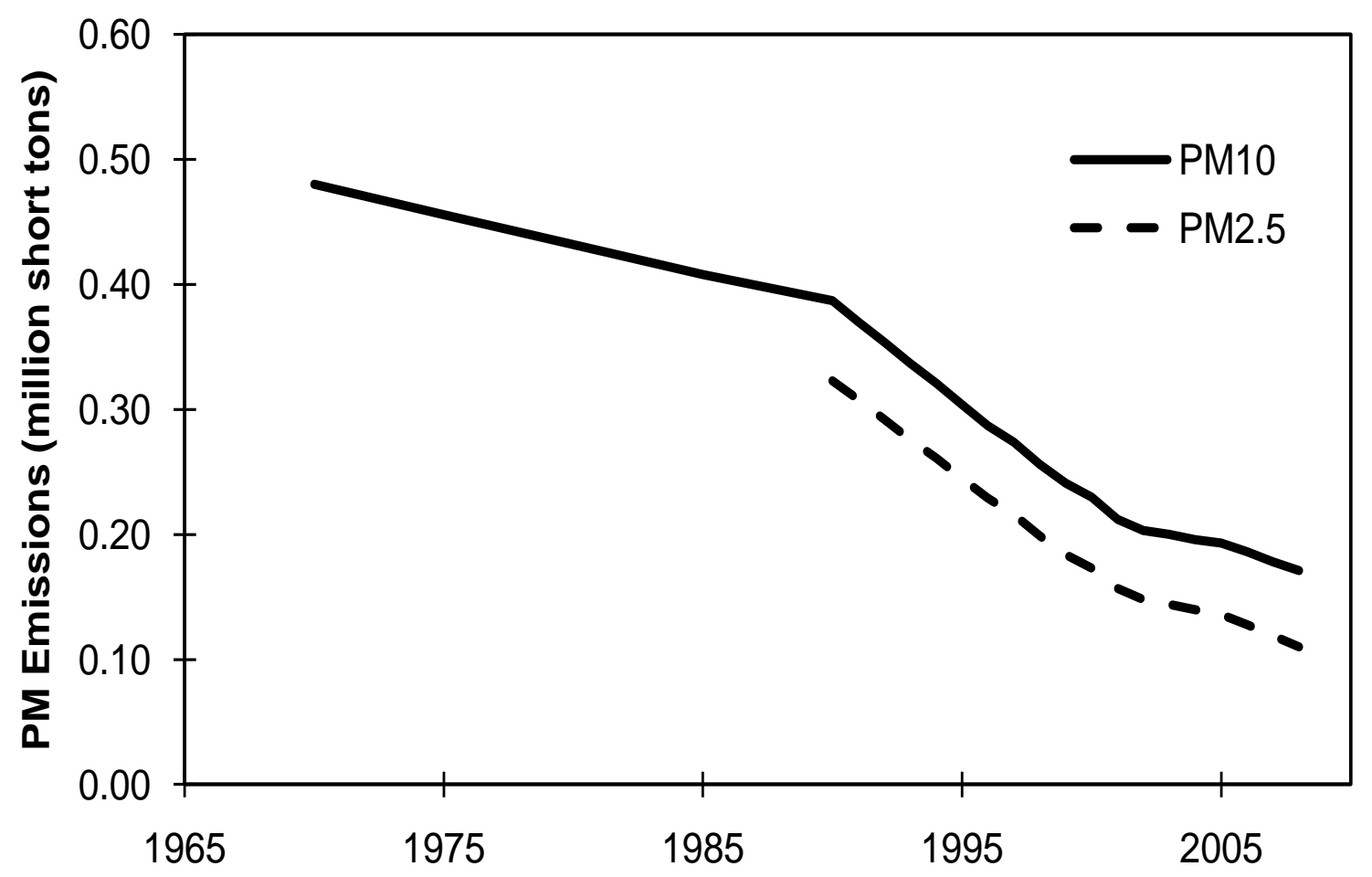

Figure 1.10 Estimated National Emissions of PM by Highway Vehicles in the U.S [1] 


\subsubsection{Approaches to Reduce Fuel Consumption}

The fuel economy of vehicles can be improved by the non-powertrain approaches and the powertrain approaches. Non-powertrain approaches to improve fuel economy are mainly focused on reducing vehicle weight, aerodynamic drag coefficient $\left(C_{D}\right)$, and rolling resistance. Since rolling resistance, inertia loss and braking loss are directly related to vehicle mass, reducing vehicle weight has proven to be an efficient way to improve fuel economy. Vehicle mass reduction can be achieved by taking advantage of lightweight materials including aluminum, magnesium, carbon fiber and metal matrix composites. Aluminum technology can cut current vehicle weight in half and has been applied by many manufacturers. Improvements in vehicle dynamics have been an important part of the overall fuel economy improvement of the U.S. light-duty fleet, with average drag coefficients being reduced from $0.45-0.50$ in 1979-1980 to 0.30-0.35 today, with some models in the 0.27-0.29 range [47]. Since vehicle speed is based on the driving cycle and the frontal area cannot be reduced to a large extent, the only opportunity to reduce air resistance goes to $C_{D}$, which can be reduced by using streamlining design. The influence of the rolling resistance on fuel economy has been recognized to be significant. The sensitivity of fuel economy to rolling resistance can be represented by the return factor in the form of $\mathrm{X}: \mathrm{Y}$, which means that a reduction of rolling resistance by $\mathrm{Y} \%$ can result in a improvement of fuel economy by X\%. Also, the rolling resistance was found to be speed dependent [55].Typical values for commercial trucks vary from 1:6 to 1:2.5 [26, 38, 52]. Rolling resistance of the vehicle can also be reduced by using new materials and new tire design. Powertrain approaches to reduce fuel consumption can be realized by improving efficiencies of components in the powertrain, mainly engine and transmission. Since engine operation is directly related to fuel efficiency, several technologies have emerged to improve engine efficiency. For example, low fuel consumption, low cold-start emissions and low cost can be achieved in both gasoline engines and diesel engines by direct injection technologies such as swirl-type fuel injectors for gasoline engines and high pressure common rail system for diesel engines [51]. Also, engine downsizing helps the engine operate more efficiently and reduces fuel consumption. Transmission technologies such as continuously variable transmissions (CVT) and automated manual transmission (AMT) play an important role in improving fuel efficiency [61]. Automatic transmission (AT) provides good driving performance but low efficiency. While conventional manual transmission (MT) offers efficiency as high as 80 90\%, however, the complexity and 
inconvenience in driving are out of favor in modern vehicles. By application of CVT which provides continuous shifting, engine speed is decoupled from the wheel speed so that high efficiency engine operation and good drivability can be reached. Vehicles with AMT offer lower fuel consumption while maintaining good driving comfort with the development of shifting controls and torque gap filling devices.

To address the issue of low fuel economy brought by conventional vehicles, several new propulsion systems have been proposed as candidates for the future. Battery-electric vehicles are favored for their performance without on-site emissions but are not going to be prevalent in the near future due to immature battery technology. Vehicles can also be propelled by $\mathrm{H}_{2}$ fuelled fuel cell with higher energy efficiency, lower operating noise and less vibration than conventional vehicles. However, fuel cell vehicles (FCVs) are currently facing several challenges such as high overall cost of the vehicle, unsatisfactory reliability and durability of the fuel cells, and high cost of $\mathrm{H}_{2}$ production [20]. Hybrid electric vehicles (HEVs) are regarded as a practical and promising solution in the short term to reduce fuel consumption and emissions. By application of engine auto-start-stops, regenerative braking, engine downsizing, and optimal control strategy, HEVs can obtain very high fuel efficiency and low emission [53].

\subsection{Objectives of This Research}

Numerical simulation plays an important role in developing and evaluating HEVs. Component and vehicle simulators of high accuracy help engineers predict vehicle fuel economy, emissions and performance without the need to build prototype vehicles, while tests of either components or vehicles can be complicated, time consuming and expensive. The Powertrain System Analysis Toolkit (PSAT), as a HEV simulation tool, has been widely used in light-duty vehicle simulations for validation, optimization and parametric study in early stage of design. However, PSAT has been rarely applied to heavy-duty vehicle simulations since components on heavyduty vehicles such as transmission, have great differences from those on light-duty vehicles so that accuracy of the current PSAT heavy-duty vehicle models is unknown.

Driving conditions have a significant influence on fuel economy for conventional vehicles as well as HEVs. The main characteristics such as idle time, stopping frequency and average speed have significant influence on the fuel economy of HEVs [14]. Deeper investigation shows that operation of the engine is the main parameter influencing the sensitivity of fuel economy to 
driving cycles [54]. Therefore, many control strategies are designed to optimize engine efficiency without consideration of efficiencies of other components such as electric motor and battery [24]. Although such a control strategy is very effective in obtaining high engine efficiency, overall efficiency of the powertrain has not been optimized and therefore overall fuel consumption is not considered optimal.

The air conditioning (A/C) systems are available in almost every vehicle sold today in the U.S. to improve thermal comfort of passengers. Research found that $\mathrm{A} / \mathrm{C}$ contributed to most of the energy loss in the vehicle auxiliary system and had great impact on fuel economy in light-duty vehicles and heavy-duty vehicles. While $\mathrm{A} / \mathrm{C}$ on light-duty vehicles has been studied in detail [30, 48, 49], A/C on heavy-duty vehicles has not been investigated much. Also how A/C behaves under different ambient conditions is still unknown. In many automobiles, the $\mathrm{A} / \mathrm{C}$ compressor is mechanically driven by the engine. In some hybrid vehicles, $\mathrm{A} / \mathrm{C}$ is driven by electric motor instead.

The objectives of this research are to simulate and optimize the performance of a heavy-duty parallel hybrid transit bus over transient cycles. The model will be developed by using PSAT as the platform. The model will be validated against the experimental data. If validation of this heavy-duty hybrid transit bus can be done accurately, more simulations and analysis of heavyduty vehicles can be carried out using PSAT. A conventional engine efficiency-based control strategy and a real-time overall efficiency-based control strategy will be developed for the U.S. emission cycles to investigate the potential of fuel economy improvement by optimization of the control strategy.

In this study, a more realistic electric accessory model was built to investigate the performance of $\mathrm{A} / \mathrm{C}$ and vehicle against critical parameters such as ambient temperature, ambient $\mathrm{RH}$, and solar load. A case study including three states across the U.S. was conducted to investigate the impact of A/C operation on fuel economy of the vehicle under different ambient conditions. 


\section{Literature Review}

\subsection{Hybrid Bus Review}

\subsubsection{Introduction}

The population of transit buses has tripled since 1960 as shown in Figure 2.1. Transit buses equipped with diesel engines are dominant in the current bus market due to their desirable fuel economy, high torque operation and excellent durability. It can be found in Figure 2.2 that in 2005 the total fuel burned by buses had increased by more than $60 \%$ since 1960 . However, diesel engines are the main sources of $\mathrm{NO}_{\mathrm{x}}$ and $\mathrm{PM}$ emissions in urban areas, both have been strictly regulated in the last twenty years. The fast-deteriorating air quality in urban areas all across the U.S. has forced regulatory bodies to enact ever more stringent regulations on automotive emissions to such an extent that they have reached the point of diminishing returns, at least so far as conventionally powered vehicles are concerned [37]. Table 2.1 shows the EPA regulated emission standard history for urban bus engines since 1991. It can be observed that the emission standard is becoming more and more stringent and emission levels from urban bus engines have declined by an order of magnitude with the exception of $\mathrm{CO}$. To address issues like oil shortage and air pollution, the application of buses will be encouraged and their population will continue growing.

The high CAFE demand and ever-increasing stringent emission standards will no doubt shrink the market of conventional vehicles due to the challenge of meeting the standard and more markets will open up to hybrid vehicles than ever before. Because of the pressure and urgency to reduce fuel consumption, GHG, and emissions (especially $\mathrm{NO}_{\mathrm{x}}$ and $\mathrm{PM}_{10}$ ) in urban areas, many bus manufacturers have begun to develop Hybrid Electric Buses (HEBs). As reported in the literature [17], HEBs are defined as buses carrying at least two sources of motive energy on board and using electric drive to provide partial or complete drive power to the vehicle's wheels. 


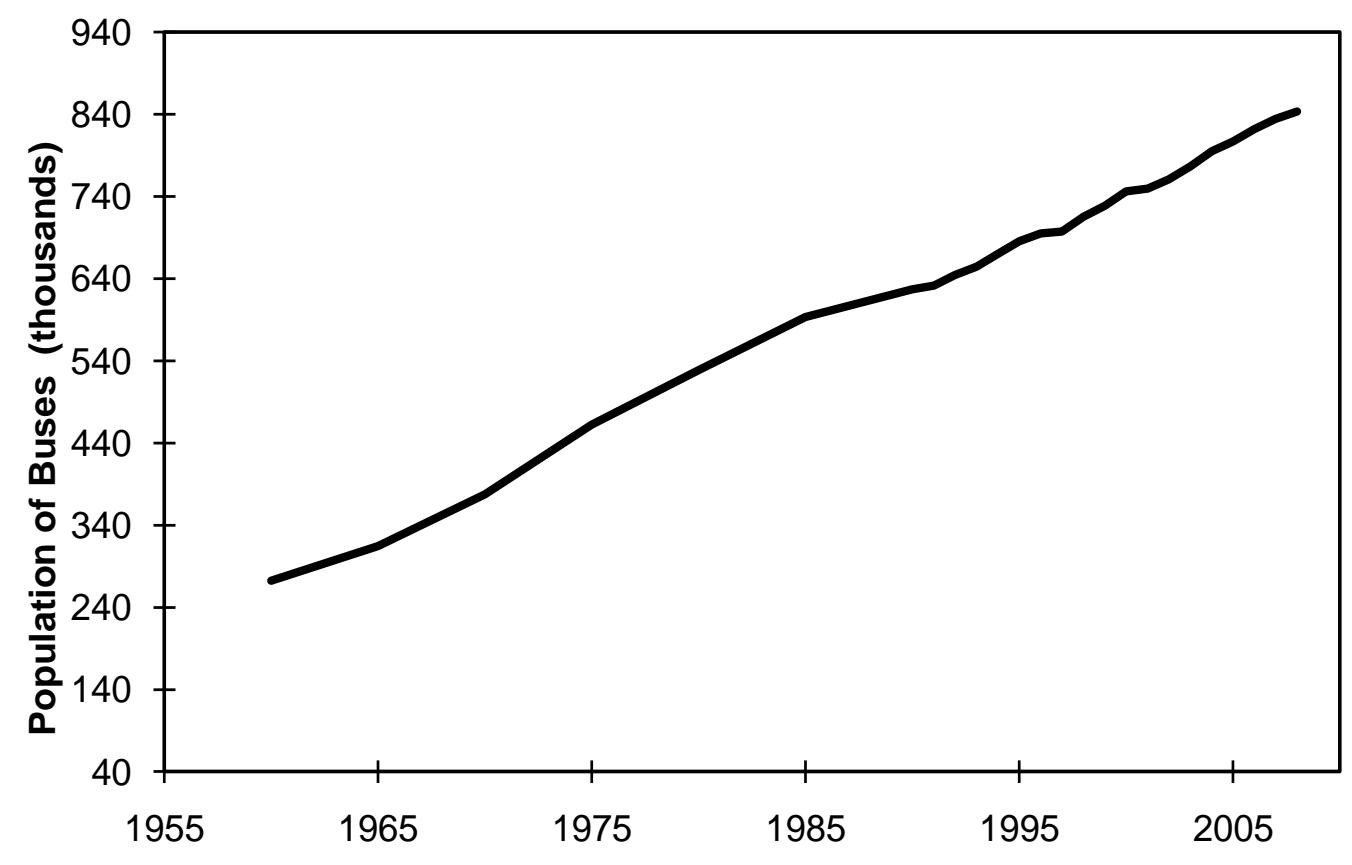

Figure 2.1 Population of Buses in the U.S., 1960-2008 [1]

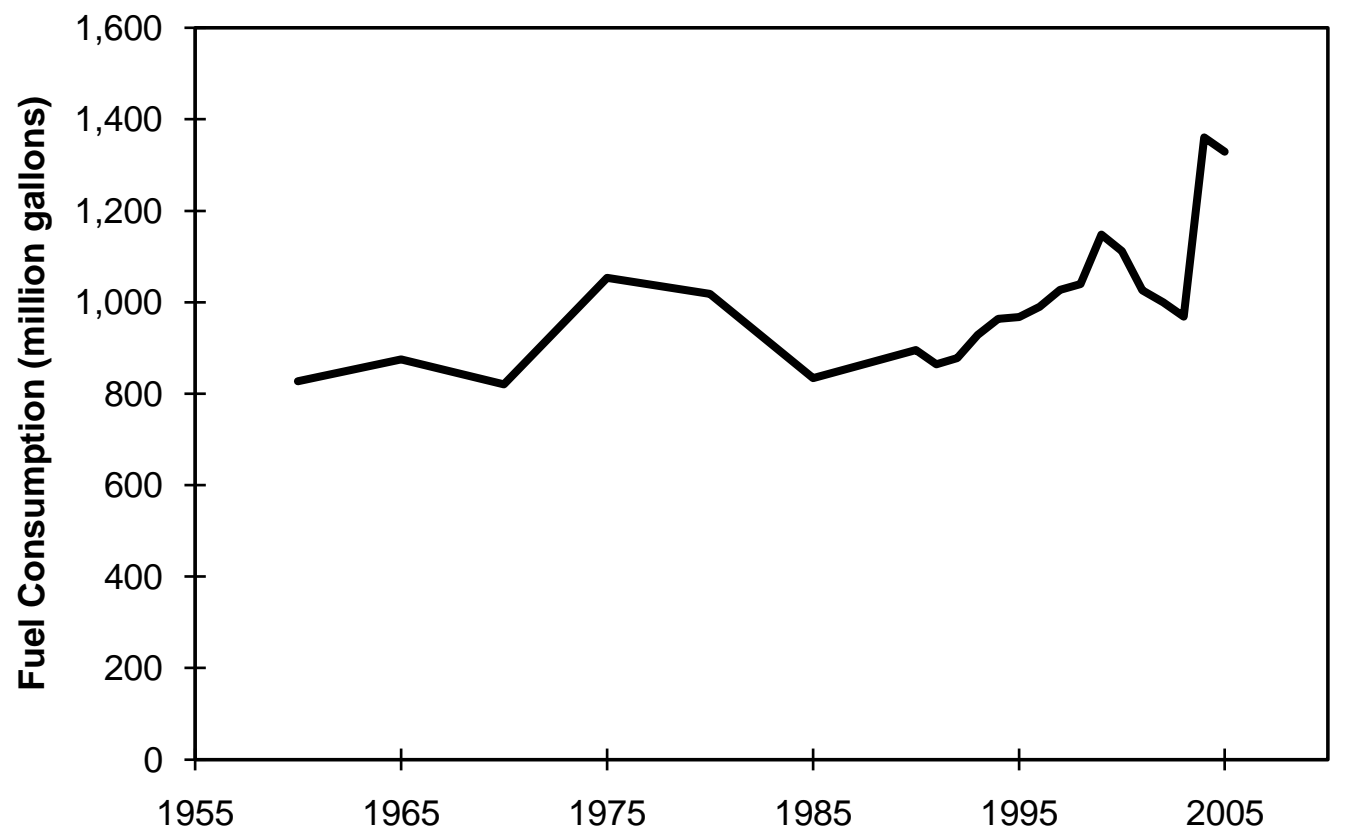

Figure 2.2 Fuel Consumption by Buses in the U.S., 1960-2005 [1] 
Table 2.1 EPA Emission Standard for Urban Bus Engines since 1991 [3]

\begin{tabular}{|c|c|c|c|c|}
\hline \multirow{2}{*}{ Model years } & $\mathrm{CO}$ & $\mathrm{HC}$ & $\mathrm{NO}_{x}$ & $\mathrm{PM}$ \\
\cline { 2 - 5 } & $\mathrm{g} / \mathrm{bhp}-\mathrm{hr}$ & $\mathrm{g} / \mathrm{bhp}-\mathrm{hr}$ & $\mathrm{g} / \mathrm{bhp}-\mathrm{hr}$ & $\mathrm{g} / \mathrm{bhp}-\mathrm{hr}$ \\
\hline $1991-1992$ & 15.5 & 1.3 & 5.0 & 0.25 \\
\hline 1993 & 15.5 & 1.3 & 5.0 & 0.1 \\
\hline $1994-1995$ & 15.5 & 1.3 & 5.0 & 0.07 \\
\hline $1996-1997$ & 15.5 & 1.3 & 5.0 & 0.05 \\
\hline $1998-2003$ & 15.5 & 1.3 & 4.0 & 0.05 \\
\hline & & $\mathrm{NMHC}$ & $\mathrm{NMHC}^{-N}$ & $\mathrm{PM}$ \\
\hline $2004-2006$ (Option 1) & 15.5 & $\mathrm{n} / \mathrm{a}$ & 2.4 & 0.05 \\
\hline $2004-2006$ (Option 2) & 15.5 & 0.5 & 2.5 & 0.05 \\
\hline & & $\mathrm{NMHC}$ & $\mathrm{NO}_{\mathrm{x}}$ & $\mathrm{PM}$ \\
\hline 2007 and later & 15.5 & 0.14 & 0.20 & 0.01 \\
\hline
\end{tabular}

The population of HEBs has increased rapidly in recent years and more and more HEBs have been put into service since the late 1980s. Figure 2.3 shows HEB population in the U.S. since 1994. New York City Transit is the world's largest hybrid transit bus fleet so far. Orion, which has delivered more than 1,700 hybrid buses in the U.S. and Canada, is estimated to have $60 \%$ of the U.S. hybrid transit bus market. New Flyer Industries Inc. received 1,253 bus orders from December 2007 to February 2008, and 248 of these were hybrids [44]. More than 600 GM Allison Hybrid $\mathrm{E}^{\mathrm{P}} 40$ System $^{\mathrm{TM}}$ and $\mathrm{E}^{\mathrm{P}} 50$ System $^{\mathrm{TM}}$ hybrid propulsion systems have been sold and installed into transit buses, such as 60-foot articulated buses, 40-foot transit buses, and 45foot coaches by 2007. [22]. In Japan, Mitsubishi Fuso, Isuzu, Hino Motors and Nissan Diesel are now producing hybrid transit buses. In China, Dongfeng Motor Corporation (DMC), the First Automobile Works (FAW), and Xiamen King Long are all producing hybrid buses. In November 2008, hybrid buses produced by Britain's Alexander Dennis Limited (ADL) entered the London transit market [44]. 


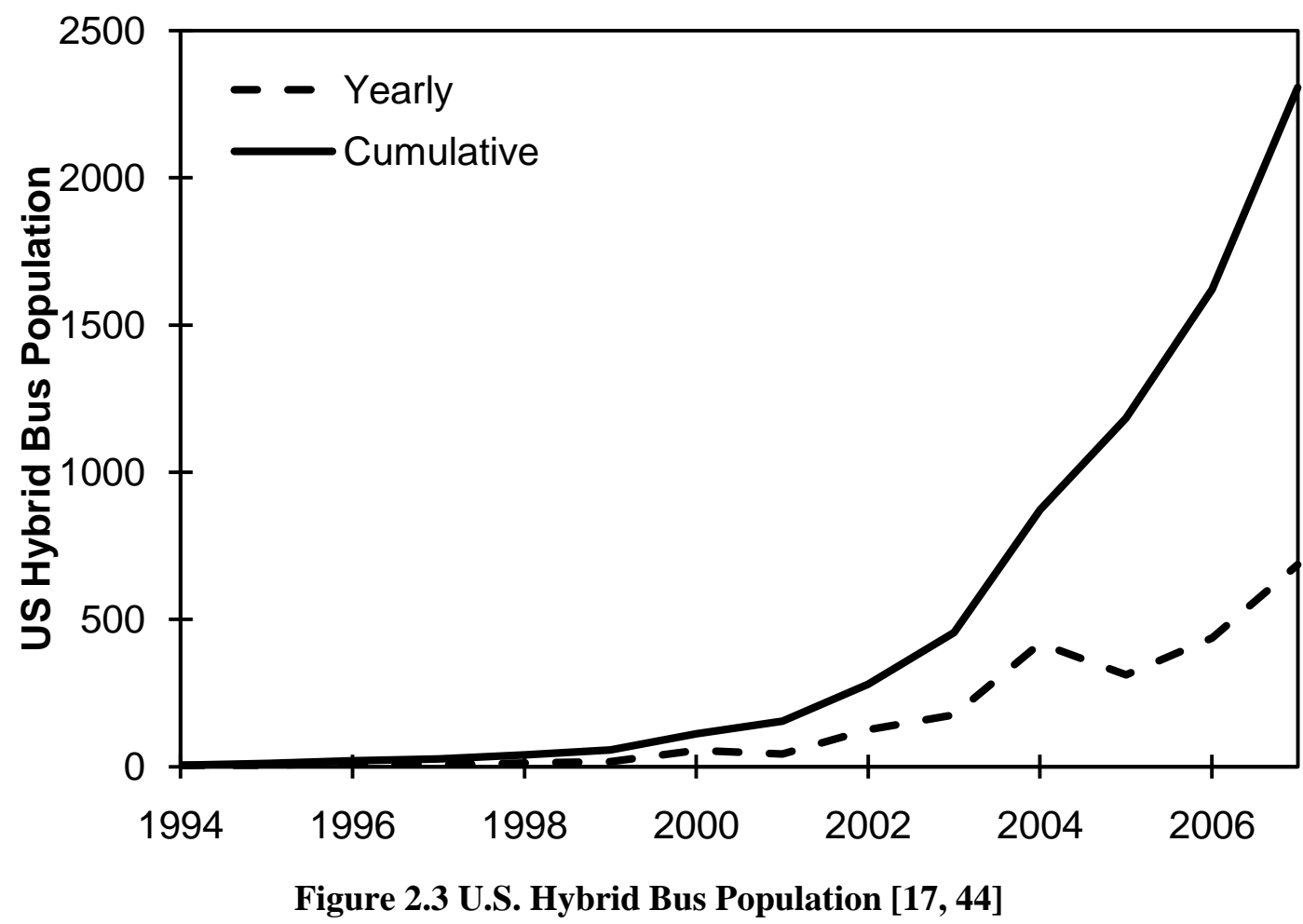

Hybrid drive has many advantages over conventional powertrain system. First of all, HEBs reduce their fuel consumption mostly due to the recovery of kinetic energy by regenerative braking. The typical "stop-start" driving cycle offers a good arena for HEBs to perform. As high as 30\% of kinetic energy of heavy-duty hybrid buses can be recaptured when operated in urban areas. In addition, HEBs are able to operate the engine less transiently in a more efficient region by decoupling engine operation from wheel operation partly or fully, and eliminate idling by turning the engine off when the vehicle stops. In addition, transit buses, as the main public transportation vehicles in urban areas where high population density exists, contribute greatly to public health. As California Air Resources Board (CARB) tightened diesel emissions in California Low Emission Vehicle (LEV) II Emission Standard, HEBs are favored more than conventional buses to improve air quality in cities. Two configurations are most commonly utilized for HEBs: series configuration, parallel configuration, and series-parallel configuration.

\subsubsection{Series HEBs}

As shown in Figure 2.4, series HEBs can only be propelled by a traction motor, which draws energy stored in battery packs or from the generator directly. Because of this distinguishing 
feature, the engine is completely decoupled from the wheels so that it has the freedom of operating in the peak efficiency zone to charge the batteries according to state of charge (SOC). Based on the power capacities of the engine and battery, series HEBs can be divided into two categories: engine-dominant HEBs and battery-dominant HEBs. For engine-dominant HEBs, the energy for driving the motor is mostly drawn from the generator directly which continuously converts mechanical work from the engine into electricity. For battery-dominant HEBs, the battery is the main power source for driving. Because of this feature, a big battery pack is required for relatively low power draw to increase charging/discharging efficiency, which result in a significant increase in vehicle weight. The weakness of the series hybrid configuration is that energy is first converted from mechanical power to electricity and then back to mechanical power, which reduces energy conversion efficiency to $80 \%$ based on current battery technology [17].

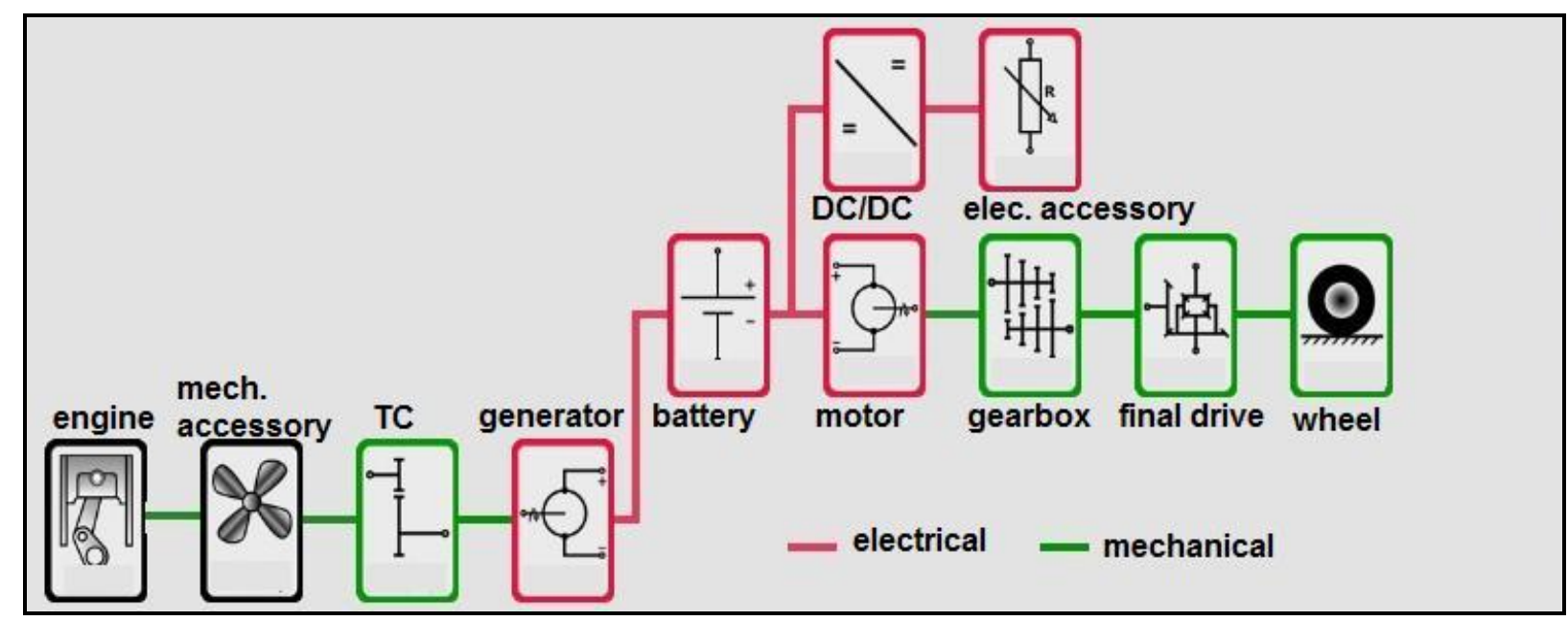

Figure 2.4 Series Hybrid Configuration

\subsubsection{Parallel HEBs}

Typical parallel HEBs combine the powertrain of the conventional bus and that of the electric bus and split the torque demanded by the driving cycle between engine and electric motor based on the applied control strategy. Parallel HEBs can be driven by the engine only, the motor only (if motor of high power capacity is used), or both of the two components. The engine on parallel HEBs is not completely independent from the driving wheel since engine speed is coupled with vehicle speed and the torque can be optimized based on fuel economy. Parallel HEBs generally 
fall into two types classified by the layout of motor: pre-transmission and post-transmission. In pre-transmission configuration shown in Figure 2.5, the motor is mounted on the engine side of gearbox, while in post-transmission configuration as shown in Figure 2.6, the motor is placed downstream of the gearbox. The post-transmission architecture is more challenging because either a dedicated transmission is used to interface the Motor/Generator $(\mathrm{M} / \mathrm{G})$ to the driven wheels or the M/G must have sufficient constant power speed range to function over the full operating regime of the vehicle [45]. The pre-transmission architecture is more favored since the current $\mathrm{M} / \mathrm{G}$ technology will be adequate to feed road load torque and speed by adjusting gear ratio.

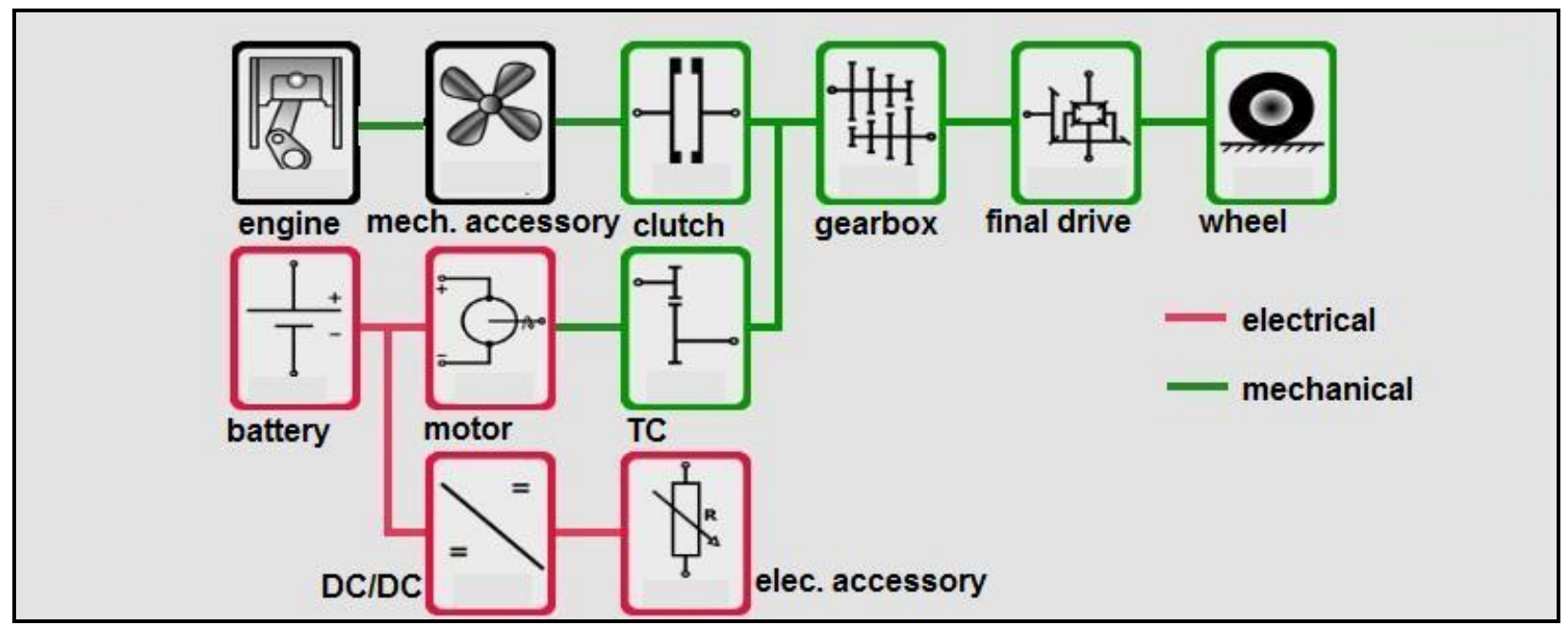

Figure 2.5 Pre-Transmission Parallel Configuration

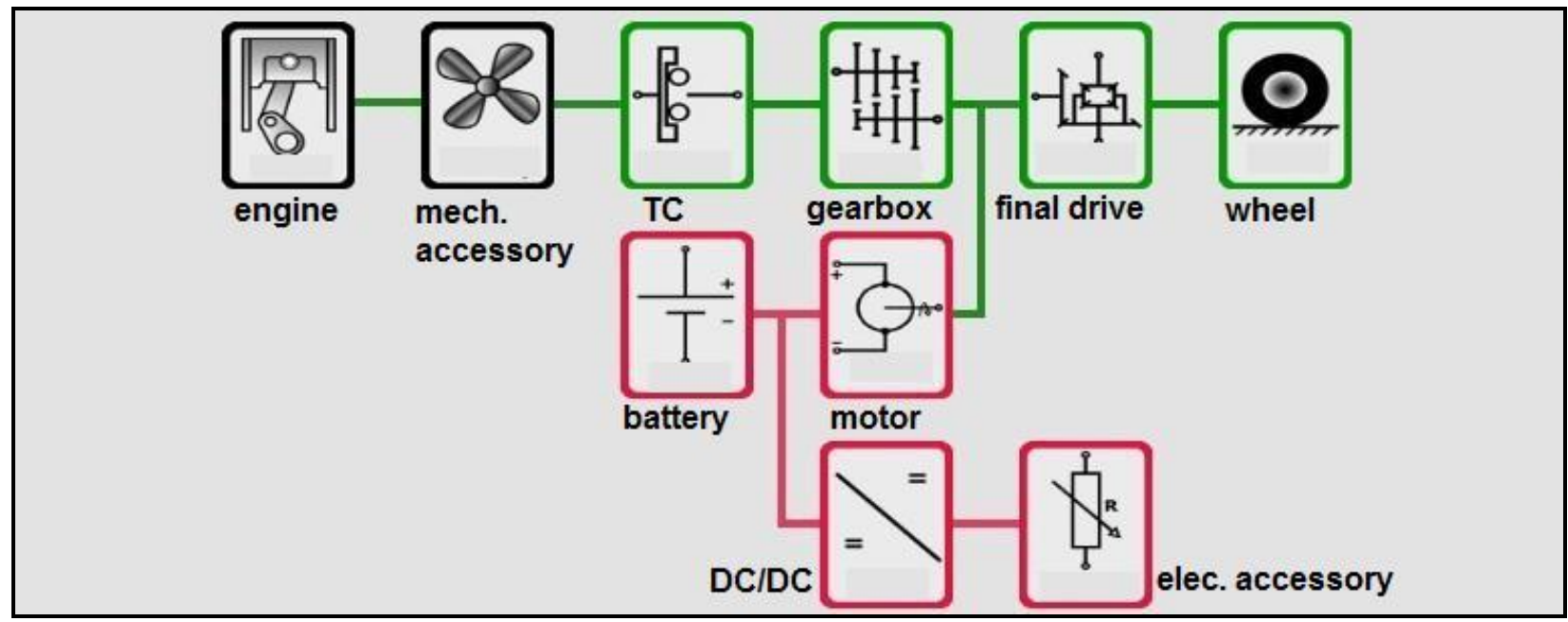

Figure 2.6 Post-Transmission Parallel Configuration 


\subsubsection{Series-Parallel HEBs}

In addition to series configuration and parallel configuration, there are other complex hybrid configurations. One of the most popular configurations emerging in the recent years is the seriesparallel (or power-split) configuration, which applies power-split devices (such as one or more planetary gear arrangements) to convert power from engine to driving wheels in mechanical path or electrical path. This configuration has been widely used in heavy-duty vehicle market such as the GM-Allison Hybrid $\mathrm{E}^{\mathrm{P}} 50$ System. The GM-Allison Hybrid $\mathrm{E}^{\mathrm{P}} 50$ System is a two-mode compound split parallel hybrid system, which combines a quick and smooth electric path and high efficiency mechanical path (nearly 100\%) to provide the optimum power split for propulsion [22].

\subsection{Review of HEV Simulation Tools}

\subsubsection{Introduction}

Modeling plays an important role in developing and evaluating HEVs. Component and vehicle simulations of high accuracy help engineers investigate vehicle fuel economy, emissions and performance with less cost and effort, while tests of either components or vehicles can be complicated, time consuming and expensive. In addition, with the help of simulation tools, advanced powertrains that have not been built can be evaluated by simulation in the early stages of vehicle development. Simulation tools also help automobile manufacturers reduce development time and win the market. The following is a brief review of the hybrid vehicle simulation software used now and before.

\subsubsection{V-Elph 2.01}

V-Elph 2.01 is a MATLAB/Simulink-based simulation and analysis package developed by Texas A\&M University [18]. V-Elph 2.01 is composed of detailed model of four types of components in the powertrain: engine, motor, battery and other support components. V-Elph 2.01 can be used to estimate the fuel economy and emissions of HEVs and EVs [19]. It is also capable of executing in-depth tasks such as configuration studies, component sizing, and control strategy studies for several types of vehicles. It is considerably understandable, allowed to read output data quickly and can be modified easily by a wide range of users. Moreover, it provides a very 
friendly graphical user interface (GUI), which allows simulations to be carried out through visual programming easily.

\subsubsection{AVL CRUISE v3.1}

AVL CRUISE v3.1 is the latest version of CRUISE, a vehicle level system simulator developed by AVL. CRUISE offers a streamlined workflow for all kinds of parameter optimization and component matching, guiding the user through practical and attainable solutions [6]. It can be used to calculate the fuel economy, emissions and performance tests from conventional powertrain to advanced HEVs, realistic vehicle system modeling and simulation, powerful vehicle simulation analysis, exploring new transmission concept such as AMT, etc.

\subsubsection{ADvanced VehIcle SimulatOR (ADVISOR)}

ADVISOR, which was originally written by NREL in 1994, is one of the most widely used computer simulation tools for HEVs. It was designed to assist the U.S. Department of Energy (DOE) in developing HEV technologies. Between 1998 when it was first released through the internet and 2003, more than 7000 individuals downloaded the free version of ADVISOR [5]. Since 2004, it has been commercialized and further developed by AVL. ADVISOR is a backward-looking model built in MATLAB/Simulink visual block diagram with a great graphical user interface (GUI). It is a fast simulation tool that is available for various kinds of vehicles including conventional vehicles, HEVs, EVs and FCVs. It can be used to undertake tasks such as estimation of fuel economy, study of energy management, evaluation of control strategies, optimization of gear ratio, and so on.

\subsubsection{Powertrain System Analysis Toolkit@ (PSAT)}

PSAT, which is being developed by Argonne National Laboratory (ANL) and sponsored by the U.S. DOE, is one of the most powerful tools for evaluation of fuel economy and vehicle performance. It was selected by the U.S. DOE as the primary vehicle simulation tool to support DOE's FreedomCAR and Fuels Partnership Program. Different from other backward-looking simulation tools, PSAT is a forward-looking tool which makes simulation in a more realistic manner. In PSAT, a driver model that follows the driving cycle sends power demand to the vehicle controller from which control commands are distributed to each component in the powertrain based on the control strategy [35]. These signals from components are then fed back 
to the vehicle controller after each simulation time step. The newest version of PSAT V6.2, released in December 2007 with control strategies redesigned in MATLAB/Simulink/StateFlow, offers more readability and flexibility for further modification [7]. Compared to ADVISOR, PSAT is able to run the simulation more accurately within the scale of time step less than one tenth of a second although more time is required.

PSAT is a far more powerful simulation tool for HEVs. It is also a powerful post processing tool for both simulation data analysis and test data analysis. Once the experimental data is imported into PSAT, it allows the users to compare the simulation result with the experimental result immediately for model validation. At the same time, PSAT-PRO, a control code based on PSAT, was developed by ANL researchers for Hardware-In-the-Loop (HIL) simulation and advanced vehicle test facilities [57].

As another advantage, PSAT provides user-friendly GUI, which allows users to choose vehicle configurations, define each component, setup trips or test cycles, run the simulation and report the simulation result in detail.

Although PSAT is a state-of-the-art powertrain modeling tool, there are still some incomplete areas remaining to be solved. The engine fan model, which is responsible for engine cooling in PSAT, is not developed yet and the fan power is set to a constant value when the engine is on, which is unpractical and will deteriorate the accuracy for simulations of heavy-duty vehicles. In fact, fan power for heavy-duty vehicles is considerable and varies greatly according to engine operation. In addition, electrical accessory power, two thirds of which is used for air conditioning, has significant impact on fuel economy but is also set to a constant in the electrical accessory model in PSAT. While there have been a lot of vehicle configurations available in PSAT, some specific configurations are not available, such as pre-transmission parallel hybrid configuration with AMT transmission. To catch up the pace of technology development, libraries of configurations and components need to be expanded accordingly. Although many control strategies have been introduced and available in PSAT, they are not guaranteed to be the best control strategies for HEVs and need to be further optimized and validated. To make it more user-friendly, it is very important to cover as many powertrain configurations as possible and provide optimal control strategy for specific configurations. 


\subsection{Review of HEV Control Strategies and Impact of Driving Cycle on Fuel Economy}

Many control strategies have been developed to improve performance of HEVs. These control strategies generally are grouped into three categories [41]. The first category employs heuristic control techniques such as control rule, fuzzy logic, and neural network for optimization [16]. The second approach is based on static optimization. It commonly transfers electric power into equivalent fuel consumption based on static efficiency maps. The third method employs dynamic programming for global optimization. To limit computation burden, no more than two inputs are usually allowed.

Many research works have been conducted to investigate the influence of driving cycle on fuel economy. Christenson, et al. [22] concluded that fuel consumption was dependent on driving cycle so that fuel consumption rates over the transient cycles were up to 3 to 4 times higher than those in steady-state driving at $40 \mathrm{~km} / \mathrm{h}$. Sharer, et al. [54] investigated the impact of drive cycle aggressiveness and speed on HEV's sensitivity to fuel consumption and found that HEVs like the Prius appeared to be more sensitive to city driving cycles than conventional vehicles like the Focus mainly due to engine operation.

Since achievable fuel economy improvement strongly depends on the powertrain and the driving conditions, it is very important to involve both the hybrid powertrain and driving cycle when optimizing the control strategies. Most of the heuristic control strategies designed for hybrid transit buses today only considered local efficiency such as engine efficiency, and battery state of charge (SOC) [24, 25]. It has been observed that these heuristic control strategies are very effective in maintaining high engine efficiency by operating the engine in a limited efficient region and requiring the motor to satisfy the remaining torque demand. However, as driving cycles vary significantly, motor torque demand changes correspondingly and therefore it is very difficult to operate the motor in its efficient region. Without supervising both engine and motor operation in the control strategy, it is very difficult to maintain a high overall efficiency. In comparison, real-time control strategies proved to have advantages over the conventional rulebased control strategy in improving the fuel economy and emissions [34]. By applying a similar technique, it is possible to develop an appropriate real-time control strategy to optimize overall efficiency and therefore improve fuel economy over transient driving cycles. 


\section{Development of Model and Control Strategy}

\subsection{PSAT Model Overview}

As shown in Figure 3.1, PSAT is a forward-looking model, which allows researchers to simulate the vehicle in a real-life manner by responding to throttle or braking commands from the driver model. The necessary torque demand to reach the desired speed is calculated in the powertrain controller. Command signals from the controller then flow into the powertrain, which assign each component with on/off signals or demands (i.e., throttle). At the same time, the controller sensors collect both signals from the powertrain and signals from the controller as feedback into the powertrain controller for calculation in the next time step.

A generic format is designed for each component unit with inputs and outputs, shown in Figure 3.2. Among the inputs, there are commands from the controller, effort from the components in the upstream (i.e., torque from engine and voltage from motor), and flow (i.e., speed from engine and current from motor) from upstream. The outputs from each component include information collected by sensors, effort, and flow. The virtual sensors are used for control and postprocessing.

The powertrain controller serves as the brain of the vehicle by sending commands to the different components. There are three blocks in the powertrain controller: a constraint block which holds the operation of components within the physical limits, a strategy block which determines the demands of components, and a component demand block which decides how components respond.

In the powertrain controller, there are three strategies including propelling strategy, gear-shifting strategy and regenerative braking strategy. These three strategies are regulated in the powertrain controller as shown in Figure 3.3.

\section{Propelling Strategy}

The propelling strategy is applied when traction force required is positive. In conventional vehicle models, the outputs from the propelling strategy are engine on/off signal and engine torque demand signal. In hybrid vehicle models, the outputs include engine on/off signal, engine torque demand, motor torque demand, and vehicle performance mode. 


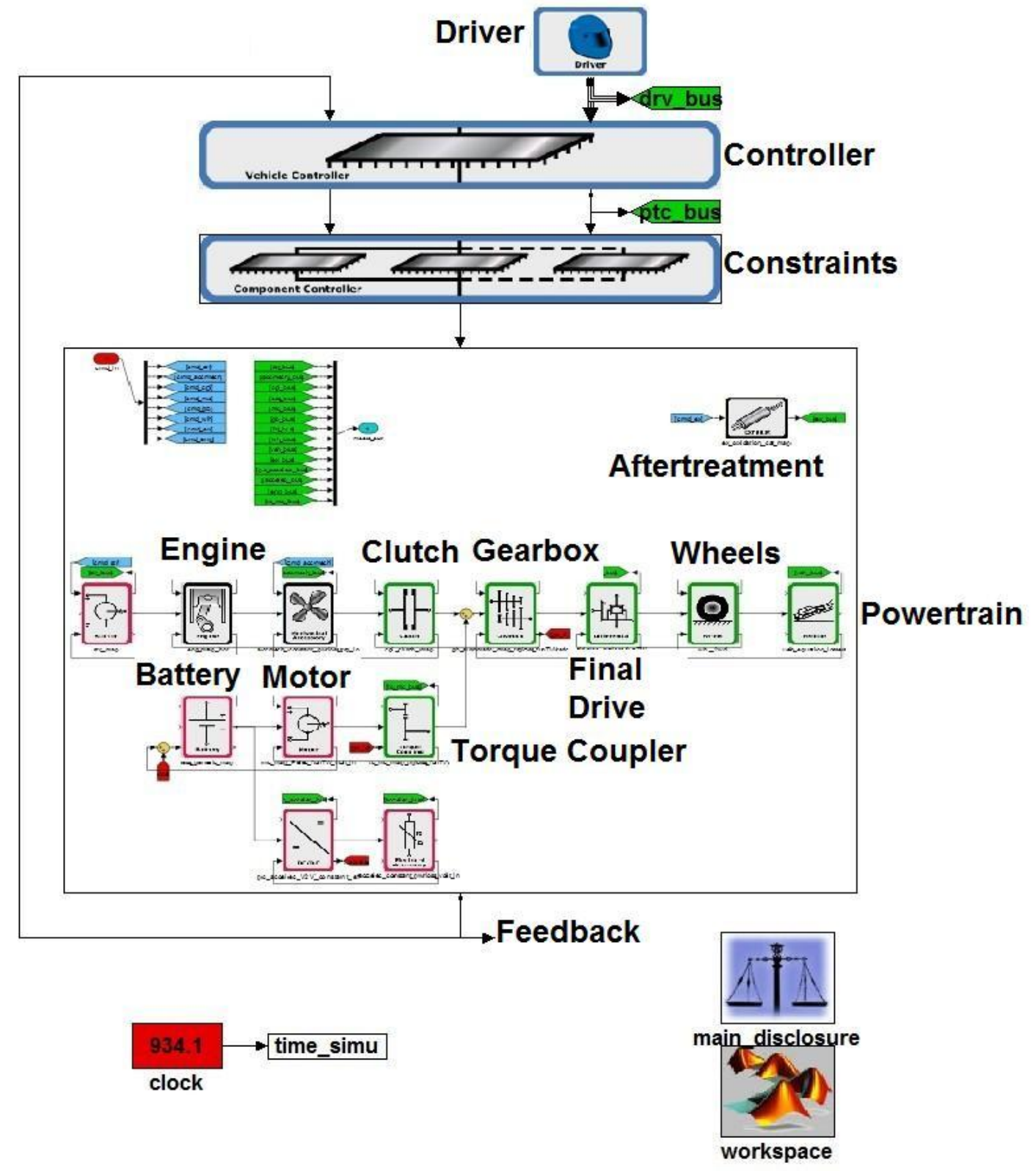

Figure 3.1 Top Level of PSAT Model [7]

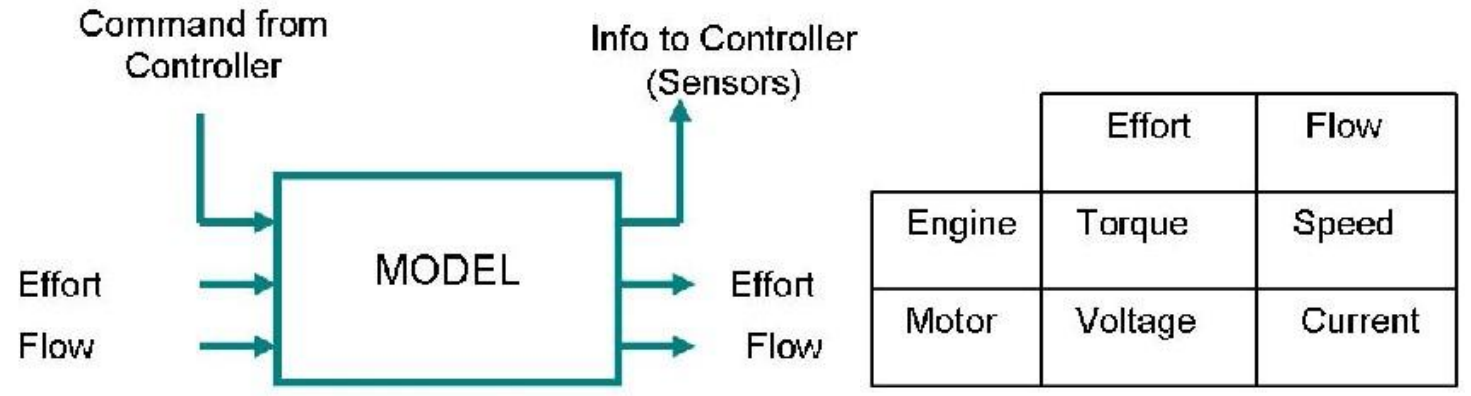

Figure 3.2 Component Generic Format [7] 


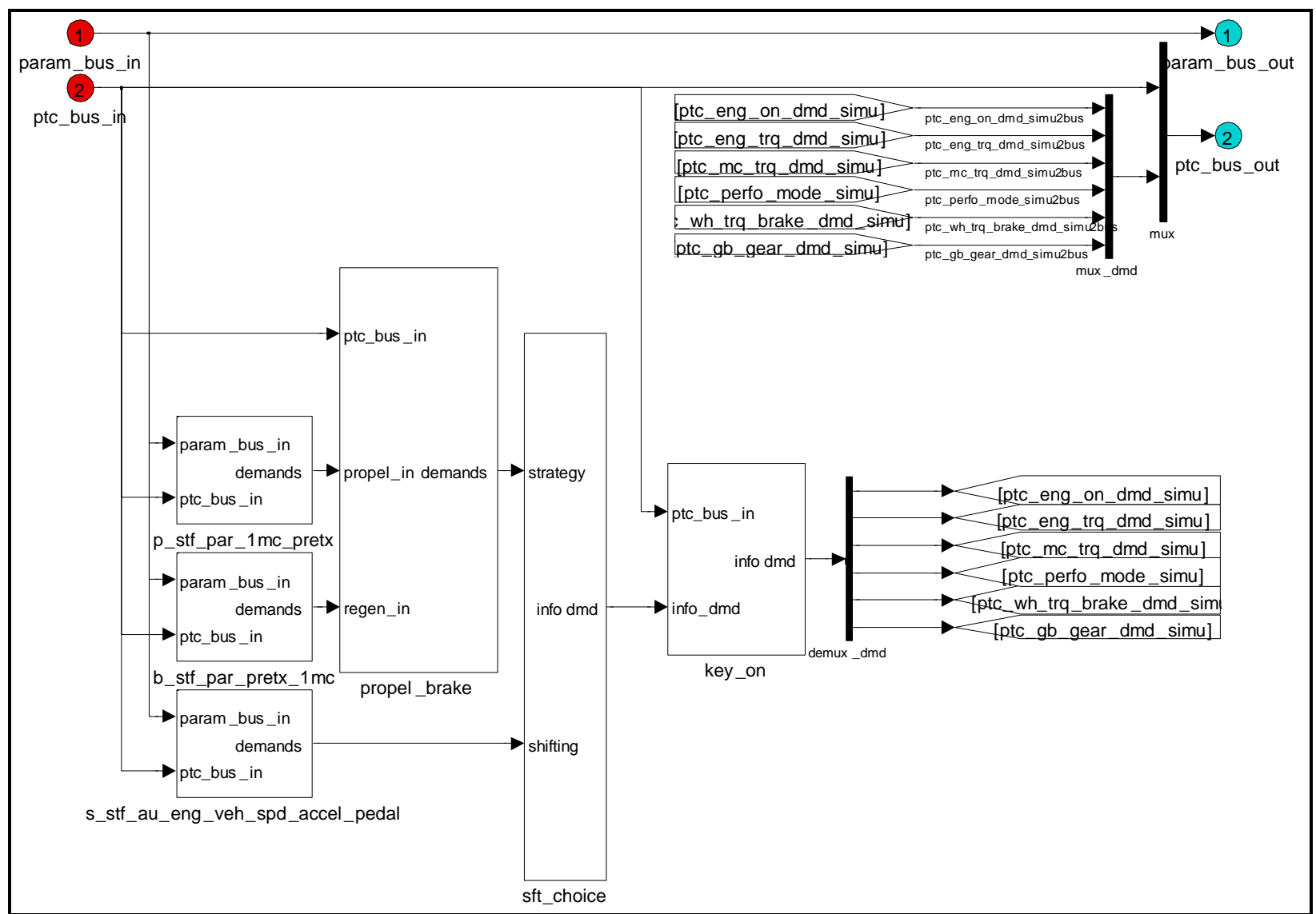

Figure 3.3 Powertrain Controller [7]

\section{Gear-Shifting Strategy}

Several shifting strategies are available in PSAT for different types of transmission such as AT, MT, and CVT. In most shifting strategies, a gear map as a function of accelerator pedal demand and vehicle speed is applied to determine the desired gear position based on fuel economy or performance mode.

\section{Regenerative Braking Strategy}

The regenerative braking strategy is applied when wheel torque is negative. In conventional vehicle models, only mechanical brake torque is available in the braking strategy. In hybrid vehicle models, motor torque demand and mechanical brake torque demand are determined by the braking strategy so that kinetic energy during braking can be recaptured as much as possible within the physical limits of motor and battery. 


\subsection{Parallel Hybrid Bus Powertrain Model}

\subsubsection{Engine Model}

There are four main blocks in the PSAT engine model. These four blocks shown in Figure 3.4 are used to calculate engine torque, engine thermal behaviors, engine fuel rate, and engine emissions, respectively. Engine torque is calculated by interpolation between the maximum torque curve and the minimum torque curve by engine torque demand. The exact calculation of engine torque is expressed in Equation 1 and Equation 2. Calculation of fuel rate is based on the brake specific fuel consumption (BSFC) map, which is a function of engine speed and engine torque. $\mathrm{HC}, \mathrm{CO}, \mathrm{NO}_{\mathrm{x}}$, and $\mathrm{PM}$ are all calculated by interpolation using emission maps indexed by engine speed and engine torque. The engine on the test transit bus is an electronically controlled in-line 4-cylinder diesel engine equipped with an intercooler and turbocharger. The rated power is $140 \mathrm{~kW}$ at $2300 \mathrm{rpm}$ and the peak torque is $646 \mathrm{Nm}$ at $1400 \mathrm{rpm}$ from the test data. The BSFC map and $\mathrm{NO}_{\mathrm{x}}$ emission map for the engine, shown in Figure 3.5 and Figure 3.6, respectively, were obtained from the test.

When $T_{c m d}>0$ or $\omega_{e}>0$,

$T_{e, \text { out }}=\left(1-T_{c m d}\right) \cdot T_{C T T}+\left(T_{c m d} \cdot T_{W O T}\right)$

Equation 1

and when $T_{c m d}=0$ or $\omega_{e}=0$,

$T_{e, \text { out }}=0$

Equation 2

Where

$T_{C T T}$ and $T_{W O T}$ denote closed throttle torque and wide open throttle torque, respectively.

$T_{c m d}$ and $T_{e, \text { out }}$ denote engine torque demand and engine torque output.

$\omega_{e}$ denotes engine speed. 


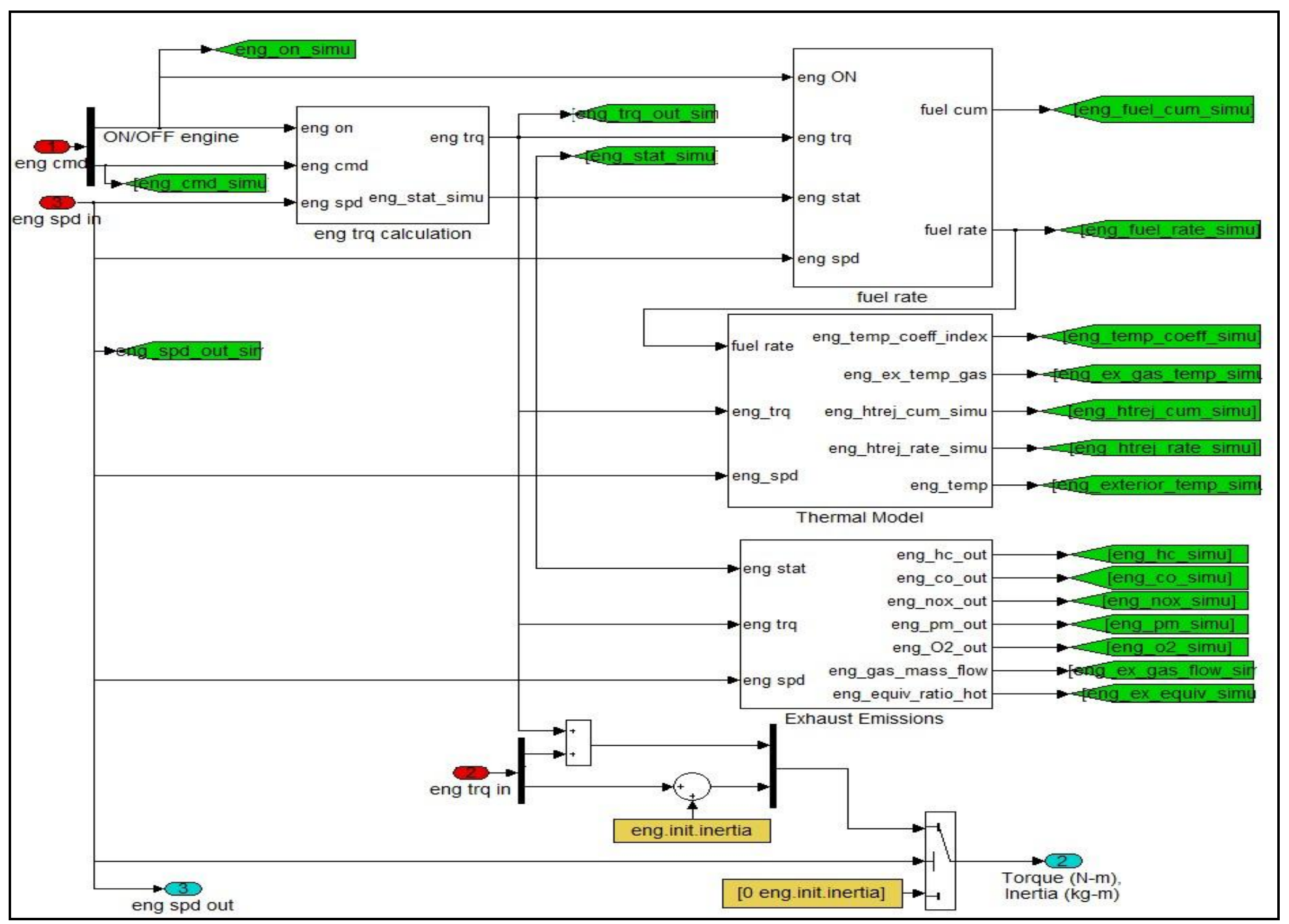

Figure 3.4 Simulink Model of Engine in PSAT [7] 


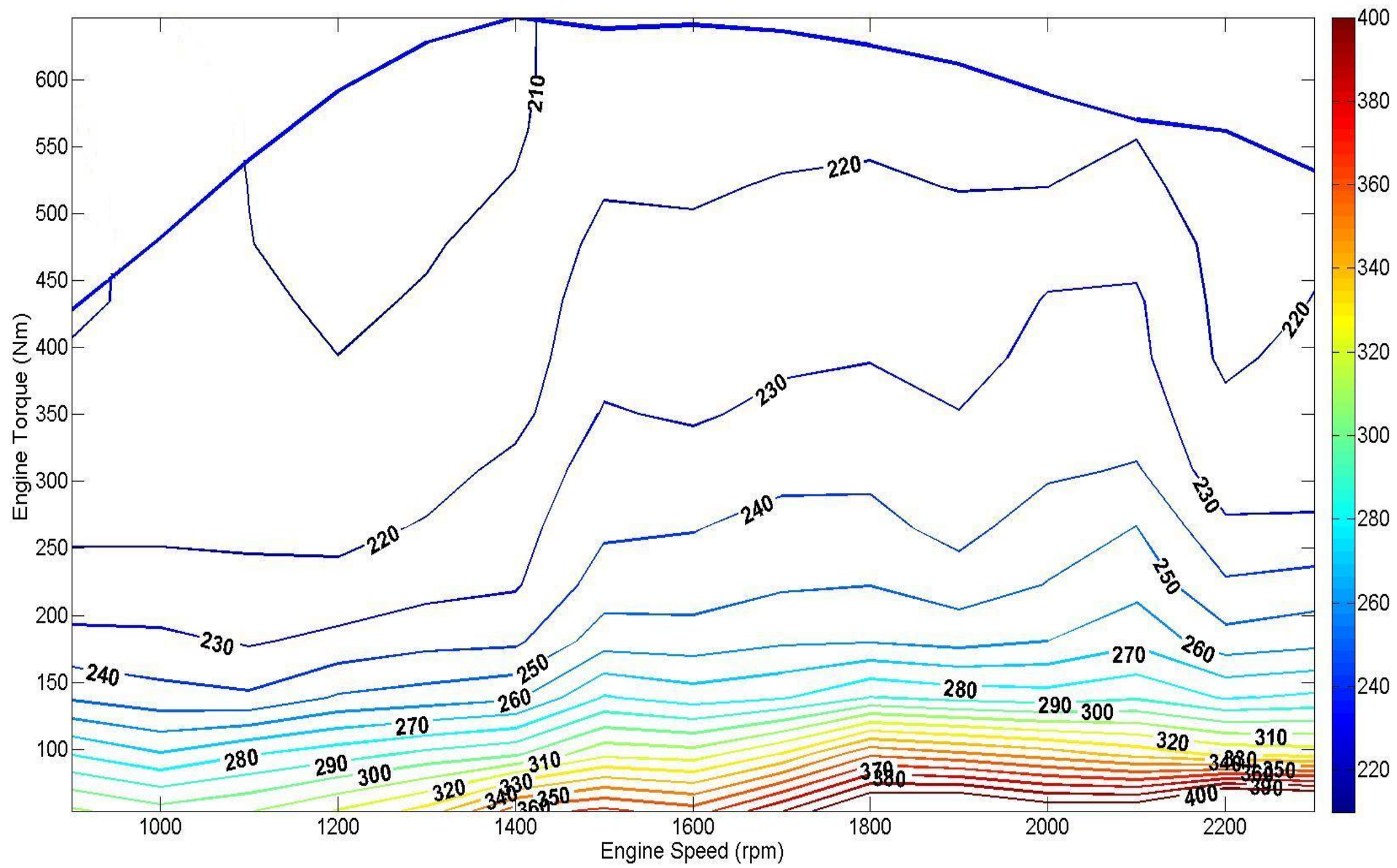

Figure 3.5 BSFC Map of Engine (Unit: g/kW-hr) [65] 


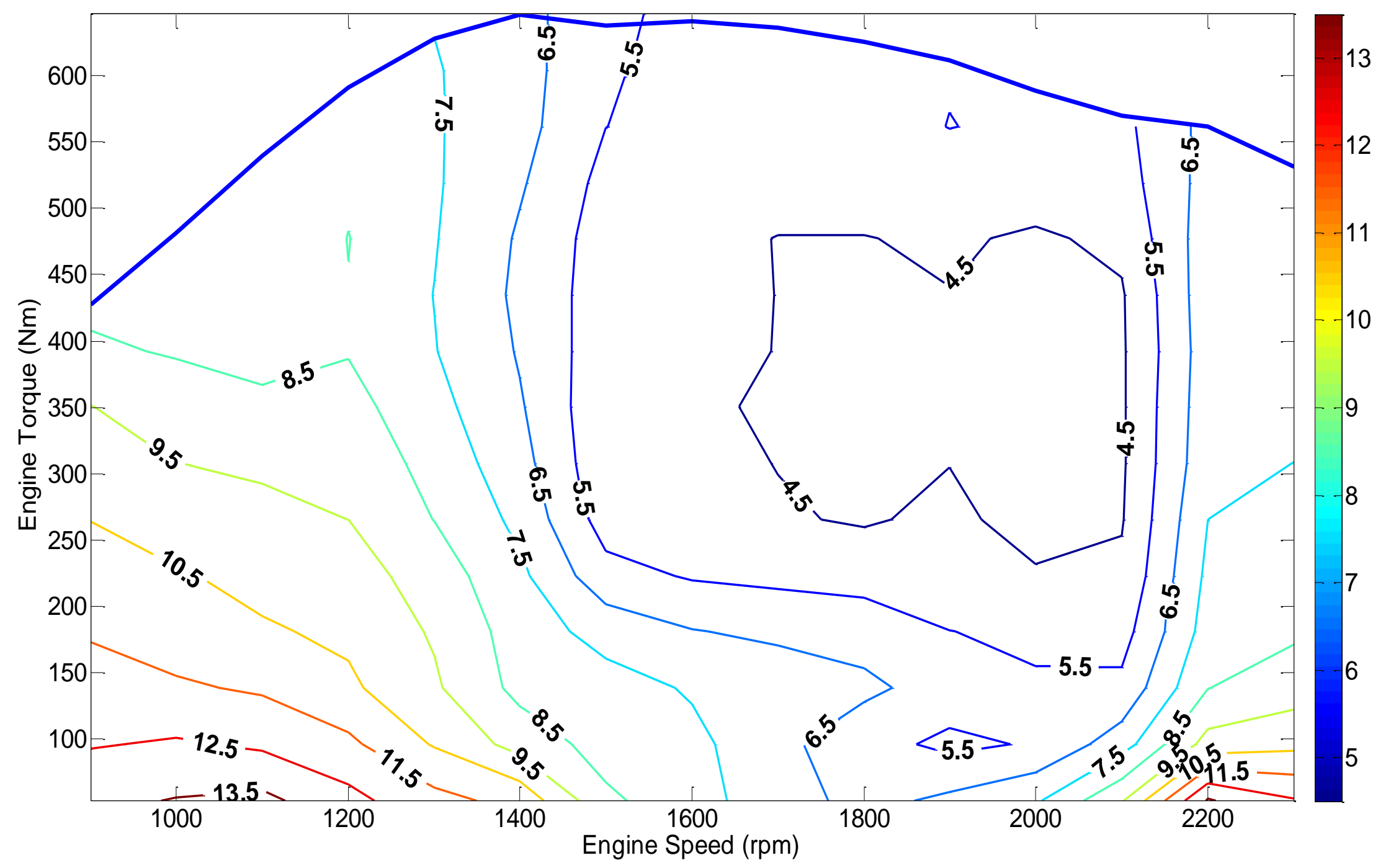

Figure 3.6 Brake Specific NO ${ }_{\mathrm{x}}$ Emission Map (Unit: g/kW-hr) [65] 


\subsubsection{Motor Model}

An electric motor is a device which converts electrical energy to mechanical energy by interaction between a magnetic field and a current-carrying motor. Also, the electric motor can produce electrical energy from mechanical energy in a reverse process. Generally electric motors can be divided into two categories: alternating current (AC) and direct current (DC). A typical motor consists of two parts: an outside stationary stator and an inside rotating rotor, with interaction of a magnetic field between them in operation. The electric motor on the test transit bus was an AC asynchronous motor with continuous power of $40 \mathrm{~kW}$ and peak power of $80 \mathrm{~kW}$.

The motor model in PSAT is map-based. Three maps required for a complete simulation are continuous torque map as a function of speed, maximum torque map as a function of speed, and efficiency map as a function of torque and speed. Figure 3.7 shows the continuous torque map and efficiency map of the test AC asynchronous motor. Figure 3.8 shows the Simulink model of the motor in PSAT where Joule's Law is applied to calculate motor current based on Equation 3 and motor torque output is determined by motor command and maximum torque available at a given temperature and speed as shown in Equation 4.

$I_{\text {in }}=\frac{P_{\text {electrical }}}{V_{\text {in }}}$

Equation 3

Where

$I_{\text {in }}$ and $V_{\text {in }}$ denote the input current and voltage of the motor, respectively.

$P_{\text {electrical }}$ denotes the electrical energy into the motor.

$T_{m, o u t}=T_{\max } \cdot \eta_{\text {cmd }}$

Equation 4

Where

$T_{m, o u t}$ and $T_{\max }$ denote the torque output and maximum torque available from the motor, respectively. $\eta_{\text {cmd }}$ represents motor torque command. 


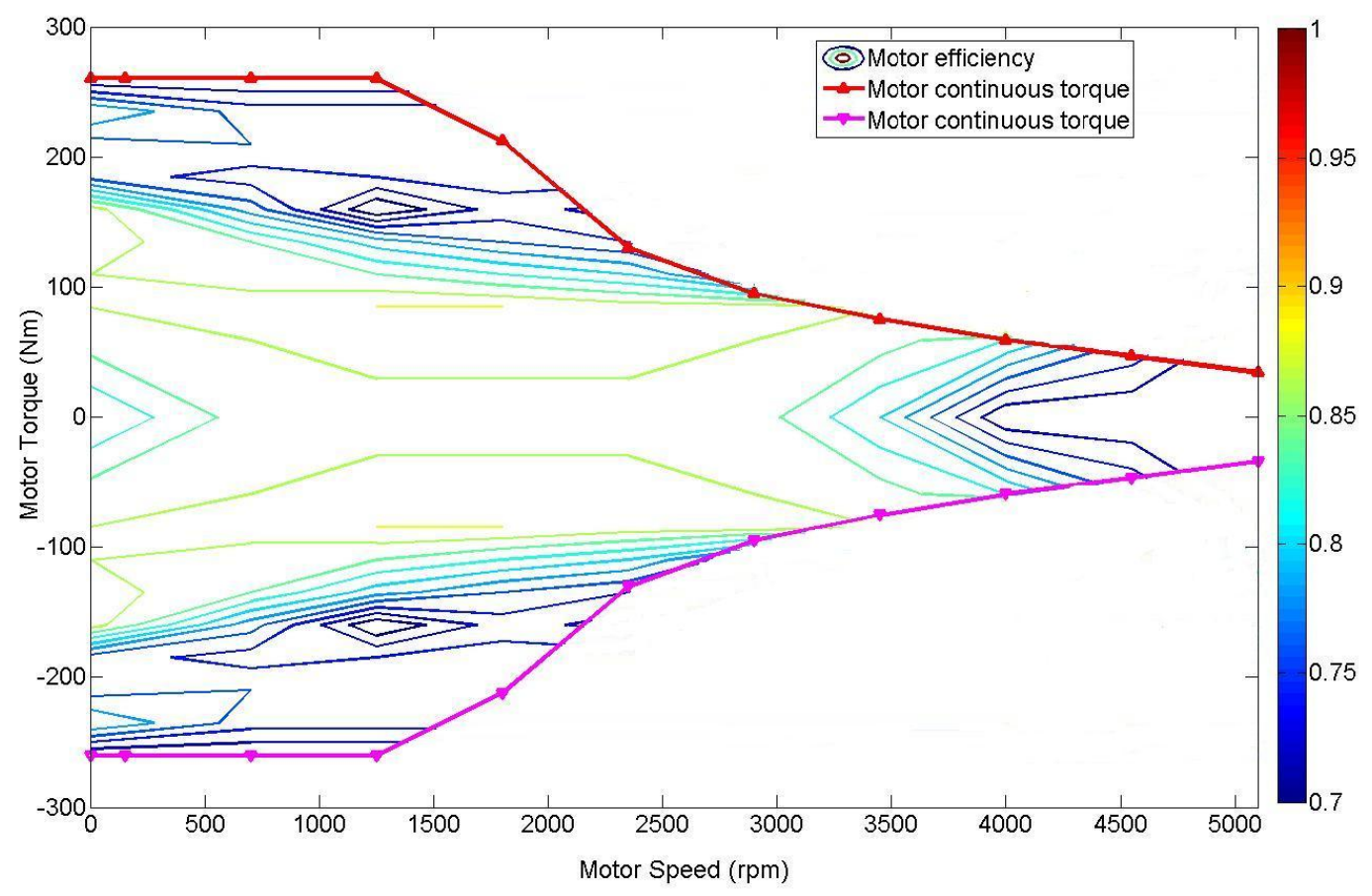

Figure 3.7 Motor Torque Map and Efficiency Map [65]

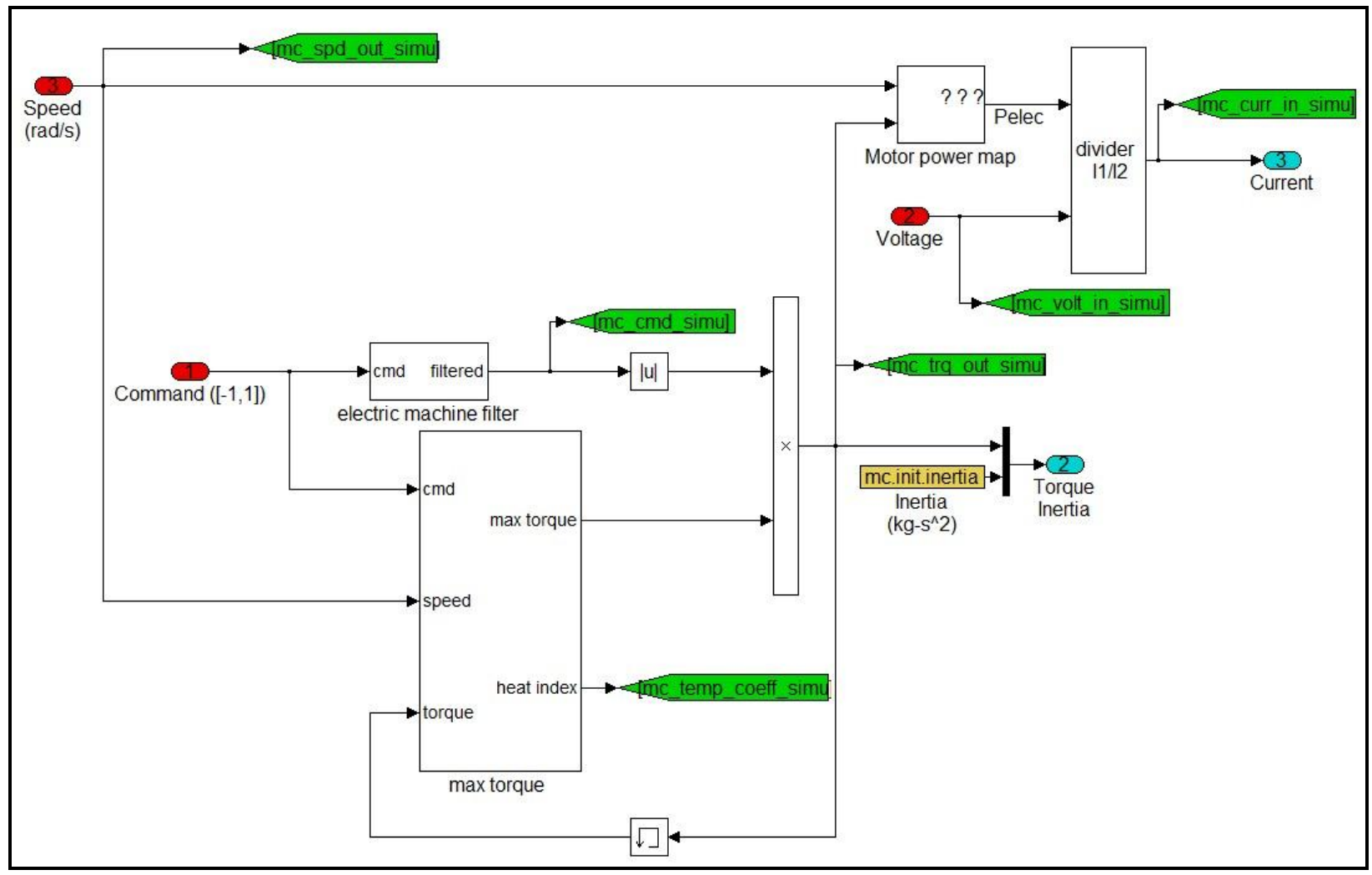

Figure 3.8 Simulink Model of Motor in PSAT [7] 


\subsubsection{Battery Model}

There are several energy storage systems (ESSs) available for hybrid vehicles: battery, flywheel and ultra-capacitor. A battery is a device that converts stored chemical energy into electrical energy when discharged and converts electrical energy to chemical energy when charged. A flywheel utilizes rotating mass to store mechanical energy as momentum. An ultra-capacitor stores electrical energy into electric field between two oppositely charged plates. The generic battery model in PSAT is shown in Figure 3.9.

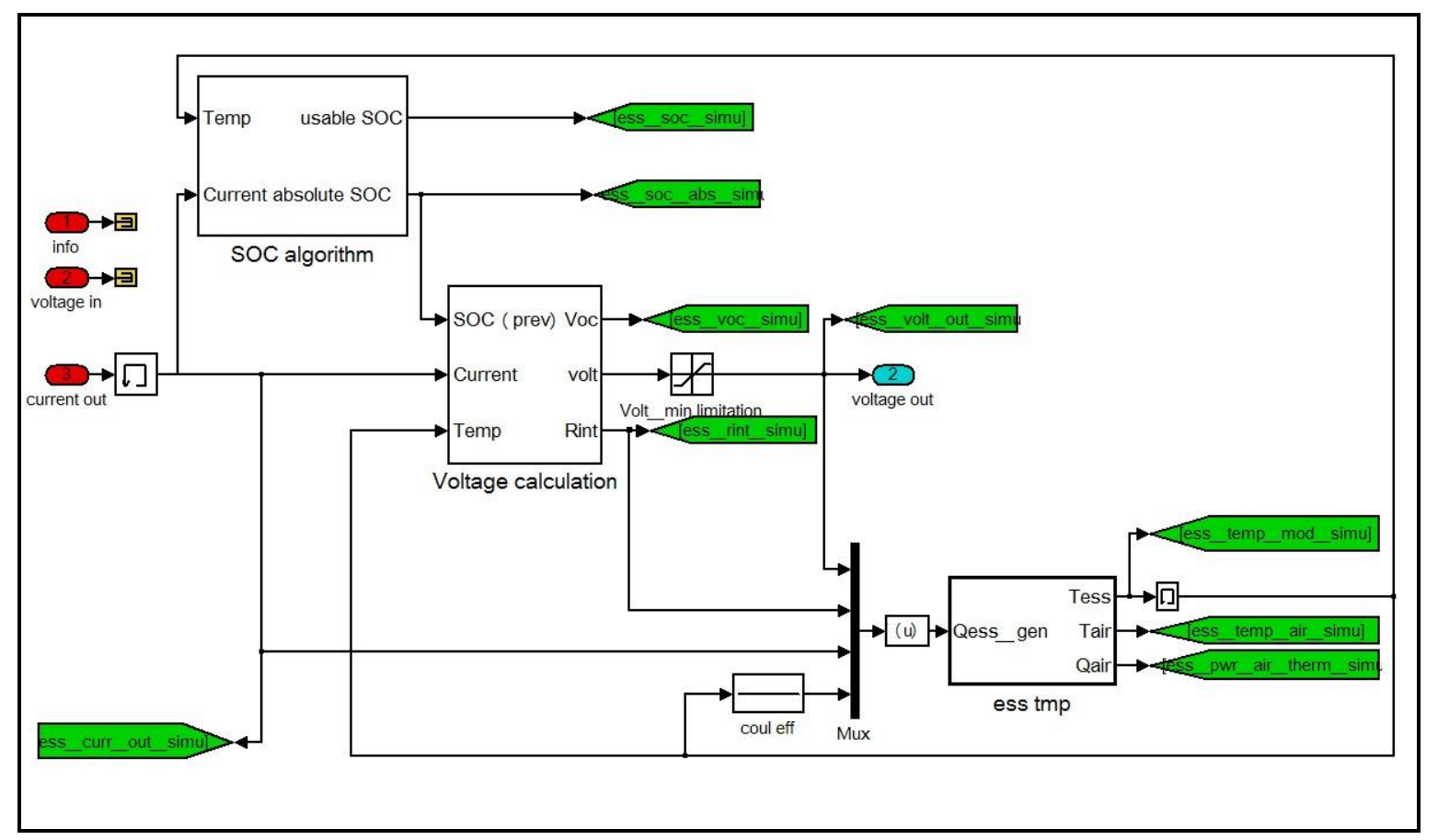

Figure 3.9 Generic Battery Model in PSAT [7]

This generic battery model can be used to simulate different battery technologies such as nickelmetal hydride $(\mathrm{NiMH})$ battery, lithium-ion battery and lead-acid battery. The test hybrid bus was equipped with NiMH batteries with the capacity of $27 \mathrm{Ah}$. The absolute SOC $\left(S O C_{a b s}\right)$ and relative SOC ( $S O C_{\text {relative }}$ ) are calculated by Equation 5 and Equation 6, respectively.

$$
\begin{array}{lr}
S O C_{a b s}=\left(\text { Capacity }_{\text {max }}-\text { Capacity }_{\text {used }}\right) / \text { Capacity }_{\text {max }} & \text { Equation 5 } \\
S O C_{\text {relative }}=\left(S O C_{\max }-S O C_{a b s}\right) /\left(S O C_{\max }-S O C_{\min }\right) & \text { Equation 6 }
\end{array}
$$

Where 
Capacity $_{\max }$ and Capacity $_{\text {used }}$ denote the rated capacity and the used capacity of energy.

$S O C_{\max }$ and $S O C_{\min }$ are maximum and minimum SOC levels allowed in operation.

The voltage output is calculated in Equation 7.

$V_{\text {out }}=V_{\text {OCV }}-I_{\text {ess }} \cdot R_{\text {ess }}$

Equation 7

Where $R_{e s s}$ and $V_{O C V}$ represent internal resistance and open circuit voltage (OCV) of the ESS, both of which are functions of battery temperature and SOC as shown in Figure 3.10 and Figure 3.11. $I_{\text {ess }}$ represents current flowing through the batteries. The internal resistance map of the battery packs during discharging is the same as that during charging in this study.

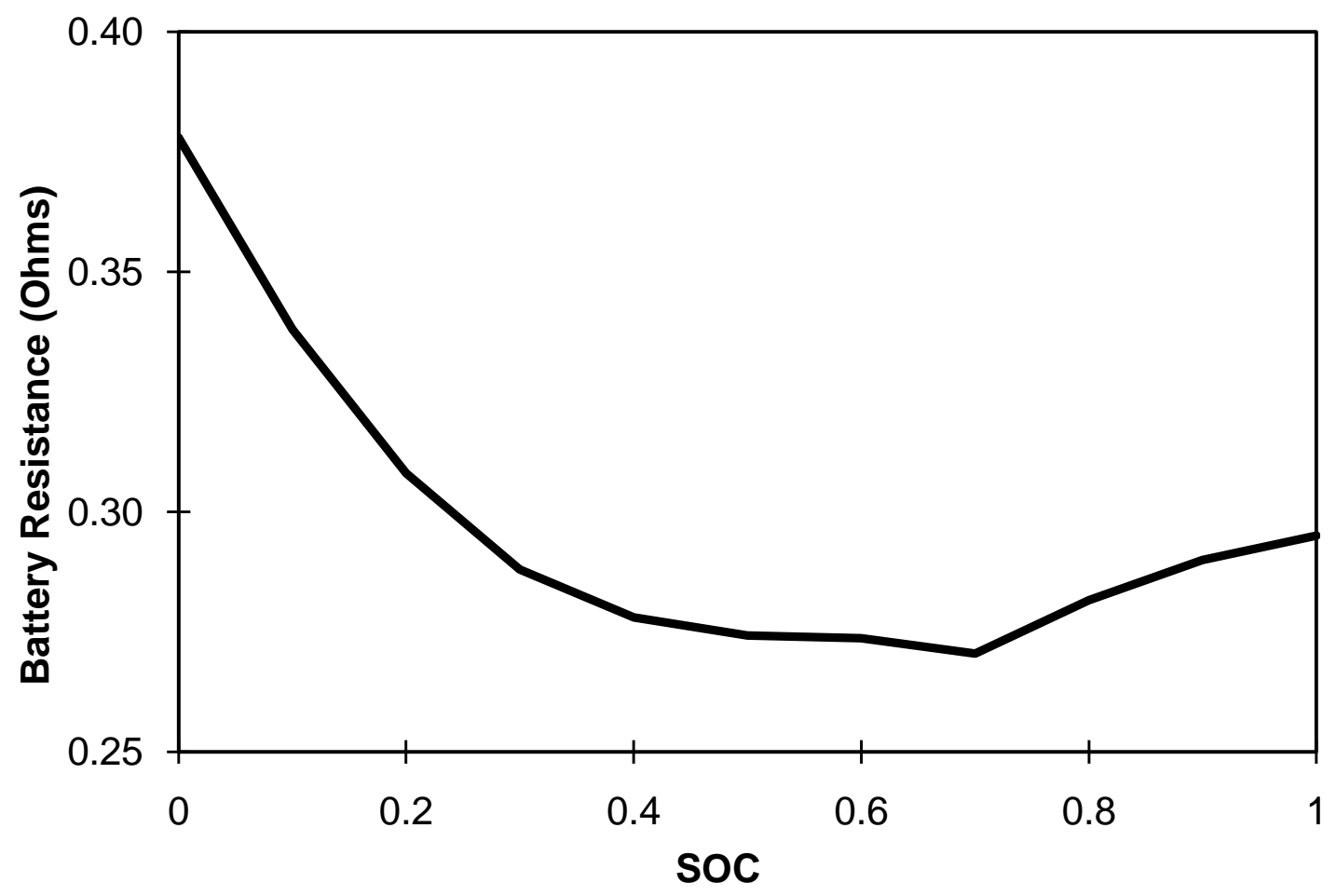

Figure 3.10 Internal Resistance of NiMH Battery Packs as a Function of SOC at $40{ }^{\circ} \mathrm{C}$ [7] 


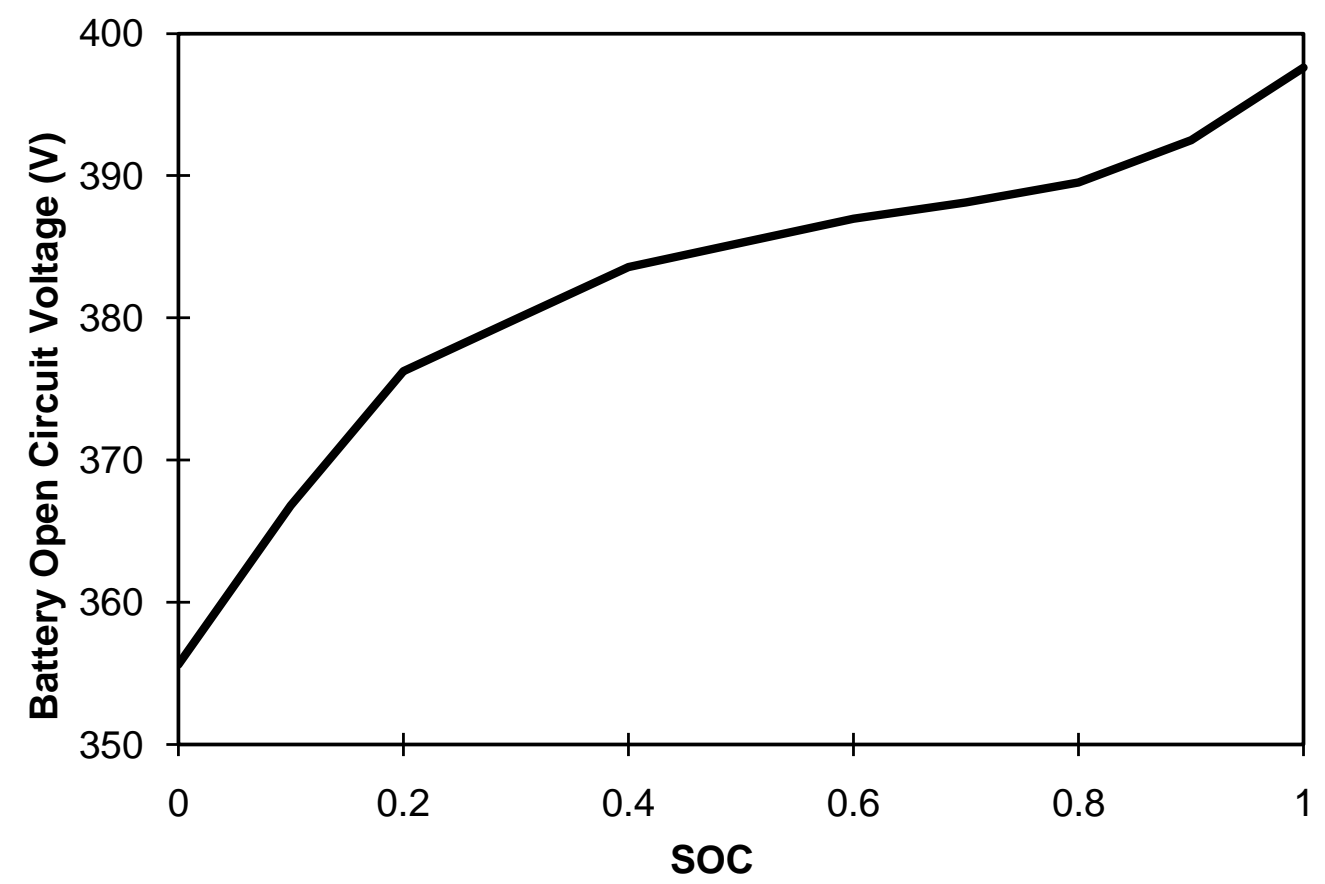

Figure 3.11 OCV Map of NiMH Battery Packs [7]

\subsubsection{Transmission Model}

The gearbox unit in PSAT was modeled as a sequence of gains by which engine speed and torque are divided and multiplied, respectively. The gearbox adjusts engine speed and torque to meet the wheel demand while keeping the engine from operating too aggressively. A complete gearbox model requires two critical maps: a gear ratio map, which is indexed by gear position, and a transmission efficiency map, which is a function of speed, torque and gear position. The test transit bus was equipped with a 6-speed AMT which combined the advantages of MT, such as light weight and high efficiency, and the advantages of AT, such as satisfied convenience to drivers. It had the potential to improve efficiency by up to $7 \%$ without the cost of driving comfort [8]. The transmission ratios were 7.285 (1st gear), 4.193 (2nd gear), 2.485 (3rd gear), 1.563 (4th gear), 1.000 (5th or direct gear), and 0.847 (6th gear).Although there is no pretransmission parallel configuration with AMT existing in the PSAT transmission library, the existing pre-transmission parallel configuration with AT was applied alternatively due to the fact that AMTs are usually performed in automatic mode for convenience when driving. The efficiency maps used in the model were derived from the efficiency maps for a 10-speed gearbox. The transmission efficiency maps in all the six gear positions are shown in Figure 3.12. 


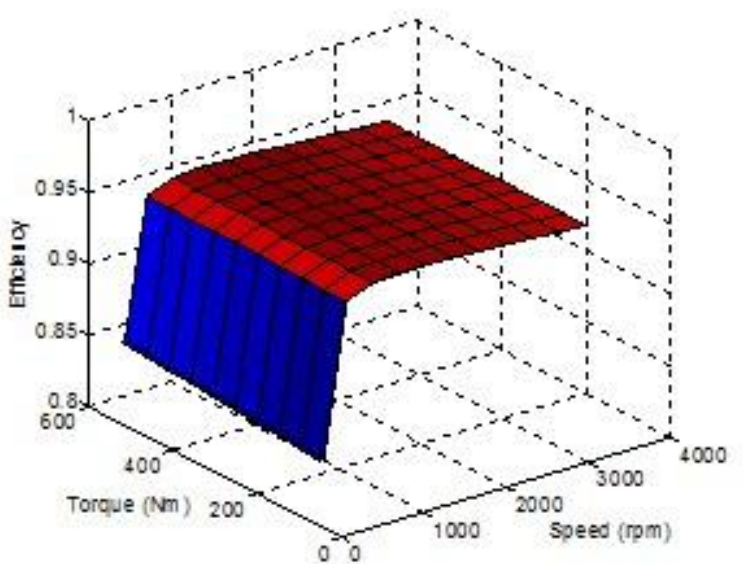

(a) lst gear

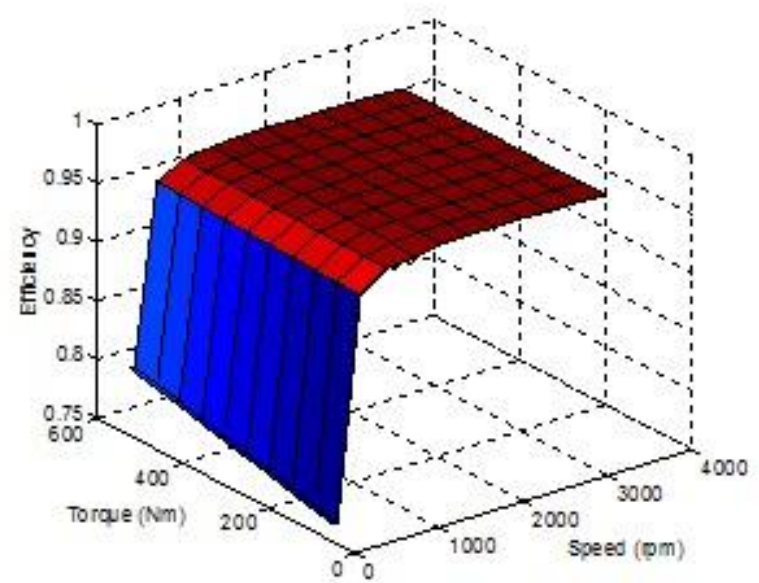

(c) 3rd gear

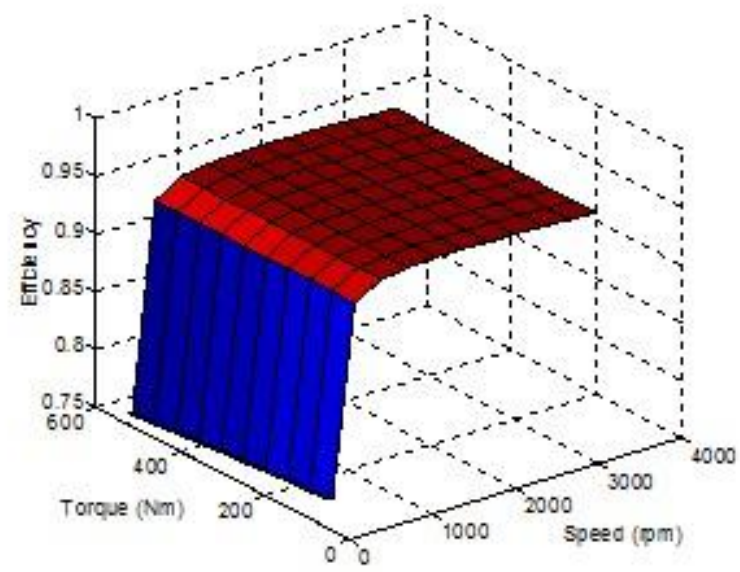

(e) 5 th gear

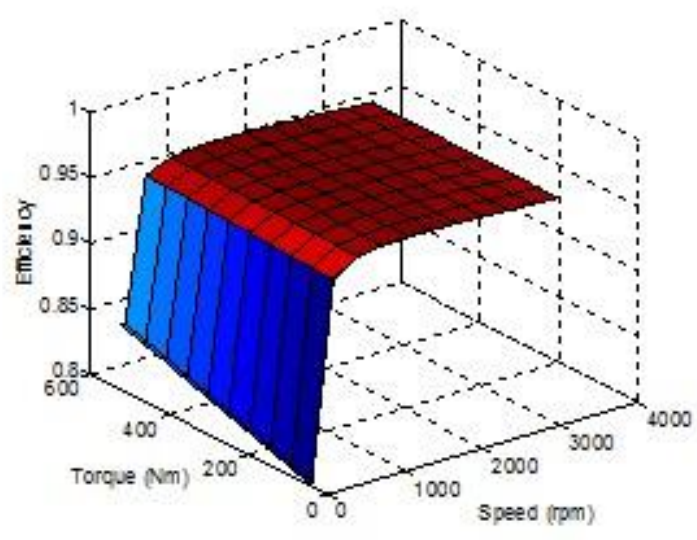

(b) 2nd gear

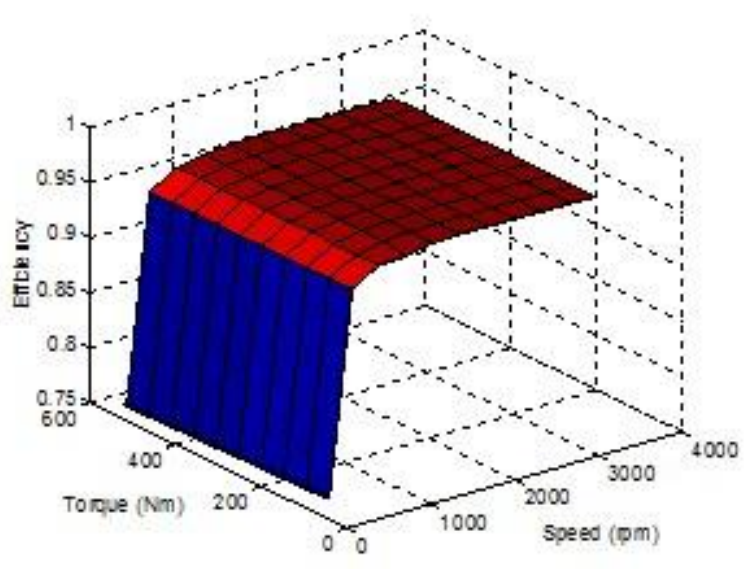

(d) 4th gear

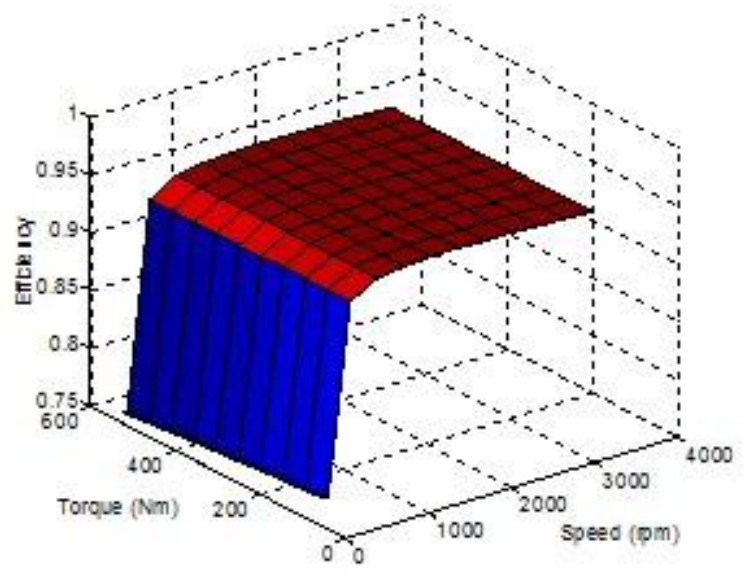

(f) 6th gear

Figure 3.12 Transmission Efficiency Map at Each Gear Position [7] 


\subsubsection{Driver Model}

The driver model in PSAT was used to simulate the effect of drivers' behaviors on the accelerator and brake pedals. By application of a proportional and integral (PI) controller to control vehicle speed, shown in Figure 3.13, the driver model converted the error between desired speed and current speed into torque demand at the wheels.

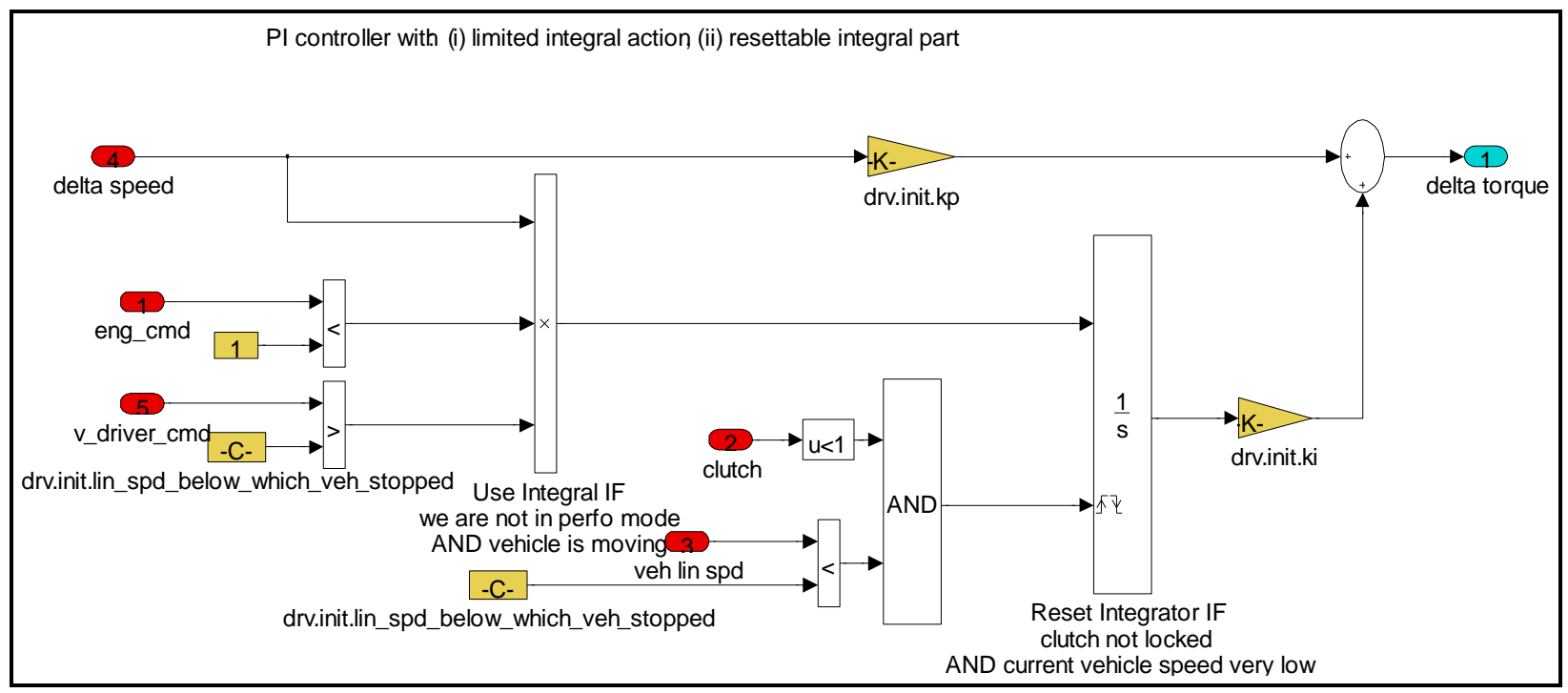

Figure 3.13 Vehicle Speed Controller in Driver Model [7]

\subsubsection{Torque Coupler Model}

A torque coupler is a device with a fixed ratio installed between the motor and the transmission, by which motor speed and torque are divided and multiplied, respectively. The torque coupler used in the bus had a ratio of 2.0 .

\subsubsection{Vehicle Model}

In PSAT the vehicle model was based on the road load equation shown in Equation 8, which considered rolling resistance, aerodynamic drag, road grade, and acceleration loss related to inertia and mass of the powertrain.

$$
\begin{aligned}
P & =P_{r}+P_{w d}+P_{g d}+P_{a c c} \\
& =\frac{1}{3600 \cdot \eta_{t}}\left(m \cdot g \cdot f \cdot \cos \alpha+\frac{C_{D} \cdot A \cdot v^{2}}{21.15}+m \cdot g \cdot \sin \alpha+\delta \cdot m \cdot \frac{d v}{d t}\right) \cdot v
\end{aligned}
$$

Equation 8 
Where $\eta_{t c}, \eta_{g b}, \eta_{f d}$, and $\eta_{t}=\eta_{t c} \cdot \eta_{g b} \cdot \eta_{f d}$ are efficiency of the torque coupler, gearbox efficiency, final drive efficiency and overall transmission efficiency. $\alpha=\tan ^{-1}(i)$ denotes grade angle. $P_{r}, P_{w d}, P_{g d}$, and $P_{a c c}$ represent power losses due to rolling resistance, wind drag, climbing and acceleration, respectively. $\delta$ represents a mass coefficient considering inertia effect.

Table 3.1 shows the main parameters of the vehicle model. The other parameters such as $C_{D}$ and $f$ are defaulted as 0.65 and 0.0098 in PSAT.

Table 3.1 Parameters in Vehicle Model

\begin{tabular}{|c|c|c|l|}
\hline Parameter & Value & Unit & Description \\
\hline$m_{\text {vehicle }}$ & 15000 & $\mathrm{~kg}$ & Vehicle mass \\
\hline$m_{c \text { arg } o}$ & 15000 & $\mathrm{~kg}$ & Vehicle load \\
\hline $\mathrm{A}$ & 6.5 & $\mathrm{~m}^{2}$ & Frontal area \\
\hline
\end{tabular}

\subsection{Control Strategy Model}

\subsubsection{Propelling Strategy Model}

The baseline control strategy, which attempted to minimize fuel consumption and maintain SOC at a normal level, was used in the real tests. According to the strategy, the engine is applied as the primary power source, while the motor is used for power assistance. Based on SOC level, two modes of operation are described here.

When SOC is above the minimum SOC $\left(\mathrm{SOC}_{\min }\right)$ level allowed for the batteries, the strategy will switch to a discharging mode, as shown in Figure 3.14. In this mode, the vehicle will be propelled solely by the electric motor. The engine will not be turned on unless torque demand from the engine is above the minimum torque envelope of the engine $\left(T_{e m i n}\right)$ and vehicle speed is above the electric launch speed.

When $\mathrm{SOC}$ is below $\mathrm{SOC}_{\min }$, the strategy will switch to the recharging mode, as shown in Figure 3.15. The engine will provide excess torque to recharge the batteries through electric motor. The 
engine will be turned off when the overall torque demand is below $\mathrm{T}_{\mathrm{emin}}$ to prevent the operation of engine in low efficiency region.

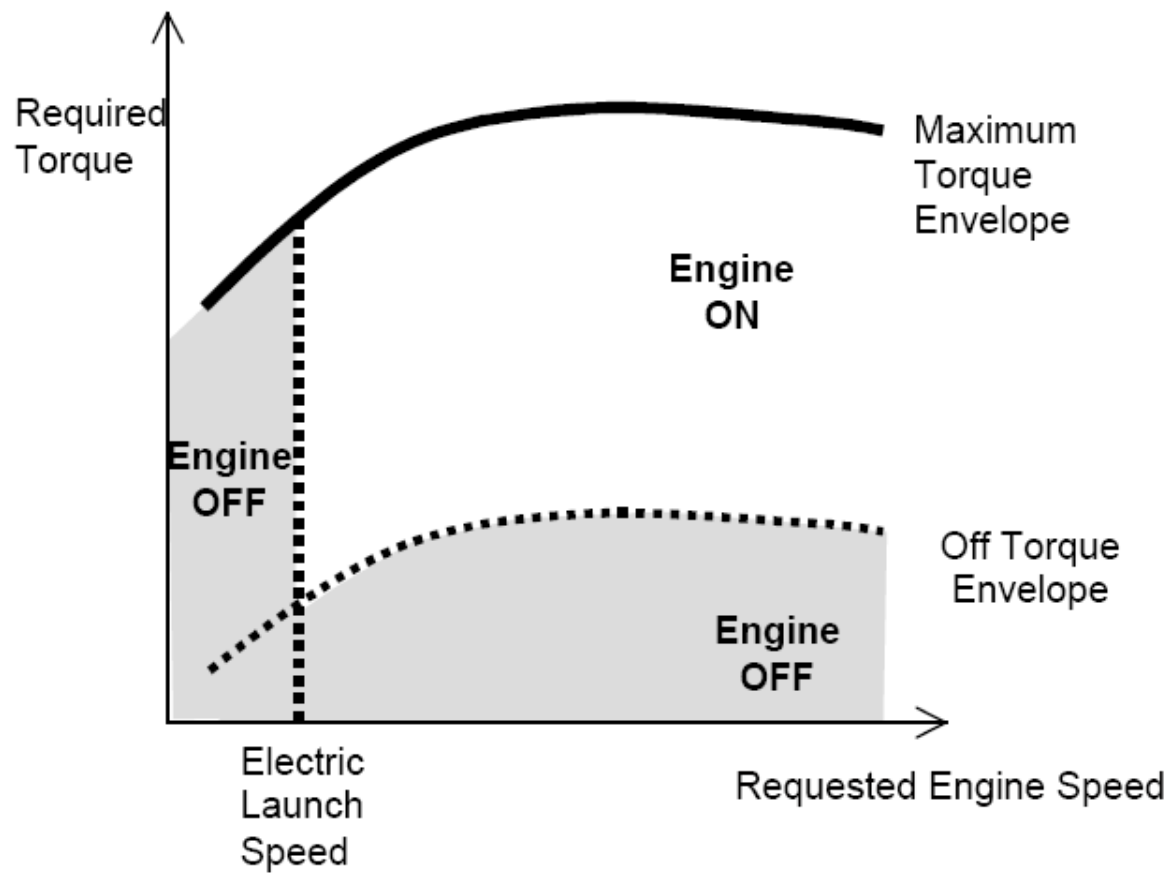

Figure 3.14 Baseline Control Strategy for Test Hybrid Transit Bus (SOC $\left.>\mathrm{SOC}_{\min }\right)$ [34]

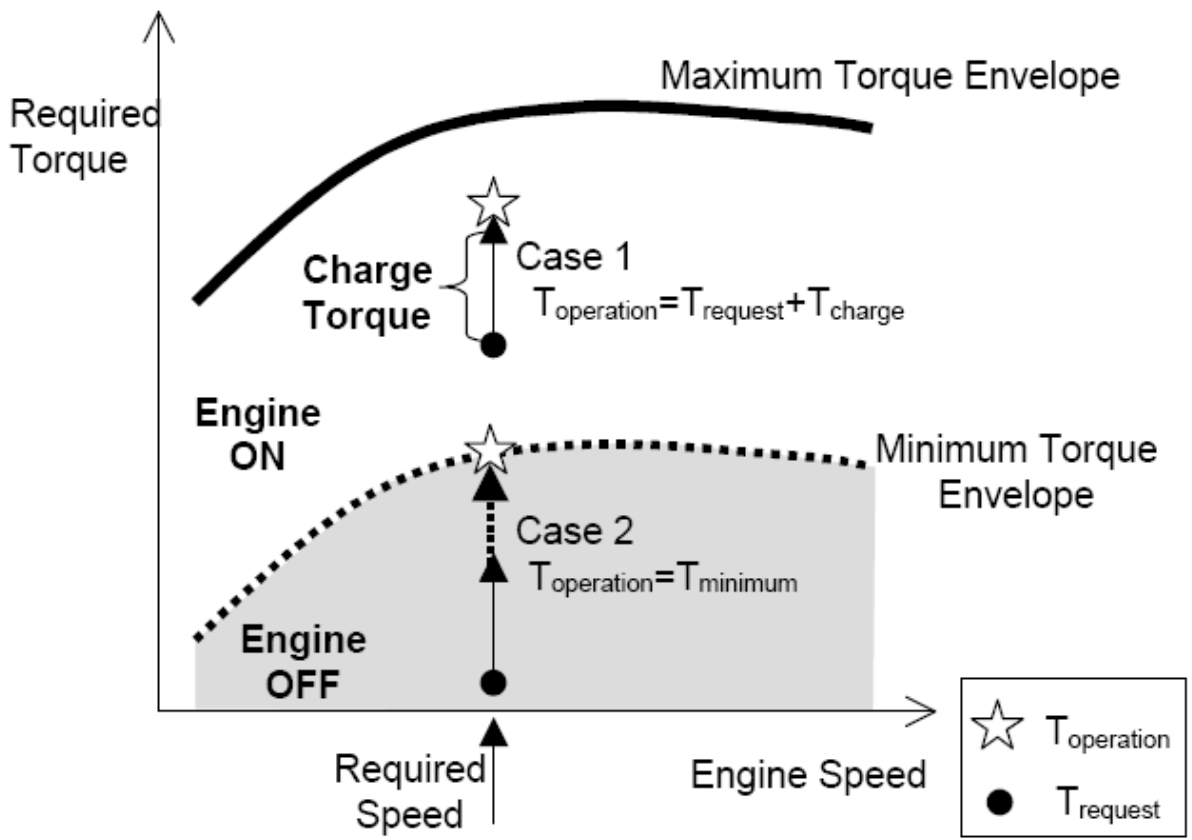

Figure 3.15 Baseline Control Strategy for Test Hybrid Transit Bus $\left(\mathrm{SOC}_{\mathrm{SOC}} \mathrm{Sin}_{\min }\right)^{[34]}$ 


\subsubsection{Gear-Shifting Strategy Model}

An existing shifting strategy for AT was applied in the model. It was based on an up-shifting map and a downshifting map, both of which were functions of accelerator pedal position and vehicle speed. Figure 3.16 shows the up-shifting map and Figure 3.17 shows down-shifting map.

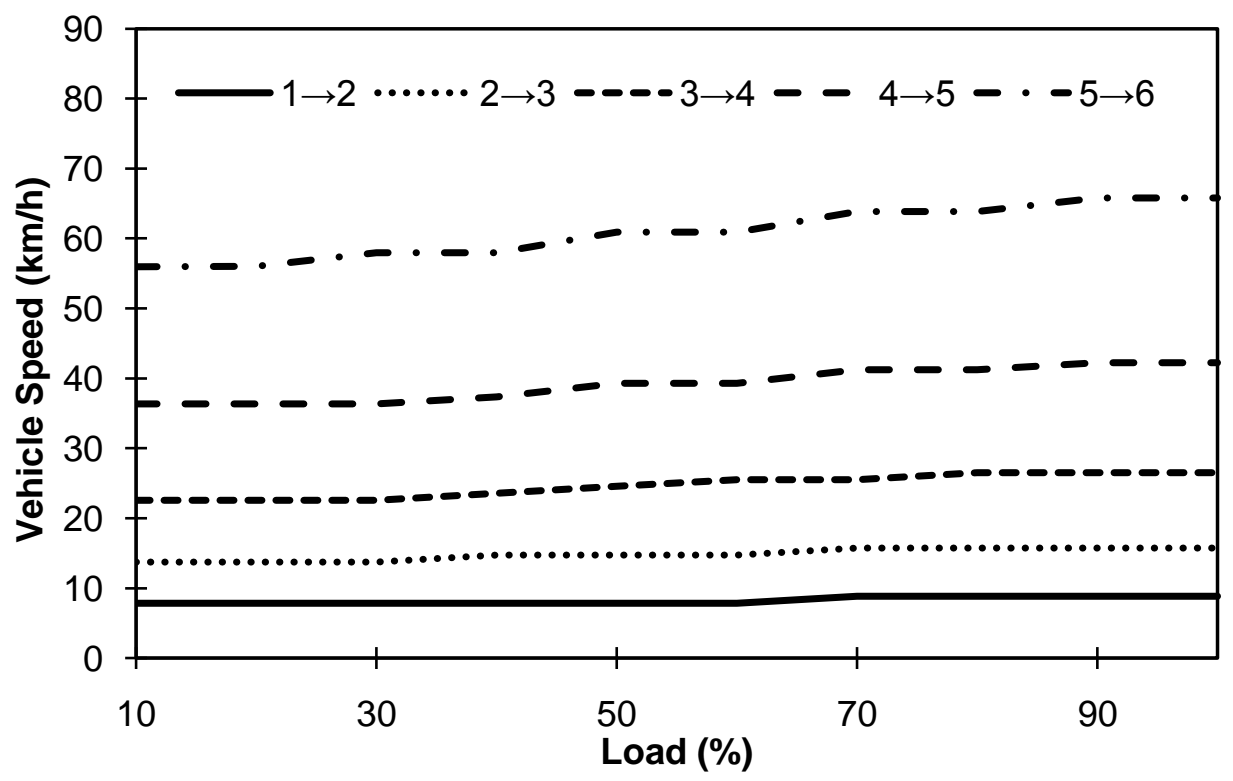

Figure 3.16 Gear Up-shifting Map as a Function of Vehicle Speed and Load [65]

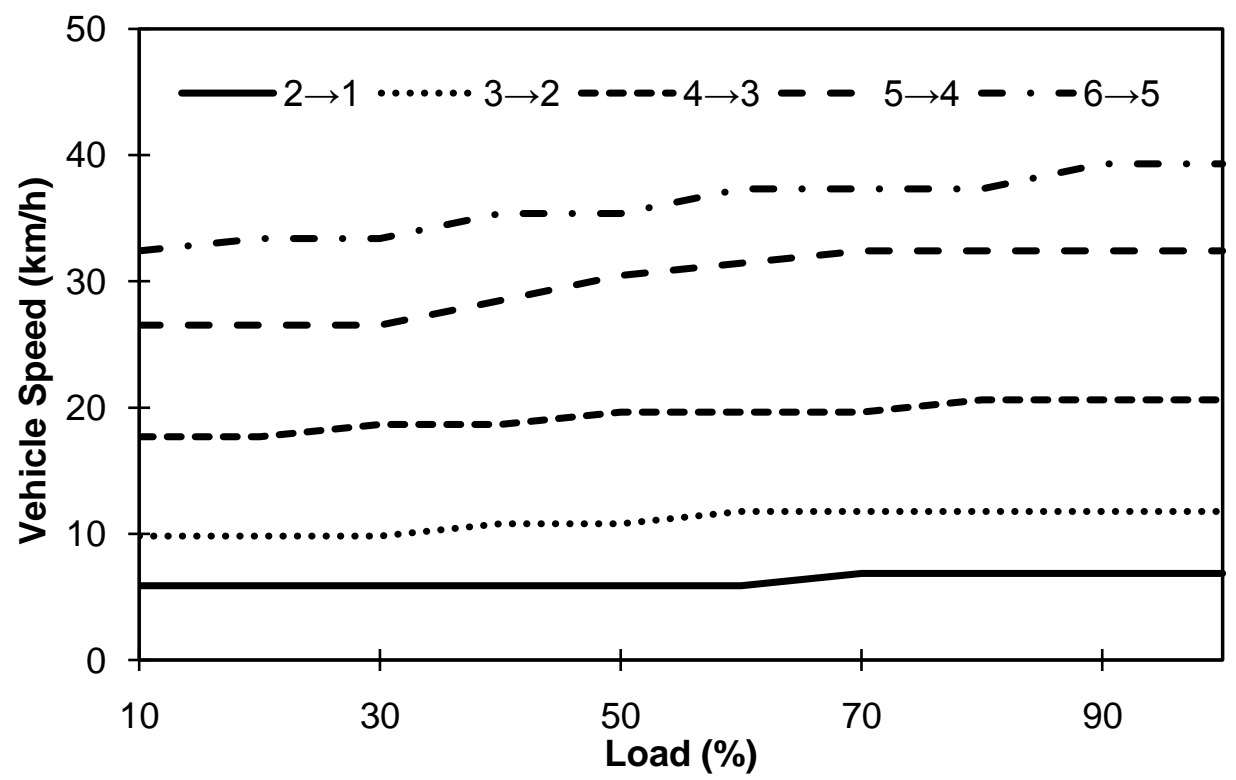

Figure 3.17 Gear Down-shifting Map as a Function of Vehicle Speed and Load [65] 
The up-shifting action is performed when either one of the following two conditions is met:

- The output of the up-shifting map is higher than the current gear and the engine speed at the next gear position is higher than the minimum acceptable speed

- The engine speed at the current gear is higher than the maximum acceptable speed Down-shifting action is implemented when either one of the following two conditions is met:

- The output of the down-shifting map is lower than the current gear and the engine speed at the next gear position is lower than the maximum acceptable speed

- The engine speed at the current gear is lower than the minimum acceptable speed

To avoid excessive shifting, a timer is applied in both up-shifting logic and down-shifting logic so that the current gear is held if the four shifting conditions above only last for a period of time less than a time threshold. However, the timer will be bypassed if the following conditions are met:

- The acceleration pedal is too low or too high, which will deteriorate engine efficiency

- The gearbox input speed is either higher than the maximum acceptable speed or lower than the minimum acceptable speed

\subsubsection{Regenerative Braking Strategy Model}

The braking strategy was applied to recapture kinetic energy in deceleration or braking processes. Compared to the propelling strategy, the braking strategy applied here is relatively simple. The braking strategy is applied when the wheel torque demand is negative. According to the regenerative braking strategy, the kinetic energy is expected to be recovered as much as possible until the power limits of the motor and battery are reached. In the case of very aggressive braking, mechanical braking will be required to stop the vehicle in a short distance and in a short time. 


\section{Model Validation and Control Strategy Optimization Using PSAT}

\subsection{Introduction of China's Bus Driving Cycles and the U.S. Bus Driving Cycles}

\subsubsection{China's Urban Bus Driving Cycle}

China's Urban Bus (CUB) driving cycle was coded as part of national standard GB/T 125451990 in China to test fuel consumption for heavy-duty buses [68]. It is composed of idle, acceleration, cruise and deceleration modes. The vehicle speed over the duration is shown in Figure 4.1. However, the CUB cycle is too simple to simulate real bus driving cycles since frequent start-stops do not exist in it. To make simulations in the CUB cycle closer to reality, a more realistic bus driving cycle was created by repeating the standard CUB cycle three times with a 40-second stop between every two [60]. In this study, the CUB cycle was repeated five times and ten times to create two new cycles named as CUB-5 and CUB-10, respectively. The characteristic parameters of the CUB-5 cycle and the CUB-10 cycle can be found in Table 4.1.

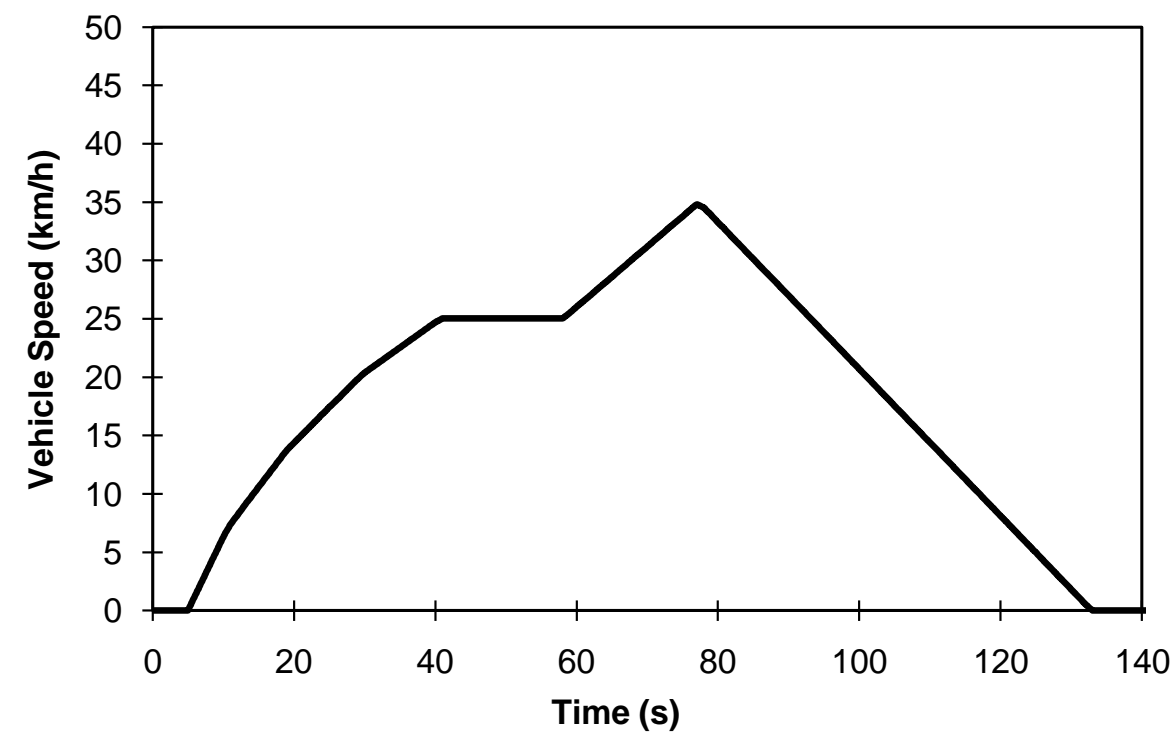

Figure 4.1 Standard CUB Cycle [68] 
Table 4.1 Characteristics of Bus Driving Cycles in China and the U.S.

\begin{tabular}{|c|c|c|c|c|c|c|}
\hline \multirow{2}{*}{ Cycles } & \multicolumn{3}{|c|}{ China } & \multicolumn{3}{c|}{ U.S. } \\
\cline { 2 - 7 } & CUB-5 & CUB-10 & Beijing & CBD & Manhattan & New York \\
\hline Duration $(\mathrm{s})$ & 709 & 1418 & 1815 & 569 & 1089 & 600 \\
\hline Distance $(\mathrm{km})$ & 3.5 & 7 & 7.9 & 3.2 & 3.3 & 1 \\
\hline Max. speed $(\mathrm{km} / \mathrm{h})$ & 34.81 & 34.81 & 36.7 & 32 & 40.46 & 49.28 \\
\hline Ave. speed $(\mathrm{km} / \mathrm{h})$ & 17.75 & 17.75 & 15.64 & 20.3 & 10.92 & 5.89 \\
\hline Max. acceleration $\left(\mathrm{m} / \mathrm{s}^{2}\right)$ & 0.35 & 0.35 & 0.42 & 0.98 & 2.04 & 2.76 \\
\hline Ave. acceleration $\left(\mathrm{m} / \mathrm{s}^{2}\right)$ & 0.18 & 0.18 & 0.14 & 0.81 & 0.54 & 1.16 \\
\hline Max. deceleration $\left(\mathrm{m} / \mathrm{s}^{2}\right)$ & -0.18 & -0.18 & -0.47 & -2.04 & -2.49 & -2.04 \\
\hline Ave. deceleration $\left(\mathrm{m} / \mathrm{s}^{2}\right)$ & -0.17 & -0.17 & -0.18 & -1.78 & -0.66 & -0.67 \\
\hline Stop frequency $(\mathrm{No} . / \mathrm{km})$ & 1.43 & 1.43 & 2.04 & 4.35 & 6.05 & 11.17 \\
\hline
\end{tabular}

\subsubsection{Beijing Cycle}

The hybrid transit bus was also tested through the Beijing cycle, which is more realistic than the CUB cycle. The parameters of the Beijing cycle can be seen in Table 4.1. The velocity speed over duration of the Beijing cycle is shown in Figure 4.2.

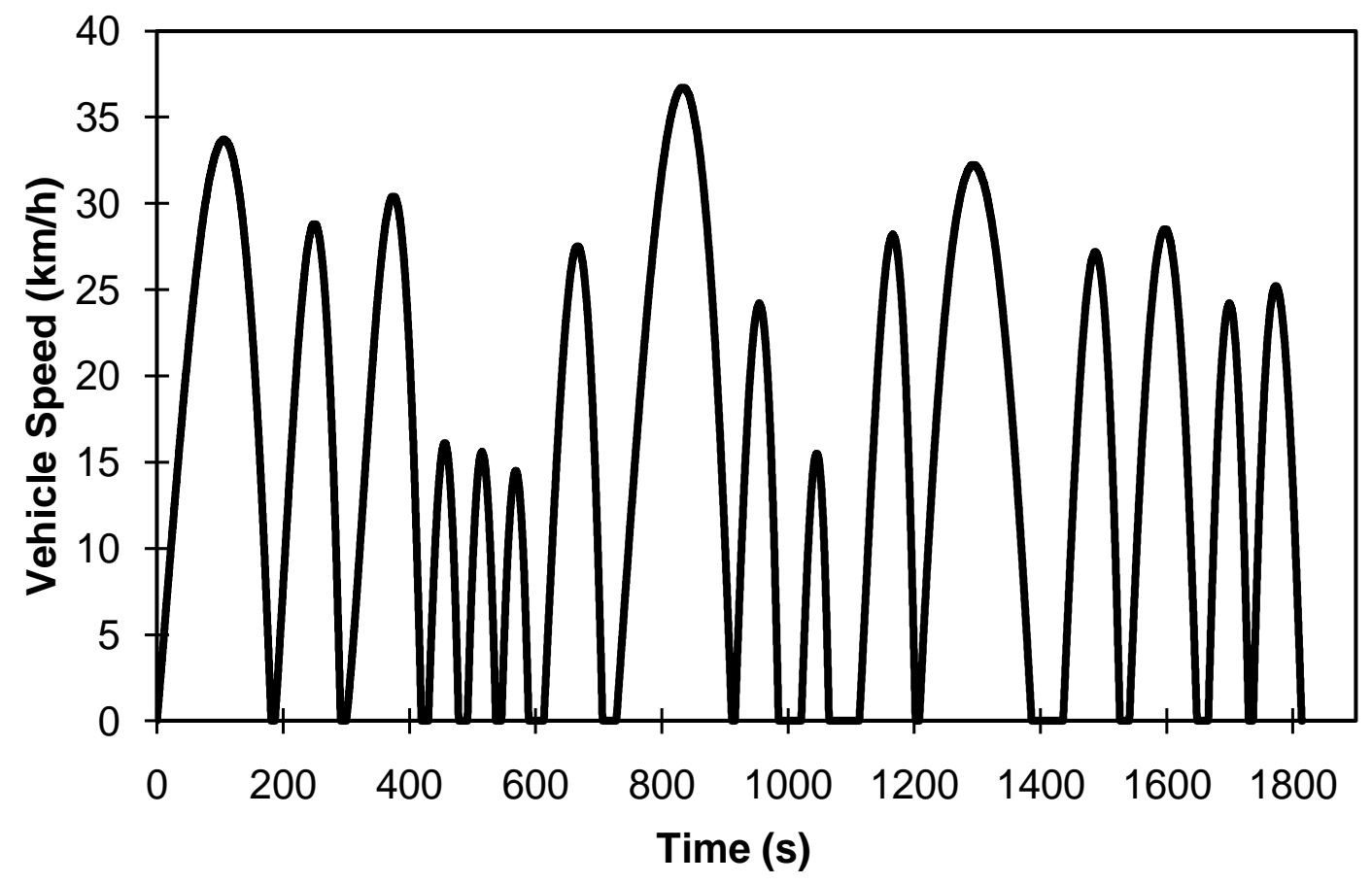

Figure 4.2 Beijing Cycle [43] 


\subsubsection{Central Business District Cycle}

The Central Business District (CBD) cycle, a saw-toothed driving pattern shown in Figure 4.3, was coded in SAE J1376 as a dynamometer test procedure for trucks and buses [69].

Characteristic parameters of CBD cycle are introduced in Table 4.1.

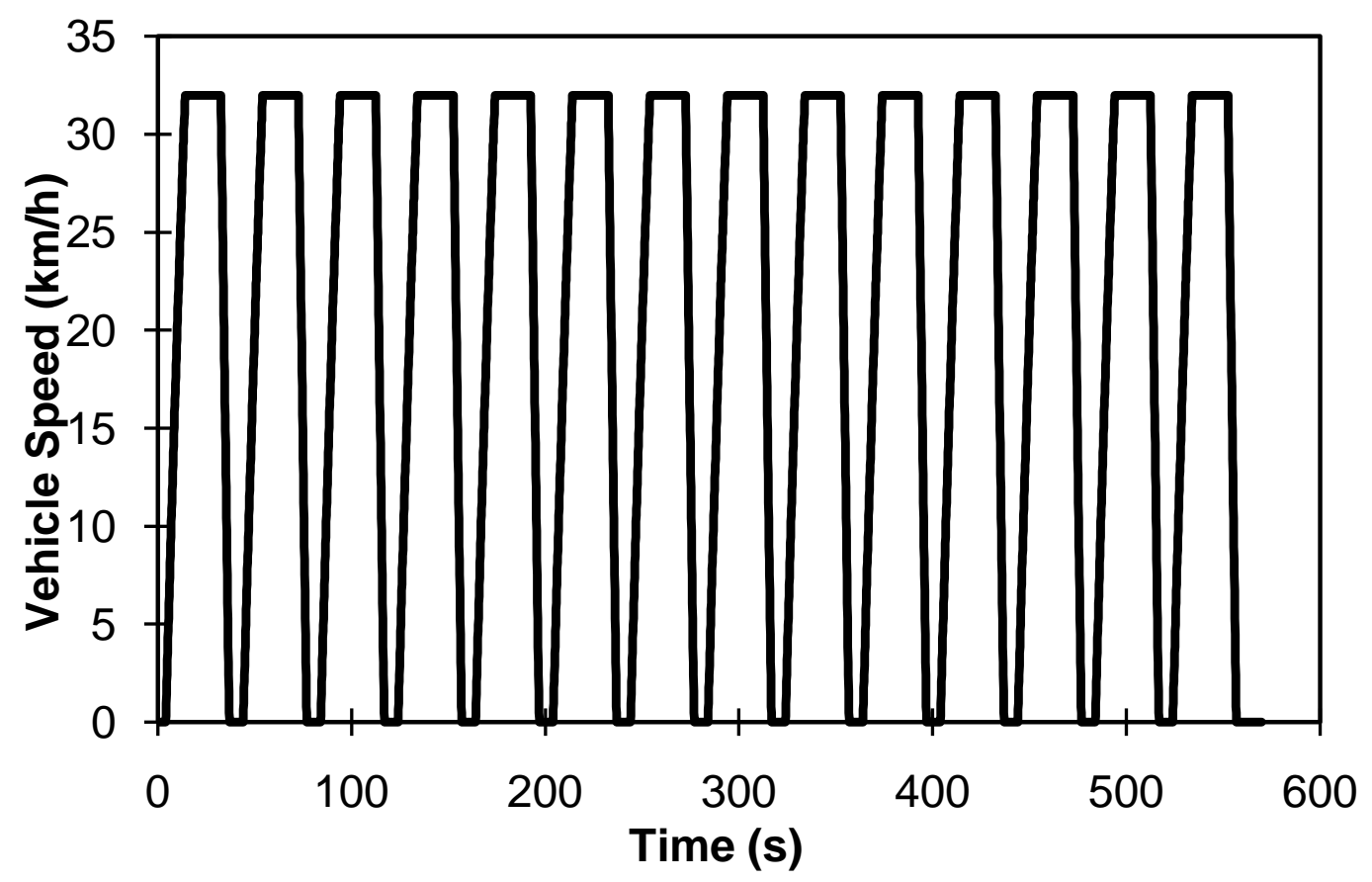

Figure 4.3 CBD Cycle [69]

\subsubsection{Manhattan Bus Cycle}

The Manhattan Bus cycle is a typical urban bus driving cycle based on actual driving patterns in the Manhattan core of New York City. The characteristic parameters of the Manhattan Bus cycle can be seen in Table 4.1. The vehicle speed profile over the duration of cycle is shown in Figure 4.4

\subsubsection{New York Bus Cycle}

The New York Bus cycle is another typical urban bus driving cycle based on driving conditions in New York City. It is characterized by long idle time, frequent stops, low speed and high acceleration. The characteristics of the New York Bus cycle can be found in Table 4.1. Figure 4.5 shows vehicle speed over the duration of New York Bus cycle. 


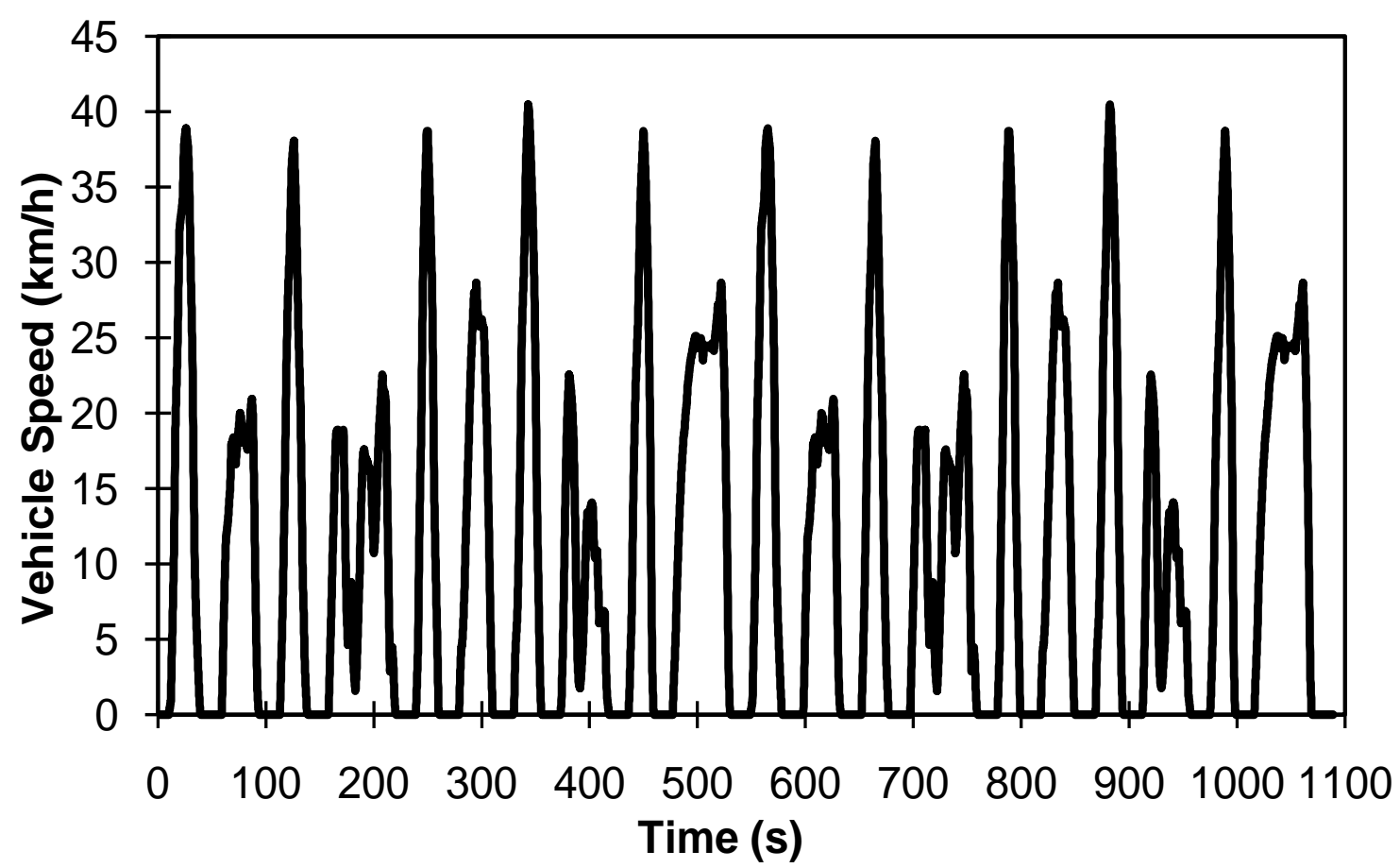

Figure 4.4 Manhattan Bus Cycle [70]

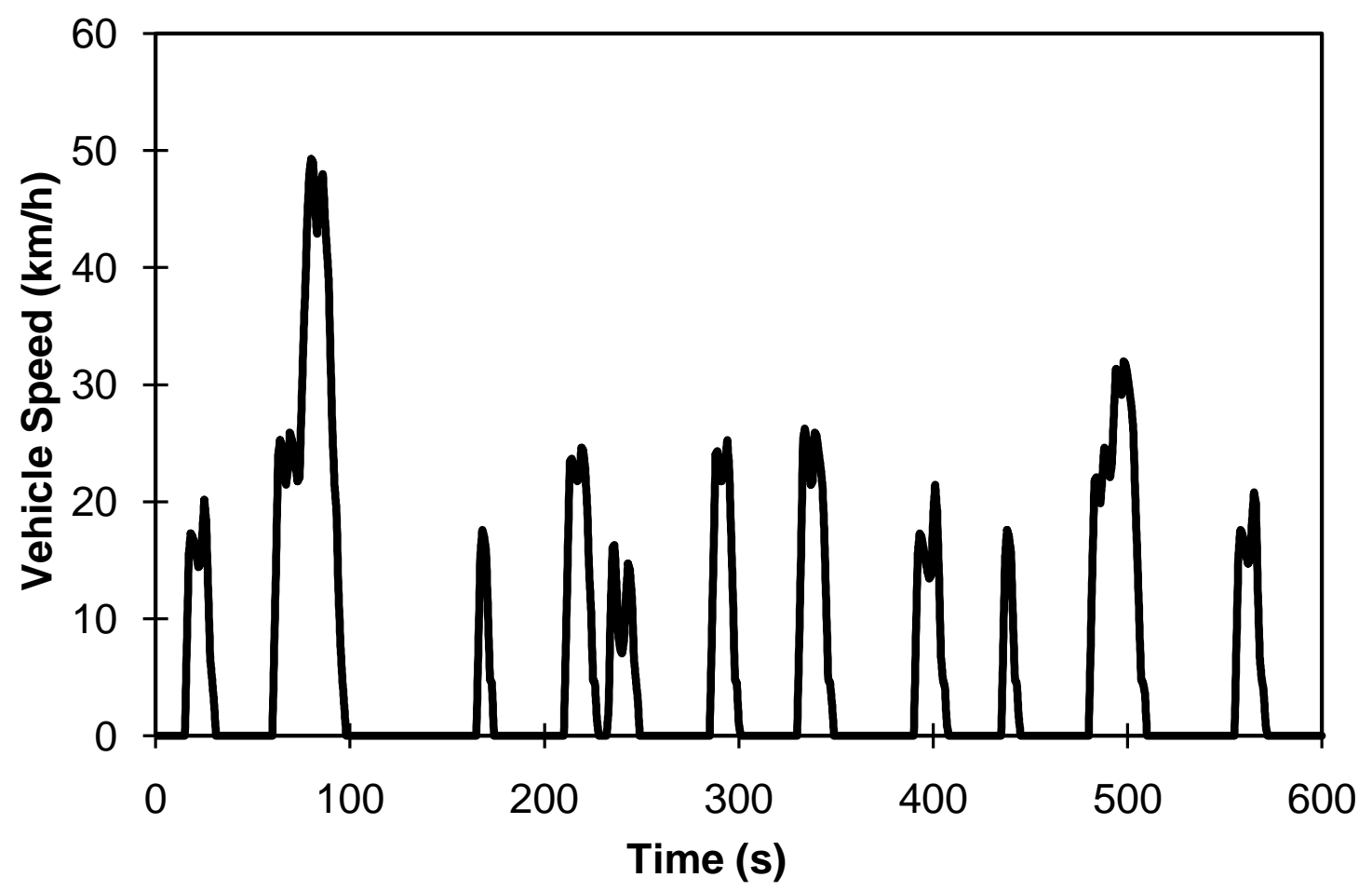

Figure 4.5 New York Bus Cycle [4] 


\subsection{Validation of Hybrid Bus Model}

According to the test results reported by Dr. Xiaohua Zeng at Jilin University [65], the fuel economy of the hybrid bus was tested using the CUB-5 cycle, the CUB-10 cycle, and the Beijing cycle with different initial SOCs. Table 4.2 below shows initial SOCs for each test cycle. The hybrid bus was tested through the CUB-5 cycle twice with initial SOCs of 0.65 and 0.69 , respectively. In order to compare fuel consumptions between test and simulation fairly, the initial SOC in each simulation was set identical to that in the test.

Table 4.2 Initial SOCs for Each Test Cycle

\begin{tabular}{|c|c|c|c|c|}
\hline Test Cycle & CUB-5(a) & CUB-5(b) & CUB-10 & Beijing \\
\hline Initial SOC & 0.65 & 0.69 & 0.70 & 0.51 \\
\hline
\end{tabular}

As an example of validation, Figure 4.6 shows a comparison of vehicle speed between simulation and test. The simulated vehicle speed agrees well with test vehicle speed. Figure 4.7, Figure 4.8 and Figure 4.9 show simulation results of engine operating points, motor operating points, and SOC, respectively. As shown in Figure 4.7, simulated engine behavior followed the described control strategy. The model was validated by comparing the fuel consumption and the change on state of charge ( $\triangle \mathrm{SOC}$ ). Figure 4.10 and Figure 4.11 show comparisons of fuel consumptions and final SOCs between the simulation and test over the four test conditions. It can be seen from Table 4.3 that the relative error between simulated fuel consumption through the four test conditions is less than $4.1 \%$ and simulated $\triangle$ SOCs match those in the test with relative error less than $4.2 \%$. If both fuel consumption and $\triangle \mathrm{SOC}$ are predicted consistently within $5 \%$ on numerous cycles, the vehicle model is considered validated $[54,58]$. Therefore, it can finally be concluded that the parallel pre-transmission hybrid transit bus model was validated successfully by PSAT. 


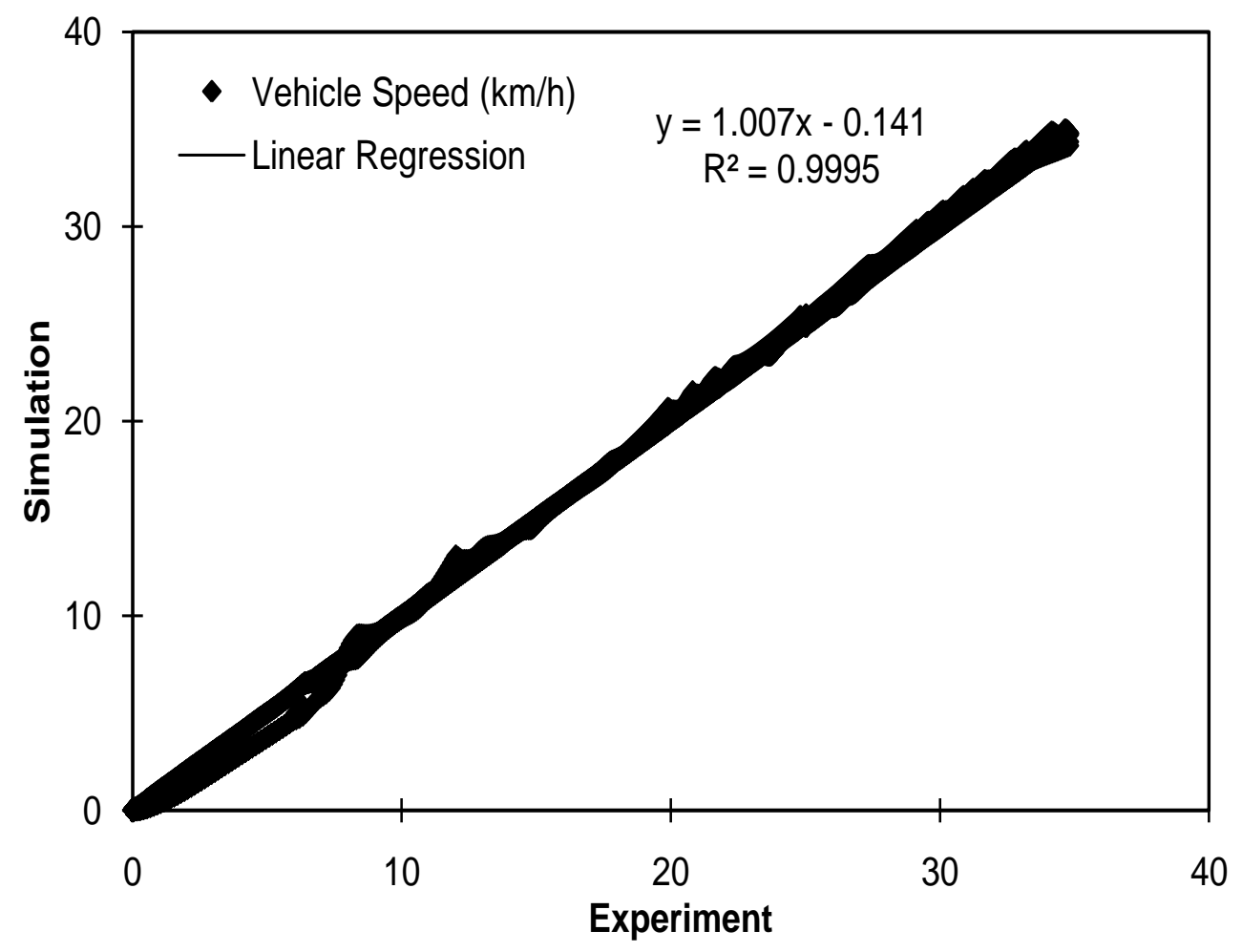

Figure 4.6 Comparison of Vehicle Speed between Test and Simulation over CUB-5 Cycle

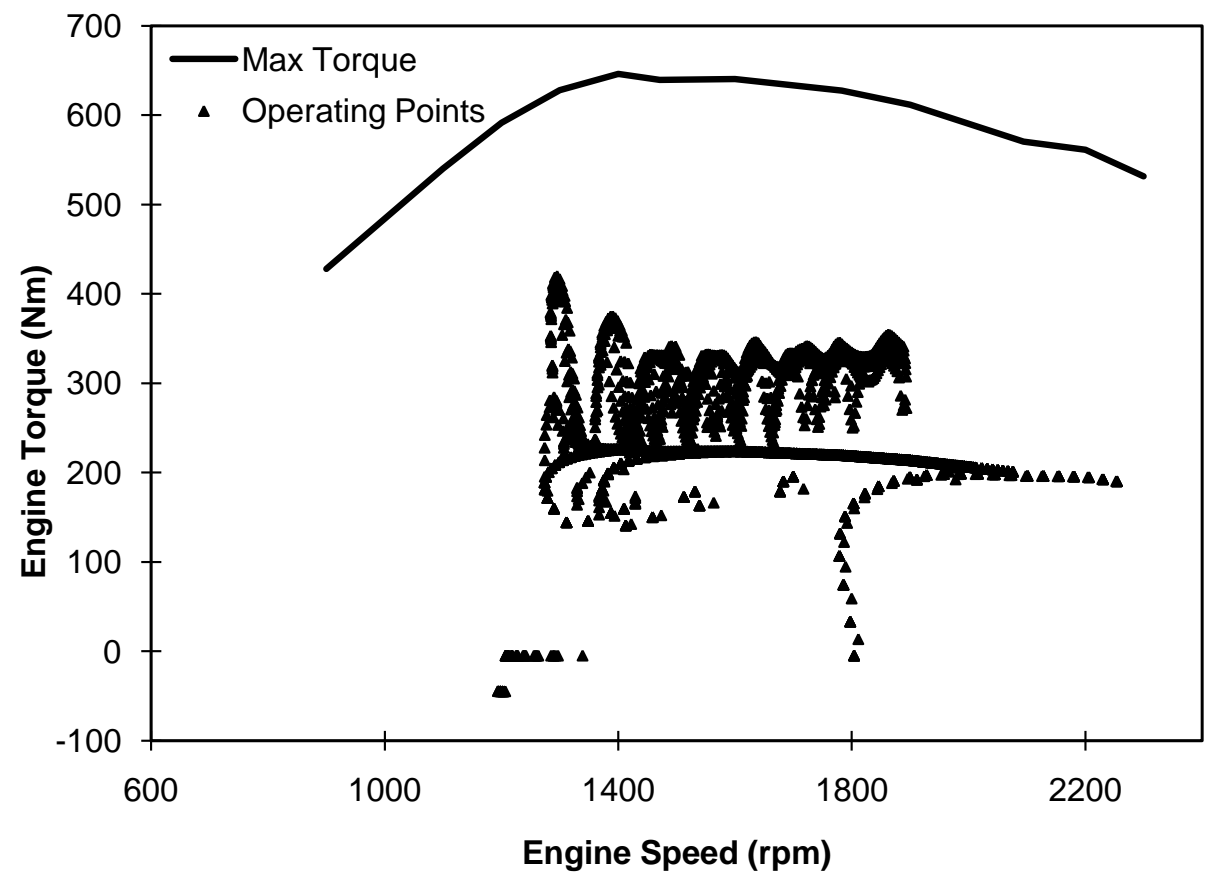

Figure 4.7 Distribution of Engine Operating Point over CUB-5 Cycle (Initial SOC=65\%) 


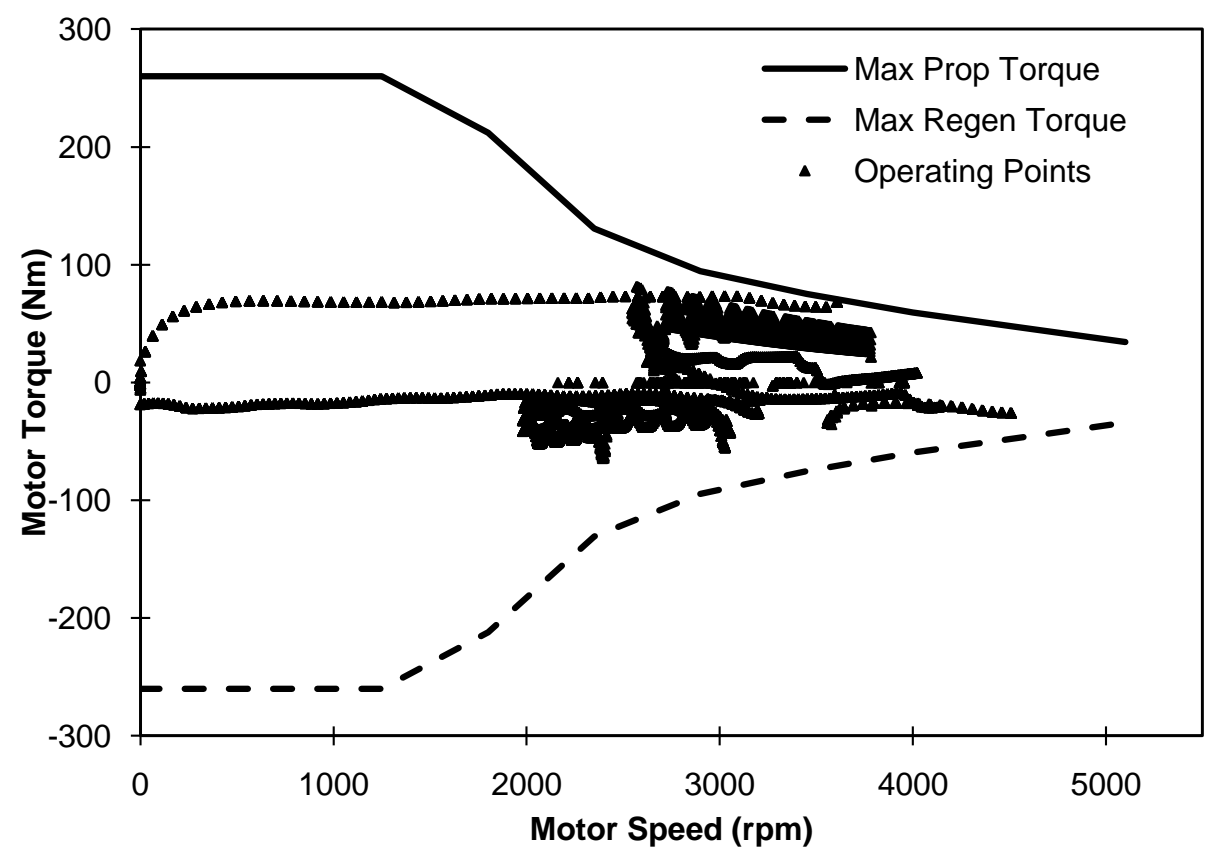

Figure 4.8 Distribution of Motor Operating Points over CUB-5 Cycle (Initial SOC $=65 \%$ )

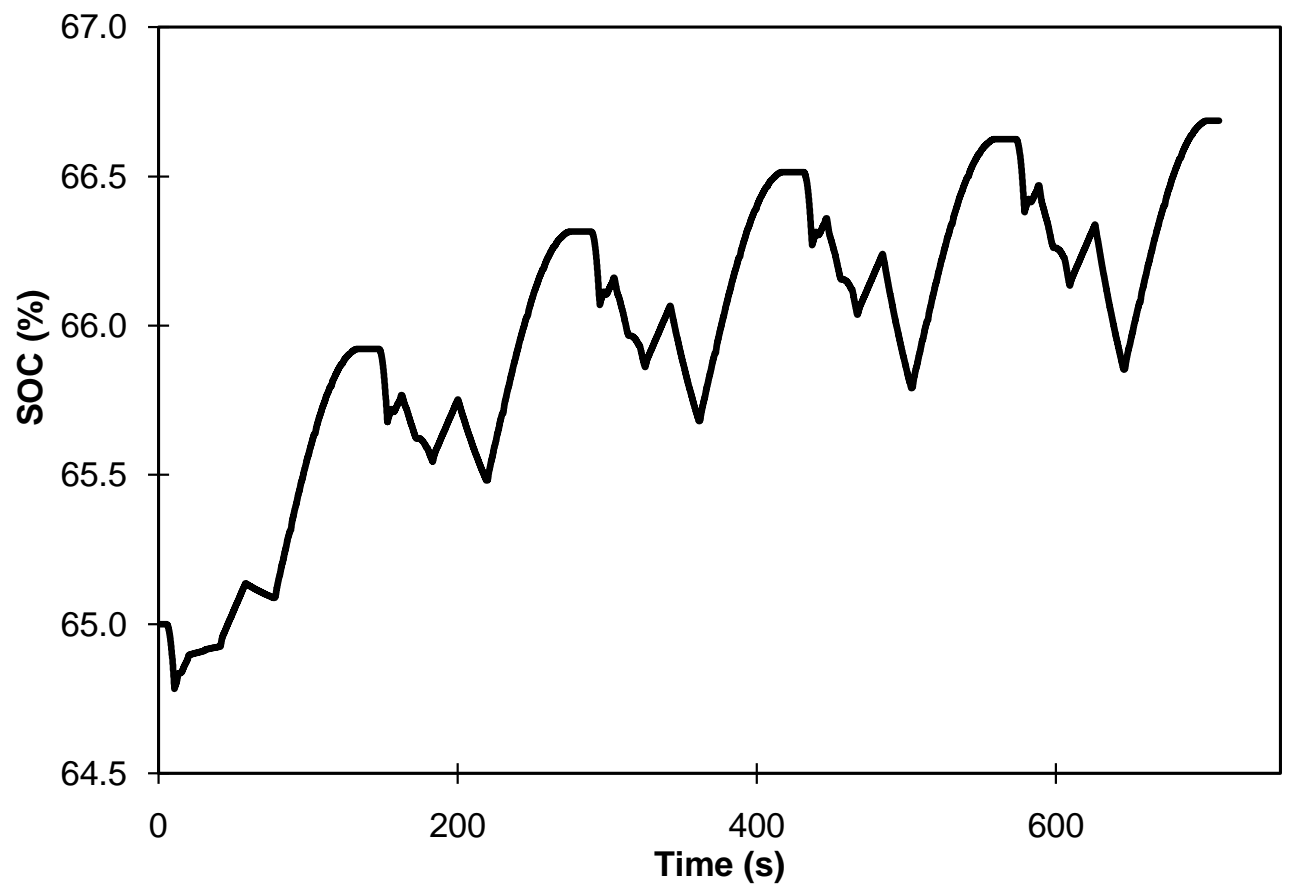

Figure 4.9 Simulation of SOC over CUB-5 Cycle (Initial SOC=65\%) 


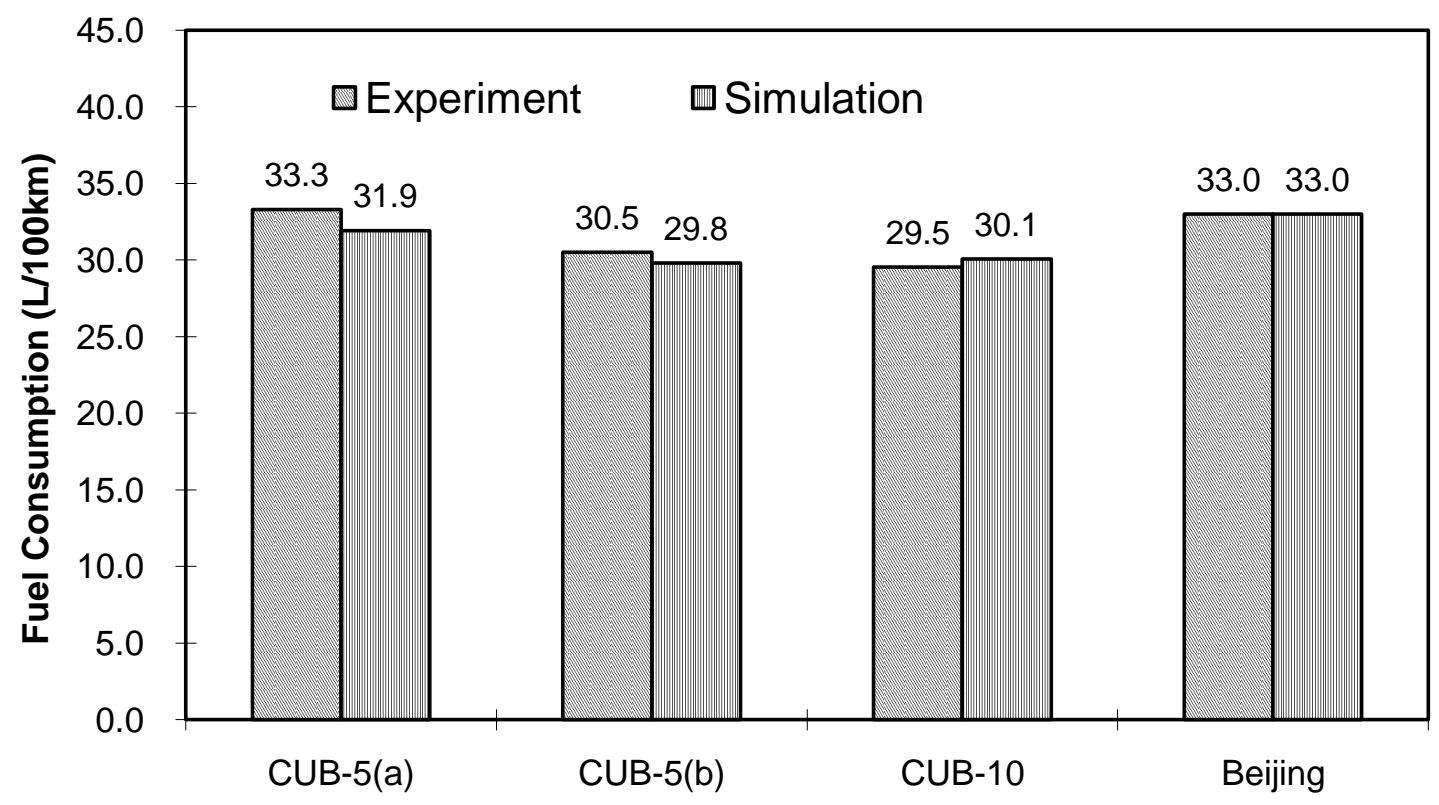

Figure 4.10 Comparison of Fuel Consumption between Test and Simulation

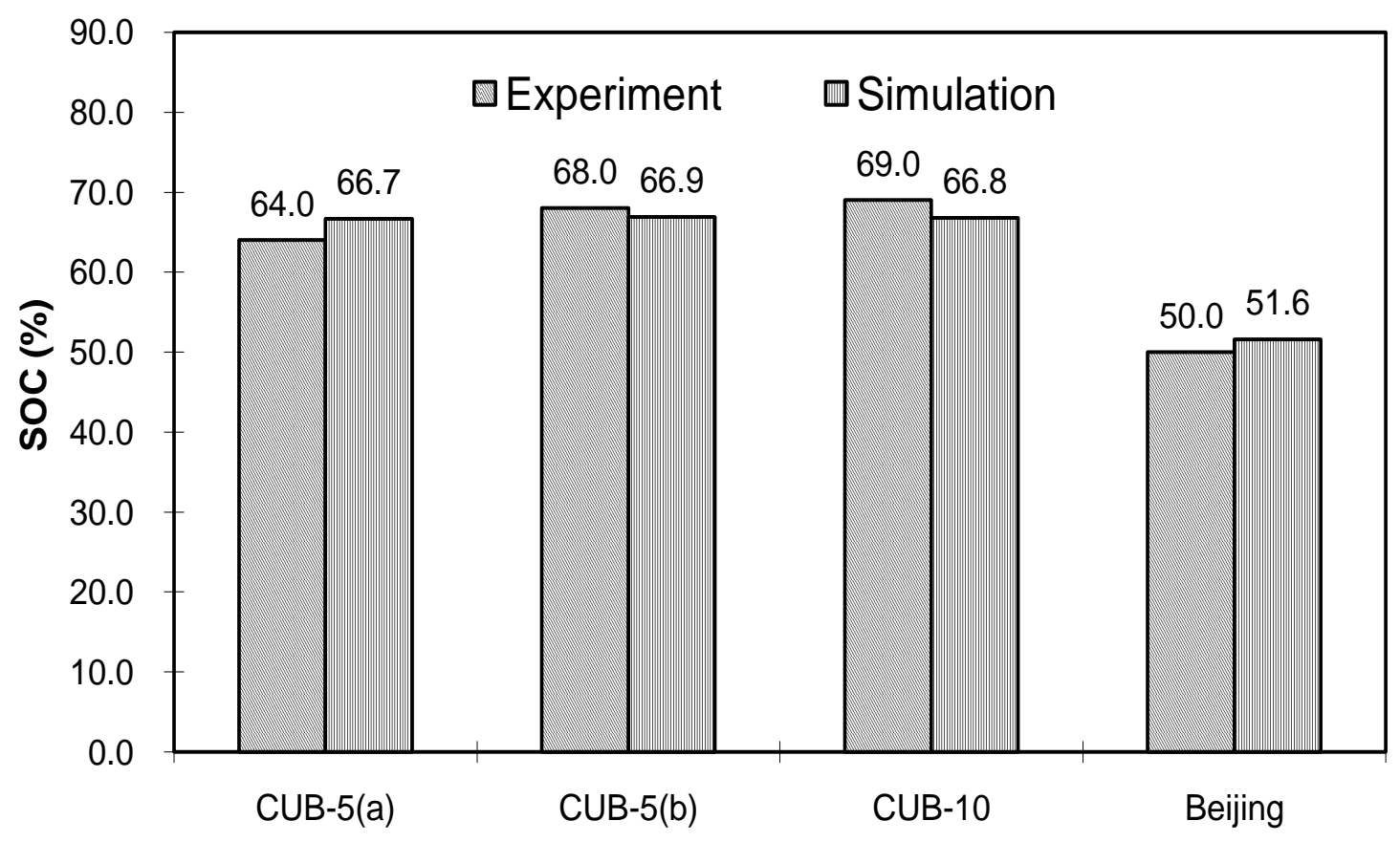

Figure 4.11 Comparison of Final SOC between Test and Simulation 
Table 4.3 Relative Errors of Fuel Consumption and SOC

\begin{tabular}{|c|c|c|c|c|c|}
\hline \multirow{2}{*}{ Data Source } & \multicolumn{2}{|c|}{ Fuel Economy } & Initial SOC & \multicolumn{2}{c|}{ Final SOC } \\
\cline { 2 - 6 } & $(\mathrm{L} / 100 \mathrm{~km})$ & Relative Error(\%) & Value (\%) & Value (\%) & Relative Error (\%) \\
\hline Experiment & 33.3 & - & 65.0 & 64.0 & - \\
\hline Simulation & 31.9 & 4.1 & 65.0 & 66.7 & 4.2 \\
\hline Experiment & 30.5 & - & 69.0 & 68.0 & - \\
\hline Simulation & 29.8 & 2.2 & 69.0 & 66.9 & 1.6 \\
\hline Experiment & 29.5 & - & 70.0 & 69.0 & - \\
\hline Simulation & 30.1 & 1.8 & 70.0 & 66.8 & 3.2 \\
\hline Experiment & 33.0 & - & 51.0 & 50.0 & - \\
\hline Simulation & 33.0 & 0.0 & 51.0 & 51.6 & 3.2 \\
\hline
\end{tabular}

\subsection{Development of the Preliminary Engine Efficiency-Based Control Strategy}

\subsubsection{Description of the Preliminary Engine Efficiency-Based Control Strategy}

The ability of the baseline control strategy to optimize fuel efficiency was very limited since it allowed the engine to operate in non-optimal regions frequently and it did not consider emissions and driving schedules as well.

The new control strategy described in this section (noted as control strategy A) was designed to control the engine's operation in the most efficient region as shown in Figure 4.12.

Based on control strategy A, the engine and motor were combined to propel the vehicle when torque demand was above the most efficient region of engine. While torque required to drive the vehicle was below the most efficient region of engine, batteries were recharged so that excess energy from the engine was stored for the future power assistance. In the extreme case of high torque demand, the engine was forced to produce the maximum torque so that the driving cycle could be satisfied. 


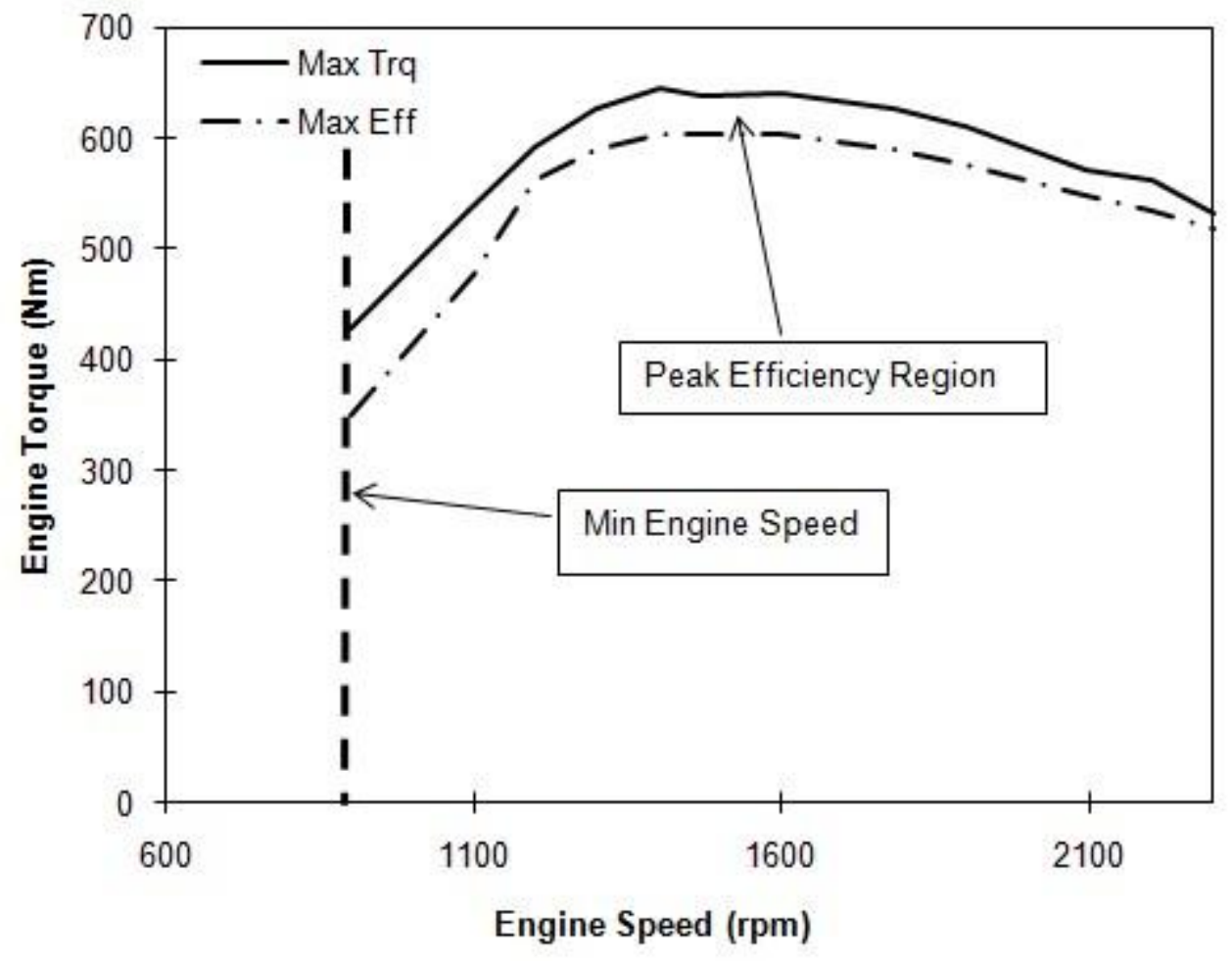

Figure 4.12 Engine Peak Efficiency Region

The benefit of control strategy A was obvious when compared to the baseline control strategy. By operating engine in the efficient region, the engine efficiency was improved. However, since it did not consider the energy loss in charging and discharging process of the battery, the overall efficiency might be deteriorated when the baseline control strategy is used. Therefore, best overall fuel economy could not be achieved. In addition, characteristics of bus cycles in different regions, such as in China and the U.S. varied very significantly. The differences of driving cycles would eventually result in different torque demands and gear-shifting strategy. According to control strategy A, the engine would consistently operate in the high efficiency region. However, as motor operation was not considered, the overall efficiency over different driving cycles would be varied significantly and would not be at the optimum level.

\subsubsection{Optimization Results and Analysis}

The validated hybrid bus model was used to simulate the performance of this bus operated over three U.S. bus cycles (CBD cycle, Manhattan Bus cycle and New York Bus cycle) with baseline control strategy and control strategy A. To simulate the hybrid bus under different operating conditions, initial SOC was varied between $70 \%$ and $55 \%$ with $5 \%$ decrement each time. The 
simulation results show that a vehicle speed deficit occurred and the driving cycles could not be followed accurately due to the vehicle power limit when initial SOC was below $\mathrm{SOC}_{\mathrm{min}}$. To illustrate fuel consumption with SOC correction, simulations with significant vehicle speed deficit were filtered. Figure 4.13, Figure 4.14, and Figure 4.15 show the comparisons of fuel consumptions with different $\triangle$ SOCs over the CBD cycle, Manhattan Bus cycle and New York Bus cycle, respectively. Compared with the baseline control strategy, the control strategy A has no or very limited potential to improve fuel economies over the three U.S. bus driving cycles over various $\triangle \mathrm{SOCs}$. Linear interpolations of fuel consumption with control strategy $\mathrm{A}$ are also shown in Figure 4.13, Figure 4.14, and Figure 4.15. It was found that control A had the potential to reduce SOC corrected fuel consumption by $1.5 \%, 1.7 \%$ and $-0.4 \%$ for the CBD cycle, Manhattan Bus cycle, and New York Bus cycle, respectively. Figure 4.16, Figure 4.17, and Figure 4.18 show comparisons of tailpipe $\mathrm{NO}_{\mathrm{x}}$ emissions in the three emission test cycles between the two control strategies, which indicated that control strategy A had the potential to increase $\mathrm{NO}_{\mathrm{x}}$ emissions by 5.6\%, 5.6\%, and 0.4\% in CBD cycle, Manhattan Bus cycle, and New York Bus cycle, respectively.

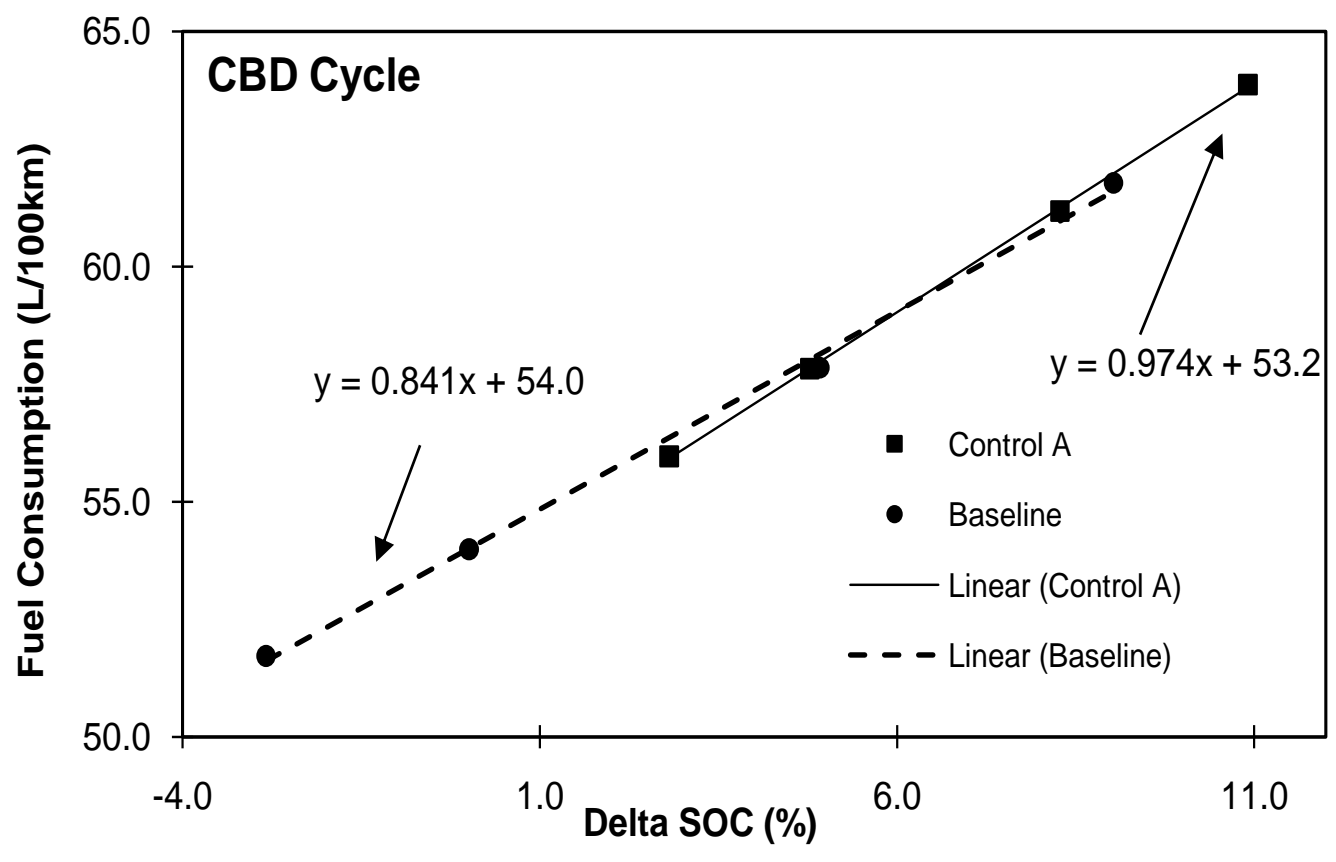

Figure 4.13 Comparison of Fuel Consumption between Control Strategy A and Baseline Control over the CBD Cycle 


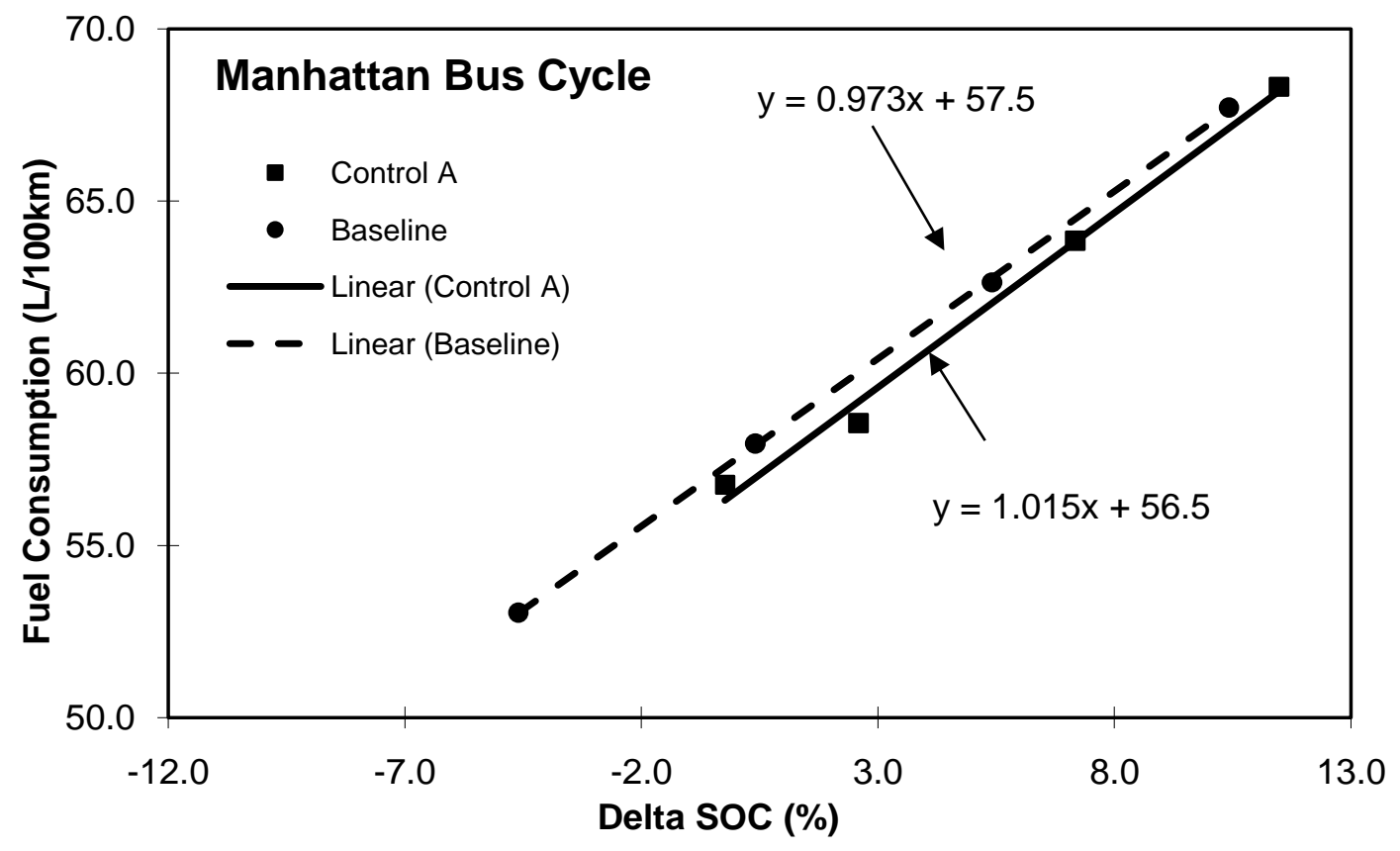

Figure 4.14 Comparison of Fuel Consumption between Control Strategy A and Baseline Control over the Manhattan Bus Cycle

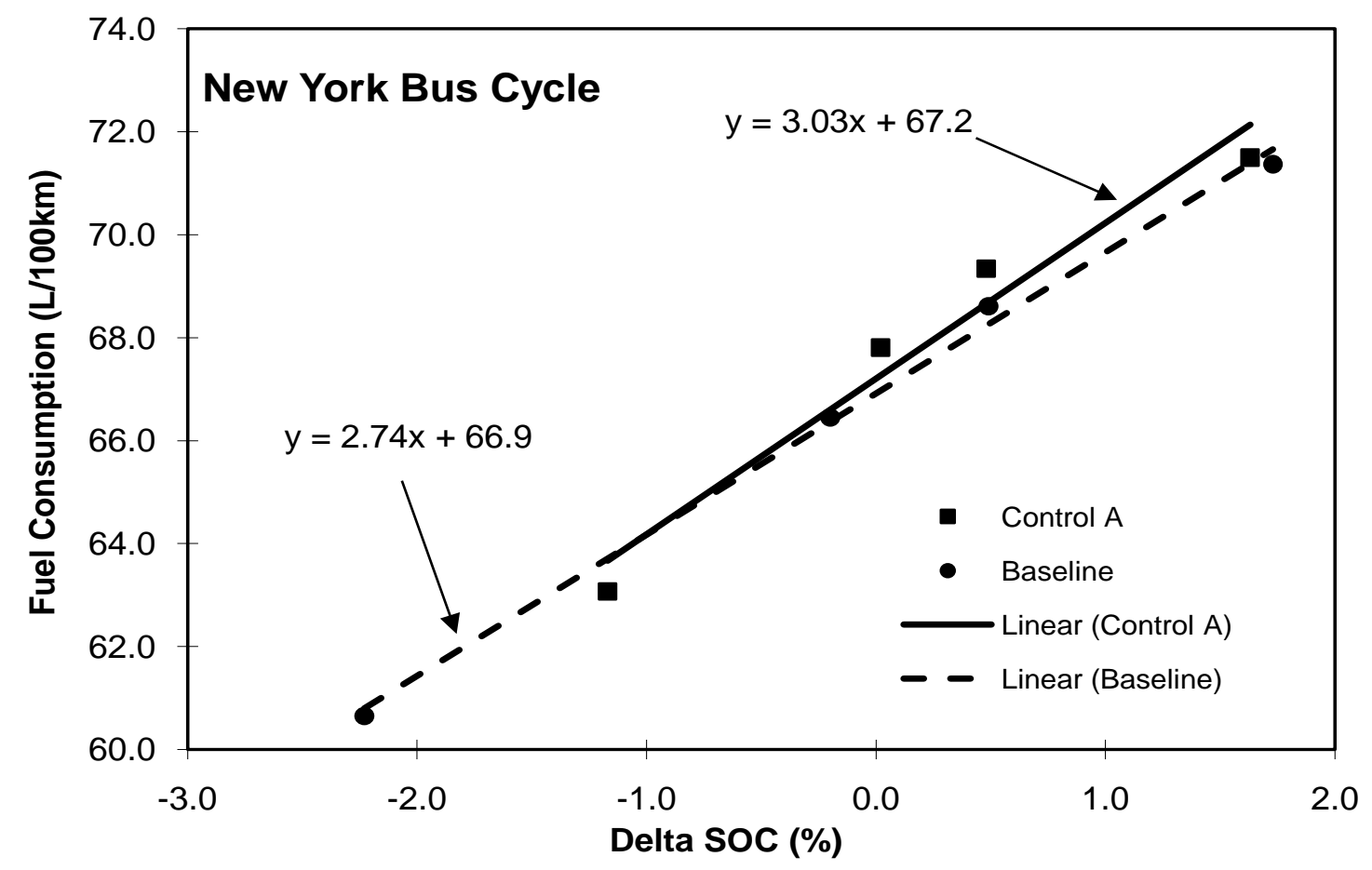

Figure 4.15 Comparison of Fuel Consumption between Control Strategy A and Baseline Control over the New York Bus Cycle 


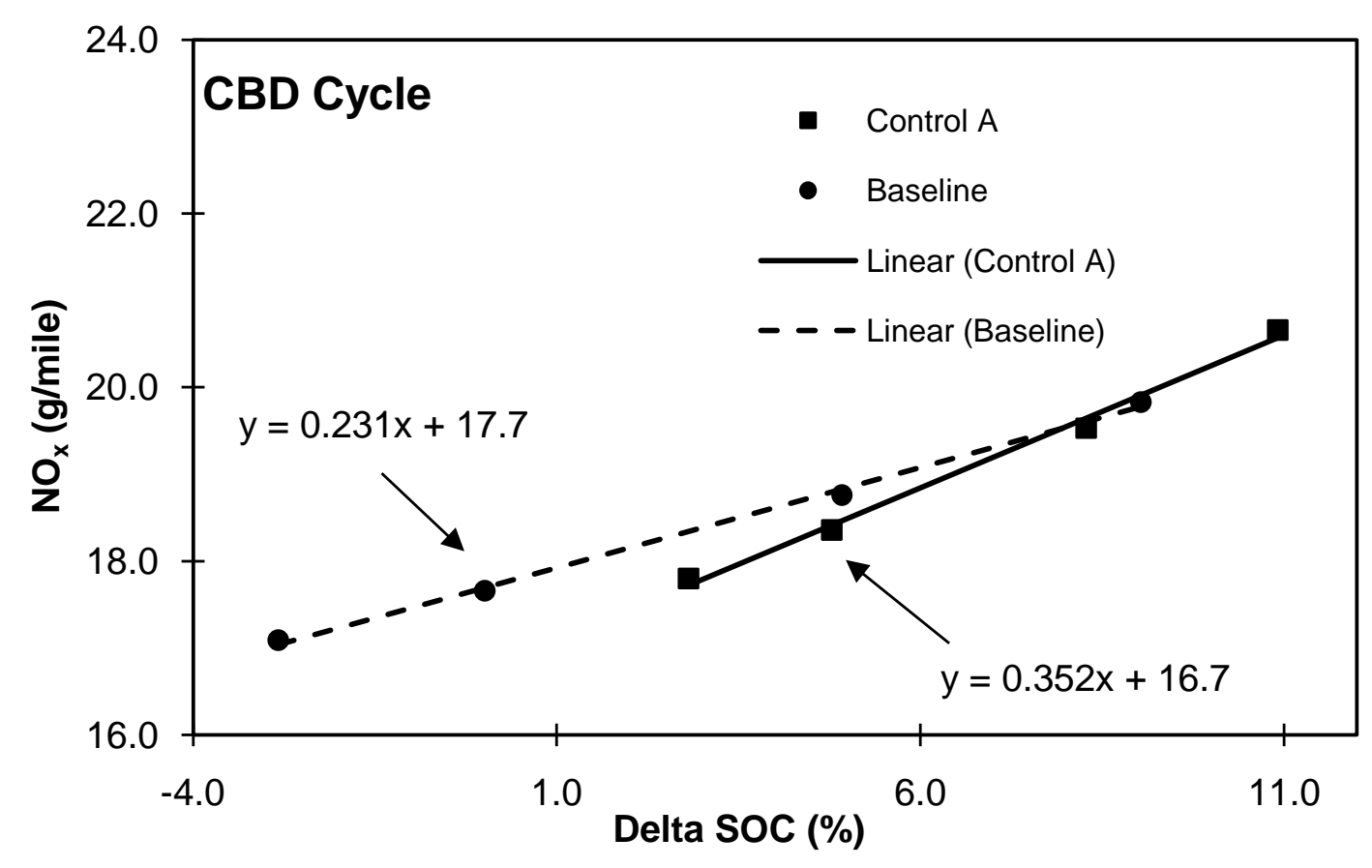

Figure 4.16 Comparison of Tailpipe $\mathrm{NO}_{\mathrm{x}}$ Emissions between Control Strategy A and Baseline Control over the CBD Cycle

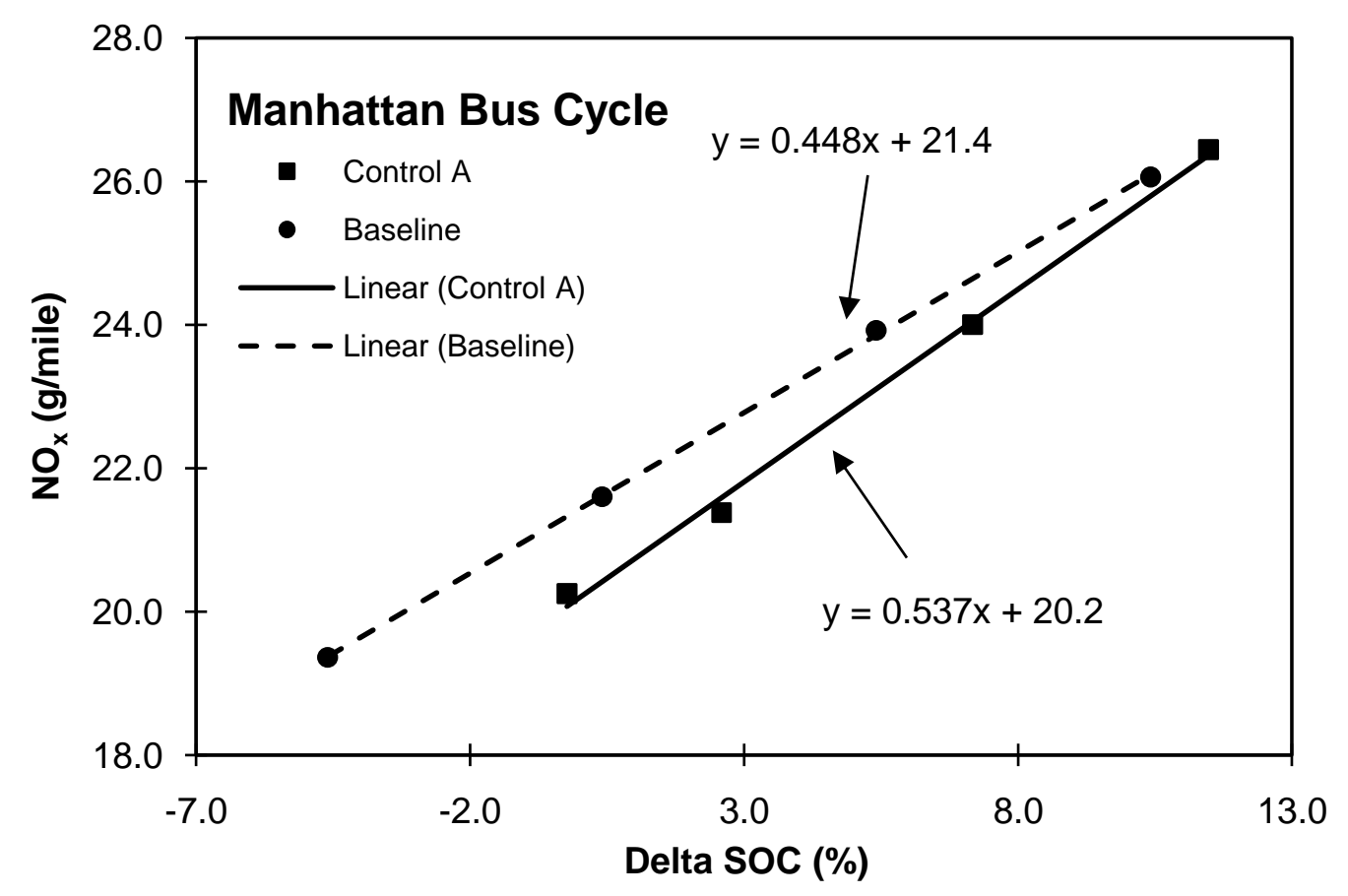

Figure 4.17 Comparison of Tailpipe $\mathrm{NO}_{\mathrm{x}}$ Emissions between Control Strategy A and Baseline Control over the Manhattan Bus Cycle 


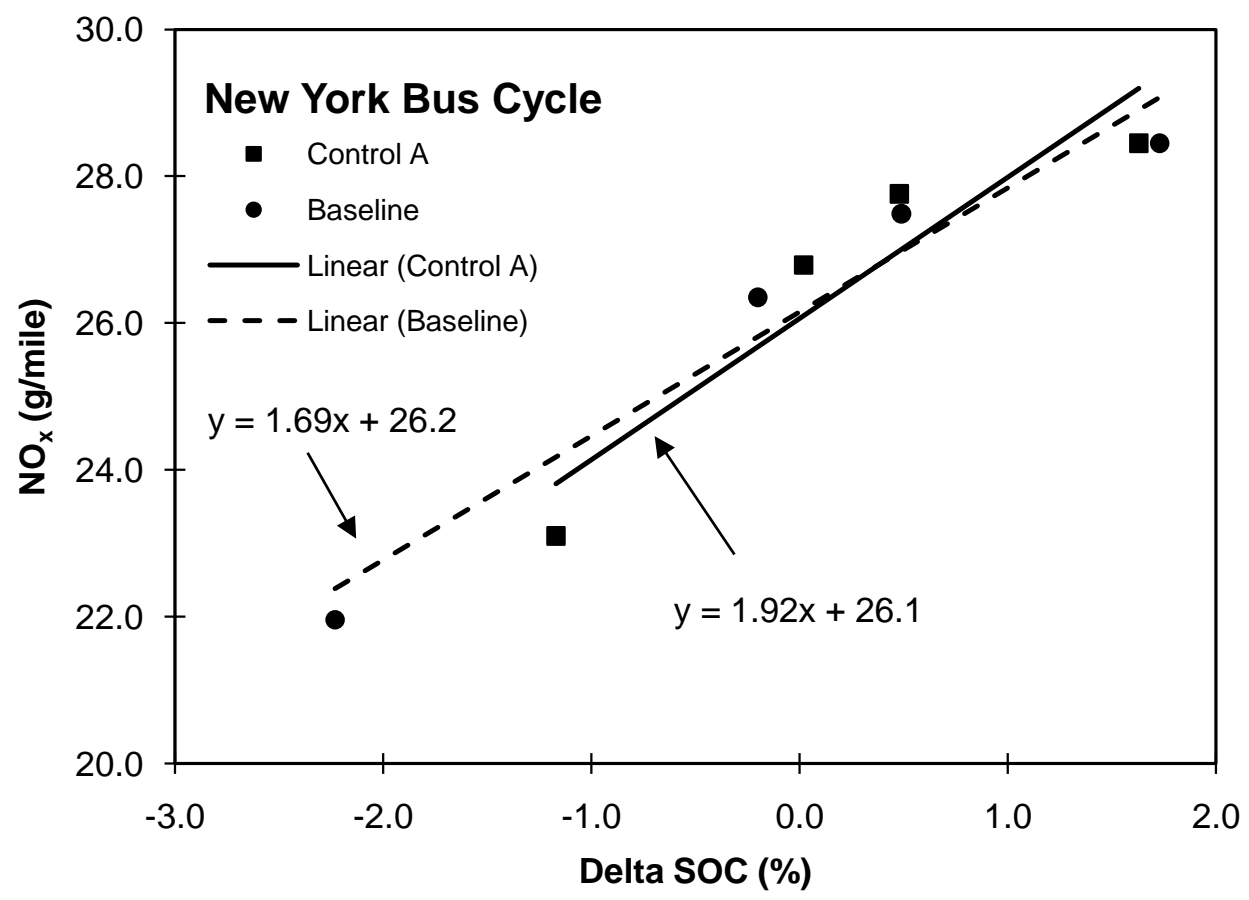

Figure 4.18 Comparison of Tailpipe $\mathrm{NO}_{\mathrm{x}}$ Emissions between Control Strategy A and Baseline Control over the New York Bus Cycle

\subsection{Development of the Real-Time Overall Efficiency-Based Control Strategy}

\subsubsection{Description of the Real-Time Overall Efficiency-Based Control Strategy Problem Formulation}

In a parallel hybrid bus, an engine and a motor are combined to deliver torque needed for propulsion. Therefore for the positive torque, the sum of engine and motor torque must equal to the total torque demand by the gearbox as below:

$T_{e}+T_{m} \times r_{t c}=T_{g b, i n}$ Equation 9

For the braking process where negative torque is required, electric energy can be supplied into the batteries through the motor. Therefore, the negative torque required should be satisfied by sum of motor torque and mechanical braking torque as below:

$T_{m} \times r_{t c}+T_{b r a k e}=T_{g b, i n}$

Equation 10 
The braking control strategy is very straightforward by recapturing regeneration energy as much as possible within battery and motor constraints. Mechanical braking torque will take over the remaining negative torque demand.

Therefore, the essence of a parallel hybrid vehicle control strategy is to find a proper torque split ratio between the engine and the motor for every speed input and torque input so that control objectives such as maximization of overall efficiency and minimization of fuel consumption (or other user-defined cost functions) can be achieved.

\section{Control Objective and Control Variable}

The control objective was taken as maximizing the overall efficiency for a given speed in every time step based on the engine efficiency map, motor efficiency map, battery efficiency map as well as energy recovery from regenerative braking. The overall efficiency is defined in

Equation 11:

$$
\eta_{\text {overall }}=\frac{T_{g b, i n} \times n_{g b, i n}}{\left(\frac{T_{e} \times n_{e}}{\eta_{e}}+\frac{T_{m} \times n_{m}}{\eta_{m}}\right) \times \Gamma}=\frac{\eta_{e} \times \eta_{m}}{\left(\eta_{e}+\left(\eta_{m}-\eta_{e}\right) \times x\right) \times \Gamma}
$$

Equation 11

Where $\eta_{\text {overall }}$ is the overall efficiency. $T_{e}, T_{m}$, and $T_{g b, i n}$ are the engine torque, motor torque, and torque input of gearbox, and $\eta_{e}$ and $\eta_{m}$ are engine efficiency and motor efficiency. According to the literature [64], about $10 \%$ of propelling energy can be recaptured for the hybrid transit bus. Therefore $\Gamma$ is introduced as a correction factor of $90 \%$ when calculating the net energy into the powertrain. The torque split ratio $x$, is defined in Equation 12.

$$
x=\frac{T_{e}}{T_{g b, i n}}
$$

\section{Equation 12}

This implies that once the optimum torque split ratio is assigned, engine torque is calculated based on this ratio and the motor should provide the remaining power to meet the total torque demand.

The purpose of this research is to determine for each time step the value of torque split ratio $x$ such that $\eta_{\text {overall }}$ is maximized while keeping the state of charge (SOC) within an allowable 
range. $x$ was chosen as the main control variable while SOC was chosen as a critical state variable.

\section{Constraints}

The control strategy must respect various hard and soft constraints. For the engine operation, engine torque has physical constraints as:

$$
\begin{cases}T_{e \max }=0 & n_{e}<n_{e \min } \\ T_{e \max }=f\left(n_{e}\right) & n_{e} \geq n_{e \min }\end{cases}
$$

\section{Equation 13}

Engine speed must satisfy that

$$
n_{e \min } \leq n_{e} \leq n_{e \max }
$$

Equation 14

The state variable in the battery is SOC and it is constrained between the maximum limit and the minimum limit for battery security and efficiency.

$$
S O C_{\min } \leq S O C \leq S O C_{\max }
$$

\section{Equation 15}

Physically, the motor torque is limited to the maximum propelling torque and maximum regenerating torque. However, when withdrawing energy from the batteries, it is necessary to take battery SOC into consideration. The constraints for motor torque were set as below:

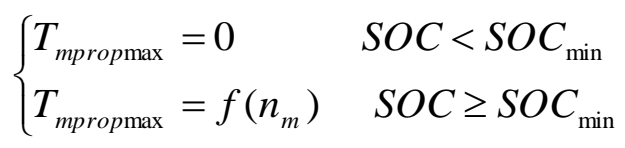

\section{Equation 16}

During the optimization, all the three components must operate under their constraints.

$$
\left\{\begin{array}{l}
0 \leq T_{e} \leq T_{e \max } \\
T_{\text {mregen } \max } \leq T_{m} \leq T_{m p r o p \max }
\end{array}\right.
$$

\section{Equation 17}

These constraints will yield to minimum and maximum limits of torque split ratio as below:

$$
\left\{\begin{array}{l}
0 \leq x \leq \frac{T_{e \text { max }}}{T_{g b, i n}} \\
1-\frac{T_{m p r o p \max } \times r_{t c}}{T_{g b, i n}} \leq x \leq 1-\frac{T_{m r e g e n \max } \times r_{t c}}{T_{g b, i n}}
\end{array}\right.
$$

\section{Equation 18}

By solving the set of inequality above, we can find the upper limit and lower limit for $x$ as: 


$$
\left\{\begin{array}{l}
x_{\min }=\max \left(0,1-\frac{T_{m p r o p \max } \times r_{t c}}{T_{g b, \text { in }}}\right) \\
x_{\max }=\min \left(\frac{T_{e \max }}{T_{g b, i n}}, 1-\frac{T_{\text {mregen } \max } \times r_{t c}}{T_{g b, i n}}\right)
\end{array}\right.
$$

\section{Equation 19}

\section{Real-Time Programming Solution}

For a given speed and torque demand at the gearbox, there are many candidates of torque split ratios between engine and motor which could be used to meet the total torque demand. For each torque split ratio, the overall efficiency is calculated. By comparison of all the overall efficiencies over the range of torque split ratio, the maximum overall efficiency can be found and the corresponding torque split ratio is considered as the optimal one. The algorithm of the realtime control strategy is described as below:

$$
\begin{aligned}
& x_{\text {step }}=\frac{\left(x_{\max }-x_{\min }\right)}{N} ; \\
& x_{\text {range }}=\left[x_{\min }: x_{\text {step }}: x_{\max }\right] \\
& \text { for } i=1: N+1 \\
& T_{e}(i)=T_{g b, \text { in }} \times x_{\text {range }}(i) ; n_{e}=n_{g b, i n} ; \eta_{e}(i)=f\left(T_{e}(i)\right) ; \\
& T_{m}(i)=\left(T_{g b, \text { in }}-T_{e}(i)\right) / r_{t c} ; n_{m}=n_{g b, \text { in }} \times r_{t c} ; \eta_{m}(i)=f\left(T_{m}(i)\right) ; \\
& \eta_{\text {overall }}(i)=\frac{\eta_{e}(i) \times \eta_{m}(i)}{\left(\eta_{e}(i)+\left(\eta_{m}(i)-\eta_{e}(i)\right) \times x_{\text {range }}(i)\right) \times \Gamma} ;
\end{aligned}
$$

end for

find $x_{\text {range }}^{*}(i)=\left\{\right.$ such that $\eta_{\text {overall }}(i)$ is max imum, $\left.i=1,2, \cdots, N+1\right\}$;

$x_{\text {opt }}=x_{\text {range }}^{*}(i)$

Except that $x=0$ when

$T_{g b, \text { in }}<0$ (braking) or

$n_{g b, i n}=0$ (vehicle stop) or 
$T_{g b, i n}<T_{\text {mpropmax }} \times r_{t c}(E V \bmod e)$

\subsubsection{Optimization Results and Analysis}

The control strategy B is then developed in MATLAB/Simulink model. To compare with control strategy A more reasonably, the validated hybrid bus model was used to simulate with control strategy B over the CBD cycle, the Manhattan Bus cycle and the New York Bus cycle, respectively. The simulation result is summarized in Table 4.4. It can be found that control B has potential to improve fuel economy by $8.1 \%$ and reduce $\mathrm{NO}_{\mathrm{x}}$ emissions by $6.1 \%$ when operated over the New York Bus cycle, when compared with the baseline control strategy. Figure 4.19 and Figure 4.20 show the engine operating points over the New York Bus Cycle with control A and Control B, respectively. As shown in Table 4.5, although higher engine efficiency was obtained in control A (37.5\% for control A vs. 36.1\% for control B), control B achieved higher forward powertrain efficiency of the two (38.2\% for control B vs. $37.1 \%$ for control A). Therefore, control B had better fuel economy performance than control A.

It can be observed that control B had the potential to improve fuel economy by $4.4 \%$ over the $\mathrm{CBD}$ cycle. However, the tradeoff between fuel economy and $\mathrm{NO}_{\mathrm{x}}$ emissions was observed in the simulation results with $4.0 \%$ increment in $\mathrm{NO}_{\mathrm{x}}$ emissions. Both fuel economy and $\mathrm{NO}_{\mathrm{x}}$ emissions were deteriorated respectively by $4.7 \%$ and $10.7 \%$ under the energy management with Control B over the Manhattan Bus cycle. The main reason behind the deterioration of fuel economy and $\mathrm{NO}_{\mathrm{x}}$ emissions is that torque split ratio when $\mathrm{SOC}$ was below $\mathrm{SOC}_{\min }$ was not considered to be globally optimal but only locally optimal in control B. Therefore, for consideration of the battery life, a simple engine-only mode was applied in the controller. Figure 4.21 and Figure 4.22 show the engine operating points over the Manhattan Bus cycle with control A and control B, respectively. It can be indicated from Figure 4.22 that this engine-only operation at low SOC condition deteriorated the engine efficiency, especially when low torque operation and low speed operation were required. Therefore, the benefit gained from high SOC operation was balanced and fuel consumption and $\mathrm{NO}_{\mathrm{x}}$ emissions were lifted higher.

Although charging the battery when the SOC level is low would decrease overall powertrain efficiency in a short time, the potential of improving fuel economy and $\mathrm{NO}_{\mathrm{x}}$ emissions can be observed in the long term by eliminating low SOC operation. According to control B, the low SOC operation would be dominant when the driving cycles were long such as the Manhattan Bus 
cycle, since control B preferred to achieve maximum overall powertrain efficiency at local time instead of over duration of the whole cycle. Therefore, it is better to applied global optimization into the control strategy in the future to avoid low SOC operation if the full knowledge of the driving cycles can be predicted by devices such as global positioning system (GPS).

Table 4.4 Comparison of Simulation Results in PSAT between Control A and Control B

\begin{tabular}{|c|c|c|c|}
\hline Driving Cycle & CBD & Manhattan & New York Bus \\
\hline \multicolumn{2}{|c|}{ SOC Corrected Fuel Consumption (L/100km) } \\
\hline Baseline & 54.0 & 57.5 & 66.9 \\
\hline Control A & 53.2 & 56.5 & 67.2 \\
\hline Improvement (\%) & 1.5 & 1.7 & -0.4 \\
\hline Control B & 51.6 & 60.2 & 61.5 \\
\hline Improvement (\%) & 4.4 & -4.7 & 8.1 \\
\hline \multicolumn{4}{|c|}{ SOC Corrected Tailpipe $\mathrm{NO}_{\mathrm{x}}$ Emissions (g/mile) } \\
\hline Baseline & 17.7 & 21.4 & 26.2 \\
\hline Control A & 16.7 & 20.2 & 26.1 \\
\hline Improvement (\%) & 5.6 & 5.6 & 0.4 \\
\hline Control B & 18.4 & 23.7 & 24.6 \\
\hline Improvement (\%) & -4.0 & -10.7 & 6.1 \\
\hline
\end{tabular}

Table 4.5 Comparison of Component and Powertrain Efficiencies between Control A and Control B (Initial $\mathrm{SOC}=\mathbf{7 0} \%$ )

\begin{tabular}{|c|c|c|c|c|}
\hline \multirow{2}{*}{ Cycles } & \multirow{2}{*}{ Controls } & \multicolumn{3}{|c|}{ Efficiency (\%) } \\
\cline { 3 - 5 } & & Engine & Motor & Powertrain (Forward) \\
\hline \multirow{2}{*}{ CBD } & Control A & 36.5 & 83.7 & 30.1 \\
\cline { 2 - 5 } & Control B & 33.8 & 82.1 & 37.8 \\
\hline \multirow{2}{*}{ Manhattan } & Control A & 37.3 & 81.9 & 34.3 \\
\cline { 2 - 5 } & Control B & 33.5 & 81.4 & 37.1 \\
\hline \multirow{2}{*}{ New York } & Control A & 37.5 & 80.8 & 37.1 \\
\cline { 2 - 5 } & Control B & 36.1 & 80.4 & 38.2 \\
\hline
\end{tabular}




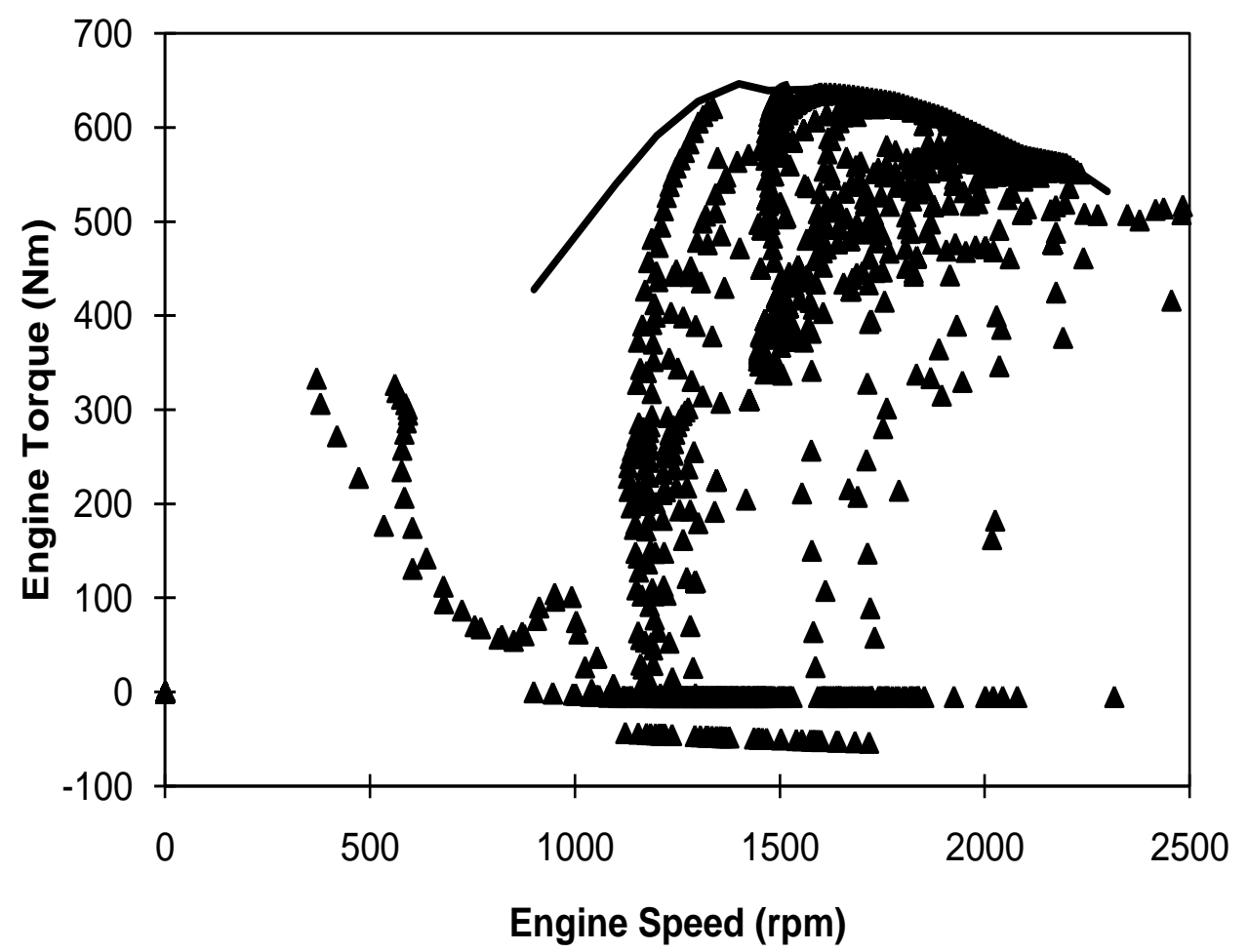

Figure 4.19 Engine Operating Points in New York Bus Cycle under Control A (Initial SOC= 70\%)

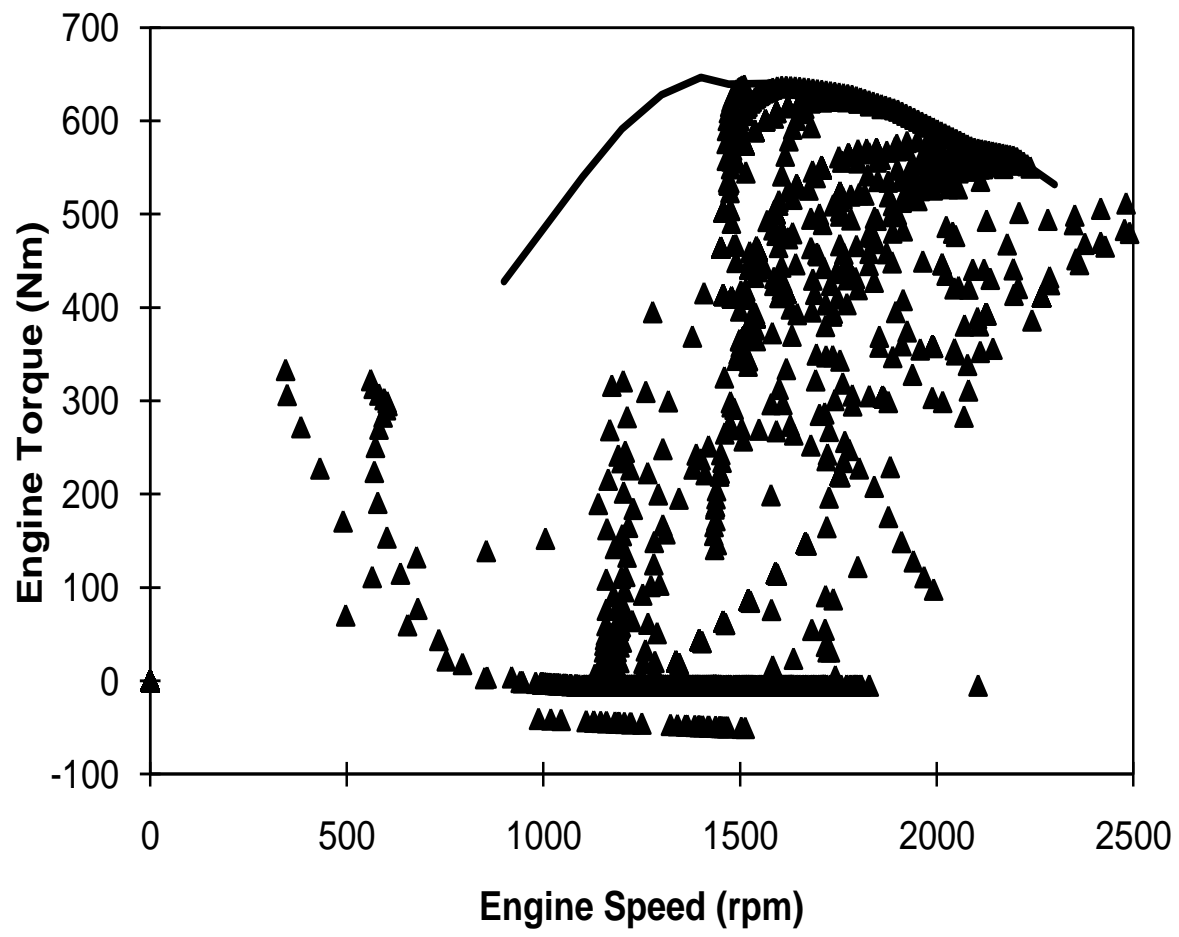

Figure 4.20 Engine Operating Points in New York Bus Cycle under Control B (Initial SOC= 70\%) 


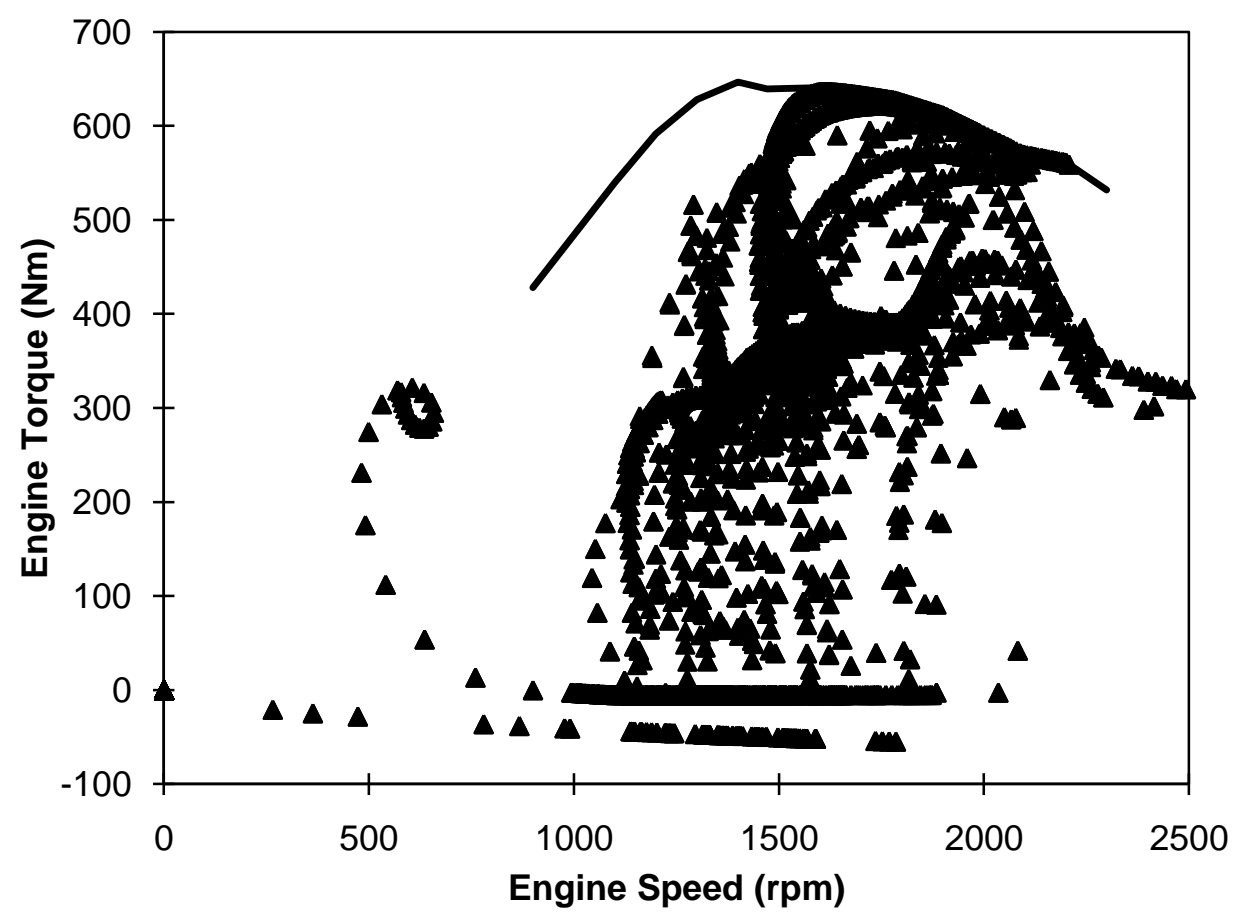

Figure 4.21 Engine Operating Points in Manhattan Bus Cycle under Control A (Initial SOC= 70\%)

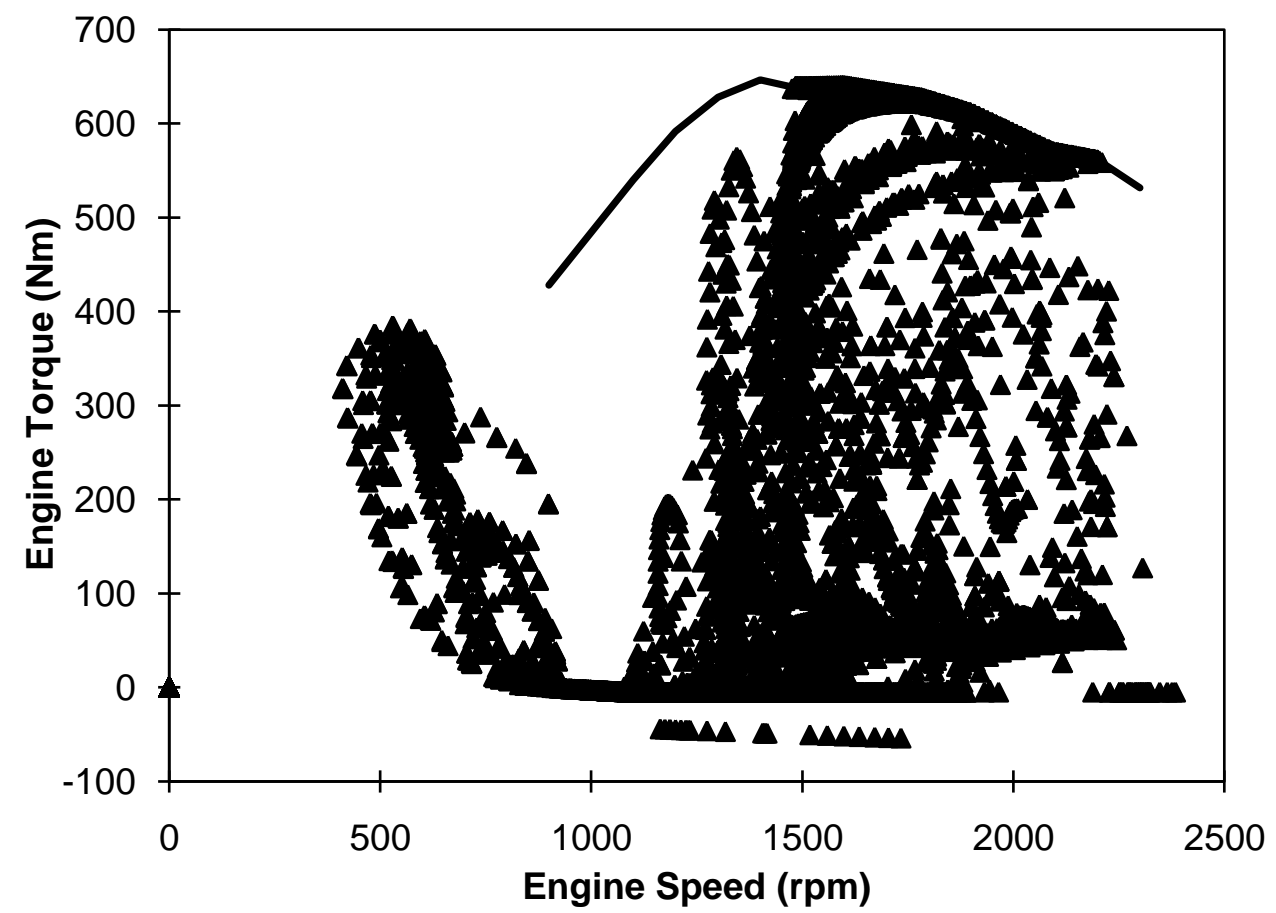

Figure 4.22 Engine Operating Points in Manhattan Bus Cycle under Control B (Initial SOC= 70\%) 


\subsection{Summary}

An heavy-duty hybrid transit bus model was validated successfully using PSAT with relative errors less than $4.2 \%$ observed for both fuel consumption and SOC. A conventional engine efficiency-based control strategy noted as control A was developed to maximize engine efficiency. Simulation results indicated control A only had the potential to improve the fuel economy over the CBD cycle and the Manhattan Bus cycle by $1.5 \%$ and $1.7 \%$, respectively while $\mathrm{NO}_{\mathrm{x}}$ emissions were reduced by $5.6 \%$ over both cycles. However, no gain was observed in improving fuel economy and $\mathrm{NO}_{\mathrm{x}}$ emissions over the New York Bus cycle for control A. Then a real-time control strategy named control B was developed to optimize the overall efficiency of the powertrain. Simulation results demonstrated that control B had the potential to improve the fuel economy and $\mathrm{NO}_{\mathrm{x}}$ emissions respectively by $8.1 \%$ and $6.1 \%$ when operated over the New York Bus cycle. Tradeoff between fuel economy and $\mathrm{NO}_{\mathrm{x}}$ emissions was observed over the CBD cycle with improvement of fuel economy by $4.4 \%$ and increment of $\mathrm{NO}_{\mathrm{x}}$ emissions by $4.0 \%$. When operated over Manhattan Bus cycle, the control strategy B was found to increase the fuel consumption and $\mathrm{NO}_{\mathrm{x}}$ emissions by $4.7 \%$ and $10.7 \%$, respectively. 


\section{Development of Electrical Accessory Model for PSAT}

\subsection{Introduction to A/C System of Transit Buses}

\subsubsection{Requirement of A/C System}

Application of $\mathrm{A} / \mathrm{C}$ systems in both passenger and commercial vehicles has increased dramatically in the last decade due to thermal comfort demand by passengers and will continue growing in the coming years. Ambient temperature plays an important role in driver's performance and is reported as the third rated influential factor out of ten, right after alcohol abuse and use of safety belt [66]. A/C systems are designed to keep drivers and passengers feeling comfortable through hot and humid ambient conditions. At the same time, A/C systems provide an important function of keeping clear vision for drivers by defogging (or defrosting). In addition, A/C provides fresh air into the passenger compartment through ventilation.

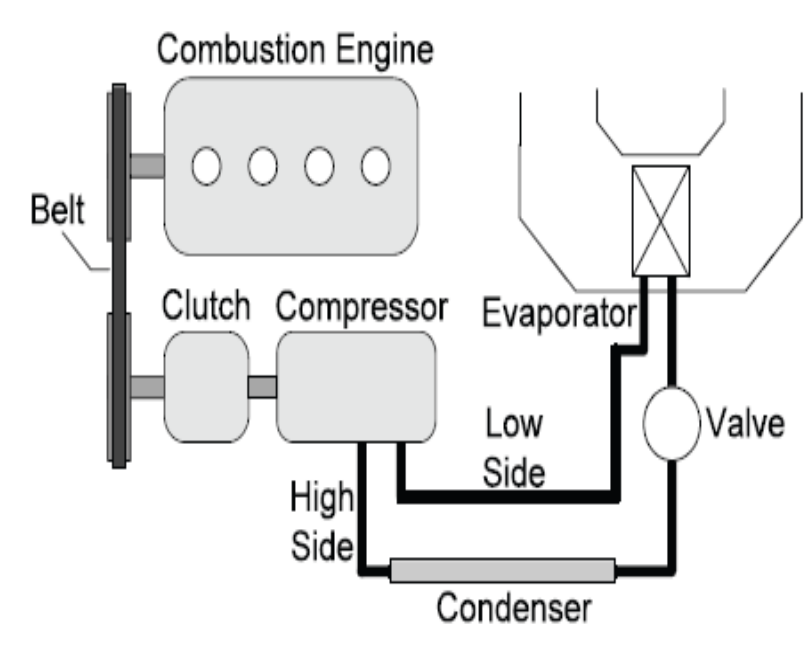

(a) Mechanically belt-driven A/C [62]

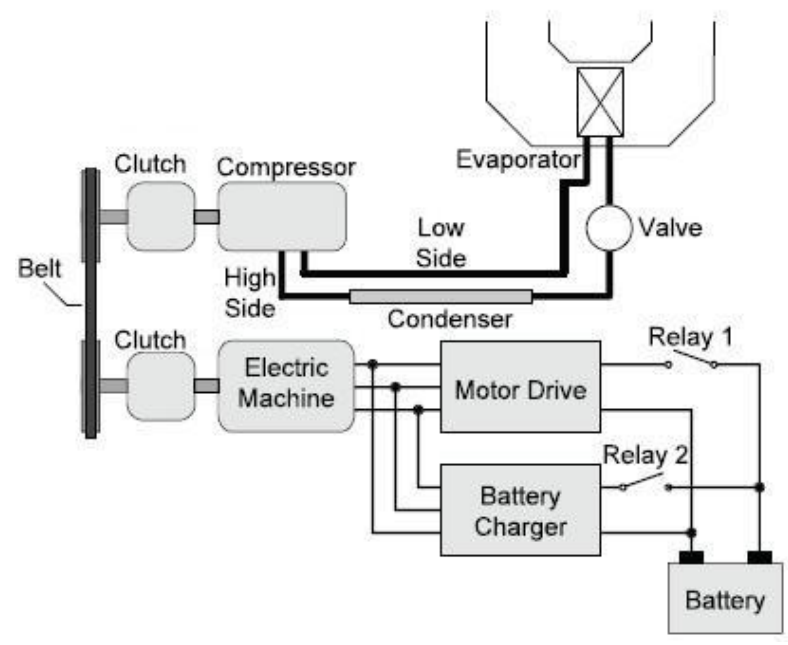

(b) Electrically motor-driven $\mathrm{A} / \mathrm{C}$

Figure 5.1 Diagrams of Two Types of A/C Systems

Two types of A/C systems are broadly used in automobiles as shown in Figure 5.1. One is mechanically belt-driven by the engine, and the other is electrically motor-driven. The conventional A/C systems, which connect the compressor to the engine crankshaft mechanically, significantly affect fuel economy. To solve this problem, more and more electrical A/C systems, 
which utilize brush DC motor to drive the compressor, have been introduced. As operation of $\mathrm{A} / \mathrm{C}$ is decoupled from engine load, the engine has more chances to operate with high efficiency. Specifically, in the condition of vehicle stops when A/C load dominates, the engine can be turned off to save more fuel since the $\mathrm{A} / \mathrm{C}$ can be powered by batteries. For the hybrid transit bus in this study, the engine start/stop function helps to improve fuel economy, while application of an electrical drive for the $\mathrm{A} / \mathrm{C}$ system has the advantages of maintaining climate comfort and improving fuel efficiency.

\subsubsection{Energy Consumption of A/C System}

While A/C improves thermal comfort and driving safety for drivers and passengers, the power necessary to operate the $\mathrm{A} / \mathrm{C}$ system is significant. In addition, the $\mathrm{A} / \mathrm{C}$ system consumes more energy than any other auxiliary equipment on board. The car A/C system causes approximately $0.5 \mathrm{~L} / 100 \mathrm{~km}$ excess fuel consumption on average [29]. Research by NREL shows that for the U.S., the total fuel consumption by $\mathrm{A} / \mathrm{C}$ is 7.0 billion gallons per year, which is equivalent to $5.5 \%$ of the total fuel consumption or $9.5 \%$ of imported crude oil [50]. With more and more hybrid buses serving in public transit agencies, the concerns of $\mathrm{A} / \mathrm{C}$ application on hybrid buses are promoted due to its impact on fuel economy. Research conducted by NREL indicates that fuel economy of hybrid vehicles is more sensitive to $\mathrm{A} / \mathrm{C}$ operation than that of conventional vehicles, with fuel economy decreasing by up to $20 \%$ for conventional vehicles and by more than $35 \%$ for hybrid vehicles [48]. This might be due to the fact that the energy consumed by A/C system is not recoverable. The cooling capacity of $\mathrm{A} / \mathrm{C}$ system for transit buses is on the order of $30 \mathrm{~kW}$ and the corresponding compressor load is on the order of $10 \mathrm{~kW}$ based on current coefficient of performance (COP), which may reduce fuel economy by up to $20 \%$ [56]. At the same time, the annual operating mileage of transit buses is higher than that of light-duty vehicles. As a result, annual fuel consumption by $\mathrm{A} / \mathrm{C}$ will be higher for transit buses than for light-duty vehicles. Analysis of A/C load is carried out in the following section.

\subsection{Thermal Load of A/C System}

\subsubsection{Passenger Thermal and Moisture Load}

Human beings, which are endothermic organisms, will disperse heat when the ambient temperature is below that of the human body, and receive heat when the ambient temperature is 
higher than that of the human body. At the same time, heat release rate from the human body differs with involved physical activity. In SAE 2711 [70], the metabolic heat per person is quantified as $67.4 \mathrm{~W}$.

Other than ambient temperature, humidity is another important environmental factor affecting thermal comfort. Relative humidity $(\mathrm{RH})$ is a measure of moisture in the air based on potential saturation level. The passengers will add considerable moisture in the passenger compartment through inhaled air and evaporated sweat. High RH of ambient air does not pose much influence on thermal comfort in the heating mode since RH will be reduced when air is warmed up. However, RH plays an important role in the cooling mode. As air is cooled down, RH will increase. RH higher than $60 \%$ may prevent evaporation of sweat from the skin which is the main method of releasing heat for human beings. Therefore, we will feel warmer in humid conditions for low heat transfer rate. In this study, humidity load per passenger is set at $55.7 \mathrm{~W}$ with ambient RH higher than 50\% based on SAE J2711 [70].

The number of passengers on the bus is estimated to be 50 including the driver.

\subsubsection{Solar Load}

Solar load has great impact on fuel economy and emissions of vehicles when the $\mathrm{A} / \mathrm{C}$ is on. A research program sponsored by the Coordinating Research Council (CRC), California Air Resources Board (CARB), and Texas Commission on Environmental Quality (TCEQ) showed that addition of solar load caused a decrease of fuel economy of $1.3 \mathrm{mpg}$ and a increase of $\mathrm{NO}_{\mathrm{x}}$ emissions from 0.10 to $0.14 \mathrm{~g} / \mathrm{mile}$ at $80^{\circ} \mathrm{F}$ (about $27^{\circ} \mathrm{C}$ ) and moderate humidity [59].

While metabolic load is pretty stable, the solar load varies significantly from day to day, season to season and year to year. On the other side, the distribution of solar load is diverse from one state to another. Generally, the solar energy will enter into the cabin through three ways: direction radiation, diffuse radiation and radiation reflected by the ground. These three parts of radiation are calculated using Equation 20, Equation 21, and Equation 22 [12,36], respectively. In SAE 2711, the apparent solar radiation (noted as A) is given as $850 \mathrm{~W} / \mathrm{m}^{2}$. The size of the hybrid bus is known as $11496 \mathrm{~mm}$ x $500 \mathrm{~mm}$ x $950 \mathrm{~mm}$. If the efficient area bearing solar load is set to be $20.0 \mathrm{~m}^{2}$ in this study, the overall solar load can be calculated using Equation 23. The main parameters to calculate solar load are included in Table 5.1. 
$I_{d i r}=\frac{A}{e^{\frac{B}{\cos \theta_{z}}}}$

Equation 20

$\dot{I}_{\text {diff }}=C \cdot \dot{I}_{\text {dir }} \cdot\left(\frac{1+\cos \beta}{2}\right)$

Equation 21

$\dot{I}_{r e f}=\dot{I}_{d i r} \cdot\left(C+\sin \theta_{i}\right) \cdot \rho_{g} \cdot\left(\frac{1-\cos \beta}{2}\right)$

Equation 22

$Q_{\text {solar }}=\left(I_{d i r}+I_{d i f f}+I_{r e f}\right) \cdot S$

Equation 23

Where $I_{d i r}, I_{d i f f}$ and $\dot{I}_{\text {ref }}$ represent the direct radiation, diffuse radiation, and reflected radiation of solar load, respectively. $S$ is the incidence surface.

Table 5.1 Main Parameters for Calculation of Solar Load [14, 36]

\begin{tabular}{|c|c|c|}
\hline Parameter & Value & Unit \\
\hline $\mathrm{B}$ (Extinction coefficient) & 0.207 & - \\
\hline $\mathrm{C}$ (Diffuse radiation factor) & 0.136 & - \\
\hline$\beta$ (Surface angle with the horizontal) & 90 & $\circ$ \\
\hline$\theta_{\mathrm{z}}$ (Zenith angle) & 30 & $\circ$ \\
\hline$\theta_{\mathrm{i}}$ (Angle of incidence of beam) & 60 & $\circ$ \\
\hline$\rho_{\mathrm{g}}($ Ground reflectivity) & 0.2 & - \\
\hline $\mathrm{S}$ (Incidence surface) & 20.0 & $\mathrm{~m}^{2}$ \\
\hline
\end{tabular}

\subsubsection{Conduction Load}

Different from solar load and metabolic load, which are independent from current temperature in the cabin room, the conduction load is proportional to the difference between air temperature inside the cabin and atmospheric temperature. The condition that the temperature outside the cabin is higher than that inside the cabin will produce a positive conduction load, which has negative impact on fuel economy when in cooling mode and positive effect on fuel economy when in heating mode. Conduction load varies before temperature inside the cabin reaches the target value, and it becomes a constant when both temperatures inside and outside remain constant. Conduction load can be determined by Newton's Law of Cooling as shown in Equation 24. 
$Q_{\text {cond }}=h_{c} A\left(T_{\text {ambient }}-T_{\text {cabin }}\right)$

Where $Q_{\text {cond }}$ denotes conduction load, $h_{c}$ and $A$ represent heat transfer coefficient and area for heat flow. The $h_{c}$ and $A$ are simplified to be constants with values of $7.9 \mathrm{~W} /\left(\mathrm{m}^{2 \circ} \mathrm{C}\right)$ and $20 \mathrm{~m}^{2}$ approximately for the test bus [9]. The heat convection on the inner and outer surfaces of the test bus is ignored in the study.

\subsubsection{Ventilation Load}

The ventilation of air is required to keep air in the passenger compartment clean since the quality of air deteriorates due to smoke, exhalation of $\mathrm{CO}_{2}$ by passengers, loss of moisture from the body, and odor, especially for buses where the number of passengers onboard is usually large. There are several strategies for ventilation, and current automotive $\mathrm{A} / \mathrm{C}$ systems are designed to blend outside air with recirculated air. Jackson has established that a mixture of $25 \%$ fresh outside air and $75 \%$ of recirculated air can maintain air quality in the passenger compartment at an acceptable level [32]. Figure 5.2 shows the mixing process of outside air and recirculated air.

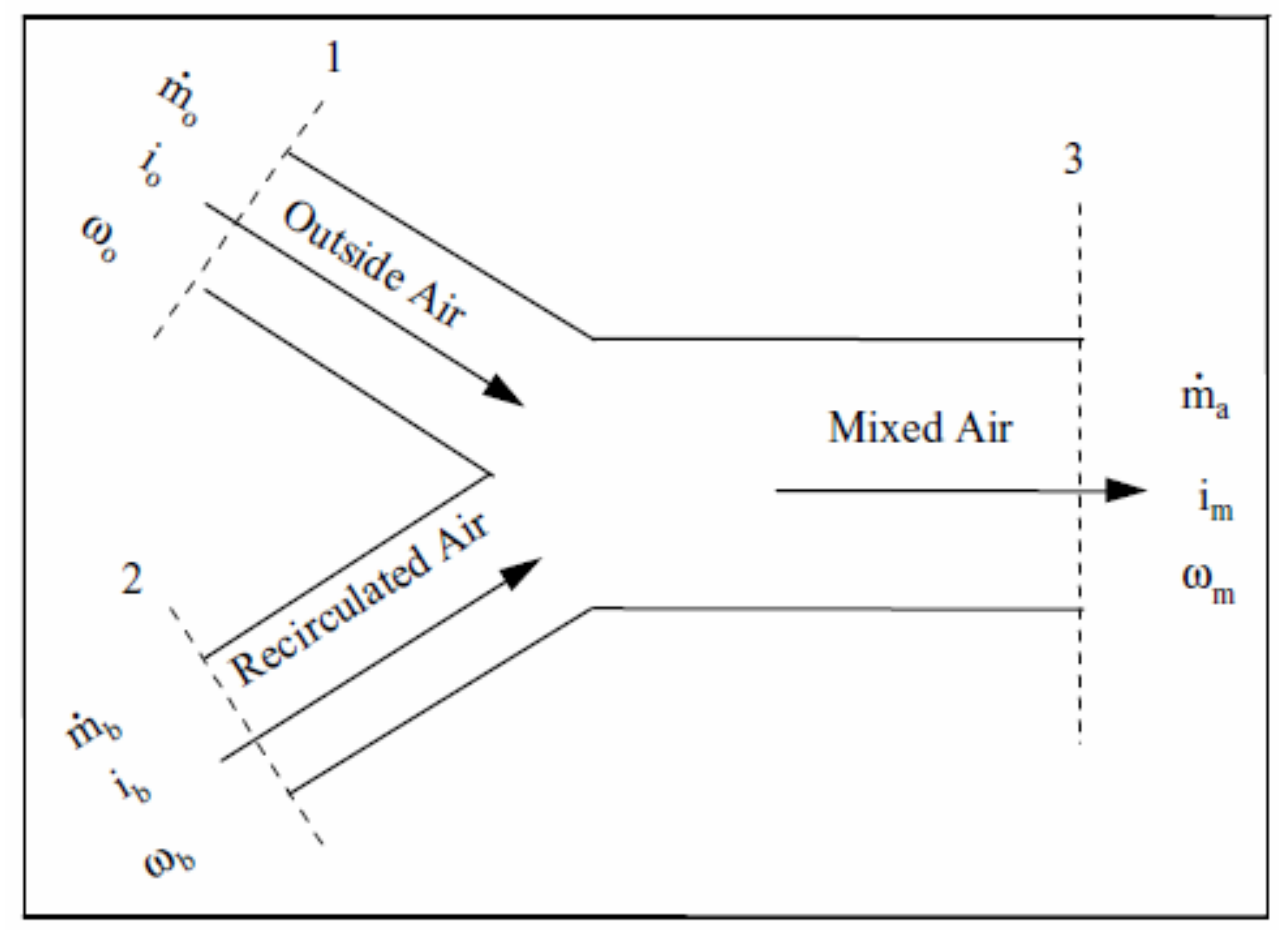

Figure 5.2 Mixing of Outside Air and Recirculated Air 
The property of mixed air is determined by properties of outside air and recirculated air based on Equation 25, Equation 26, and Equation 27 below:

Mass balance of air

$$
\dot{m}_{a}=(1-\beta) \dot{m}_{b}+\beta \dot{m}_{o}
$$

Enthalpy balance of air

$$
\dot{m}_{a} i_{m}=(1-\beta) \dot{m}_{b} i_{b}+\beta \dot{m}_{o} i_{o}
$$

Mass balance of water vapor:

$$
\dot{m}_{a} \omega_{m}=(1-\beta) \dot{m}_{b} \omega_{b}+\beta \dot{m_{o}} \omega_{o}
$$

\section{Equation 27}

It is assumed that mass flow rate of waste air out of the passenger compartment is the same as that of fresh air into the cabin. A blower is applied to carry the air flow in and out of the passenger compartment known as $\dot{Q}_{\text {blower }}$ is determined by Equation 28:

$$
\dot{Q}_{\text {blower }}=\dot{m}_{a} C_{p}\left(T_{o}-T_{i}\right)
$$

\section{Equation 28}

Where

$\beta$ denotes mass ratio of fresh air and equals $25 \%$ in this study.

$\dot{m}_{o}, \dot{m}_{b}$ and $\dot{m}_{a}$ are the mass flow rates of fresh air, recirculated air and mixed air, respectively.

$i_{o}, i_{b}$ and $i_{m}$ denote enthalpies of fresh air, recirculated air and mixed air, respectively.

$\omega_{o}, \omega_{b}$ and $\omega_{m}$ represent absolute humidity of fresh air, recirculated air and mixed air.

$C_{p}$ is the specific heat constant of air known to be $1005 \mathrm{~J} /\left(\mathrm{kg}^{\circ} \mathrm{C}\right)$.

$T_{i}$ is temperature at the inlet of the passenger compartment in ${ }^{\circ} \mathrm{C}$.

$T_{o}$ is temperature at the exit of the passenger compartment in ${ }^{\circ} \mathrm{C}$. 
Figure 5.3 describes the dehumidification process in the $\mathrm{A} / \mathrm{C}$ system. Point $\mathrm{A}$ is where the fresh air enters the mixing duct and point $\mathrm{B}$ is where the recirculated air enters the mixing duct. Point $\mathrm{C}$ is where fresh air and recirculated air are mixed. The mixed air is then cooled to the initial dew point $\mathrm{D}$ where $\mathrm{RH}$ is $100 \%$. The cooled air is then further cooled along the saturation line until it reaches point $\mathrm{E}$ where the condensed water exits. From point $\mathrm{E}$ to point $\mathrm{F}$, the cooled air is reheated by the heating coil and is introduced into the passenger compartment at point $\mathrm{F}$. Through the process moisture is removed and $\mathrm{RH}$ is reduced and point B moves in the direction of point $\mathrm{F}$ until the comfort region is reached. Point $\mathrm{E}$ and point $\mathrm{F}$ are designed $15{ }^{\circ} \mathrm{C}$ and 25 ${ }^{\circ} \mathrm{C}$ in this study.

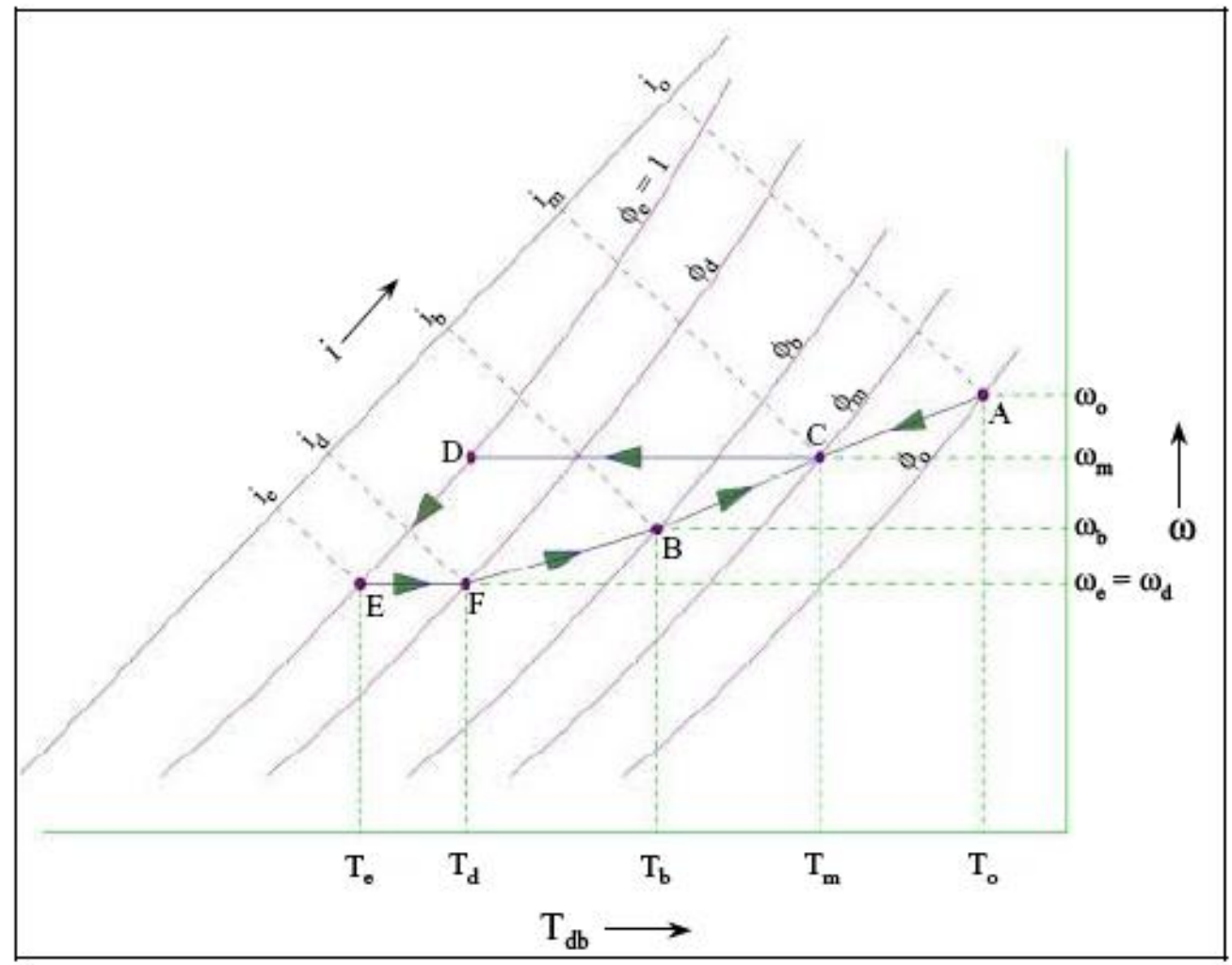

Figure 5.3 Ventilation Process on Psychrometric Chart [28]

The mass flow rate of condensate water in the dehumidifier at point E can be calculated by mass balance in Equation 29 or Equation 30.

$\dot{m}_{w}=\stackrel{\bullet}{m_{a C}}-\dot{m}_{a E}$

Equation 29 
Where $\dot{m}_{v C}, \dot{m}_{v E}$ and $\dot{m}_{w}$ are mass flow rates of water vapor at point $\mathrm{C}$, point $\mathrm{E}$, and mass flow rate of condensate water in the dehumidifier, respectively.

The ventilation load for cooling air and dehumidification known as $\dot{Q}_{C \rightarrow E}$ is determined by Equation 31.

$0=\dot{Q}_{C \rightarrow E}+\dot{m}_{c}\left(i_{m}-i_{e}\right)-\dot{m}_{w}\left(h_{w}-i_{e}\right)$

Equation 31

Ventilation load at the heating coil denoted as $\dot{Q}_{E \rightarrow F}$ is determined by Equation 32 .

$0=\dot{Q}_{E \rightarrow F}+\dot{m}_{E} i_{e}-\dot{m}_{F} i_{d}$

Equation 32

The overall ventilation load denoted as $\dot{Q}_{\text {ventilation }}$ is determined by Equation 33 .

$\dot{Q}_{\text {ventilation }}=\dot{Q}_{C \rightarrow E}+\dot{Q}_{E \rightarrow F}+\dot{Q}_{\text {blower }}$

Equation 33

In this model, dehumidification function is turned off when humidity ratio is below the target one, which corresponds to $50 \% \mathrm{RH}$ at $25^{\circ} \mathrm{C}$.

\subsubsection{Natural Ventilation Load}

While conduction load, occupant load, solar load, and dehumidification load are predictable and have been investigated for many years, natural ventilation load accompanied by door open/close is very difficult to predict since it is intensively related to door open frequency, duration of time, and ambient conditions. Although current design of thermal comfort has not taken the effect of natural ventilation into account, it has significant impact on $\mathrm{A} / \mathrm{C}$ performance and human comfort, particularly for the buses which have door open/close frequently when picking up and dropping passengers. There are two types of natural ventilation: wind driven ventilation due to pressure difference and stack ventilation due to temperature difference. To simplify the model, the wind driven ventilation is ignored and only stack ventilation is considered. By operation of $\mathrm{A} / \mathrm{C}$ system, the temperature difference between the inside and outside of the cabin produces buoyancy force which drives flow whenever doors are open. If the air in the cabin is cooler 
compared to the environment, then a single door opening will allow hot air flow inwards and cool air flow outwards. As a result, this presence of natural ventilation will result in variation of air quality and thus passenger comfort inside the cabin. On the other side, since cooling of hot air cost energy, natural ventilation will result in significant energy losses.

Single-sided ventilation is one of the most common forms of natural ventilation and is assumed to occur in this study when there is only one door opening into the environment. This flow through the open door is modeled as the exchange flow through a rectangular opening in a vertical wall of height $\mathrm{H}$ and area of $\mathrm{A}$. The mass flow rate through the door due to stack ventilation is calculated by Equation 34 [42]:

$m=\frac{1}{3} \rho C_{D} A \sqrt{g^{\prime} H}$

\section{Equation 34}

Where

$C_{D}$ is a discharge coefficient accounting for streamline contraction and taking a value of 0.98 for streamline shapes.

A represents the area of the door and takes a value of $2.0 \mathrm{~m}^{2}$ in this study.

$\mathrm{H}$ represents the height of the door and takes a value of $2 \mathrm{~m}$ in this study.

$g^{\prime}$ is reduced gravity defined as $g^{\prime}=g \frac{T_{i}-T_{o}}{T_{i}}$ and is used to describe buoyancy force.

$T_{i}$ and $T_{o}$ denote the temperatures inside and outside of passenger compartment in Kelvin.

Energy loss due to stack ventilation is determined by Equation 35.

$Q_{\text {door }}=c \dot{m}\left(T_{o}-T_{i}\right)$

Equation 35

\subsection{Net Cooling Load}

The net cooling load is the net power output from the $\mathrm{A} / \mathrm{C}$ to remove heat from the passenger compartment. In this study, the net cooling load was designed to be a function of the temperature difference between current temperature in the passenger compartment and desired temperature in the compartment as shown in Figure 5.4. The farther the current temperature was away from the 
target temperature, the higher the net cooling load. Current automotive A/C systems have the capability of reaching their target temperature within 30 minutes after $\mathrm{A} / \mathrm{C}$ is on.

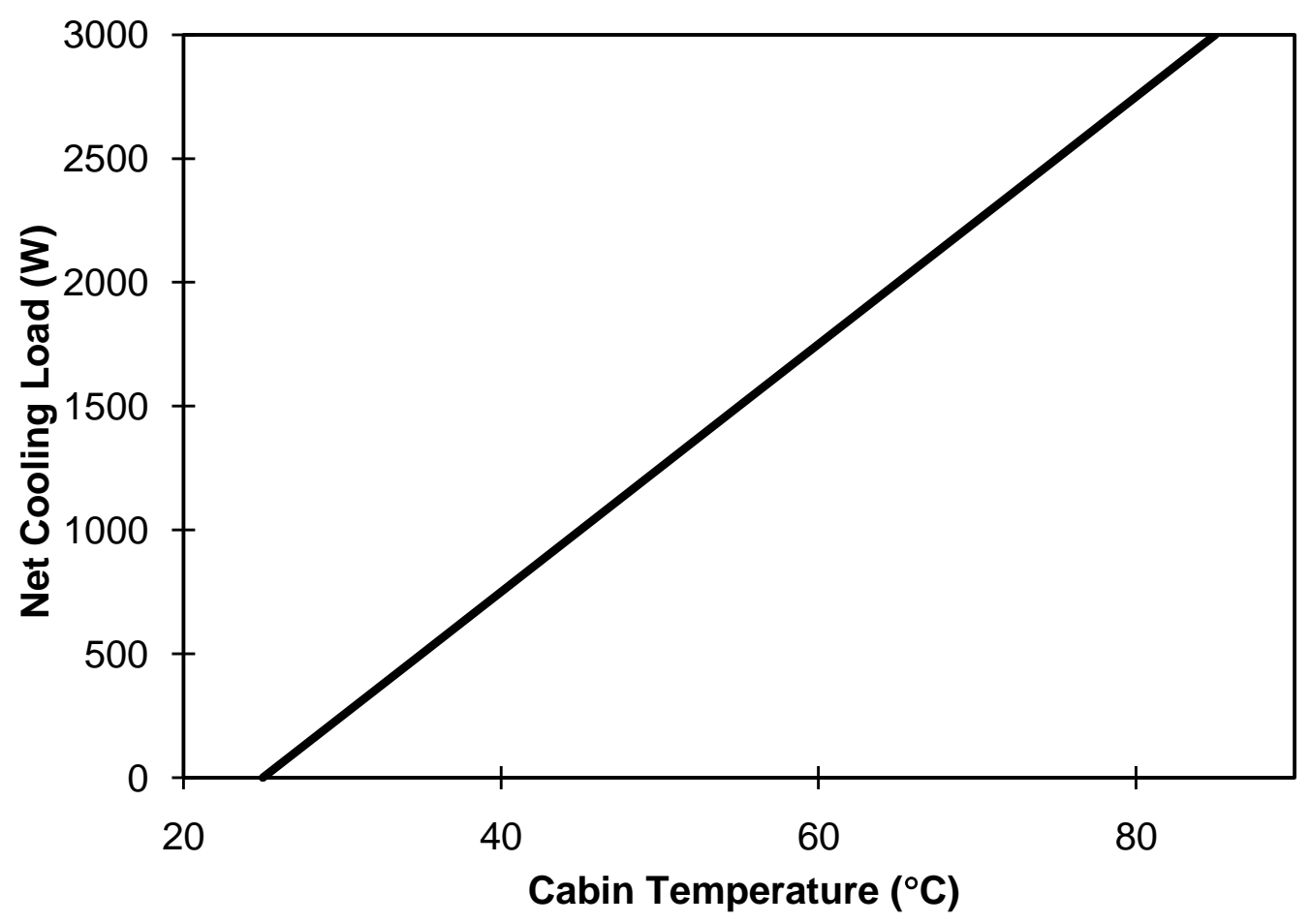

Figure 5.4 Net Cooling Load as a Function of Cabin Temperature

\subsection{A/C System Modeling and Its Integration with PSAT}

\subsubsection{A/C System Modeling}

The $\mathrm{A} / \mathrm{C}$ is a machine operated on the vapor compression cycle. As shown in Figure 5.5, the vapor-phase refrigerant in the machine is compressed by a compressor, causing the temperature to increase. The hot, high-pressure refrigerant then enters a condenser, where it is cooled by transferring its heat to the outdoor environment through the air flow induced by an outdoor fan. As a result of the heat transfer, the refrigerant condenses from vapor to liquid. The liquid refrigerant passes through an expansion valve, in which the pressure and temperature both decrease, and enters an evaporator. In the evaporator, the cold refrigerant absorbs heat from the passenger compartment via the air flow induced by an indoor fan. The refrigerant leaves the evaporator as superheated vapor and the vapor is routed back into the compressor. 


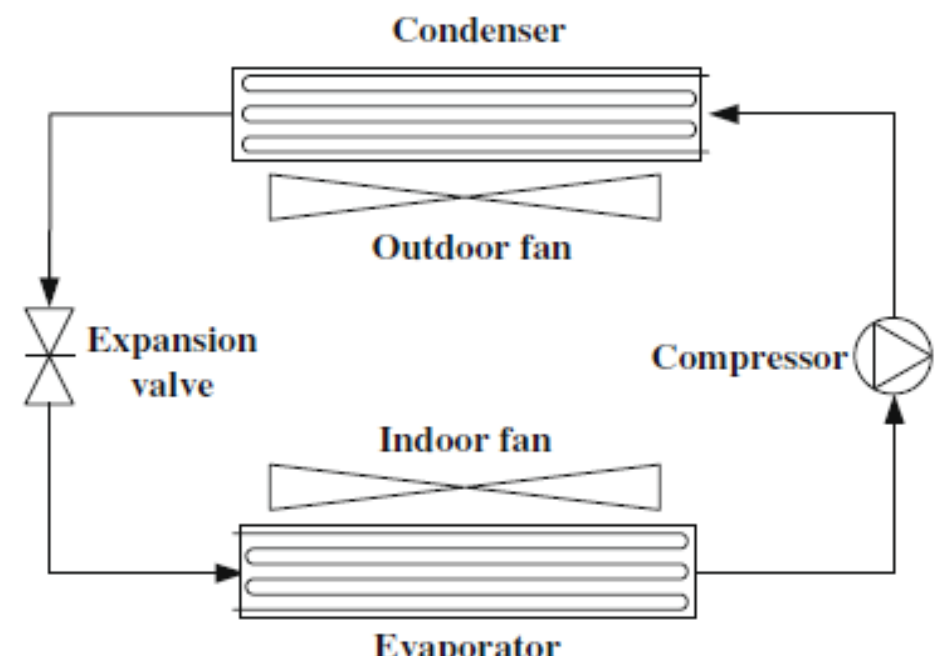

Figure 5.5 Schematic of Vapor Compression Cycle

To execute this task, the evaporator and blower work together by taking energy from the battery packs. The A/C system is treated as a "Black Box" in this study so that the performance of the $\mathrm{A} / \mathrm{C}$ is based on COP. Figure 5.6 shows the COP map of A/C with R-134a for different ambient temperatures. The reference $\mathrm{COP}$ at $35{ }^{\circ} \mathrm{C}$ was set to be 2.0 in this case based on $\mathrm{A} / \mathrm{C}$ performance in current automobiles.

To simplify the cabin model, the following assumptions are made:

- Ideal gas behavior.

- Perfect air mixing.

- Neglect the change in potential energy in all parts.

- Neglect thermal losses between components.

- Neglect infiltration and exfiltration effects.

- Neglect transient effect in components and channels.

- Negligible energy storage in air conditioning components.

- Negligible engine heat and exhaust heat

- Air exiting the cabin has the same properties as that inside the cabin.

- Initial air parameters in passenger compartment are the same as those in the environment. 


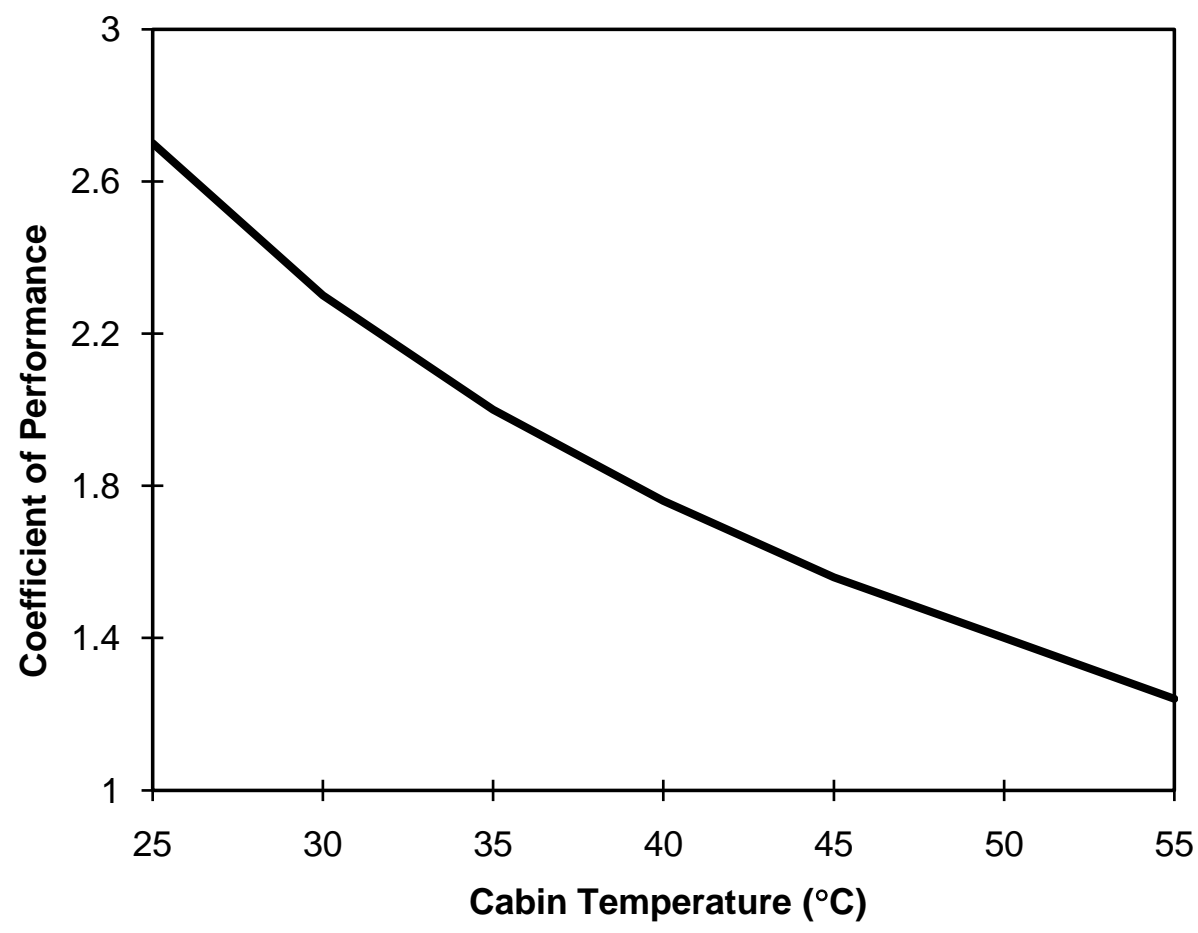

Figure 5.6 COP of R-134a A/C System as a Function of Outdoor Temperature [31, 62]

The power required by the A/C was determined by First Law of Thermodynamics in Equation 36 .

$C m_{\text {cabin }} \frac{d T}{d t}=\dot{Q}_{\text {solar }}+\dot{Q}_{\text {cond }}(T, t)+\dot{Q}_{\text {occupant }}+\dot{Q}_{\text {ventilation }}(T, t)-\dot{W}_{A / C}(T, t) \times C O P(T, t)$

Equation 36

Where $\dot{Q}_{\text {solar }}, \dot{Q}_{\text {cond }}, \dot{Q}_{\text {occupant }}, \dot{Q}_{\text {ventilation }}$ and $\dot{W}_{A / C}$ represent solar load, conduction load, occupant load, ventilation load and power input required by the A/C.

\subsubsection{Integration of A/C System with PSAT}

In PSAT, the electrical accessory model is simplified with constant power. However, in reality the power of the $\mathrm{A} / \mathrm{C}$ is related intensively to environmental factors such as solar load, ambient temperature, and ambient humidity, so that the original naïve model should be developed to investigate behaviors of the $\mathrm{A} / \mathrm{C}$ system when influential factors change. The electric accessory model was then applied to calculate cabin temperature, cabin humidity ratio, conduction load, ventilation load, and $\mathrm{A} / \mathrm{C}$ power. In the electric accessory model, ambient temperature, $\mathrm{RH}$, and 
solar load were chosen as the inputs, and the useful outputs from this model included humidity ratio in the passenger compartment, cabin temperature in the passenger compartment, ventilation load, conduction load and power loss due to A/C operation. Figure 5.7 shows the top level model of the improved A/C system in PSAT. In addition, this model was integrated with PSAT to investigate the impact of the $\mathrm{A} / \mathrm{C}$ system on overall fuel consumption.

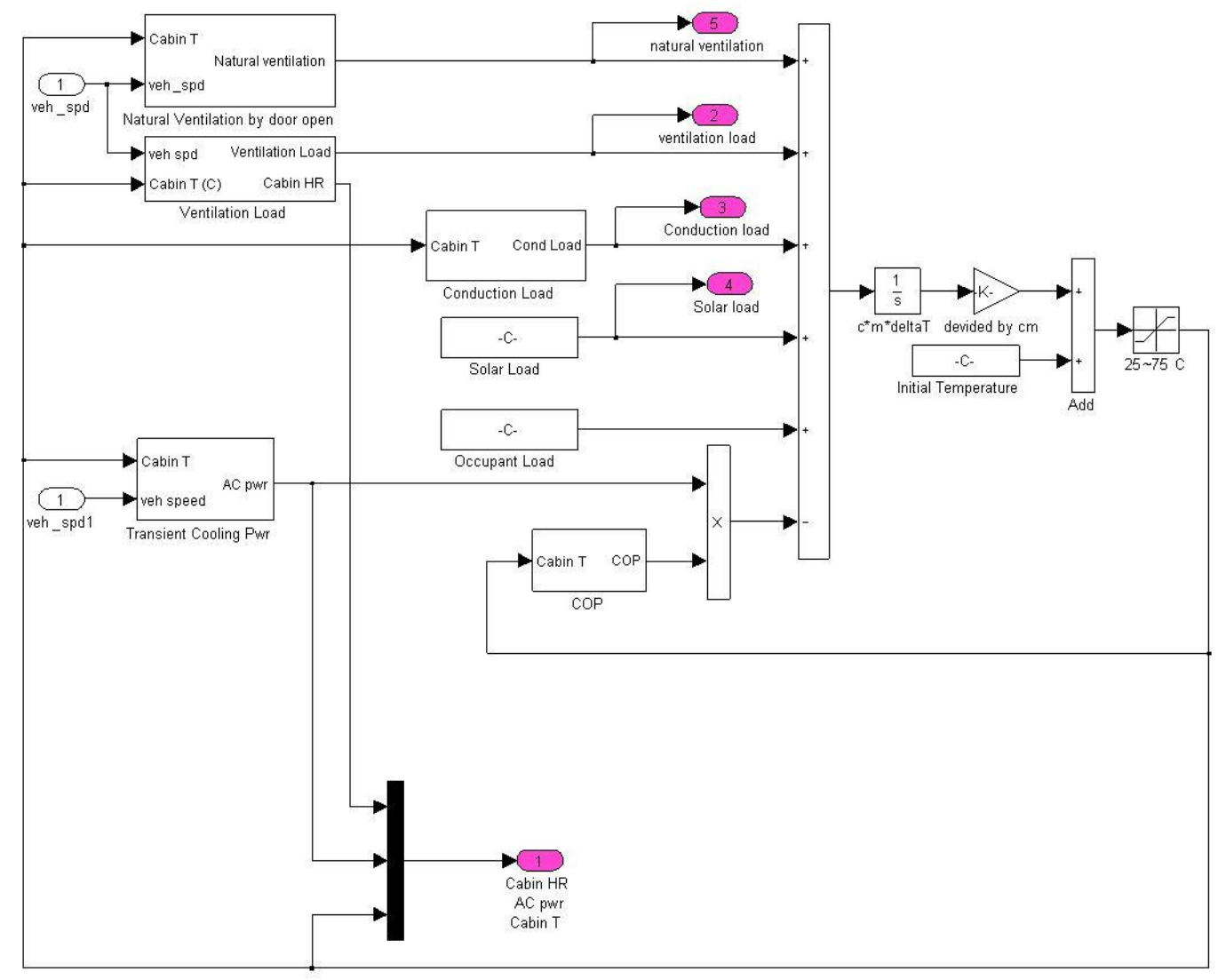

Figure 5.7 Simulink Model of A/C System

\subsection{Simulation Results and Analysis}

A parametric study under various ambient temperature, $\mathrm{RH}$, and solar load was conducted first before the case study in three states with typical ambient conditions was carried later. The driving cycle used for the parametric study is shown in Figure 5.8 below. This cycle is originally derived from the Supplemental Federal Test Procedure (SFTP)-SC03, which was introduced to represent the engine load and emissions associated with the $\mathrm{A} / \mathrm{C}$ operation in light-duty vehicles [46]. Considering that heavy-duty bus operation is less transient than passenger cars and it requires 1800 seconds to cool down the passenger compartment, the SC03 test cycle was then 
scaled by a factor of 0.5 and was repeated for three test cycles to investigate the influence of the $\mathrm{A} / \mathrm{C}$ operation on fuel consumption in this research. Figure 5.9 represents the predicted interior air temperature profiles with change of ambient temperature from $25^{\circ} \mathrm{C}$ to $40{ }^{\circ} \mathrm{C}$. Figure 5.10 demonstrates the $\mathrm{A} / \mathrm{C}$ power requirements corresponding to different ambient temperatures. It can be found in Figure 5.10 that a temperature difference of $15^{\circ} \mathrm{C}$ between the target temperature and the ambient temperature can double $\mathrm{A} / \mathrm{C}$ load at the beginning. $\mathrm{A} / \mathrm{C}$ load changed with cabin temperature since different amounts of net cooling and ventilation load were required. Figure 5.11 represents the impact of ambient temperature on fuel consumption. It can be seen from Table 5.2 that an increase of ambient temperature by $5{ }^{\circ} \mathrm{C}$ will result in an increase of fuel consumption by $1.43 \mathrm{~L} / 100 \mathrm{~km}$ on average, which represents a $7.0 \%$ increase of fuel consumption.

Figure 5.12 demonstrates the simulation of humidity ratio with respect to different ambient $\mathrm{RH}$ values from $30 \%$ to $90 \%$. Figure 5.13 shows the impact of ambient RH on A/C power. When the humidity ratio is below the target humidity ratio, dehumidification is not required and therefore fuel consumed by $\mathrm{A} / \mathrm{C}$ is low. As humidity ratio goes higher than the target value, dehumidification is required to reduce humidity ratio until the target value is reached. As a result, the higher RH, the more fuel will be consumed by the A/C. Figure 5.14 shows the influence of ambient RH on fuel economy under different ambient temperatures. For a mild temperature of 25 ${ }^{\circ} \mathrm{C}$, an increase of ambient $\mathrm{RH}$ by $20 \%$ will result in an increase of overall fuel consumption by $2.6 \%$ on average. It can be observed that as ambient temperature increases, the dehumidification load for reducing the same amount of RH increases generally due to the fact that for the same $\mathrm{RH}$, the humidity ratio corresponding to a high temperature is higher. As summarized in Table 5.2 , an increase of ambient $\mathrm{RH}$ by $20 \%$ at a high temperature of $35^{\circ} \mathrm{C}$ will result in increase of overall fuel consumption by $3.4 \%$ on average.

Figure 5.15 shows the simulation of solar load on the test bus with different apparent solar radiation values. Figure 5.16 indicates requirements of $\mathrm{A} / \mathrm{C}$ power for different apparent solar radiation intensities. Figure 5.17 shows the potential impact of solar radiation on fuel consumption. It was found from Figure 5.15 to Figure 5.17 that an increase of apparent solar radiation intensity by $200 \mathrm{~W} / \mathrm{m}^{2}$ will result in an increase of fuel consumption by $1.80 \mathrm{~L} / 100 \mathrm{~km}$ on average, which accounts for $9.5 \%$ of overall fuel consumption. 


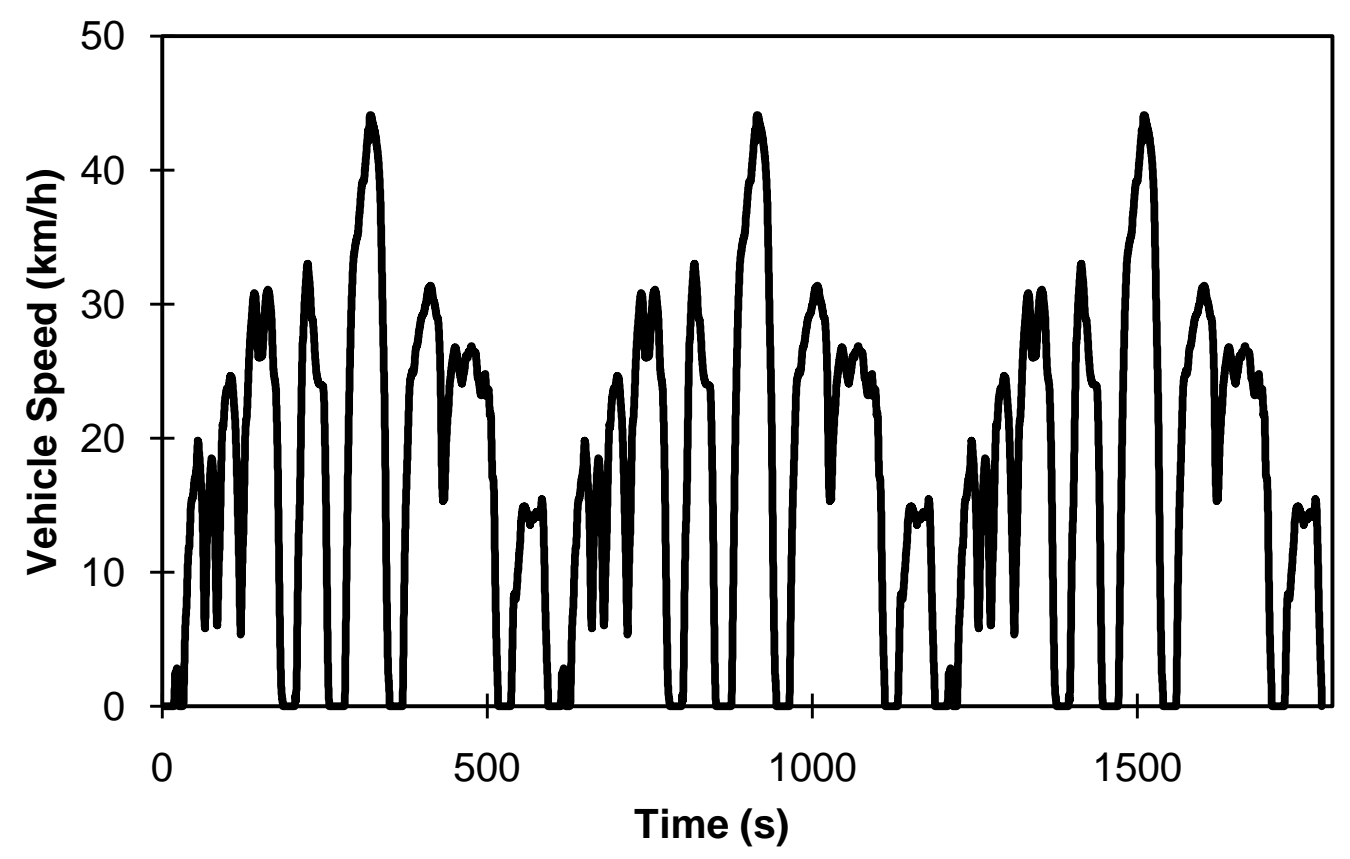

Figure 5.8 Scaled SFTP-SC03 Cycle Used in Parametric Study

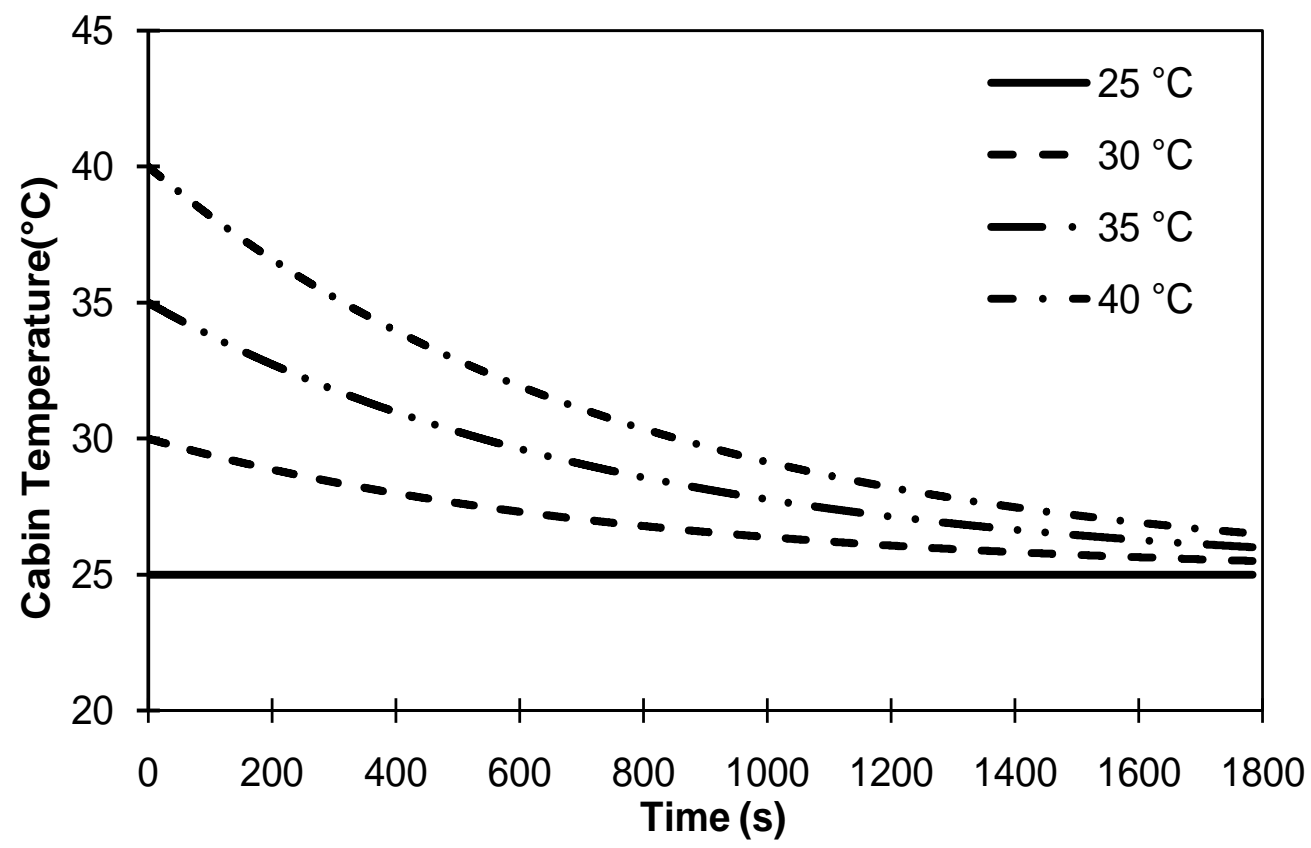

Figure 5.9 Simulation of Cabin Temperature with Different Ambient Temperatures (RH=50\%) 


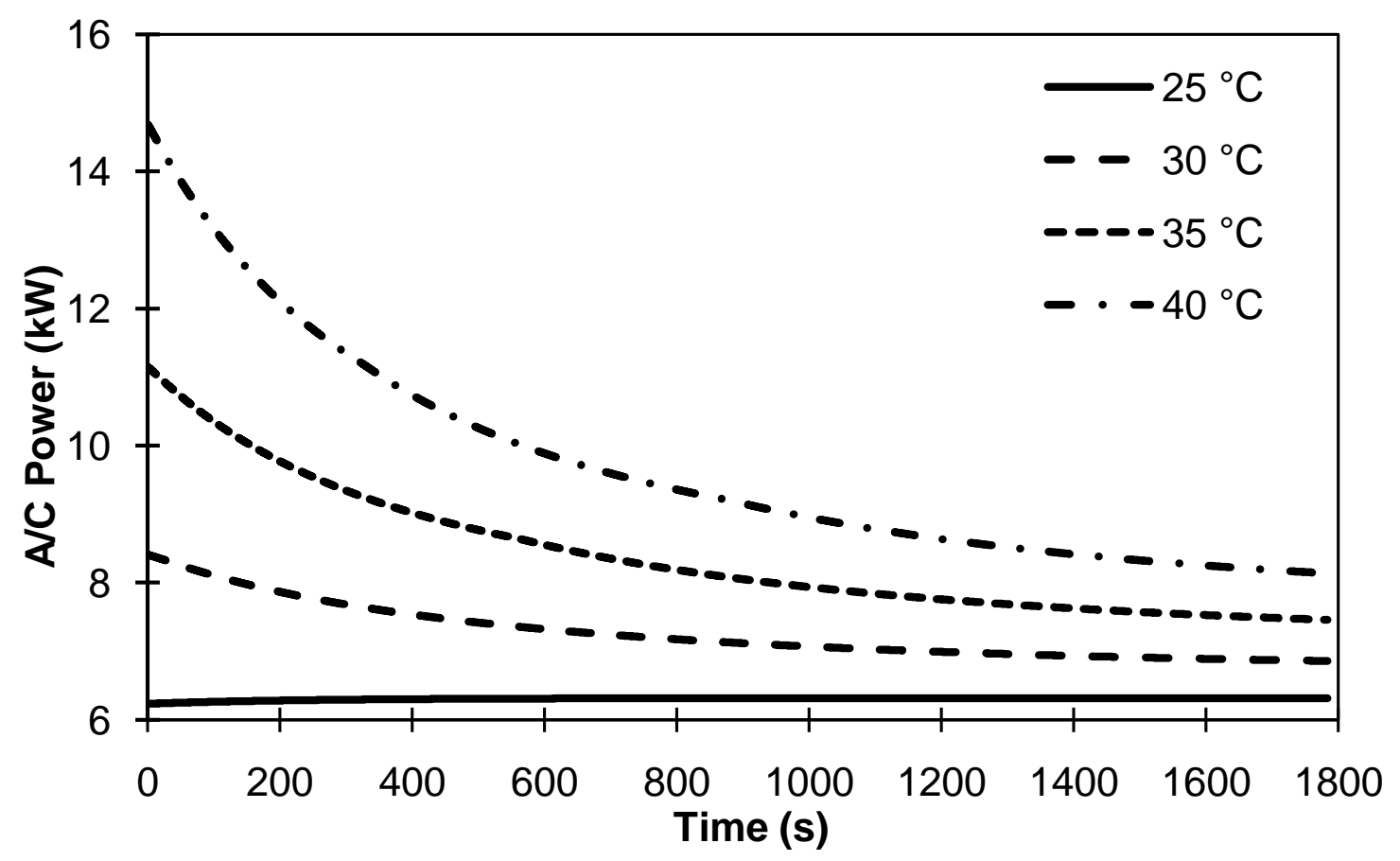

Figure 5.10 Simulation of A/C Power with Different Ambient Temperatures (RH=50\%)

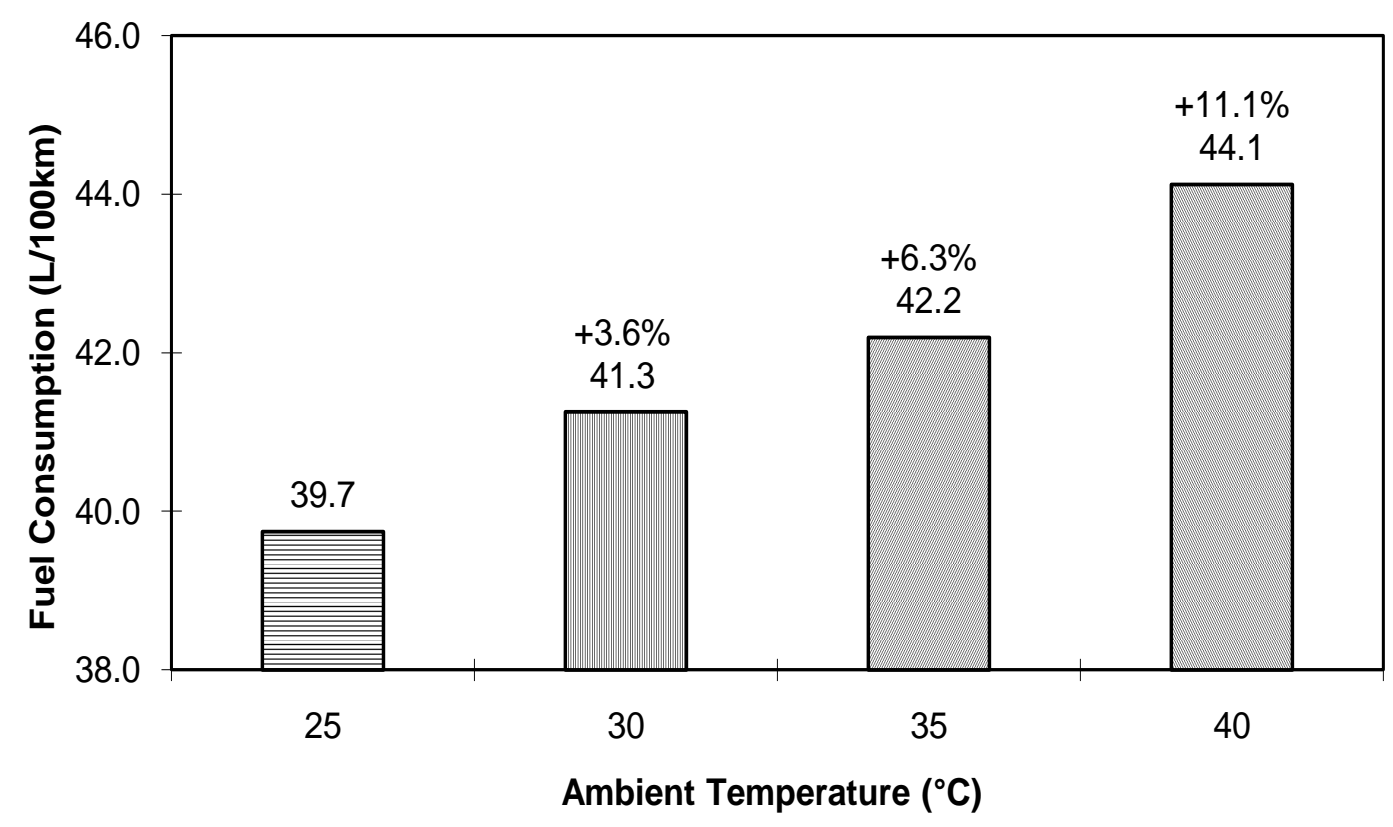

Figure 5.11 Impact of Ambient Temperature on Fuel Consumption (RH=50\%) 


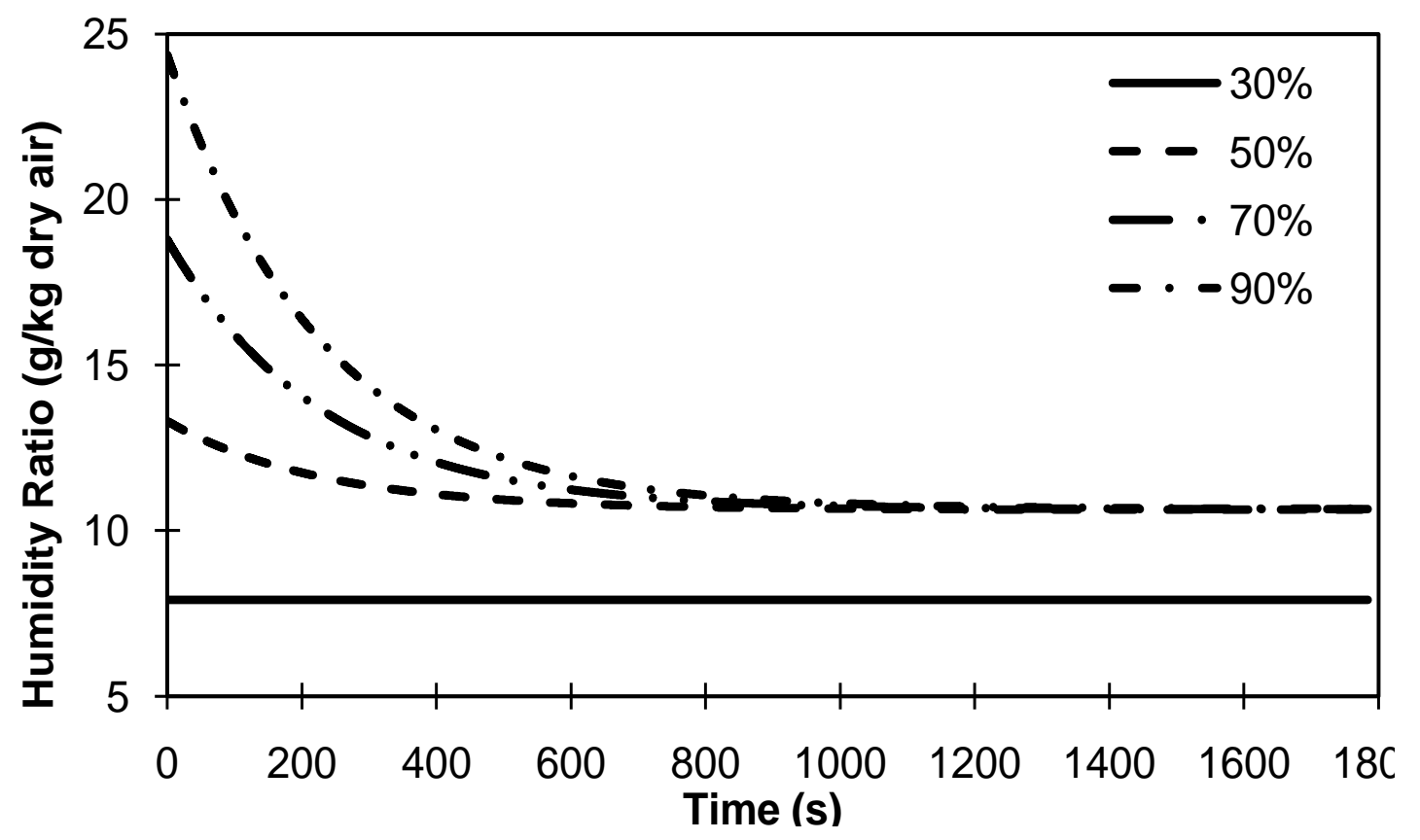

Figure 5.12 Simulation of Humidity Ratio with Different Ambient $R H\left(T_{\text {cab }}=30^{\circ} \mathrm{C}\right)$

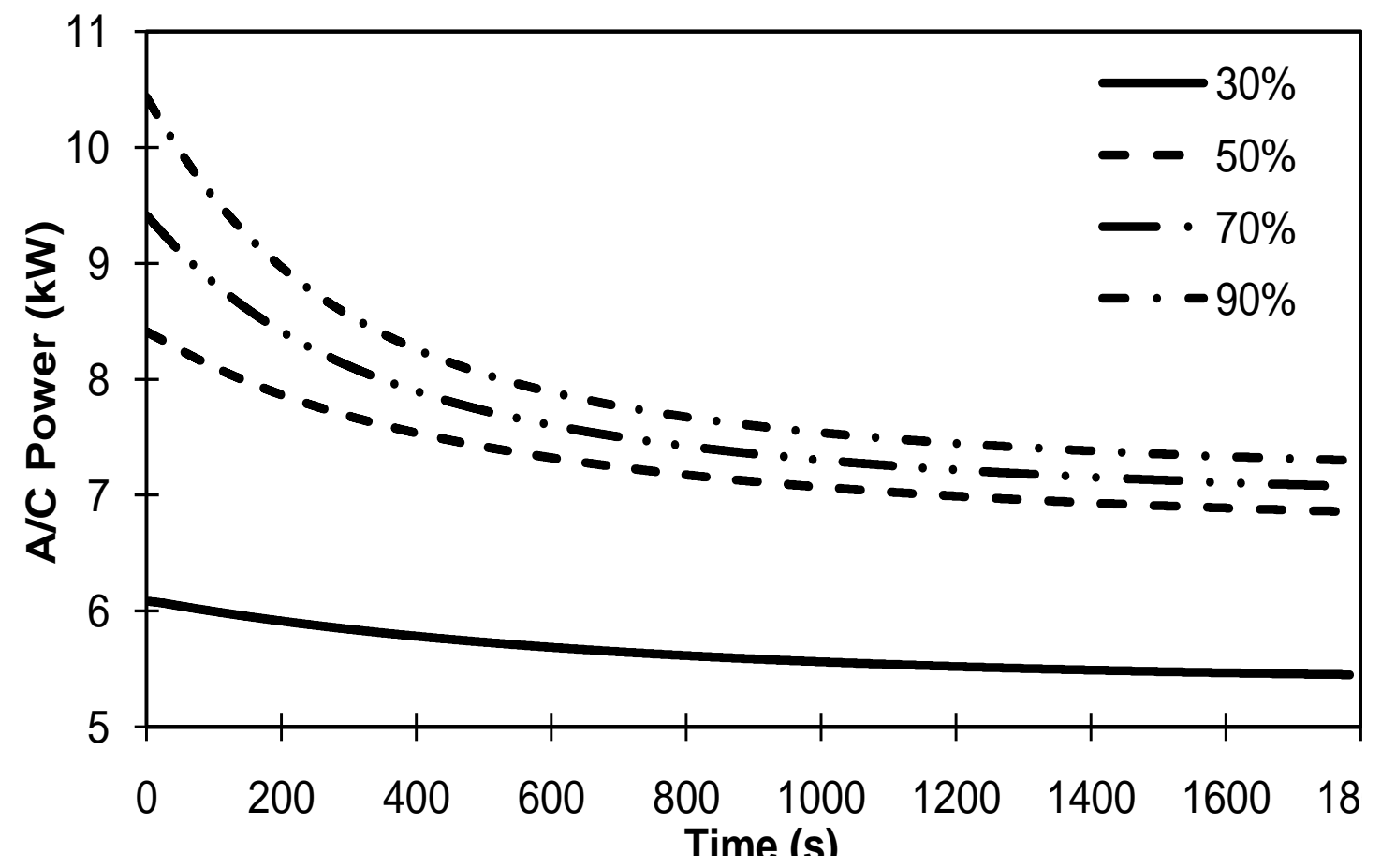

Figure 5.13 Simulation of A/C Power with Different Ambient $R H\left(T_{c a b}=30^{\circ} \mathrm{C}\right)$ 


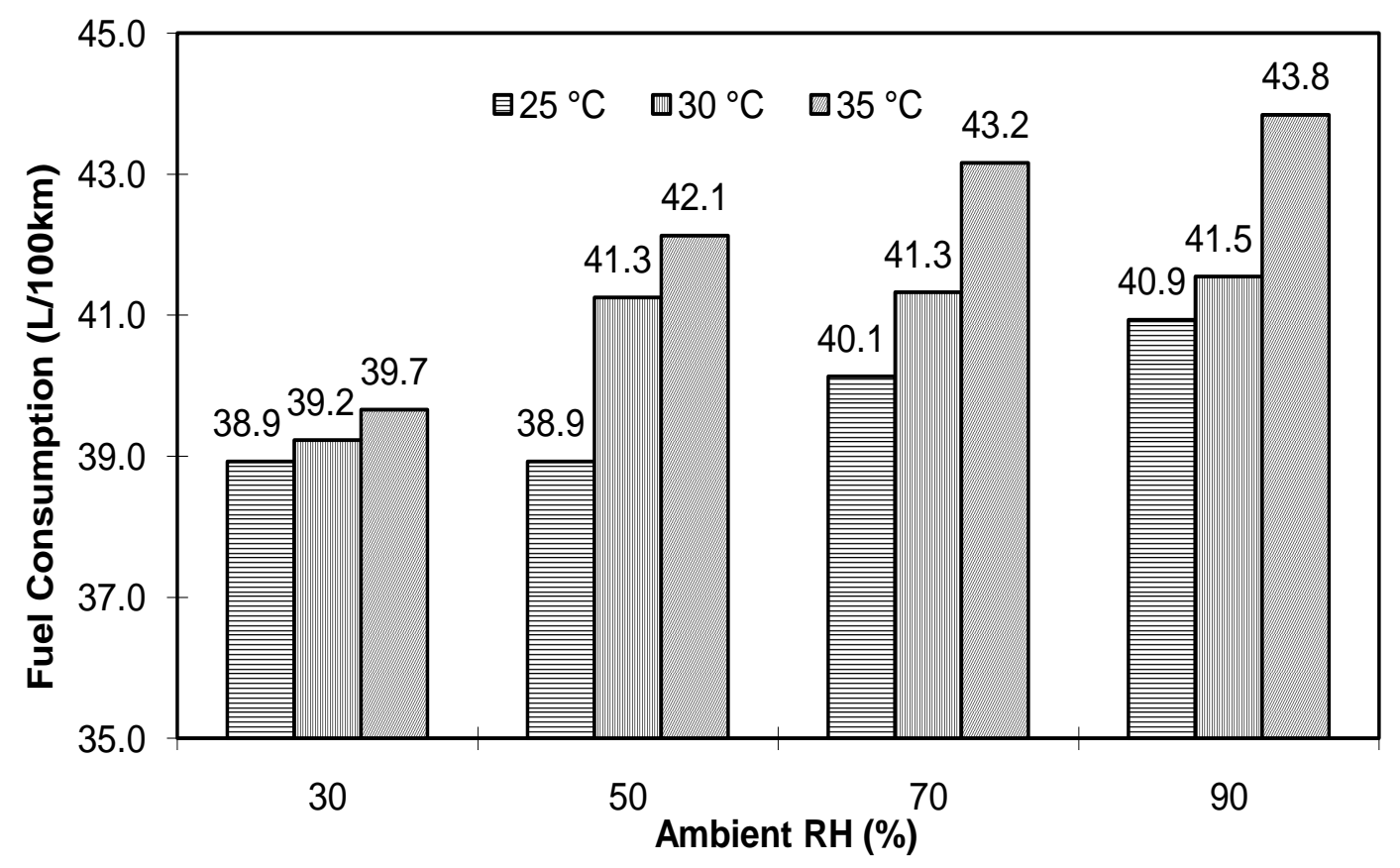

Figure 5.14 Impact of Ambient RH on Fuel Consumption under Different Ambient Temperatures

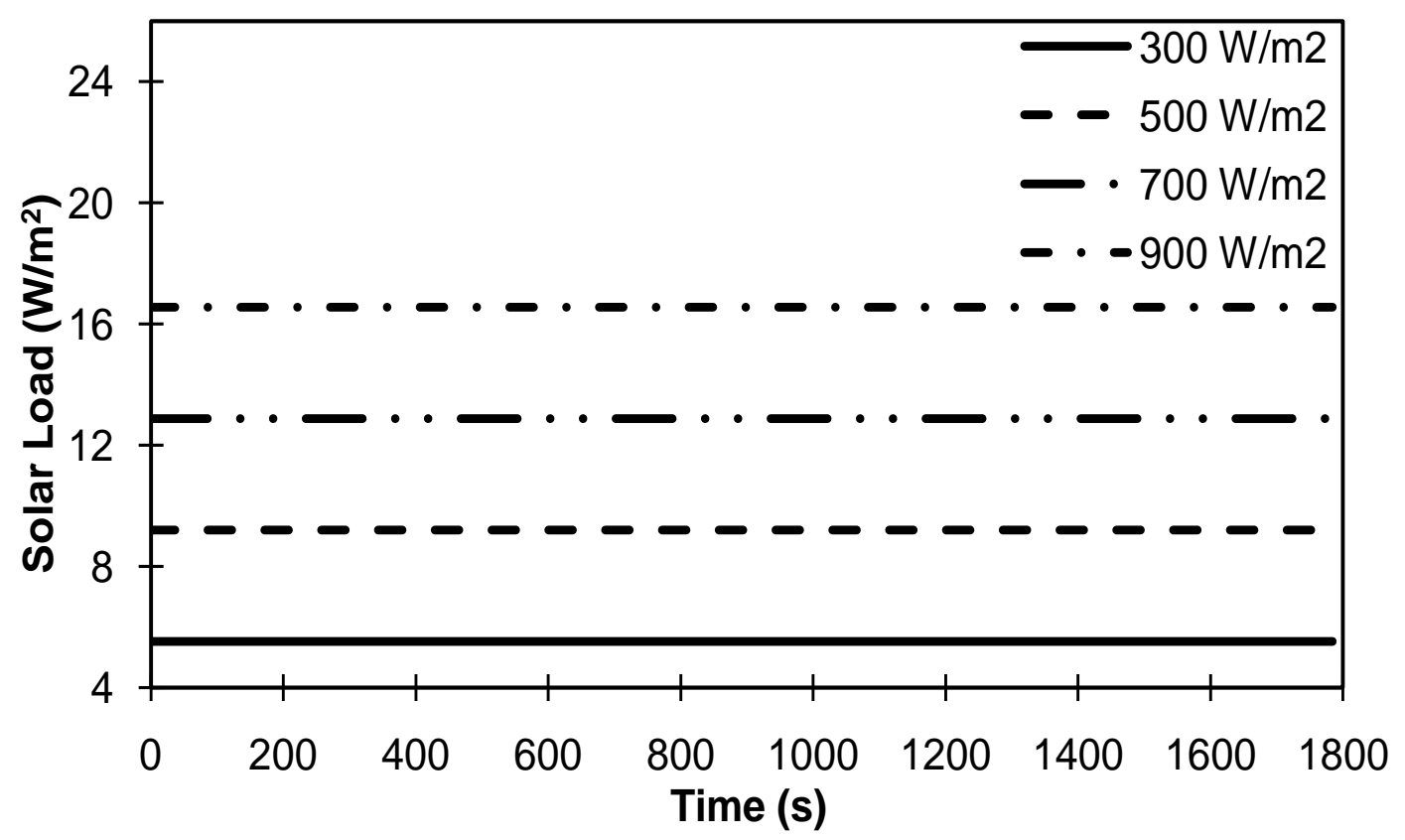

Figure 5.15 Simulation of Solar Load on Vehicle with Different Apparent Solar Radiation

$$
\left(\mathrm{T}_{\mathrm{cab}}=\mathbf{3 0}{ }^{\circ} \mathrm{C}, \mathbf{R H}=\mathbf{5 0 \%}\right)
$$




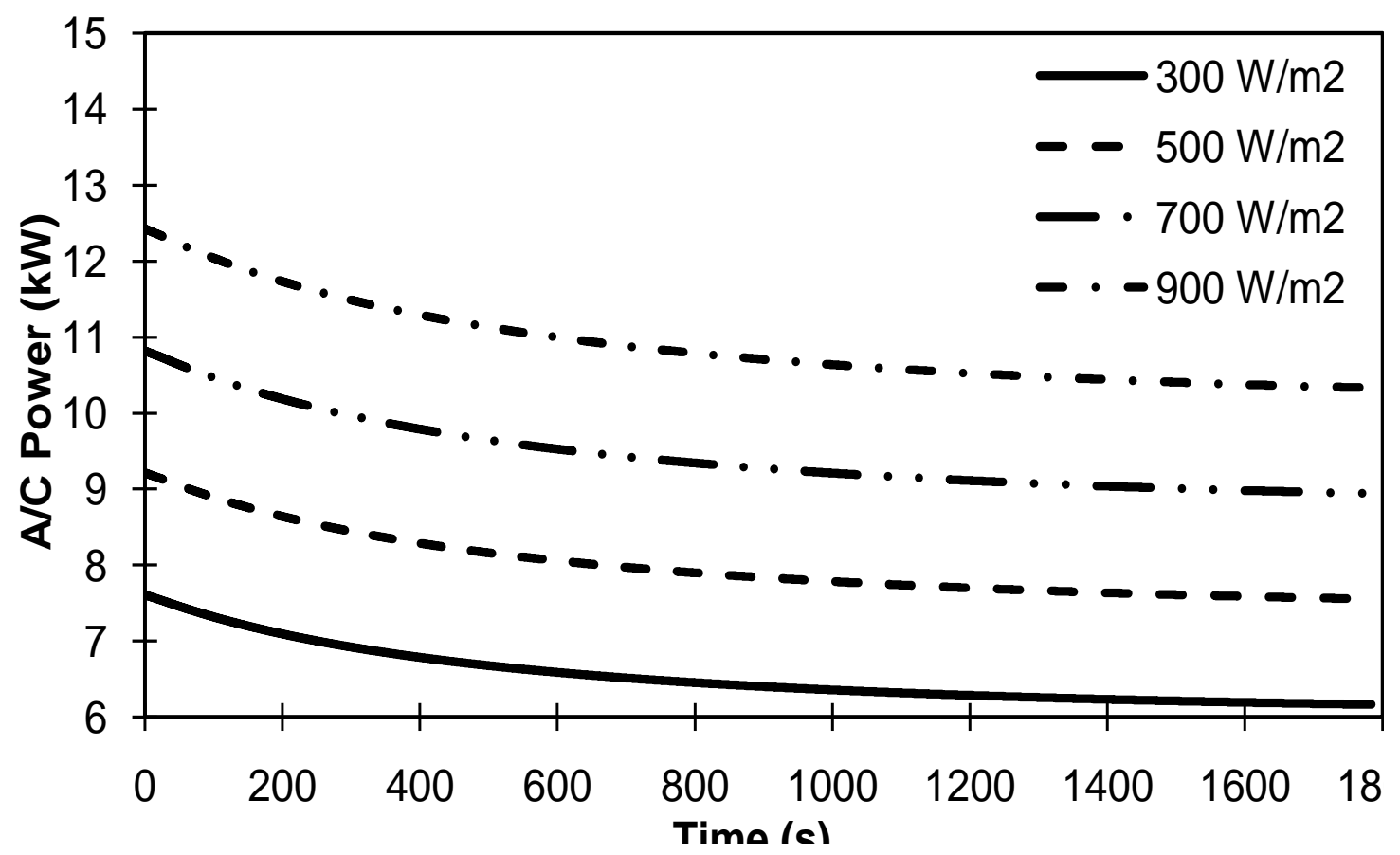

Figure 5.16 Simulation of A/C Power with Different Solar Radiation $\left(T_{\text {cab }}=30^{\circ} \mathrm{C}, \mathbf{R H}=50 \%\right)$

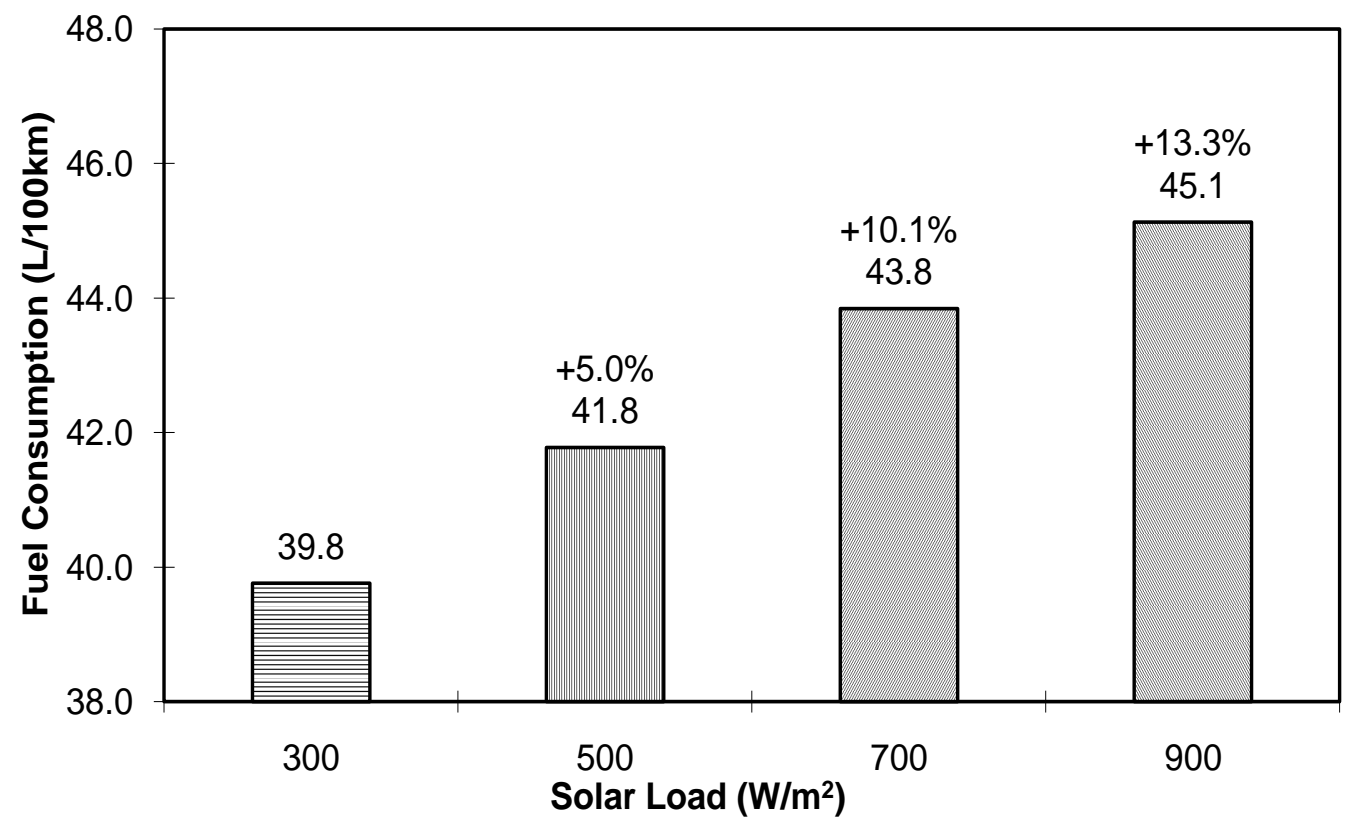

Figure 5.17 Impact of Solar Radiation on Fuel Consumption $\left(\mathrm{T}_{\mathrm{cab}}=\mathbf{3 0}{ }^{\circ} \mathrm{C}, \mathrm{RH}=\mathbf{5 0 \%}\right)$ 
Table 5.2 Effect of Ambient Condition on the Overall Fuel Consumption

\begin{tabular}{|l|l|l|l|}
\hline Parameters & Temp $\left(25 \sim 40^{\circ} \mathrm{C}\right) *$ & $\mathrm{RH}(\%)^{* *}$ & Solar $\left(\mathrm{W} / \mathrm{m}^{2}\right) * * *$ \\
\hline Effects & $\sim 7.0 \%$ per $5{ }^{\circ} \mathrm{C}$ & $\sim 3.4 \%$ per $20 \%$ & $\sim 9.5 \%$ per $200 \mathrm{~W} / \mathrm{m}^{2}$ \\
\hline$* \mathrm{RH}=50 \%$, Solar load $=400 \mathrm{~W} / \mathrm{m}^{2} ;$ \\
$* *$ Temperature $=35^{\circ} \mathrm{C}, \mathrm{RH}>=50 \%$, Solar load $=400 \mathrm{~W} / \mathrm{m}^{2} ;$ \\
$* * *$ Temperature $=35^{\circ} \mathrm{C}, \mathrm{RH}=50 \% ;$
\end{tabular}

Natural ventilation poses significant impact on thermal comfort and fuel consumption, especially for transit buses since the door is frequently open for picking up and dropping passengers at each bus station. As a result, it will take longer time and cost more energy to reach the comfort region as cool air inside flows outwards while hot air outside flows inwards. To represent a typical bus driving cycle in the urban areas, the Manhattan Bus cycle was applied after the vehicle speed was scaled by a factor of 0.7 due to power limit of the hybrid bus. Figure 5.18 presents the natural ventilation load over the Manhattan Bus cycle. It can be seen that natural ventilation increased as the temperature difference between inside and outside of cabin increased due to operation of A/C. Figure 5.19 and Figure 5.20 present fluctuation of the cabin temperature and the cabin $\mathrm{RH}$ due to natural ventilation. Figure 5.21 shows variation of $\mathrm{A} / \mathrm{C}$ power over the bus cycle. The saw teeth in the cabin temperature, cabin $\mathrm{RH}$ and the $\mathrm{A} / \mathrm{C}$ power were introduced by fluctuation of the natural ventilation load.

As mentioned above, ambient temperature, ambient RH, and solar load are key environmental factors that influence the $\mathrm{A} / \mathrm{C}$ power, and these factors are varied from one state to another in the U.S. In this study, three states of different typical ambient conditions (West Virginia, Arizona, and Florida) were chosen to examine fuel consumption variation from one state to another when the $\mathrm{A} / \mathrm{C}$ is on. It can be seen from Figure 5.22 that most of West Virginia has humid continental climate with warm to hot (and usually humid) summers. While the upper part of Arizona has semi-arid climate, the rest of Arizona is accompanied with mid-latitude desert climate with hot and dry summers. Florida has both humid subtropical climate and tropical wet/dry season climate with humid and hot summers. Therefore, West Virginia is characterized by its comfortable ambient temperature and moist air. Arizona is known for its high ambient temperature and low ambient RH in the air. And Florida is known for its high ambient temperature and highly moist 
air due to its special location near the sea. The average ambient parameters of the three states used in the simulation are shown in Table 5.3.

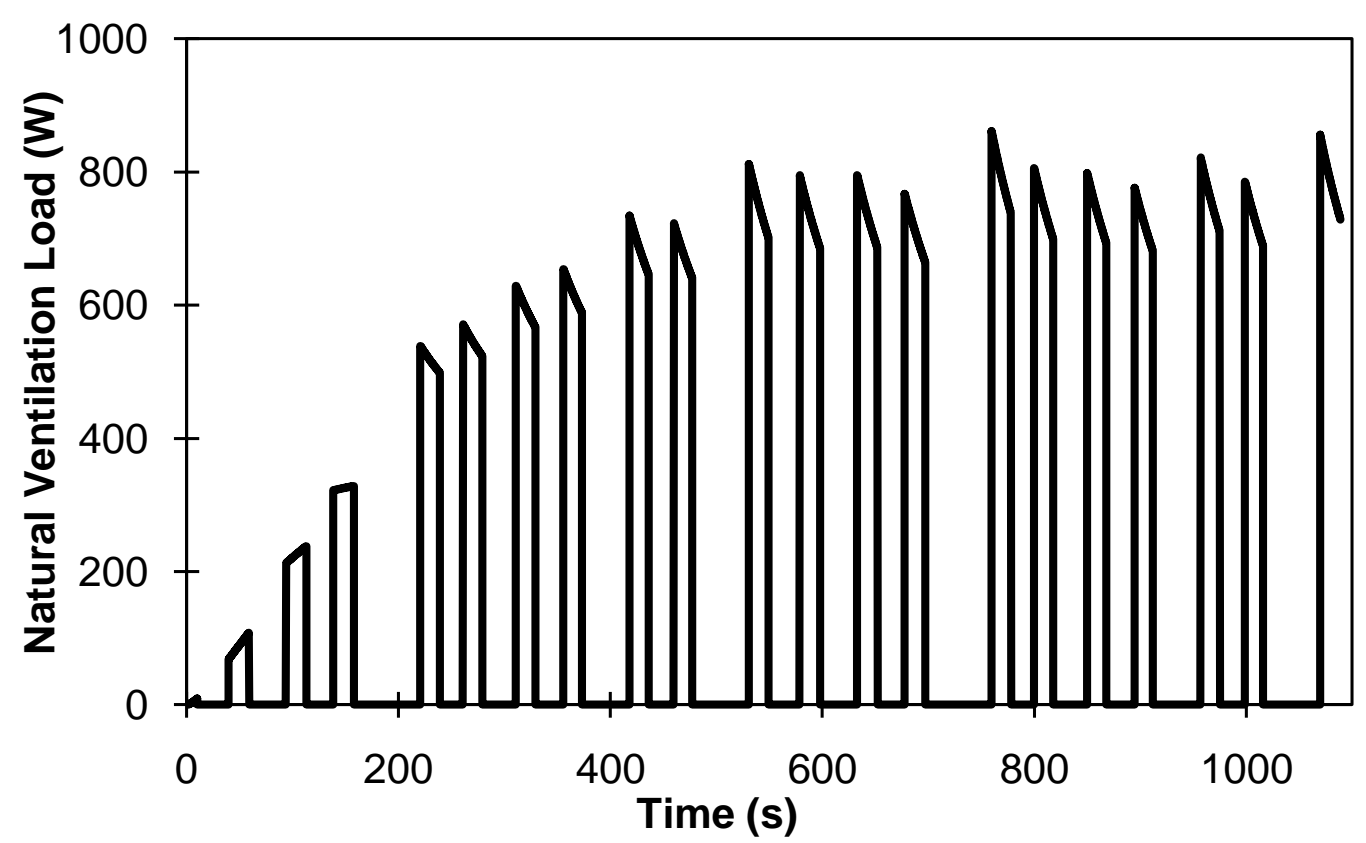

Figure 5.18 Simulation of Natural Ventilation Load over Scaled Manhattan Bus Cycle

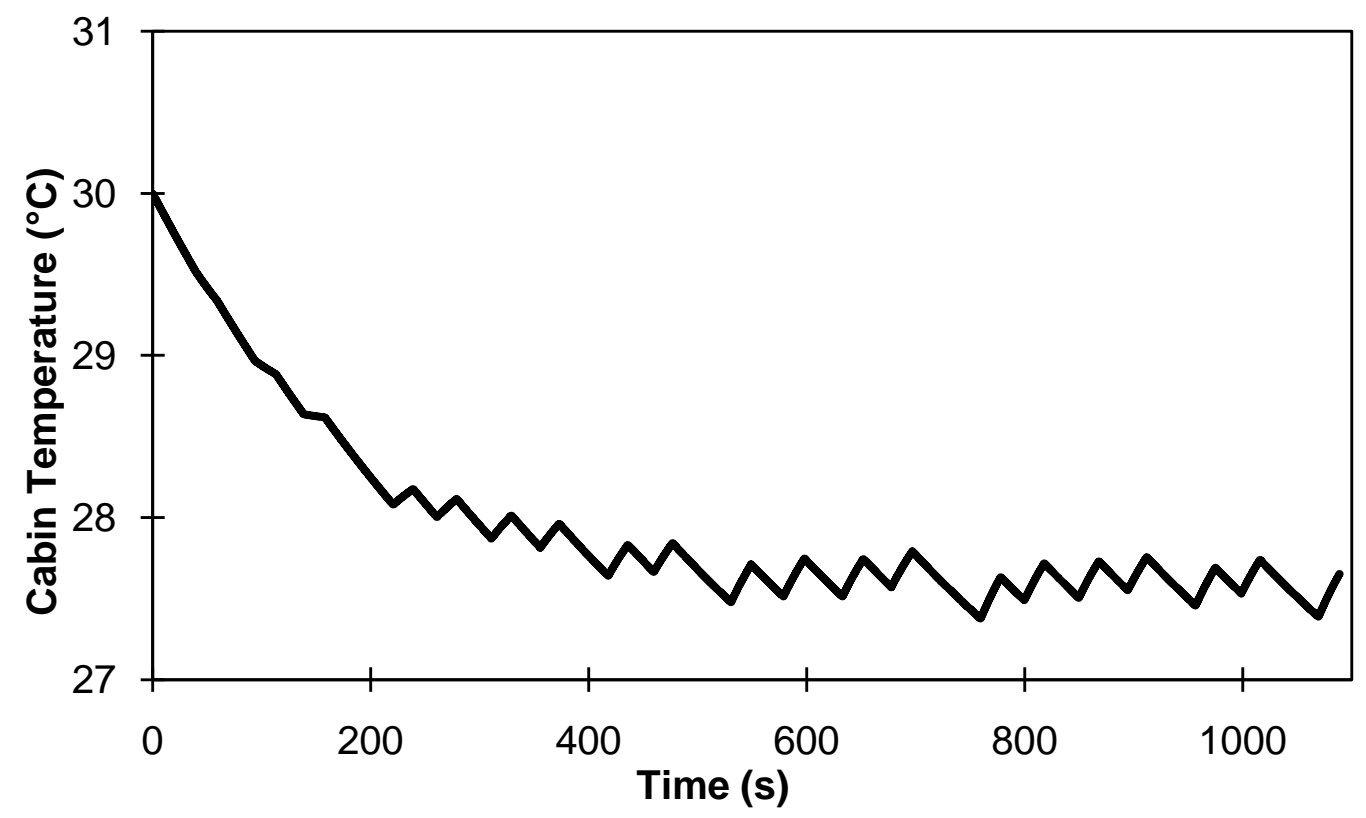

Figure 5.19 Variation of Cabin Temperature over Scaled Manhattan Bus Cycle 


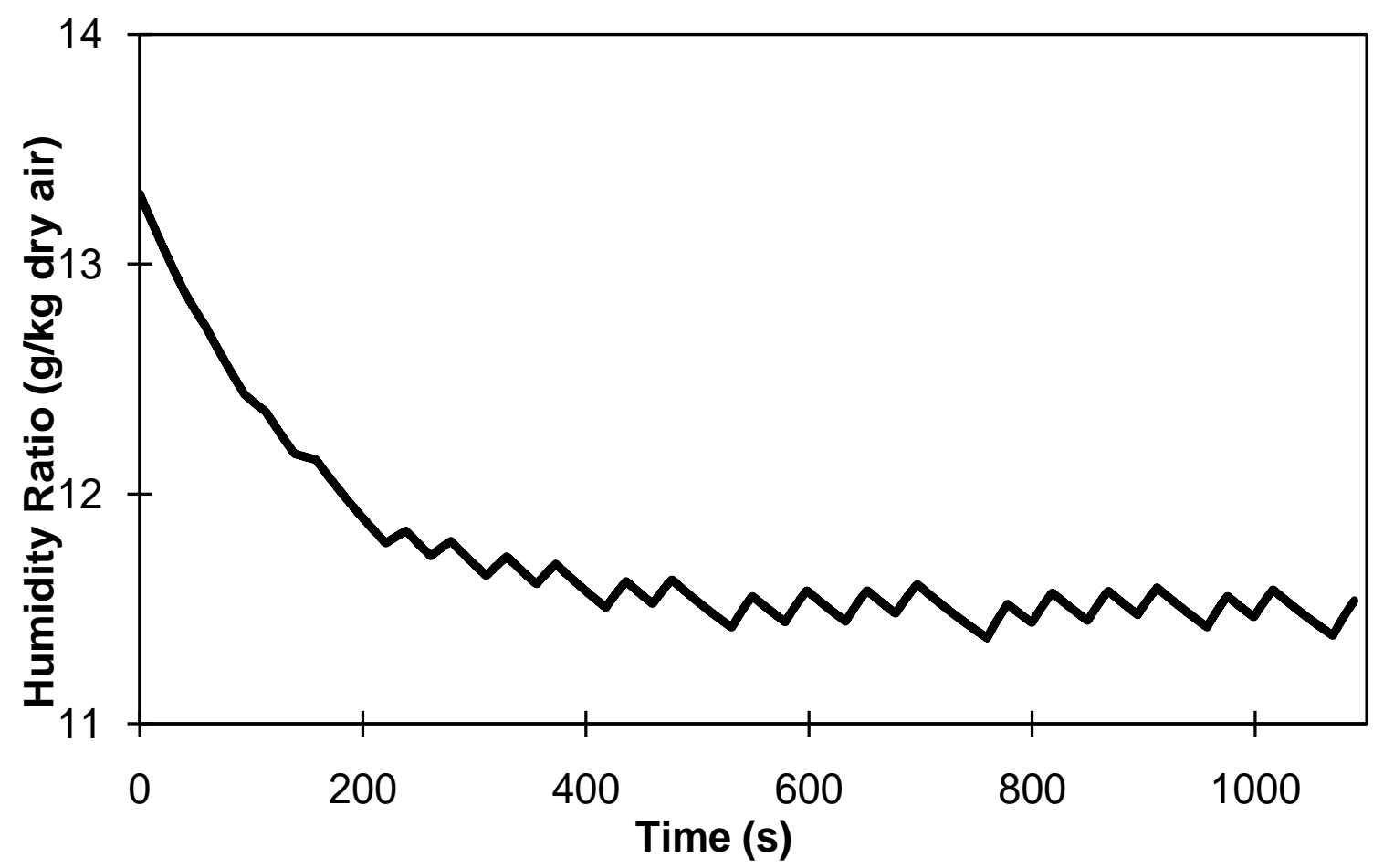

Figure 5.20 Variation of Cabin RH over Scaled Manhattan Bus Cycle

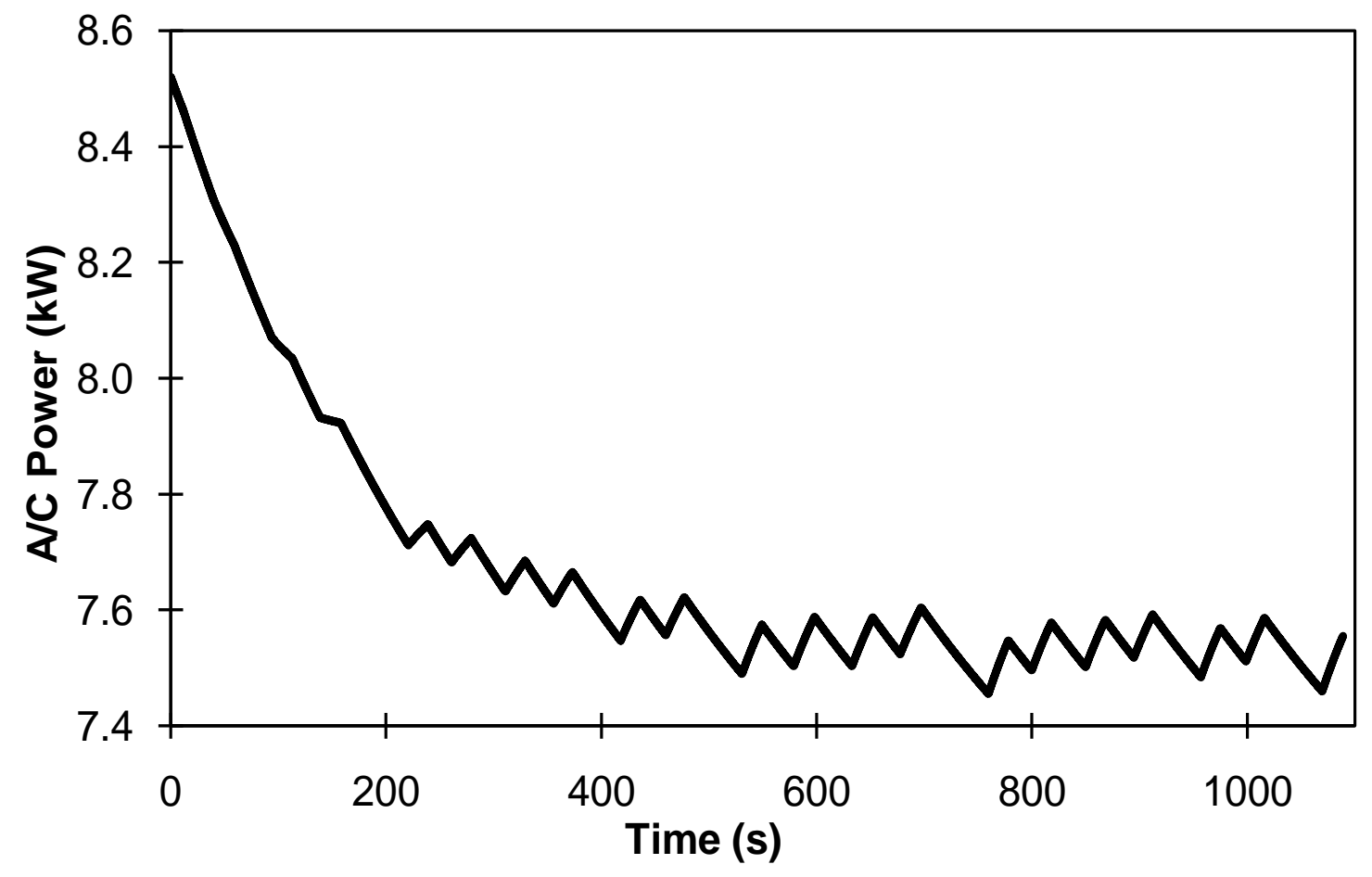

Figure 5.21 Variation of A/C Power over Scaled Manhattan Bus Cycle 


\section{Climate Zones of the Continental United States}

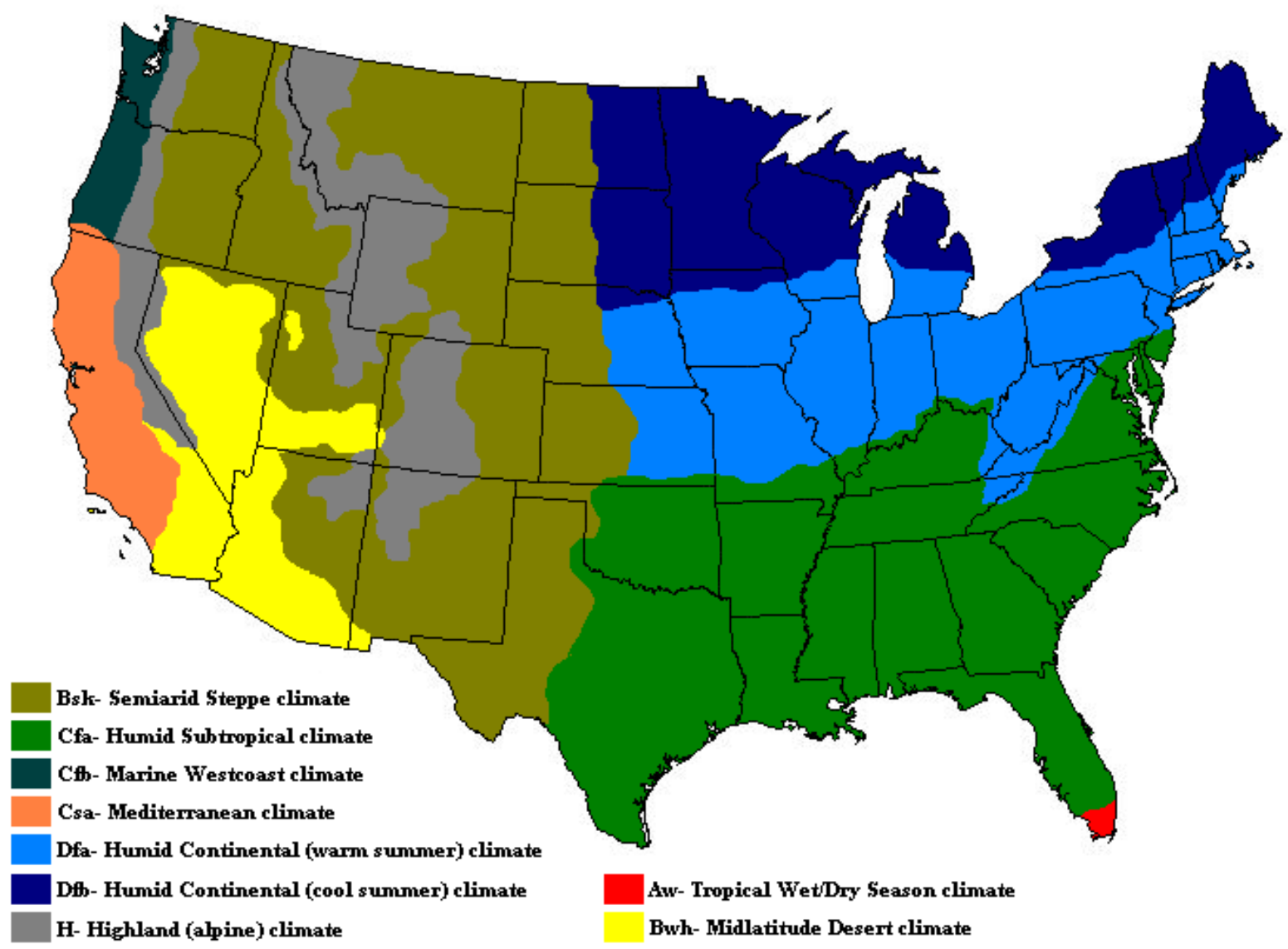

Figure 5.22 Climate Zones of the Continental United States [13]

Table 5.3 Average Ambient Parameters in West Virginia, Arizona, and Florida when A/C is on [10,11]

\begin{tabular}{|c|c|c|c|}
\hline State & $\begin{array}{c}\text { Average } \\
\text { Temperature }\left({ }^{\circ} \mathrm{C}\right)\end{array}$ & $\begin{array}{c}\text { Average Relative } \\
\text { Humidity }(\%)\end{array}$ & $\begin{array}{c}\text { Average Solar } \\
\text { Load }\left(\mathrm{W} / \mathrm{m}^{2}\right)\end{array}$ \\
\hline West Virginia & 27 & 70 & 456 \\
\hline Arizona & 40 & 20 & 823 \\
\hline Florida & 35 & 90 & 703 \\
\hline
\end{tabular}

Figure 5.23 and Figure 5.24 demonstrate cabin temperature profile and humidity ratio profile in the three states. It can be seen that the comfort region, which is bounded by RH between $30 \%$ and $60 \%$ and by cabin temperature between $24{ }^{\circ} \mathrm{C}$ and $26{ }^{\circ} \mathrm{C}$, can be reached within 30 minutes. Figure 5.25, Figure 5.26, Figure 5.27 and Figure 5.28 represent the simulations of the ventilation load, conduction load, solar load and A/C power, respectively. It can be observed from Figure 
5.25 that high ambient RH resulted in high energy loss due to high dehumidification load.

Similarly, more energy was required to overcome greater temperature surplus to reach the target temperature. As shown in Figure 5.29 simulation results indicated that turning the A/C on would cause the most fuel consumption increase in Florida by $50.2 \%$ due to high conduction load, high dehumidification load, and high solar load. Arizona had $45.9 \%$ of increase in fuel consumption due to high conduction load and high solar load. West Virginia had $31.9 \%$ of increase in fuel consumption due to high dehumidification load.

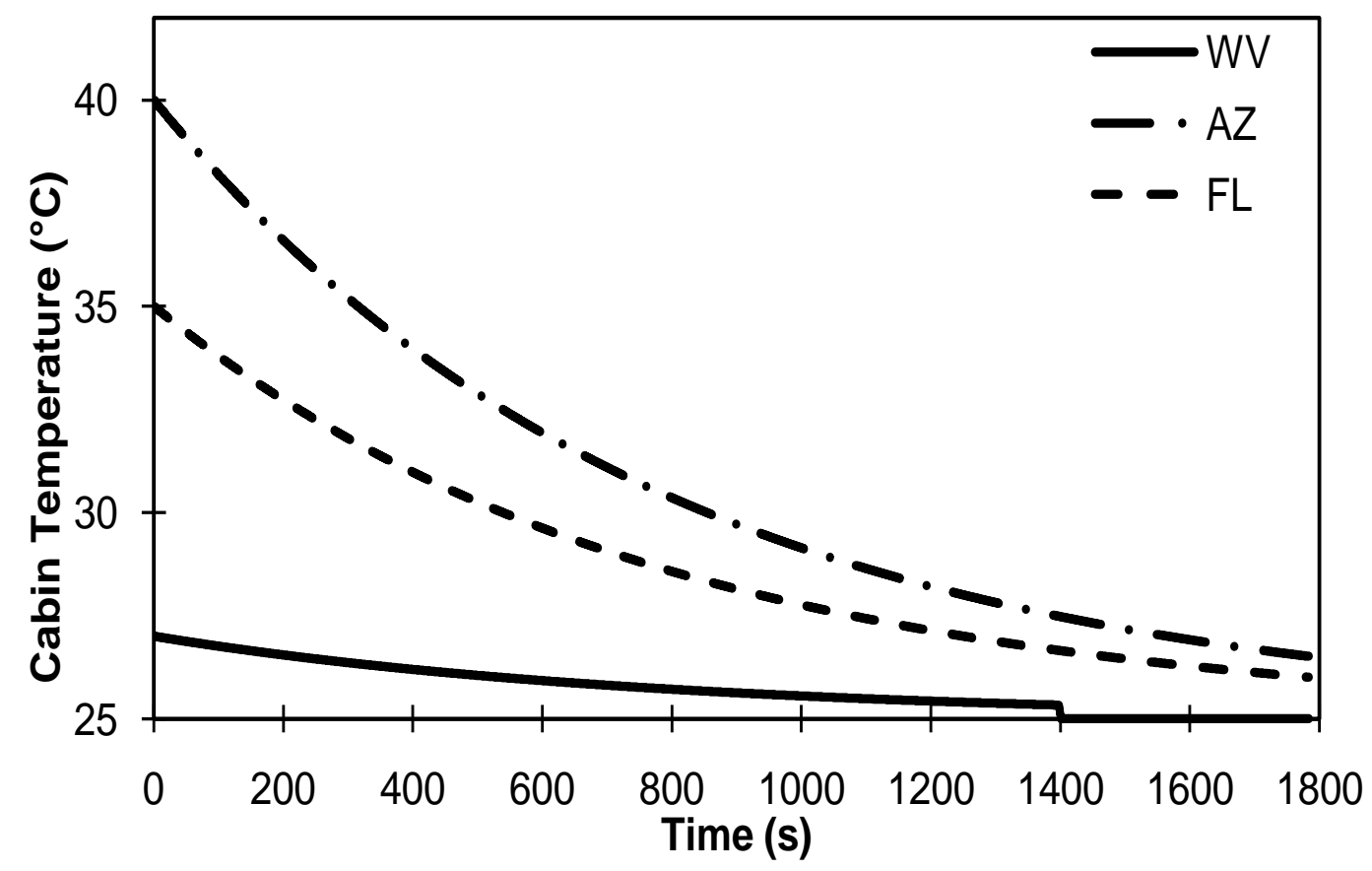

Figure 5.23 Simulation of Cabin Temperature in Florida, Arizona, and West Virginia 


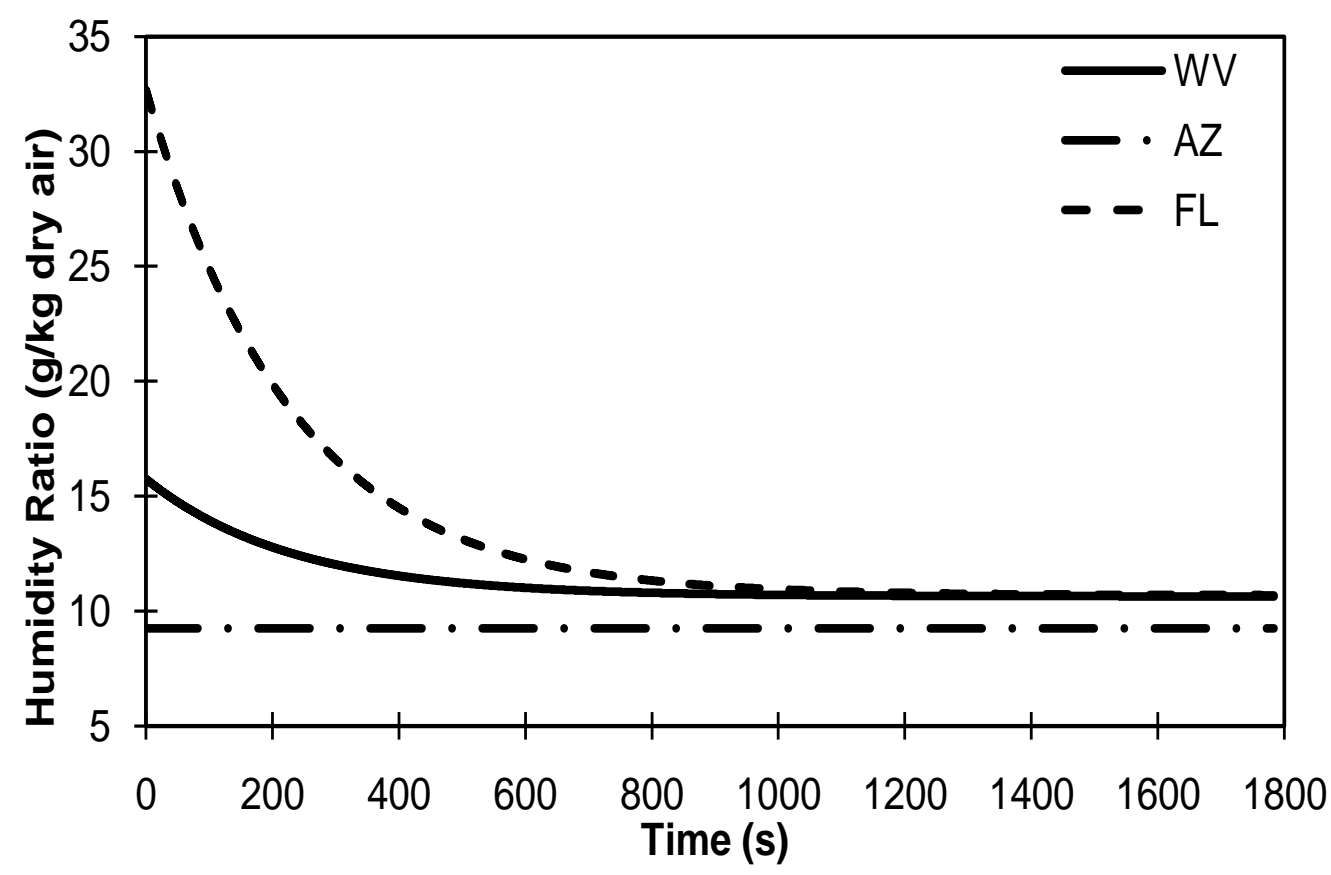

Figure 5.24 Simulation of Cabin Humidity Ratio in Florida, Arizona, and West Virginia

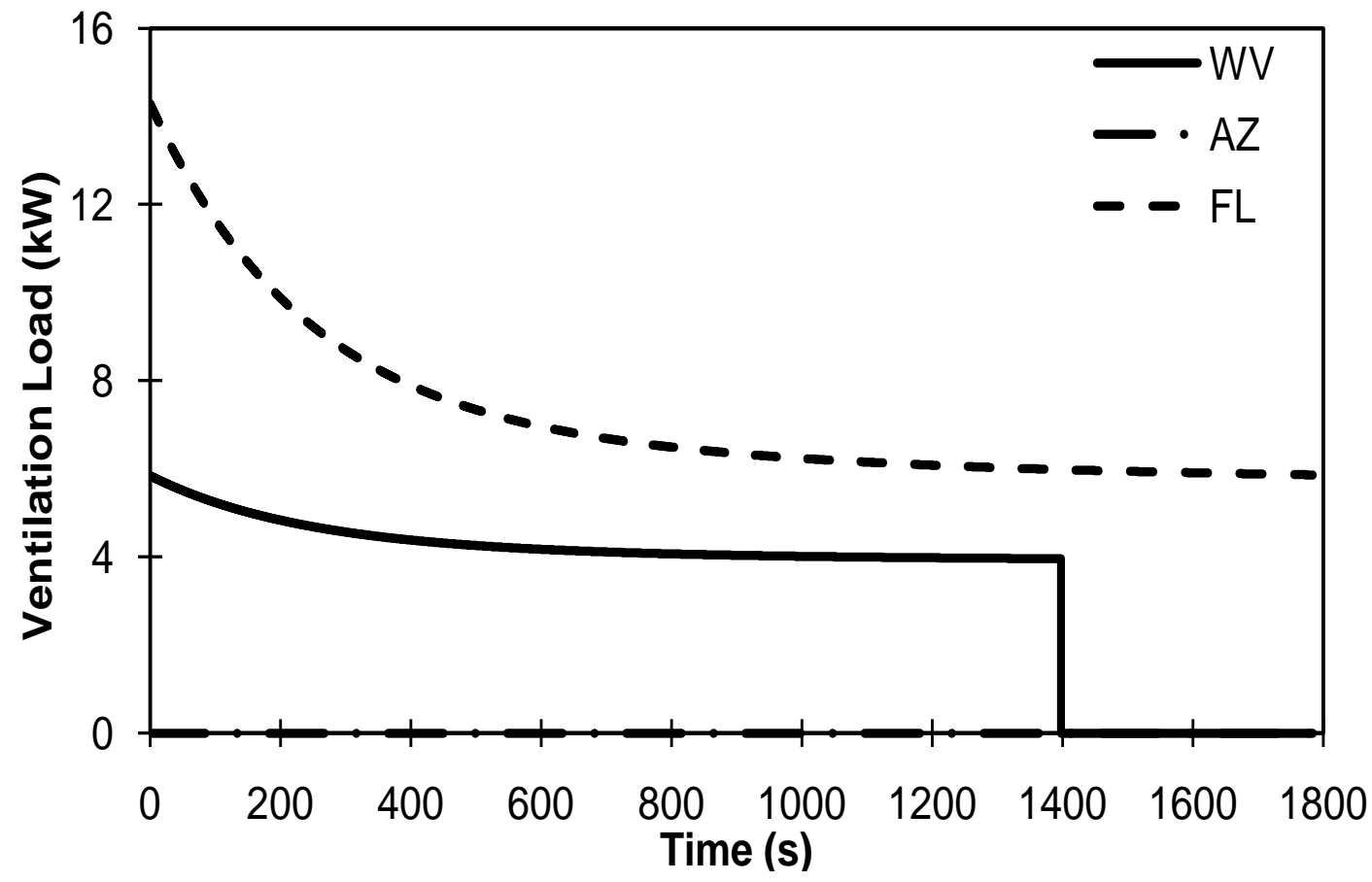

Figure 5.25 Simulation of Ventilation Load in Florida, Arizona, and West Virginia 


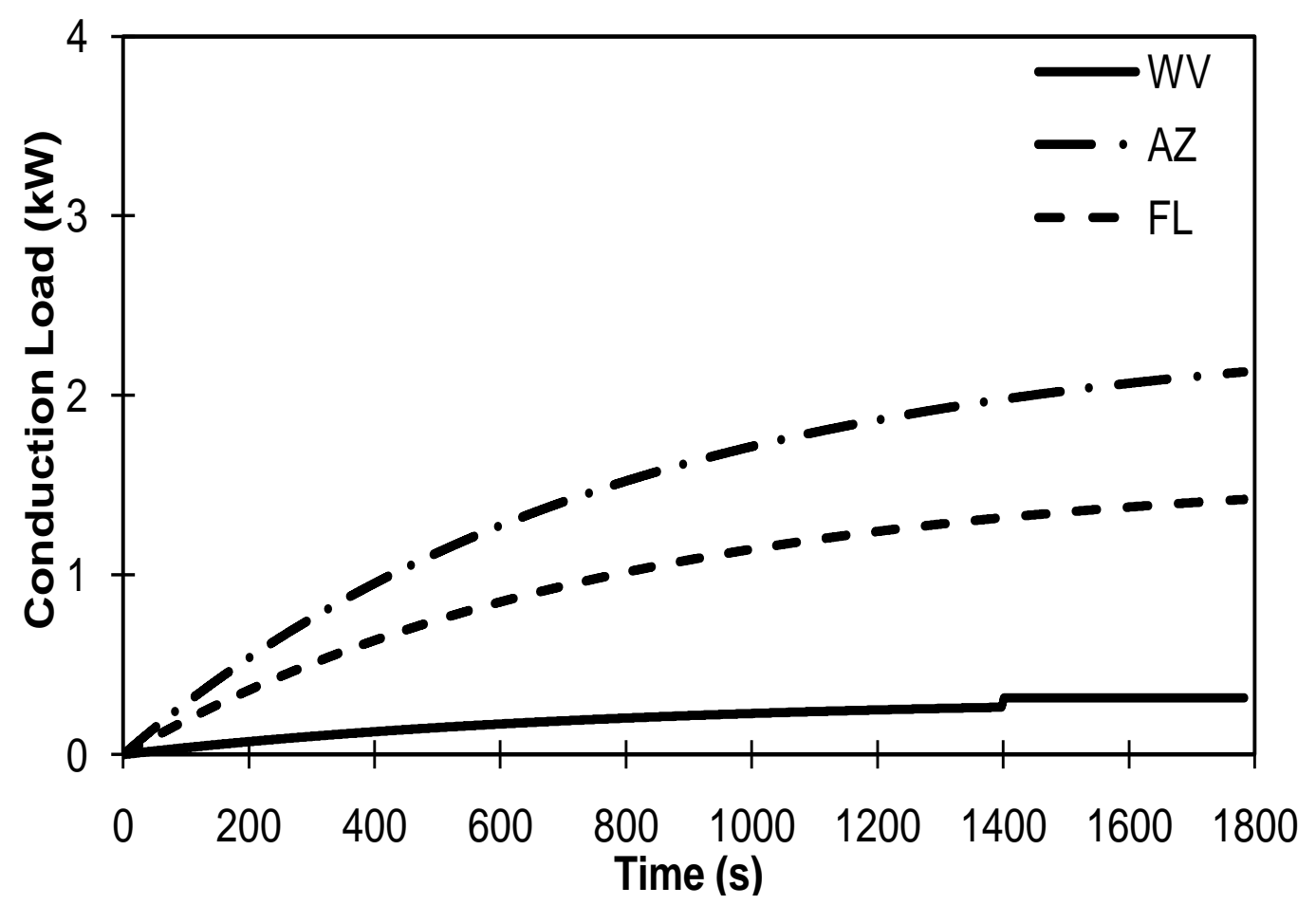

Figure 5.26 Simulation of Conduction Load in Florida, Arizona, and West Virginia

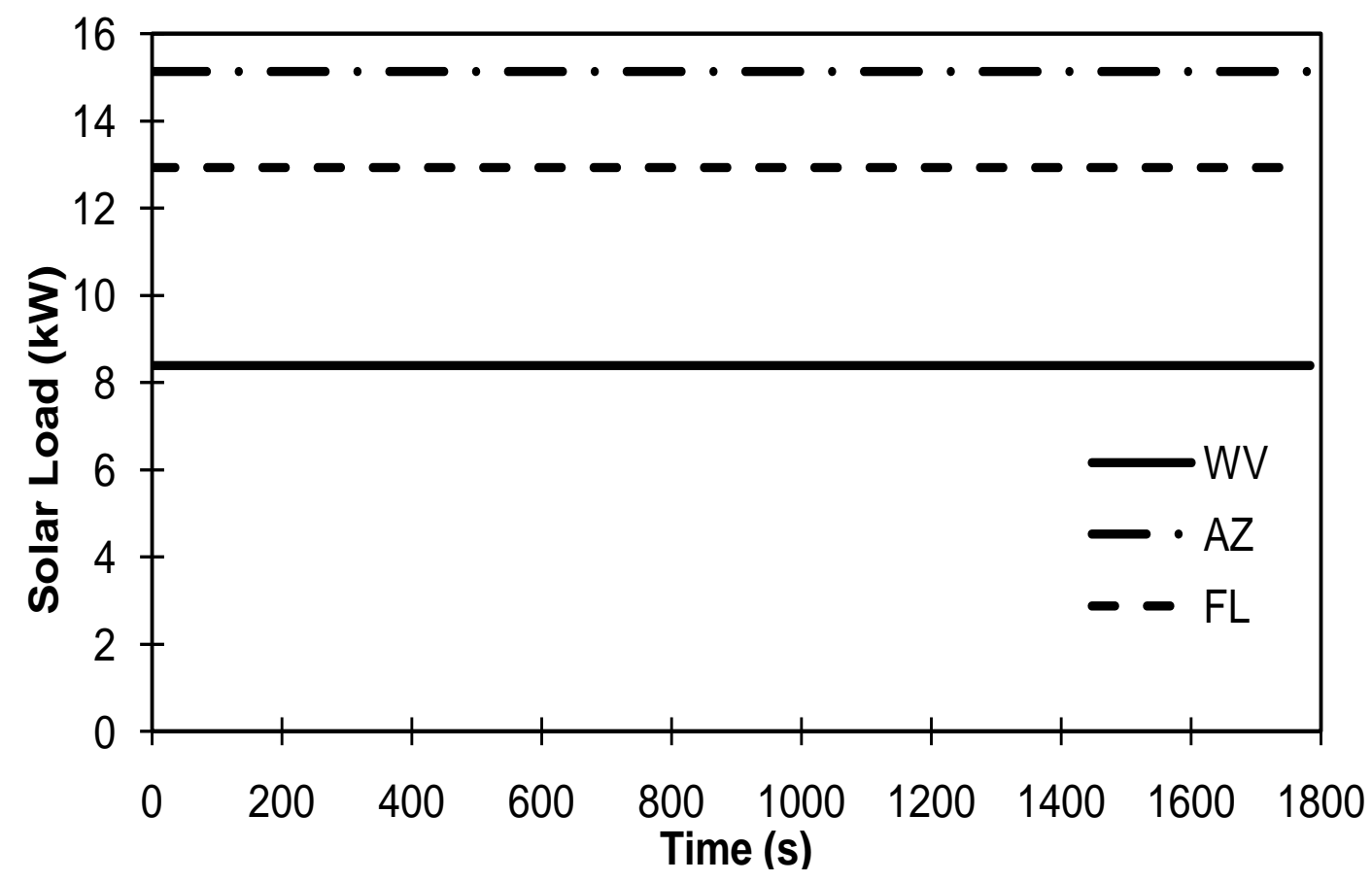

Figure 5.27 Simulation of Solar Load in Florida, Arizona, and West Virginia 


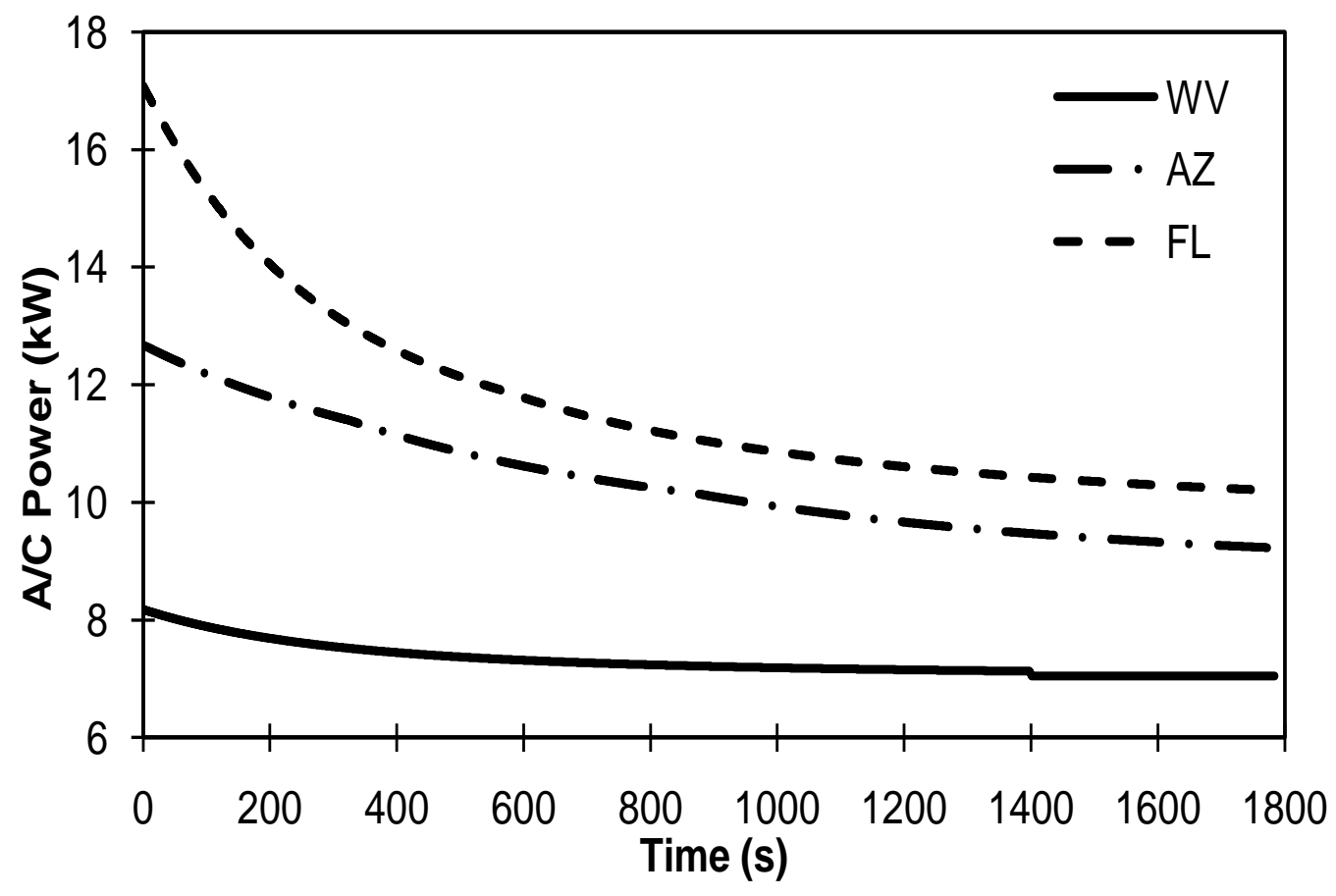

Figure 5.28 Simulation of A/C Power in Florida, Arizona, and West Virginia

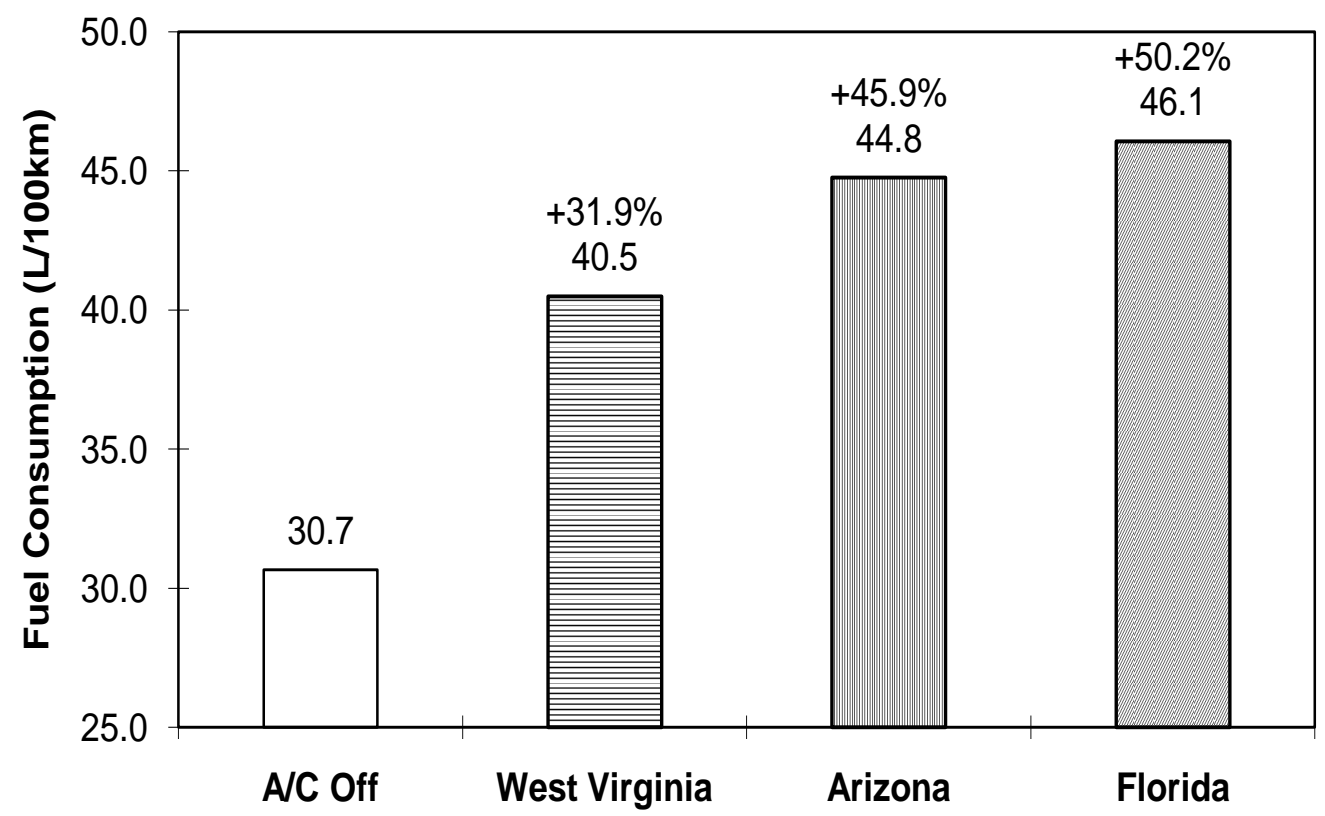

Figure 5.29 Impact of A/C Influence on Fuel Consumption in Florida, Arizona, and West Virginia 


\subsection{Summary}

In this chapter, an improved A/C model was developed based on the analysis of thermal loads and was then integrated with PSAT for simulation. To evaluate thermal comfort and fuel consumption under different ambient conditions, a parametric study was carried out including ambient temperature, ambient RH, solar load, natural ventilation which is related to vehicle type. Simulation results demonstrated that ambient temperature, ambient $\mathrm{RH}$ and solar load all posed significant effect on A/C operation and vehicle overall fuel economy. An increase of ambient temperature by $5{ }^{\circ} \mathrm{C}$ resulted in $7.0 \%$ of increase in fuel consumption on average. An increase of ambient $\mathrm{RH}$ by $20 \%$ at $35^{\circ} \mathrm{C}$ resulted in an increase of fuel consumption by $3.4 \%$ on average. An increase of solar load by $200 \mathrm{~W} / \mathrm{m}^{2}$ increased the fuel consumption by $9.5 \%$ on average. A case study compared the influence of $\mathrm{A} / \mathrm{C}$ operation on power demand and the overall fuel economy among three states characterized by three typical ambient conditions. Simulation results indicated that turning the $\mathrm{A} / \mathrm{C}$ on would cause the most fuel consumption increase in Florida by $50.2 \%$ due to high conduction load, high dehumidification load, and high solar load. Arizona had a $45.9 \%$ increase in fuel consumption due to high conduction load and high solar load. West Virginia had a $31.9 \%$ increase in fuel consumption due to high dehumidification load. 


\section{Conclusions and Future Work}

\subsection{Conclusions}

In this research, a heavy-duty hybrid transit bus model was developed using PSAT as platform. The model was validated against experimental data measured over China's bus cycles. After the validation process, two control strategies, an engine efficiency-based control strategy and a realtime overall efficiency-based control strategy, were developed and used to optimize the performance of fuel economy and exhaust emissions of the hybrid transit bus over three U.S. bus cycles (CBD cycle, Manhattan Bus cycle, and New York Bus cycle). An A/C model was developed and integrated with PSAT to investigate influence of A/C operation on passenger comfort and fuel consumption. The conclusions are summarized as:

a) In this research, a pre-transmission heavy-duty hybrid transit bus model was validated in PSAT accurately with small relative errors less than $4.2 \%$ for both fuel consumption and battery SOC. With suitable vehicle parameters, component maps and control strategy, PSAT model can be used to simulate the performance of heavy-duty hybrid buses.

b) The engine efficiency-based control strategy (control A) modestly improved fuel economy over the CBD cycle and the Manhattan Bus cycle by $1.5 \%$ and $1.7 \%$. Also $\mathrm{NO}_{\mathrm{x}}$ emissions, when operated with control A, were reduced by $5.6 \%$ over both CBD cycle and Manhattan Bus cycle. However, simulation results showed that control A did not have considerable potential to improve fuel economy and $\mathrm{NO}_{\mathrm{x}}$ emissions when compared with the baseline control strategy. This indicated that engine efficiency-based control strategy has very limited potential to improve fuel economy and emissions in the U.S. cycles for this hybrid bus.

c) The real-time overall efficiency-based control strategy (control B) significantly improved the performance of this hybrid bus over the New York Bus cycle. When compared with the baseline control strategy, fuel economy was improved by $8.1 \%$, while $\mathrm{NO}_{\mathrm{x}}$ emissions were reduced by $6.1 \%$. By comparison of simulation results between control $\mathrm{A}$ and control $\mathrm{B}$, it was concluded that the control strategy based on maximizing the overall powertrain efficiency had more potential in improving fuel economy and $\mathrm{NO}_{\mathrm{x}}$ emissions than the control strategy based on maximizing the engine efficiency. 
d) For the low SOC condition, the engine-only mode was not considered as the best operating mode for the HEB due to deteriorating engine efficiency. By operating engine in high efficiency region when SOC is low has the trend of increasing battery SOC with potential of improving both engine efficiency and overall system efficiency through motor assistance in the later operation.

e) A parametric study by single parameter variation demonstrated the significant effect of ambient conditions on the fuel consumption of hybrid bus when A/C is turned on. Simulation results showed that a sole increase of ambient temperature by $5^{\circ} \mathrm{C}$ increased fuel consumption by $7.0 \%$ on average. An increase of ambient $\mathrm{RH}$ by $20 \%$ at $35{ }^{\circ} \mathrm{C}$ resulted in an increase of fuel consumption by $3.4 \%$ on average. Also, an increase of solar load by 200 $\mathrm{W} / \mathrm{m}^{2}$ caused more fuel consumption by $9.5 \%$ on average.

f) A case study covering West Virginia, Arizona, and Florida showed that turning the A/C on in the scaled SFTP-SC03 cycle caused an increase of fuel consumption by $50.2 \%$ in Florida, by 45.9\% in Arizona, and by $31.9 \%$ in West Virginia. Therefore, it can be concluded from the simulation results that turning the $\mathrm{A} / \mathrm{C}$ on in summer in subtropical or tropical climate zones will cost more fuel consumption to the vehicle operation than in humid continental climate zones.

\subsection{Future Work}

\subsubsection{Development of Mechanical Auxiliary Model in PSAT}

Typical auxiliary components in current vehicles include the cooling fan, oil pump, coolant pump, power steering pump, air compressor and $\mathrm{A} / \mathrm{C}$ compressor. To take the power loss by these auxiliary components into account, an accurate mechanical accessory model is very beneficial. In PSAT, the current mechanical accessory model used for simulation is oversimplified with constant power loss. However, in reality the power of mechanical accessories vary with operating load. For example, the power of the engine cooling fan is a function of engine speed. With electrification of the $\mathrm{A} / \mathrm{C}$ systems, the engine cooling system contributes to most of the mechanical auxiliary load. Since the operation of the engine cooling system is intensively related to the operation of engine and can pose significant impact on fuel economy 
and emissions, it is very important to develop an accurate engine cooling system model for PSAT in the future.

\subsubsection{Optimization of Control Strategy for both Fuel Economy and $\mathrm{NO}_{\mathrm{x}}$ Emissions}

Diesel engines are considered one of the main sources of $\mathrm{NO}_{\mathrm{x}}$ and $\mathrm{PM}$ emissions. As emission standards become more and more stringent for heavy-duty vehicles, emission control technologies play an important role in vehicle development. Selective Catalytic Reduction (SCR) has already proven its capacity as an effective method for achieving high $\mathrm{NO}_{\mathrm{x}}$ reduction rates in both stationary and transient test cycles of Japanese, European, and the U.S. test procedures [27]. $\mathrm{NO}_{\mathrm{x}}$ conversion efficiency has been investigated for many years. Since the performance of SCR can be influenced by catalyst operating temperature, $\mathrm{NO}_{2}: \mathrm{NO}$ ratio, and SCR catalyst volume, quantifying the cost of SCR operation will be complicated. The mass flow rate of urea solution to operate a SCR system can be calculated roughly by Equation 37 based on the following assumptions:

- The urea solution used in the SCR is $32.5 \%$ urea, $67.5 \%$ water

- The molar $\mathrm{NO}: \mathrm{NO}_{2}$ ratio is $1: 1$

- $\mathrm{NO}_{\mathrm{x}}$ conversion efficiency was set to $80 \%$ when catalyst operating temperature was above $200{ }^{\circ} \mathrm{C}$ and 0 when catalyst operating temperature is below $200{ }^{\circ} \mathrm{C}$ [21]

- Cost of urea solution $(32.5 \%) C_{\text {urea }}$ is 1.99 \$/gallon [33]

- Cost of diesel $C_{\text {diesel }}$ is $2.94 \$$ /gallon [33]

$m_{\text {urea }}=2.99 \cdot m_{N O_{x}}$ Equation 37

The equivalent fuel consumption to urea consumption by SCR can be calculated based on Equation 38 below:

$m_{\text {fuel }}=\frac{m_{\text {urea }} \cdot C_{\text {urea }}}{\rho_{\text {urea }}} \cdot \frac{\rho_{\text {diesel }}}{C_{\text {diesel }}}$

Equation 38

Where $\rho_{\text {urea }}$ and $\rho_{\text {diesel }}$ denote the density of urea solution and density of diesel fuel, respectively. 
Figure 6.1 shows the cost of urea solution consumed by the SCR system in equivalent brake specific fuel consumption (BSFC). Figure 6.2 shows the BSFC map of the engine. Figure 6.3 represents the overall cost of engine operation in an overall BSFC map by considering both the cost of urea consumption and the cost of fuel consumption.

Current control strategies mainly focus on optimization of engine efficiency or overall powertrain efficiency without consideration of emission performances. However, as fuel economy performance is improved, the $\mathrm{NO}_{\mathrm{x}}$ emission performance is usually deteriorated. $\mathrm{By}$ optimization of fuel economy based on the overall BSFC map in the future, both good fuel economy performance and good $\mathrm{NO}_{\mathrm{x}}$ emission performance can potentially be achieved.

\subsubsection{Intelligent Hybrid Bus Control Strategies}

So far many control strategies have been developed for HEBs by applying heuristic control concept (including rule-based control, fuzzy logic control, and so on) and optimal control theory (such as dynamic programming if the full knowledge of driving cycle is accessible). However, on the one hand the heuristic controls depend strongly on the HEB system and the driving conditions, while optimal control strategies are generally based on a fixed driving cycle and as such do not deal with variability in the driving conditions [39]. On the other hand, the variability in the driving conditions due to different driving behaviors and traffic conditions is inevitable, which may cause vehicle operation far away from the optimal trajectory proposed by the control strategy. To optimize the performance of fuel economy and exhaust emissions over different driving cycles, it is very beneficial in the future to develop intelligent hybrid bus control strategies which have the capability of adapting to the variation of driving cycles (even variation of ambient conditions if $\mathrm{A} / \mathrm{C}$ operation is involved). 


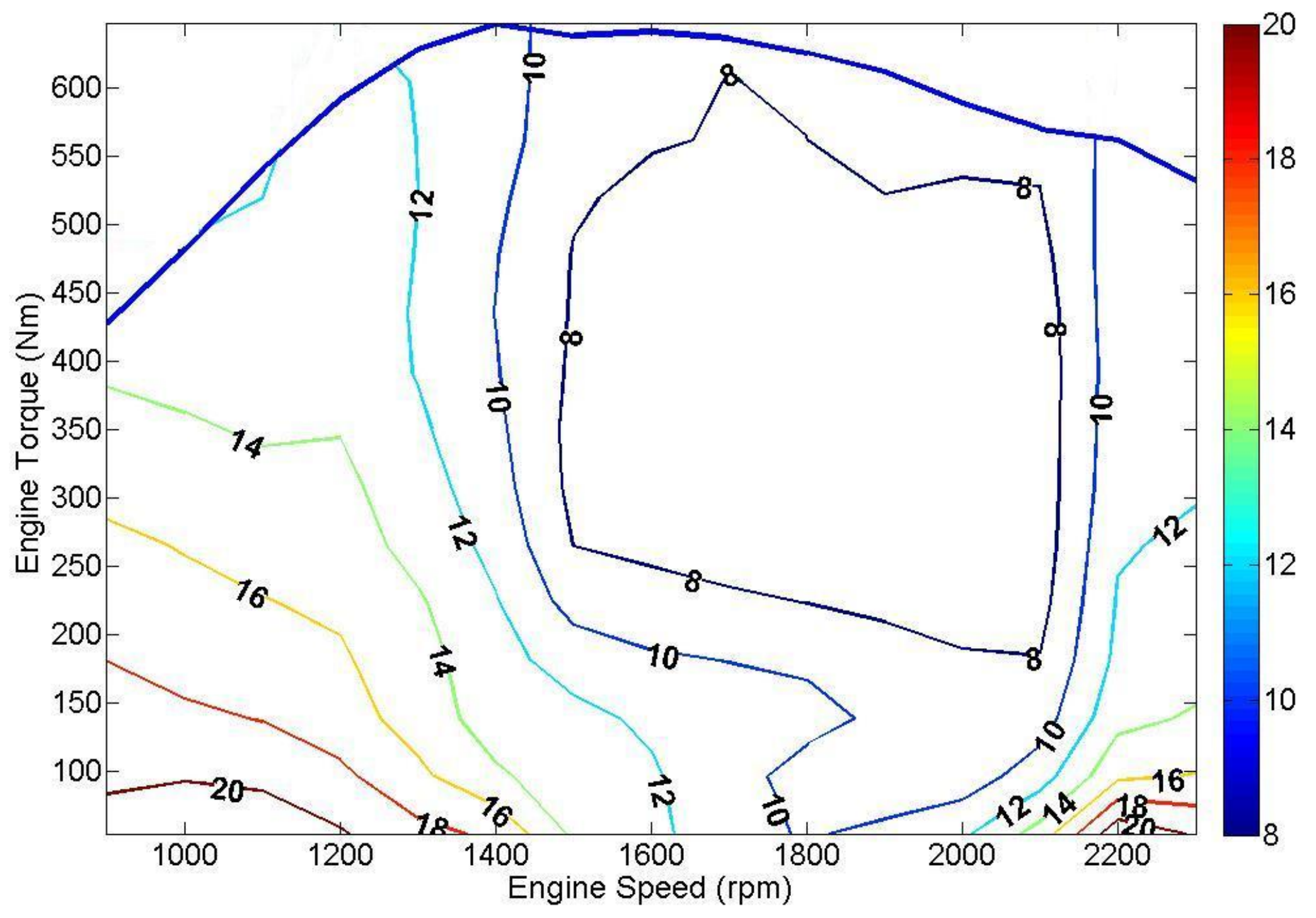

Figure 6.1 Cost of Urea Solution Consumption by the SCR System in Equivalent BSFC (Unit: g/kW-hr) 


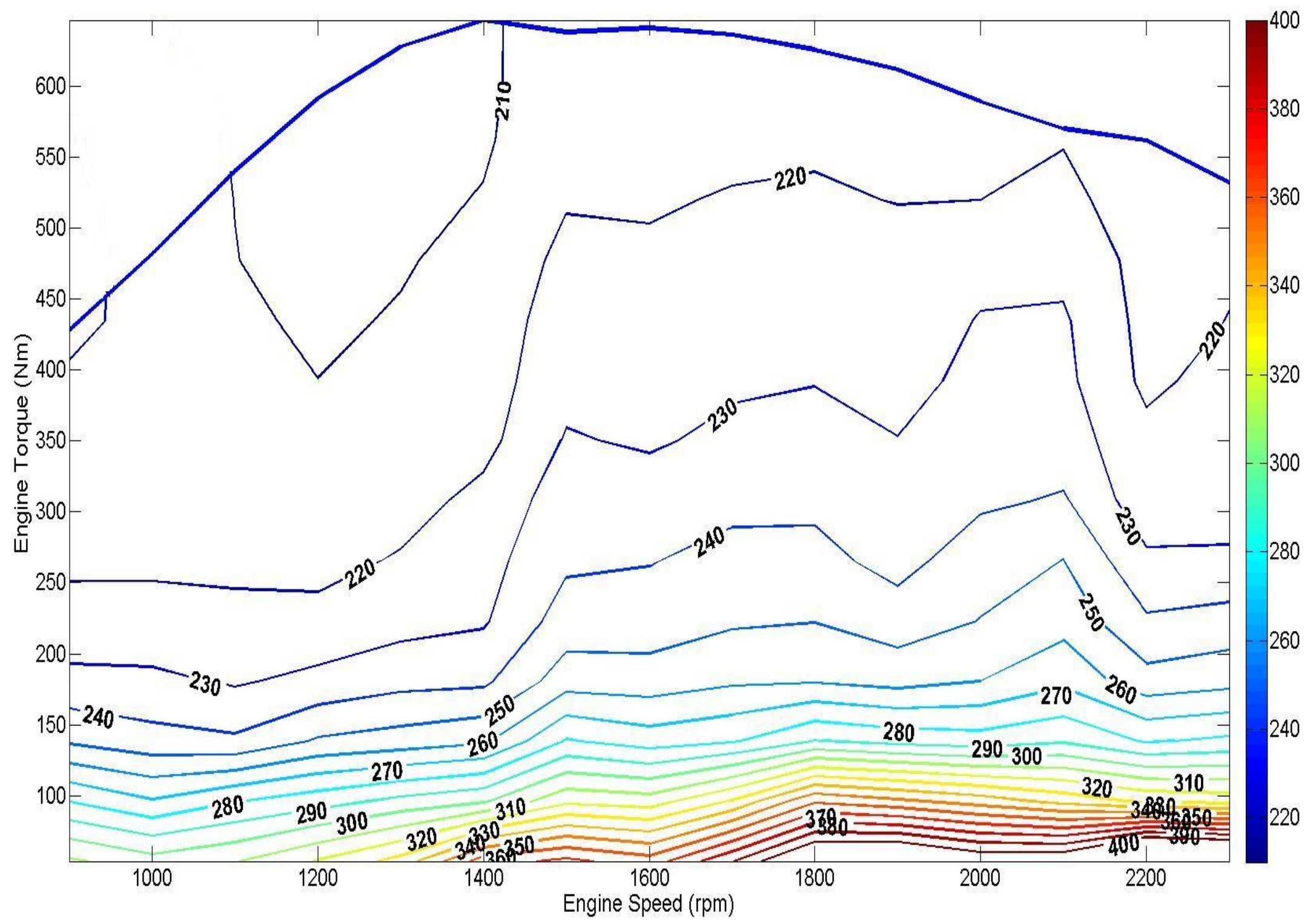

Figure 6.2 BSFC Map of the Engine (Unit: g/kW-hr) 


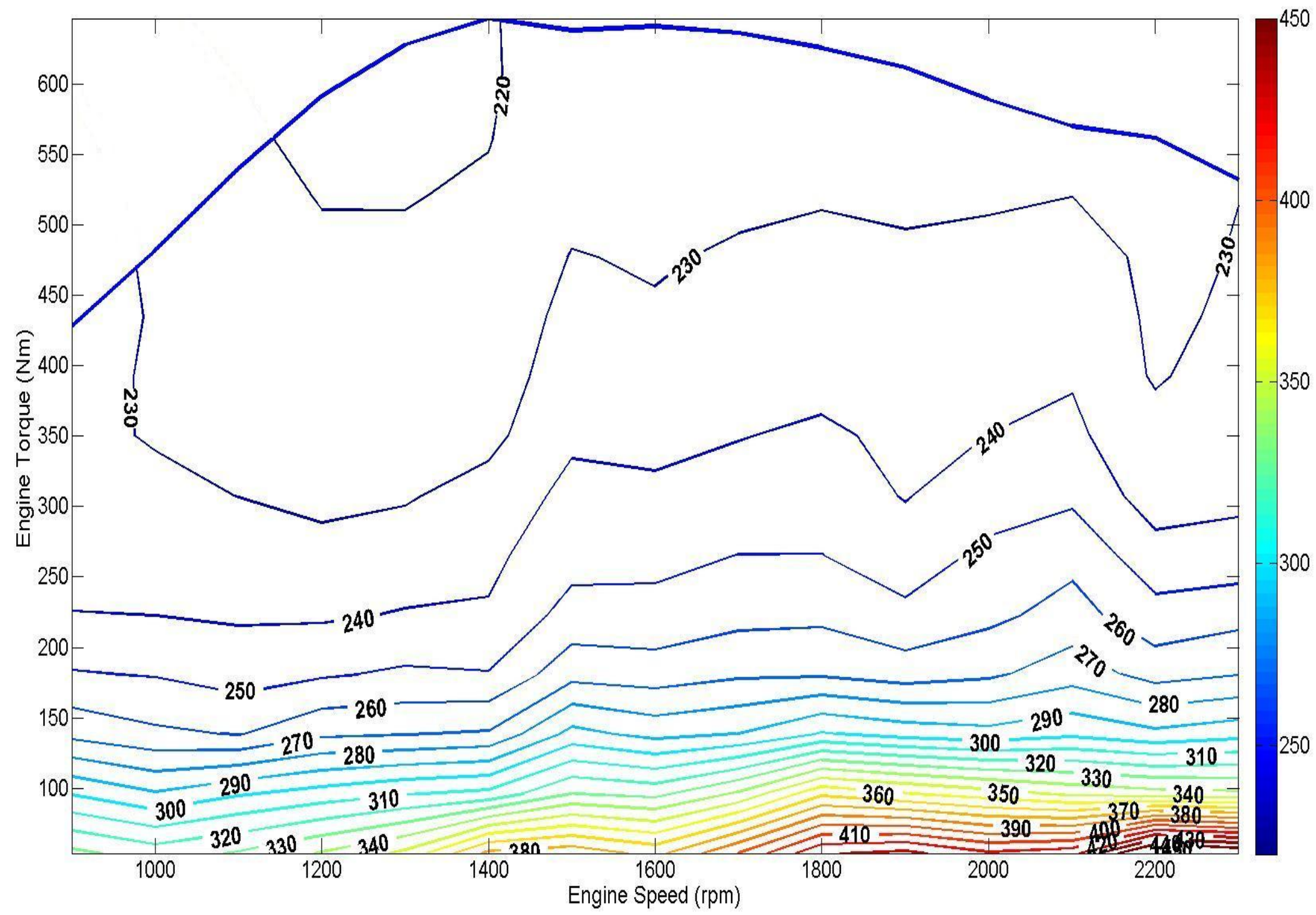

Figure 6.3 Overall BSFC Map Considering the Cost of Urea Solution Consumption and the Cost of Fuel Consumption (Unit: g/kW-hr) 


\section{References}

1.http://www.bts.gov/publications/national_transportation_statistics/ Accessed: April $2^{\text {nd }}$, 2010

2.http://www.eia.doe.gov/oil_gas/petroleum/data_publications/wrgp/mogas_history.html Accessed: May $1^{\text {st }}, 2010$

3.http://www.dieselnet.com/standards/us/hd.php Accessed: April 2 ${ }^{\text {nd }}, 2010$

4.http://www.dieselnet.com/standards/cycles/\#us-hden Accessed: November $8^{\text {th }}, 2010$

5.http://www.avl.com/wo/webobsession.servlet.go?app=bcms\&page=view\&nodeid=400030 459 Accessed: April 2 ${ }^{\text {nd }}, 2010$

6.http://www.avl.com/emag/AST_CRUISE/\#/3/ Acessed: April 2 ${ }^{\text {nd }}, 2010$

7.Argonne National Laboratory, PSAT (Powertrain System Analysis Toolkit) Documentation, http://www.transportation.anl.gov/

8.http://www.fueleconomy.gov/feg/tech_transmission.shtml Accessed: April 25, 2010

9.Overall heat transfer coefficient, available at http://www.engineeringtoolbox.com/overallheat-transfer-coefficients-d_284.html Accessed: May 13, 2010

10.http://www.nrel.gov/gis/solar.html Accessed: August 20, 2010

11.http://www.solarfeeds.com/cleanbeta/2525-101-us-cities-with-best-solar-energy-resources Accessed: August 19, 2010

12.http://personal.cityu.edu.hk/ bsapplec/solar2.htm Accessed: Oct. 27, 2010

13.http://upload.wikimedia.org/wikipedia/en/5/57/Climatemapusa2.PNG Accessed: Nov. 1st 2010

14.ASHARE, "Fundamentals handbook," Chapter 27, 1985

15.Bass, E., and Alfermann, T., "The Influence of Idle, Drive Cycle and Accessories on the Fuel Economy of Urban Hybrid Electric Buses Chassis Dynamometer Tests," SAE Paper No. 2003-01-3438, 2003

16.Baumann, B., Rizzoni, G., and Washington, G., "Intelligent Control of Hybrid Vehicles Using Neural Networks and Fuzzy Logic," SAE Paper No. 981061, 1998

17.Bradley, M., and Associates, "TCRP Report - Hybrid-Electric Transit Buses: Status, Issues, and Benefits," Northeast Advanced Vehicle Consortium, Transport Research Board, 2000

18.Bulter, K. L., Ehsani, M., and Kamath, P., "A Matlab-Based Modeling and Simulation Package for Electric and Hybrid Electric Vehicle Design," Vehicular Technology, IEEE Transaction on Vehicular Technology, Vol. 48, No. 6, PP. 1770 - 1778, 1999

19.Bulter, K. L., Steven, K. M., and Ehsani, M., "A Versatile Computer Simulation Tool for Design and Analysis of Electric and Hybrid Drivetrains," SAE Paper No. 970199, 1997 
20.Chan, C. C., "The State of the Art of Electric, Hybrid, and Fuel Cell Vehicles," Proceedings of the IEEE, Vol. 95, No. 4, PP. $704-718,2007$

21.Chi, N. J., "Control Challenges for Optimal $\mathrm{NO}_{\mathrm{x}}$ Conversion Efficiency from SCR Aftertreatment Systems," SAE Paper No. 2009-01-0905, 2009

22.Chiang, K. P., "Two-Mode Urban Transit Hybrid Bus In-Use Fuel Economy Results From 20 Million Fleet Miles," SAE Paper No. 2007-01-0272, 2007

23.Christenson, M., Loiselle, A., Karman, D., and Graham, L., "The Effect of Driving Conditions and Ambient Temperature on Light Duty Gasoline-Electric Hybrid Vehicles (2): Fuel Consumption and Gaseous Pollutant Emission Rates," SAE Paper No. 2007-012137, 2007

24.Chu, L., Ming, S.,Zhang, Y., and Zhu, Y., "Development and Validation of New Control Algorithm for Parallel Hybrid Electric Transit Bus," SAE Paper No. 2006-01-3571, 2006

25.Chu, L., Wang, Q., Liu, M., and Zhao, Z., "Development and Validation of Logic Threshold Control Algorithm for Parallel Hybrid Power Train," SAE Paper No. 200301-2312, 2003

26.Ehlbeck, J., and Mayenberg, M., “Increasing Heavy-Duty Truck Fuel Economy,” SAE Paper No. 912662, 1991

27.Fischer, S., Hofmann, L., and Zürbig, J., "SCR A Technology for Global Emissions Control of Diesel Engines," SAE Paper No. 2004-05-0390, 2004

28.Forrest, W., and Bhatti, M., "Energy Efficient Automotive Air Conditioning System," SAE Paper No. 2002-01-0229, 2002

29.Heckenberger, T., Kroner, P., Weinbrenner, M., Manski, R., Kemle, A., and Tepas, J., "Contribution of the Air Conditioning System to Reduced Power Consumption in Cars," SAE Paper No. 2008-21-0047, 2008

30.Hendricks, J. T., "Optimization of Vehicle Air Conditioning Systems Using Transient Air Conditioning Performance Analysis," SAE Paper No. 2001-01-1734, 2001

31.Hendricks, J. T., "Multi-Variable Optimization of Electrically-Driven Vehicle Air Conditioning Systems Using Transient Performance Analysis," SAE Paper No. 2003-040011,2003

32.Jackson, H. W., "The Physiological Aspect of Automotive Heating, Ventilating, and Air Conditioning," General Motor Engineering Journal, PP.2 - 6, July-August-September 1961

33.Jackson, D. M., Schubert, R., and Pont, Jenny., "Distributing Urea for the On-Road Vehicle Market," Diesel Engine-Efficiency and Emissions Research 2006

34.Johnson, V. H., Wipke, K. B., and Rausen, D. J., "HEV Control Strategy for Real-Time Optimization of Fuel Economy and Emissions," SAE Paper No. 2000-01-1543, 2000

35.Karbowski, D., Kwon, J., Kim, N., and Rousseau, A., "Instantaneously Optimized Controller for a Multimode Hybrid Electric Vehicle," SAE Paper No. 2010-01-0816, 2010 
36.Khayyam, H., Kouzani, Z. A., and Hu, J. E., "Reducing Energy Consumption of Vehicle Air Conditioning System by an Energy Management System," Intelligent Vehicle Symposium, IEEE, PP. 752 - 757, 2009

37.King, D., Haefner, B., Salasoo, L., and Koegl, A., "Hybrid Electric Transit Bus Pollutes Less, Conserves Fuel," Spectrum, IEEE, Vol. 32, No. 7, PP. 26 -31, 1995

38.Knight, R. E., "Correction of Truck Tire Rolling Resistance as Derived from Fuel Economy and Laboratory Tests," SAE Paper No. 821266, 1982

39.Langari, R., and Won, J-S., "Intelligent Energy Management Agent for a Parallel Hybrid Vehicle - Part I: System Architecture and Design of the Driving Situation Identification Process," IEEE Transaction on Vehicular Technology, Vol. 54, No. 3, PP. 925 - 934, 2005

40.Li, H., and Karim, A. G., "Exhaust Emissions from an SI Engine Operating on Gaseous Fuel Mixtures Containing Hydrogen," Internal Joural of Hydrogen Energy, Vol. 30, PP. $1491-1499,2005$

41.Lin, CC., Peng, H., Grizzle, W. J., and Kang, J., "Power Management Strategy for a Parallel Hybrid Electric Truck," Control Systems Technology, IEEE, Vol. 11, No. 6, PP. $839-849,2003$

42.Linden, P. F., "The Fluid Mechanics of Natural Ventilation," Annu. Rev. Fluid Mech. 1999. 31: $201-38$

43.Liu, Ming-hui., Zhao, Zi-liang., and Li, Jun., "A Study on the Development of Driving Cycle for Public Buses in Beijing," Automotive Engineering, Vol. 27, No. 6, PP. 687 690, 2005

44.Lowe, M., Aytekin, B., and Gereffi, G., "Public Transit Buses: A Green Choice Gets Greener," Manufacturing Climate Solutions, October 26, 2009

45.Miller, M. J., "Propulsion Systems for Hybrid Vehicles," The Institution of Electrical Engineers, 2004

46.Nam, K. E., and Colvin, D. A., "An Experimental Procedure for Simulating an SC03 Emission Test with Air Conditioner on," SAE Paper No. 2004-01-0594, 2004

47.Plotkin, S., "Technologies and Policies for Controlling Greenhouse Gas Emissions from the U.S. Automobile and Light Truck Fleet," January 2000

Available at http://www.transportation.anl.gov/pdfs/TA/47.pdf

48.Rugh, P. J., and Farrington, R., "Vehicle Ancillary Load Reduction Project Close-Out Report: An Overview of the Task and a Compilation of the Research Results," Technical Report NREL/TP-540-42454, January 2008

49.Rugh, P. J., Hendricks, J. T., and Koram, K., "Effect of Solar Reflective Glazing on Ford Explorer Climate Control, Fuel Economy, and Emissions," SAE Paper No. 2001-013077, 2001

50.Rugh, P. J., Hovland, V., and Andersen, O. S., "Significant Fuel Savings and Emission Reductions by Improving Vehicle Air Conditioning," 15th Annual Earth Technologies Forum and Mobile Air Conditioning Summit, April 15, 2004 
51.Schommers, J., Duvinage, F., Stotz, M., Peters, A., Ellwanger, S., Koyanagi, K., and Gildein, H., "Potential of Common-Rail Injection System for Passenger Car DI Diesel Engines," SAE Paper No. 2000-01-0944, 2000

52.Schuring, D. J., "The Rolling Loss of Pneumatic Tires," Rubber Chemistry and Technology, Vol. 53, No. 3, PP. 600 - 727, 1980

53.Sciarretta, A., and Guzzella, L., "Control of Hybrid Electric Vehicles," Control System Magazine, IEEE, PP. 60 - 70, April 2007

54.Sharer, P., Leydier, R., and Rousseau, A., "Impact of Drive Cycle Aggressiveness and Speed on HEVs Fuel Consumption Sensitivity," SAE Paper No. 2007-01-0281, 2007

55.Smith, R. J., Tracy, C. J., and Potter, S. D., "Tire Rolling Resistance $\sim$ a Speed Dependent Contribution," SAE Paper No.780255, 1978

56.Teng, H., "A Thermal Energy Operated Heating/Cooling System for Buses," SAE Paper No. 2010-01-0804, 2010

57.Rousseau, A., and Pasquier, M., "Validation of a Hybrid Modeling Software (PSAT) Using Its Extension for Prototyping (PSAT-PRO)," Global Powertrain Congress, 2001

58.Rousseau, A., Sharer, P., and Pasquier, M., "Validation Process of a HEV System Analysis Model: PSAT," SAE Paper No. 2001-01-0953, 2001

59.Welstand, J., Haskew, H., Gunst, R., and Bevilacqua, O., "Evaluation of the Effects of Air Conditioning Operation and Associated Environmental Conditions on Vehicle Emissions and Fuel Economy," SAE Paper No. 2003-01-2247, 2003

60.Wang, W., Zeng, X., and Wang, Q., "Develop Hybrid Transit Buses for Chinese Cities," SAE Paper No. 2003-01-0087, 2003

61.Yamamoto, K., and Aoki, T., "Analysis of the Influence on Fuel Economy by Transmission Type and the Estimation of Fuel Economy," SAE Paper No. 2000-05-0146 2000

62.Yana Motta, S., and Domanski, A. P., "Impact of Elevated Ambient Temperatures on Capacity and Energy Input to a Vapor Compression System - Literature Review," ARTI 21-CR Research Project: 605-50010/605-50015, 2000

63.Yeung, Y. P. B., Cheng, K. W. E., Chan, W. W., Lam, C. Y., Choi, W. F., and Ng, T. W., "Automobile Hybrid Air Conditioning Technology," $20093^{\text {rd }}$ International Conference on Power Electronics Systems and Applications, 2009

64.Zeng, X., Wang, Q., Wang, W., and Chu, L., "Analysis and Simulation of Conventional Transit Bus Energy Loss and Hybrid Transit Bus Energy Saving," SAE Paper No. 200501-1173, 2005

65.Zeng, X., Performance and Fuel Economy Test Report of Hybrid Transit Bus, Jilin University, 2005

66.Zlatoper, T. J., "Determinants of Motor Vehicle Deaths in the United States: a CrossSectional Analysis," Special Issue: Theoretical Models for Traffic Safety. Accid. Anal. Prev. 23 (5), PP. 431 - 436, 1991 
67. "Light-Duty Automotive Technology, Carbon Dioxide Emissions, and Fuel-Economy Trends: 1975 Through 2009," EPA420-R-09-014, November 2009

68.China's National Standard GB/T 12545-1990, "Motor Vehicles-Fuel Consumption Test Method," 1990

69.SAE J1376. "Fuel Economy Measurement Test (Engineering Type) for Trucks and Buses," SAE International, December 1997

70.SAE J2711, "Recommended Practice for Measuring Fuel Economy and Emissions of Hybrid-Electric and Conventional Heavy-Duty Vehicles," SAE International, September 2002

71.U.S. Environmental Protection Agency, Clearinghouse for Inventories and Emissions Factors (CHIEF), Current Emission Trends Summaries, available at http://www.epa.gov/ttn/chief/trends/index.html Jan. 19, 2010 